\title{
PAMPering immune responses : spotlight on helper cells for dendritic cell vaccination
}

Citation for published version (APA):

Oth, T. (2015). PAMPering immune responses : spotlight on helper cells for dendritic cell vaccination. [Doctoral Thesis, Maastricht University]. Maastricht University. https://doi.org/10.26481/dis.20151218to

Document status and date:

Published: 01/01/2015

DOI:

10.26481/dis.20151218to

Document Version:

Publisher's PDF, also known as Version of record

\section{Please check the document version of this publication:}

- A submitted manuscript is the version of the article upon submission and before peer-review. There can be important differences between the submitted version and the official published version of record.

People interested in the research are advised to contact the author for the final version of the publication, or visit the DOI to the publisher's website.

- The final author version and the galley proof are versions of the publication after peer review.

- The final published version features the final layout of the paper including the volume, issue and page numbers.

Link to publication

\footnotetext{
General rights rights.

- You may freely distribute the URL identifying the publication in the public portal. please follow below link for the End User Agreement:

www.umlib.nl/taverne-license

Take down policy

If you believe that this document breaches copyright please contact us at:

repository@maastrichtuniversity.nl

providing details and we will investigate your claim.
}

Copyright and moral rights for the publications made accessible in the public portal are retained by the authors and/or other copyright owners and it is a condition of accessing publications that users recognise and abide by the legal requirements associated with these

- Users may download and print one copy of any publication from the public portal for the purpose of private study or research.

- You may not further distribute the material or use it for any profit-making activity or commercial gain

If the publication is distributed under the terms of Article $25 \mathrm{fa}$ of the Dutch Copyright Act, indicated by the "Taverne" license above, 


\section{PAMPering immune responses}

Spotlight on helper cells for dendritic cell vaccination 


\section{(C) Tammy Oth, Maastricht 2015.}

All rights reserved. No part of this book may be reproduced, stored in a retrieval system of any nature, or transmitted in any form or by any means (electronic, mechanical, photocopying, recording or otherwise) without prior written permission of the author, or when appropriate, by the publishers of the publications.

\section{ISBN:}

978-94-6233-168-6

Cover art:

Gast Oth

Cover design

Tammy Oth \& Gildeprint

Layout \& figure design: Tammy Oth

Fonds National de la Recherche Luxembourg
The studies presented in this dissertation were conducted at the Department of Internal Medicine, Division of Haematology at Maastricht University Medical Centre+. Financial support was obtained by the 'Fonds National de la Recherche' (FNR), Luxembourg (AFR PhD Grant 1039369). 


\section{PAMPering immune responses}

\section{Spotlight on helper cells for dendritic cell vaccination}

\section{DISSERTATION}

to obtain the degree of Doctor at Maastricht University, on the authority of the Rector Magnificus, Prof. dr. L.L.G. Soete

in accordance with the decision of the Board of Deans, to be defended in public

on Friday, December $18^{\text {th }} 2015$ at 10 o'clock

$$
\text { by }
$$

\section{Tammy Oth}

born on March 20 1986 in Luxembourg, Luxembourg 


\section{Supervisor}

Prof. dr. G.M.J. Bos

\section{Co-supervisors}

Dr. J. Vanderlocht

Dr. W.T.V. Germeraad

\section{Assessment Committee}

Prof. dr. P. Lambin (Chairman)

Dr. V.F.I. van Tendeloo, Universiteit Antwerpen, Antwerp

Prof. dr. M.G.J. Tilanus

Prof. dr. I.J.M. de Vries, Radboud Universitair Medisch Centrum, Nijmegen

Dr. T.G.A.M. Wolfs 


\section{CONTENTS}

$\begin{array}{lll}\text { Chapter } 1 \quad \text { General introduction } & 7\end{array}$

Chapter 2 Monitoring the initiation and kinetics of human dendritic cell- 45 induced polarization of autologous naive $\mathrm{CD}^{+} \mathrm{T}$ cells

Chapter 3 Potency of both human Th1 and NK helper cell activation is $\quad 75$ determined by IL-12p70-producing PAMP-matured DC

Chapter 4 Pathogen recognition by NK cells amplifies the pro-inflammatory cytokine production of monocyte-derived DC via IFN- $\gamma$ but not $\mathrm{TNF}-\alpha$

Chapter 5 Inflammation-restraining effects of Prostaglandin $\mathrm{E}_{2}$ on NK-DC interaction are imprinted during dendritic cell maturation

Chapter 6 General discussion

Chapter 7

Summary

Zesummefaassung (Luxembourgish)

Chapter 8 Valorisation 


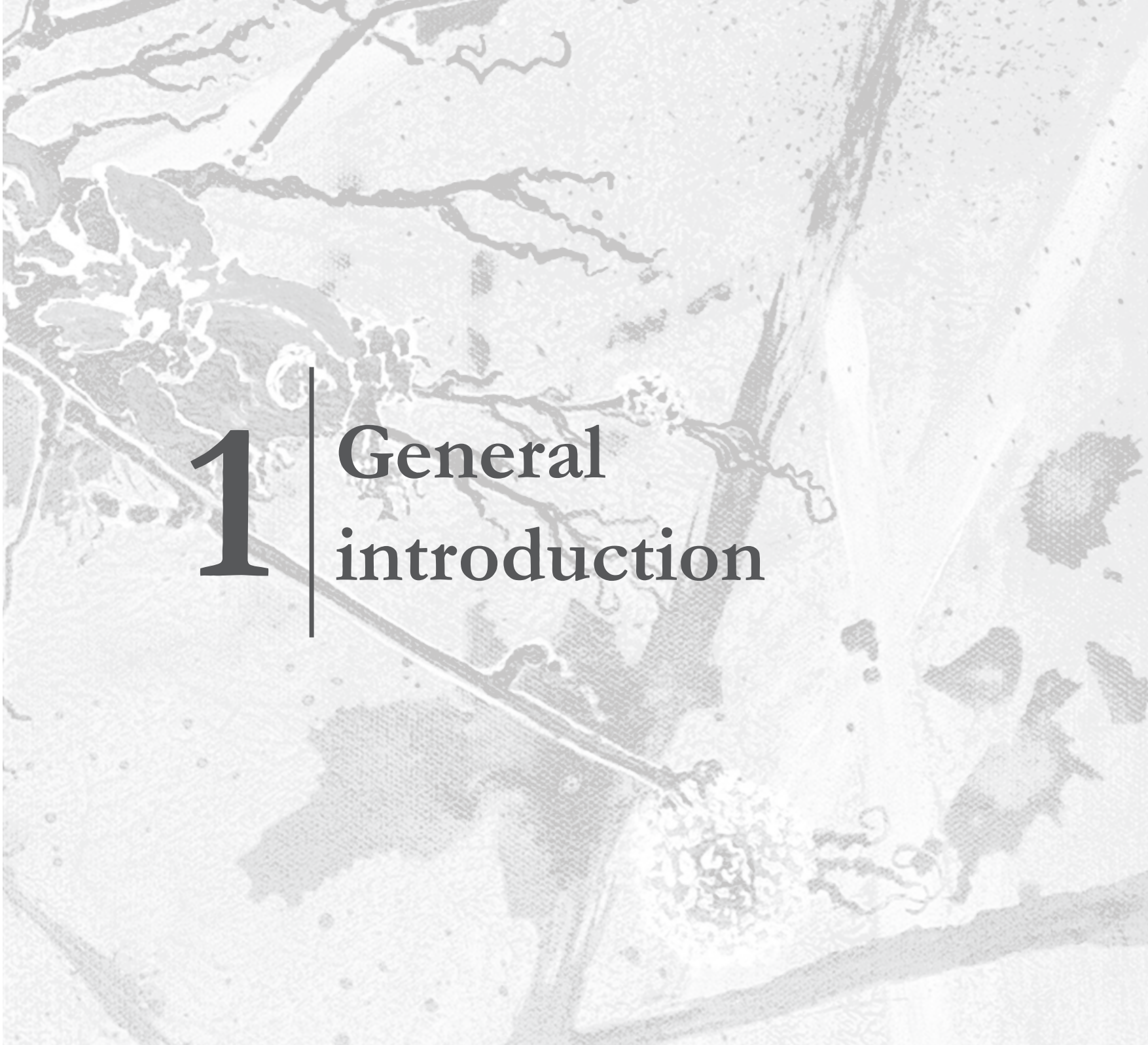

Part of this chapter has been adapted from:

Natural killer cells: the secret weapon in dendritic cell vaccination strategies

Van Elssen C.H.M.J. ${ }^{1}$, Oth T. ${ }^{1}$, Germeraad W.T.V. ${ }^{1}$, Bos G.M.J. ${ }^{1}$, Vanderlocht J. ${ }^{2}$

${ }^{1}$ Division of Haematology, Department of Internal Medicine, MUMC+, Maastricht

${ }^{2}$ Tissue Typing Laboratory, Department of Transplantation Immunology, MUMC+, Maastricht

Clin Cancer Res. 2014 Mar 1;20(5):1095-103. Review. 



\section{INNATE IMMUNITY \& PATHOGEN RECOGNITION}

During their lifespan, humans are continuously exposed to a variety of pathogens including viruses, bacteria, fungi, and parasites. The immune system is equipped with various sophisticated innate and adaptive strategies to counteract these pathogenic insults.

The innate immunity is the first line of host defence, and this non-specific response is initiated within hours upon exposure to an infectious agent. The innate immunity consists of anatomic (e.g. skin), physiologic (e.g. pH), phagocytic (e.g. macrophages) and inflammatory barriers. Pattern recognition plays a crucial role in inducing an innate immune response. Highly conserved and unique microbial structures of pathogens (pathogen-associated molecular patterns; PAMPs) are detected by so-called pattern recognition receptors (PRR), which are germ-line encoded receptors and are either secreted, membrane-bound or located in the cytoplasm ${ }^{1,2}$. A variety of innate immune cells, such as dendritic cells (DC) and macrophages, are equipped with various PRR, which enable the cells to discriminate between different classes of microorganisms, and to tailor appropriate immune responses against the nature of the pathogen ${ }^{3,4}$. In addition, necrotic and apoptotic cells, as well as stressed cells are able to trigger these PRR via the release of damage-associated molecular patterns (DAMPs) ${ }^{5}$. PRR expression is, however, not limited to innate immune cells; also cells of the adaptive immune systems (e.g. T cells) and non-immune cells (e.g. stromal cells) are equipped with diverse PRR ${ }^{6}$. Triggering of PRR leads to the production of pro-inflammatory cytokines and type I interferons (IFNs) and the induction of innate host defence. Moreover, the sensing of pathogens via PRR is indispensable for the orchestration of proper and coordinated pathogen-tailored adaptive immune responses including the activation of antigen-specific B (induction of humoral immune responses) and/or T cells (induction of cell-mediated responses). This cellular interplay of innate and adaptive immune cells is required for the successful elimination of a pathogenic threat and the generation of immunological memory ${ }^{4,7}$.

PRR recognize distinct classes of PAMPs, initiate different signalling pathways and responses, and display different expression patterns among (immune) cell (sub)types. They can be divided into different families according to their function, localisation and ligand specificity: Toll-like receptors (TLR) ${ }^{8,9}$, nucleotide oligomerisation receptors (NOD)like receptors (NLR) ${ }^{10}$, C-type lectin receptors (CLR) ${ }^{11,12}$, retinoic acid-inducible gene (RIG)-I-like receptors (RLR) ${ }^{13,14}$, and AIM2-like receptors (ALRs) ${ }^{15}$. Depending on the nature of the pathogen different members of PRR classes get triggered as listed in Table 1. In general, the TLR family recognizes bacteria, viruses, fungi, and parasites, whereas NLR sense bacteria, CLR detect fungi and bacteria, RLR the presence of viral RNA, and ALR sense DNA viruses. The particular combination of PRR being triggered during a pathogenic 
insult determines the type, quality, magnitude, and duration of the initiated immune response ${ }^{4}$. Additionally, the cell type-specific expression of PRR affects the induction of immune responses. Figure 1 exemplifies the TLR expression pattern of different immune cells and in particular of different DC subsets. This expression pattern is linked to their respective function.

Table 1 | PRR classes and properties.

\begin{tabular}{|c|c|c|c|c|c|}
\hline $\begin{array}{c}\text { PRR } \\
\text { family }\end{array}$ & members & localization & structure & ligand sources & ligands \\
\hline \multirow{10}{*}{ TLR } & TLR1 & cell membrane & $\mathrm{TM}$ & bacterial lipids & triacylated lipopeptides \\
\hline & TLR2 & cell membrane & TM & $\begin{array}{l}\text { bacterial lipids, } \\
\text { fungal cell wall }\end{array}$ & diacylated lipopeptides \\
\hline & TLR3 & endosome & TM & viral RNA & dsRNA \\
\hline & TLR4 & $\begin{array}{l}\text { cell membrane/ } \\
\text { endosome }\end{array}$ & $\mathrm{TM}$ & bacterial lipids & lipopoly-saccharides \\
\hline & TLR5 & cell membrane & $\mathrm{TM}$ & bacterium, parasite & flagellin \\
\hline & TLR6 & cell membrane & $\mathrm{TM}$ & bacterial lipids & lipopeptides \\
\hline & TLR7 & endosome & TM & viral RNA & ssRNA \\
\hline & TLR8 & endosome & TM & viral RNA & ssRNA \\
\hline & TLR9 & endosome & TM & bacterial/ viral RNA & CpG DNA \\
\hline & TLR10 & endosome & $\mathrm{TM}$ & bacterium, parasite & profiling-like proteins \\
\hline \multirow{3}{*}{ RLR } & RIG-I & \multirow{3}{*}{ cytoplasm } & \multirow{3}{*}{ soluble } & \multirow{3}{*}{ viral RNA } & \multirow{3}{*}{ ssRNA, dsRNA } \\
\hline & MDA-5 & & & & \\
\hline & LGP2 & & & & \\
\hline \multirow{2}{*}{ CLR } & Dectin-1 & \multirow{2}{*}{ cell membrane } & \multirow{2}{*}{ TM } & \multirow{2}{*}{ fungal cell wall } & b-glucan \\
\hline & Dectin-2 & & & & mannan \\
\hline \multirow{4}{*}{ NLR } & NOD1 & \multirow{4}{*}{ cytoplasm } & \multirow{4}{*}{ soluble } & \multirow{4}{*}{ bacterium, virus, host } & peptidoglycan \\
\hline & NOD2 & & & & peptidoglycan \\
\hline & NALP1 & & & & peptidoglycan \\
\hline & NALP3 & & & & ATP, RNA, DNA \\
\hline \multirow{2}{*}{ ALR } & AIM-2 & \multirow{2}{*}{ cytoplasm } & \multirow{2}{*}{ soluble } & \multirow{2}{*}{ DNA viruses } & dsDNA \\
\hline & IFI16 & & & & ssDNA, dsDNA \\
\hline
\end{tabular}

CLR and NLR: not all family members are listed. ALR: AIM-2-like receptors; CLR: C-type-lectin receptors; NLR: nucleotide-binding oligomerisation domain (NOD)-like receptors; RLR: RIG-I-like receptors; TLR: Toll-like receptors; TM: transmembrane. 


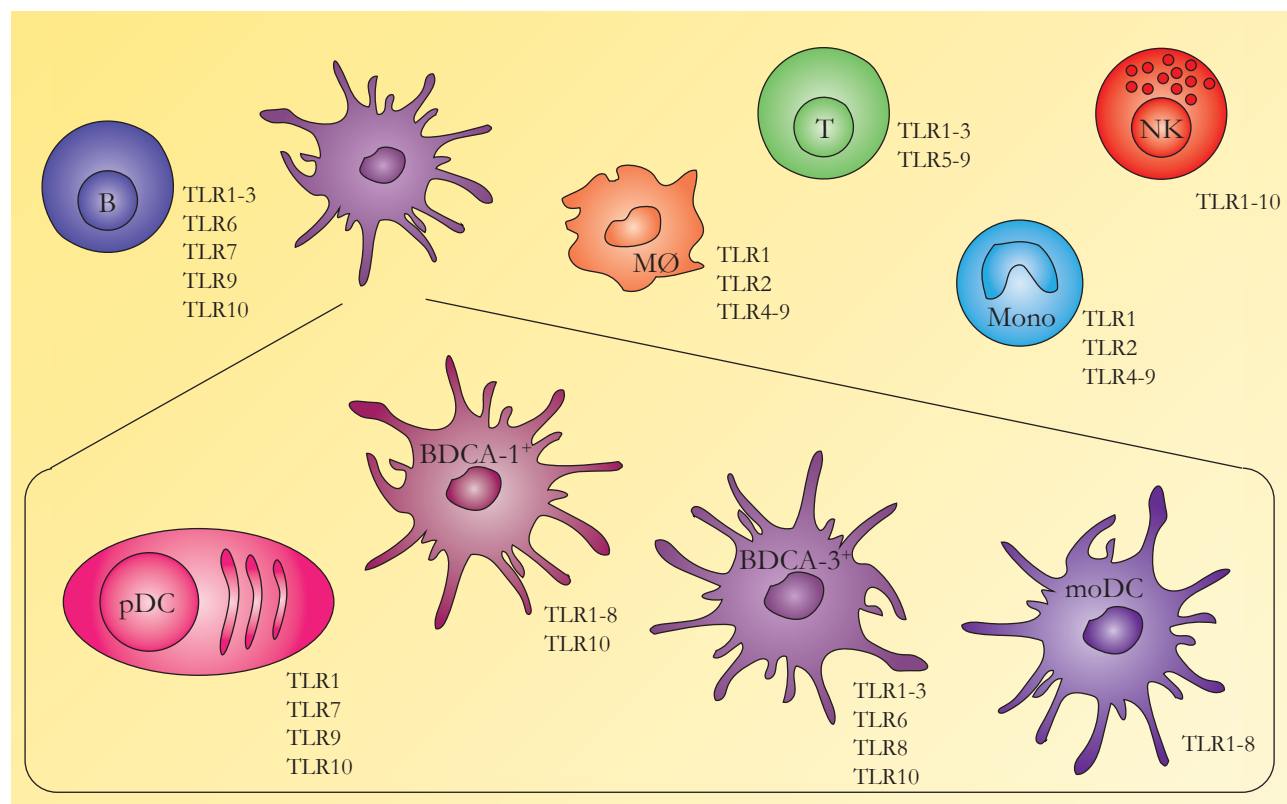

Figure 1 | TLR expression of human immune cells. Cells of the innate and adaptive immune system express a diverse repertoire of TLR. Expression patterns of blood DC subsets $\mathrm{pDC}$ and cDC $\left(\mathrm{BDCA}-1^{+}\right.$and $\mathrm{BDCA}-3^{+}$) as well as inflammatory moDC are shown. B: B cells; MØ: macrophages; Mono: Monocytes; NK: NK cells; T: T cells ${ }^{16-20}$.

The best characterized class of PRR is the TLR family. Up-to-date 10 human TLR members have been identified. Extracellular TLR (TLR1, 2, 4, 5, 6, 10) are specialized in the recognition of unique bacterial products allowing a good self-non-self-discrimination. The intracellular TLR (TLR3, 7, 8, 9) are mainly responsible for viral detection. TLR signalling occurs via two main adaptor molecules: MyD88 (TLR1, 2, 4, 5, 6, 7, 8, 9) and TRIF (TLR3 and 4). Further recruitment of different kinases initiates the signalling cascade which includes MAP kinase pathway, NFkB pathway or IRF pathway and leads to the production of pro- (e.g. Interleukin [IL]-6, TNF- $\alpha$, IL-12) and anti-inflammatory cytokines (e.g. IL-10), chemokines or type I IFNs.

NLR constitute a group of at least 22 identified human proteins, sensing microbial components as well as metabolic stress. NLR can be divided into different functional subgroups. Receptors like NOD1 and NOD2 homo-oligomerize, recognize peptidoglycan components of bacterial cell walls, and their activation leads to the production of type I IFNs. The second subgroup oligomerizes to form a multi-protein signalling complex including adaptor proteins and caspase-1, the inflammasome. Via their caspase activity these inflammasomes activate the pro-inflammatory cytokines IL-1 $\beta$ and IL-18. ALR also form these complexes ${ }^{10}$. CLR synergize with the fungal TLR sensing system. CLR are located 
at the cell surface and are involved in several biological processes, including antigen-uptake and presentation. Dectin-1 is an example of CLR, which recognizes the fungal component zymosan ${ }^{11,12}$. RLR are cytosolic receptors and like intracellular TLR, these receptors act as viral sensors mediating immune responses via the release of type I IFNs ${ }^{13,14}$. The different classes of PRR cooperate in the recognition of pathogens ${ }^{4,9,21,22}$. For example, poly(I:C) can be recognized by TLR3 and RIG-I/MDA-5. This interplay is required for the induction of robust immune responses ${ }^{23}$.

In general, responses induced by PRR-triggering lead to the shaping of $\mathrm{T}$ cell responses via release of cytokines and upregulation of co-stimulatory molecules on immune cells, recruitment of other immune cells to the site of infection, upregulation of chemokine receptors allowing migration towards lymph nodes, secretion of anti-microbial molecules as well as enhanced antigen uptake and presentation ${ }^{4,7}$. The importance of the PRR system, which is partly overlapping and redundant, in sensing pathogens and mediating appropriate immune responses is illustrated by several reports indicating increased susceptibility to human diseases in case of receptor polymorphisms ${ }^{24,25}$.

\section{PATHOGEN SENSING BY DENDRITIC CELL SUBSETS}

Dendritic cells (DC) constitute a heterogeneous population of bone marrow-derived cells which are equipped with molecular sensors allowing the detection of pathogens and with an antigen-processing machinery. As such, DC are described as the most potent antigenpresenting cells (APC) of our body able to survey their environment and instruct the immune system to induce appropriate immune responses. DC have a unique role in linking the innate and adaptive immunity ${ }^{26}$.

Under physiological conditions immature DC (iDC) act as sentinels at infection sites where they capture and ingest antigens, which induces phenotypic changes/functional maturation and their migration to secondary lymphoid organs. This recognition occurs via the expression of diverse PRR. During the maturation process DC lose their phagocytic and endocytic properties, upregulate co-stimulatory molecules and major histocompatibility complex (MHC) molecules, and secrete inflammatory cytokines ${ }^{27,}{ }^{28}$. Mature DC (mDC) present the processed peptides from the original antigen in the context of MHC molecules which are in turn recognized by $\mathrm{T}$ cells. DC are able to initiate, program and regulate antigen-specific immune responses by activating different immune effector cells (T cells, B cells, NK cells) ${ }^{29}$. Depending on the environmental stimuli DC encounter, the transmitted signals to various immune effector cells are of immunogenic or tolerogenic origin ${ }^{30,31}$.

Different DC subsets have been identified which can be divided according to their 
development, function, and location ${ }^{19}$. In general, DC are $\mathrm{MHC}$ class $\mathrm{II}^{+}$and $\mathrm{LIN}^{-}\left(\mathrm{CD}^{-}\right.$, CD56, $\mathrm{CD}^{-} 9^{-} / \mathrm{CD}^{-} 0^{32}$ and are divided into myeloid/conventional (myDC/cDC; $\mathrm{CD}^{+} \mathrm{c}^{+} /$ $\mathrm{BDCA}^{-} 1^{+}$and $\mathrm{CD} 141^{+} / \mathrm{BDCA}^{-} 3^{+}$), plasmacytoid (pDC; $\mathrm{CD} 303^{+} \mathrm{CD} 304^{+} \mathrm{CD} 123^{+}$) or monocyte-related DC (moDC). DC are either migratory or lymphoid tissue-resident. In human peripheral blood, spleen and tonsils three major DC subsets have been identified: $\mathrm{pDC}, \mathrm{CD} 1 \mathrm{c}^{+} \mathrm{cDC}$ and $\mathrm{CD} 141^{+} \mathrm{cDC}^{33-36}$. Blood DC are considered to be more immature than their tissue-resident counterparts ${ }^{32}$.

$\mathrm{CDc}^{+} \mathrm{cDC}$ (mouse counterpart: $\left.\mathrm{CD} 11 \mathrm{~b}^{+}\right)^{37}$ constitute the dominant $\mathrm{cDC}$ population in blood, tissue, and lymphoid organs ${ }^{33,38,39}$. $\mathrm{CDc1}^{+} \mathrm{cDC}$ express various TLR $(1-8,10)$ and recognize LPS, flagellin, R848 and poly(I:C) ${ }^{40}$. Furthermore, the expression of Dectin-1 and Dectin- 2 indicates a role in fungal recognition ${ }^{41,42}$. In general, matured CD1 $\mathrm{c}^{+}$cells are good stimulators of naive $\mathrm{CD}^{+}{ }^{+} \mathrm{T}$ cells responses, but less efficient at cross-presentation ${ }^{43-45}$. Cross-presentation is the capacity to process and present exogenous antigens not only in the conventional MHC class II pathway but also in the context of MHC class I. This is an important mechanism for the induction of cytotoxic $\mathrm{CD}^{+} \mathrm{T}$ cells in case the $\mathrm{DC}$ are not infected themselves ${ }^{46}$. Depending on the encountered stimuli, $\mathrm{CDc}^{+} \mathrm{DC}$ have the potential to secrete TNF- $\alpha$, IL-8, IL-10, IL-12p70, and IL-23. CD141 ${ }^{+}$cDC (mouse counterpart $\left.\mathrm{CD}^{+}\right)$are more efficient in cross-presentation ${ }^{44,47,48}$. They also express a wide range of TLR (1-3, 6, 8, and 10) and are efficient in detecting dead and necrotic cells via CLEC9A ${ }^{45}$. TNF- $\alpha$, CXCL10, IFN- $\lambda$ are efficiently produced by these CD $141^{+}$DC, however, they are less potent producers of IL-12p70 43, 48, 49.

PDC are specialized in anti-viral defence and express mainly TLR7 and TLR9, but also TLR1 and TLR $6{ }^{19}$. They are potent producers of type I IFNs (IFN- $\left.\alpha, \beta, \omega, \lambda\right)^{50,51}$. Under steady-state conditions pDC have low MHC class II and costimulatory molecule expression levels and reside in low numbers in tissues, but constitute $20 \%$ of lymph node HLA-DR ${ }^{+}$ cells ${ }^{52}$. Upon inflammation, rapid recruitment and accumulation occurs in lymphoid and non-lymphoid tissue. Freshly isolated blood pDC are only able to prime $\mathrm{CD}^{+}{ }^{+} \mathrm{T}$ cell polarization after activation ${ }^{53-55}$. $\mathrm{pDC}$ secrete a diverse cytokine and chemokine repertoire (IL-12p70, IL-6, TNF- $\alpha$, CXCL9, CXCL10, CCL3, CCL4, CCL5) enabling them to attract among others $\mathrm{CD}^{+}$and $\mathrm{CD}^{+}$cells to the site of inflammation. Same as $\mathrm{cDC}, \mathrm{pDC}$ are able to present the processed antigens in the context of MHC class I or II ${ }^{56-59}$. Immunogenic pDC play a role in the induction of CTL, memory $\mathrm{T}$ cell induction and survival, and $\mathrm{T}$ helper (Th)1/Th17 polarization of $\mathrm{CD}^{+}{ }^{+} \mathrm{T}$ cells ${ }^{56,57}$. Moreover, TLR9-activated pDC are able to activate NK cells increasing their cytotoxic potential and proliferation ${ }^{60,61}$.

Monocyte-related DC can be divided into three groups: CD14 ${ }^{+}, \mathrm{CD}_{16}{ }^{+}$, and inflammatory DC. The latter DC subset arises only under pathogenic inflammation from circulating 
monocytes which have migrated towards the inflamed tissue. Inflammatory DC migrate to secondary lymphoid organs where they effectively stimulate naive $\mathrm{CD} 4^{+} \mathrm{T}$ cell responses and cross-present antigens to $\mathrm{CD}^{+}{ }^{+} \mathrm{T}$ cells. They are producers of IL-1, IL6, TNF- $\alpha$, IL-12p70 and IL-23 ${ }^{62,63}$. Currently under investigation is whether the inflammatory environment encountered during differentiation of monocytes will induce various moDC with specific functions ${ }^{64}$. In vitro IL-4/GM-CSF-differentiated moDC express all TLR except 9 and $10^{18}$.

Thus, the different DC subsets are equipped with selected combinations of PRR which are partly overlapping (exemplified for the TLR family in Figure 1). Several studies underpinned the importance of PRR-triggering for the functional maturation of DC ${ }^{65,66}$. Depending on the encountered pathogen and the DC subset a specific response is mediated by the DC to efficiently counteract the nature of the invading pathogen ${ }^{7,27,67,68}$. Likewise, the sensing of intracellular pathogens (e.g. bacteria, virus) initiates a type 1 immune response, including induction of Th1 cells, CTL, NK cells and IFN- $\gamma$-producing innate lymphoid cells (ILC) ${ }^{69}$. The dysregulation of type 1 immune responses can lead to autoimmune diseases ${ }^{70}$.

\section{IMMUNOMODULATORY ROLE OF T HELPER CELLS}

Naive $\mathrm{CD}^{+}{ }^{+} \mathrm{T}$ cells are characterized by the expression of CD45RA, CD62L, and CCR7 allowing their circulation between peripheral blood and lymph nodes ${ }^{71,72}$. These cells still lack adhesion molecules and specific chemokine receptors enabling their migration into non-lymphoid tissues. The polarization of naive $\mathrm{CD}^{+} \mathrm{T}$ cells into different specific Th cell subsets is induced by pathogen-triggered DC and is of capital importance in orchestrating specific adaptive immune responses against the nature of the pathogenic insult. This multistep process is tightly controlled and regulated. Uncontrolled activation and dysregulation of this process is associated with immune-related diseases ${ }^{73-75}$. The polarization includes the activation of naive $\mathrm{CD}^{+}$cells via a two-signal model in which the first signal consists in antigen recognition in the context of MHC-II-TCR ligation and the second one in the costimulation ${ }^{27}$ (Figure 2). Whereas initial studies postulated that different Th cell responses would be induced according to the encountered DC subtype ${ }^{76}$, it is now clear that the environmental instruction of the DC also plays a critical role in this process ${ }^{77}$. The cytokine milieu is the third signal which is of crucial importance for determining the Th cell fate and inducing a tailored immune response ${ }^{77,78}$. More recently, the role of a fourth DC-derived signal has been described, instructing $\mathrm{T}$ cells with a certain homing potential by inducing expression of particular chemokine receptors and integrins ${ }^{79},{ }^{80}$. Classically, a Th subset is defined by differentiation-inducing cytokines, its transcription factors, cell surface markers (e.g. co-stimulatory molecules, cytokine and chemokine receptors), signature cytokines and tissue localization. Moreover, each Th subset induces immune responses against a specific 
class of pathogens ${ }^{81-83}$ (Figure 2). Notably, Th cell subsets specific for one particular pathogen may also belong to different subsets. This is depending on the various antigens expressed by a pathogen, the timing of DC encounter (early or late priming), interaction with a second stimulating DC, or DC subsets mediating the polarization ${ }^{84}$.

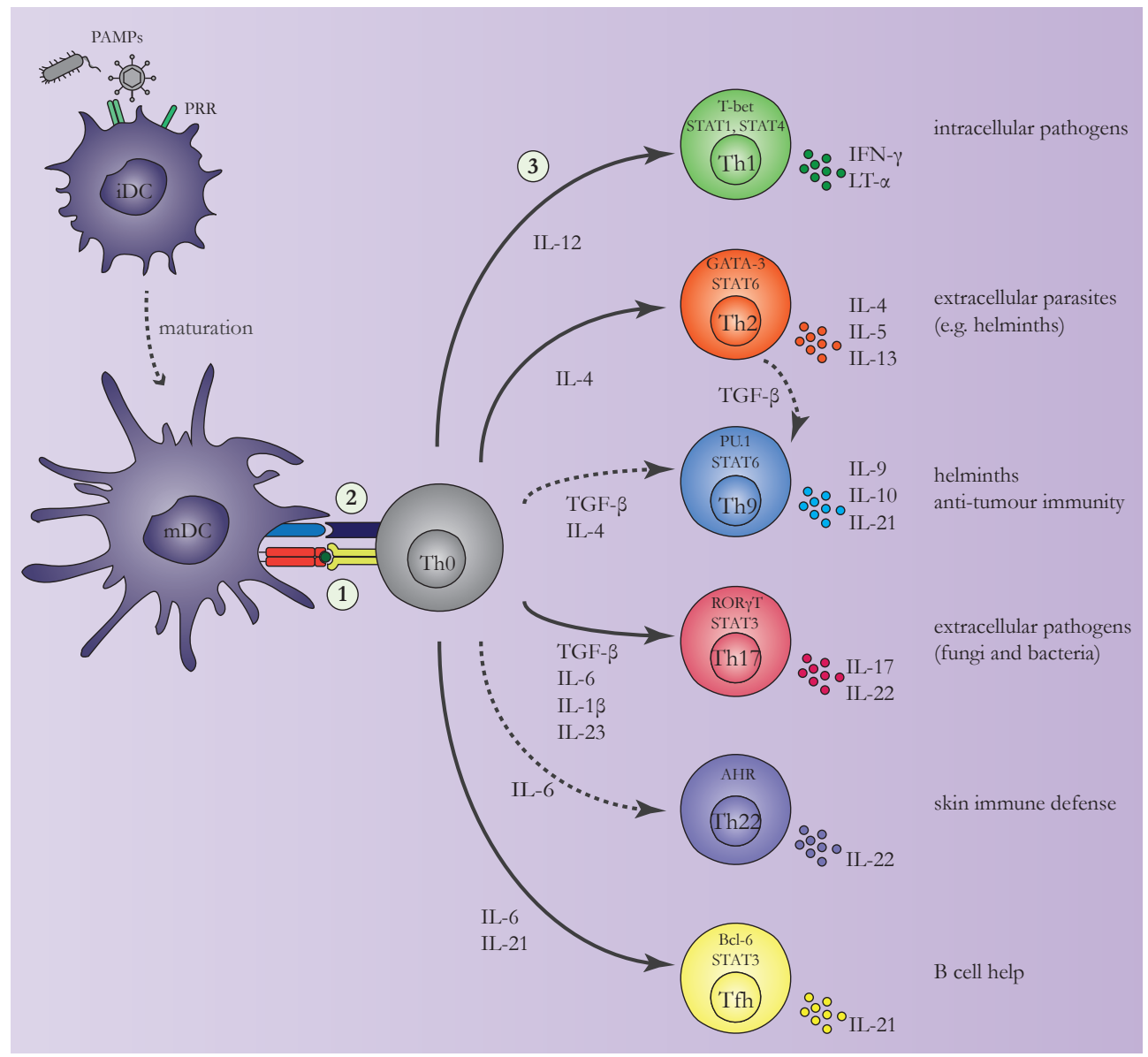

Figure 2 Polarization of $\mathrm{CD}^{+}{ }^{+} \mathbf{T}$ helper cells. Matured DC interact with naive $\mathrm{CD} 4^{+} \mathrm{T}$ cells and provide antigen-specific signal 1 (MHC-II-TCR interaction), signal 2 (co-stimulation), and signal 3 (polarizing cytokines), which influence the generation of a specific Th cell subtype. Lineage-specifying transcription factors are indicated for each Th cell subset. Th cell subset-specific cytokines and mediated immune responses are displayed next to the various Th cells. 


\section{T helper cell commitment, phenotype stability, and plasticity}

Since the first description of two different subsets of activated murine Th cells in $1986^{85}$, our understanding on the induction, phenotypic discrimination, and functional consequences of different $\mathrm{CD}^{+}{ }^{+}$Th subsets has enormously expanded. Almost two decades later, the presence of a third distinct Th subset was described in both human and mice: Th17 cells ${ }^{86,87}$. Nowadays, the possible fates of Th cells are: Th1, Th2, Th9, Th17, Th22, Thf and diverse Treg subsets ${ }^{88}$. The three best described effector Th cell subsets are Th1, Th2 and Th17. Th1 cells provide help for eliminating intracellular viral and bacterial pathogens and lead to cellular immunity. The expression of T-bet induces IFN- $\gamma$ production and the upregulation of CXCR3 on the cell surface. IFN- $\gamma$ activates macrophages and enhances IL-12 production by DC and thus represents a positive feedback loop. CXCR3 allows the Th1 cells to migrate to peripheral tissues ${ }^{89}$. Th2 effector cells are primarily responsible for mediating immune responses to eliminate extracellular parasites, such as helminths, and to induce humoral immunity. The induction of GATA-3 is followed by the secretion of Th2-specific cytokines IL-4, IL-5, and IL-13 as well as the upregulation of CCR4 and CRTh2 ${ }^{90-92}$. IL-4 blocks the differentiation into Th1 and Th17 cells and induces IgE production by B cells. IL-5 leads to activation of eosinophils ${ }^{92,93}$. Th17 cells are required to fight extracellular bacteria and fungi. Committed Th17 cells express RORC, produce mainly IL-17 and express CCR6 and IL-23R. IL-17 is involved in recruiting neutrophils and CCR6 is required for Th17 cells to migrate into inflamed tissues ${ }^{94-96}$. Even though the induction of Th responses is a tightly regulated process, dysregulation can lead to cellular-mediated autoimmune disorders (Th1), atopy (Th2), and chronic tissue inflammation (Th17) ${ }^{83,97,98 .}$

The functional differentiation of Th cells is a complex process including multiple lineages, interaction of signaling pathways, transcription factors, microRNAs, and epigenetic regulation. The signals received upon activation such as strength of TCR stimulation, co-stimulation and cytokines determine the state of a helper T cell. The classical view defines the different Th cell subsets as terminally differentiated cells expressing Th-specific master regulators, e.g. Tbet (Th1), GATA-3 (Th2), ROR- $\gamma$ T (Th17), and BCL-6 (Tfh) ${ }^{99}$. Whereas it was believed for a long time that expression of such a Th-specific master regulators would be both required and sufficient to determine the fate of naive $\mathrm{CD}^{+}{ }^{+} \mathrm{T}$ cells and that its expression would equal a specific Th phenotype, this concept has been proven to be more complex over the last few years.

The fate of $\mathrm{CD}^{+} \mathrm{T}$ cells is more flexible and diverse as evidenced by recent research. For example, the so-called master regulators can be co-expressed (transiently or permanently) in one Th cell subtype. This co-expression can be either cooperative or antagonistic depending on the regulators and the Th subtype. As such the co-expression of T-bet and Bcl-6 is needed 
to establish Th1 cells, as Bcl-6 is repressing other Th cell fates ${ }^{100}$. In addition, also other factors are crucial for the initiation of Th cell polarization, such as the cytokine-regulated environmental response factors (ERF). Among these, the signal transducer and activator of transcription (STAT) proteins, interferon regulatory factors (IRF), and activator protein 1 (AP-1) specifically regulate lineage-specific enhancers and induce the transcription of master regulator transcription factors ${ }^{101,102}$. Due to their evidenced restricted function as master regulators, they are currently called lineage-specifying transcription factors. Even though they are not solely responsible for inducing the $\mathrm{CD}^{+} \mathrm{T}$ cell differentiation process and have a minimal role in the de novo activation of enhancers, these transcription factors still play a crucial role on regulatory DNA elements and enhancers ${ }^{102}$, by binding to previously activated regulatory elements to augment or tune the activity of the $\mathrm{CD}^{+} \mathrm{T}$ cell. In this way, the lineage-specifying transcription factors are able to inhibit the expression of genes instructing other Th lineages and to stimulate their own Th fate via a positive feedback loop.

Furthermore, it has been shown that polarized Th cells are not terminally differentiated and committed cells, but that they retain a certain degree of flexibility (e.g. cytokine gene expression) and plasticity and are able to respond and adapt their phenotype to changing environmental cues ${ }^{103}$. When cultured in Th2-favoring conditions, human memory Th1 were shown to upregulate secretion of Th2 cytokines ${ }^{104}$. Another example are the Th1/ Th17 cells; under certain environmental conditions, such as chronic inflammation, Th17 cells can acquire properties of Th1 cells and secrete IFN- ${ }^{105,106}$. These IL-17/IFN- $\gamma$ double producing cells are increased in patients with autoimmune diseases ${ }^{94,107}$. In this line, the classification of the more recently discovered Th9 and Th22 cells is still ongoing; whether they can be considered as separate subsets or represent different states of Th2 respectively Th17 cells is still debatable ${ }^{108-110}$.

Besides their helper function, $\mathrm{CD} 4^{+} \mathrm{T}$ cells can also acquire cytolytic capacities under certain environmental circumstances, such as chronic activation and the associated persistent antigen exposure. During the development of $\mathrm{CD}^{+}{ }^{+}$Th cells, the transcriptional regulator ThPOK plays an important role in repressing the cytolytic gene expression programme and thus repressing the $\mathrm{CD}^{+} \mathrm{T}$ cell fate. In mature $\mathrm{CD}^{+} \mathrm{T}$ cells, the expression of ThPOK can be downregulated allowing the induction of the cytolytic gene expression programme and the generation of $\mathrm{CD}^{+} \mathrm{CTL}^{111,112}$. These $\mathrm{CD} 4^{+}$CTL cells gradually appear with persistent viral infections and seem to be of importance in controlling these chronic infections ${ }^{113}$.

\section{Differences between mice and men}

Up-to-date the majority of our current knowledge on $\mathrm{T}$ cell polarization has been generated by using murine models. These models are great tools to study e.g. the importance of 
specific transcription factors or other proteins involved in the differentiation process of naive $\mathrm{CD}^{+} \mathrm{T}$ cells ${ }^{114}$. Nevertheless, a pivotal limitation of using these models is the discrepancy of some crucial aspects between murine and human immune systems ${ }^{115}$. This makes it challenging to use and to extrapolate knowledge generated from murine models in the context of human $\mathrm{CD}^{+}{ }^{+} \mathrm{T}$ cell polarization.

Murine and human DC subsets differ in terms of cytokine profiles ${ }^{116}$, their PRR expression patterns ${ }^{117-122}$, and ligand recognition ${ }^{123}$. In mice, LPS triggers TLR3, whereas in humans the only ligand for TLR3 is dsRNA. Moreover, divergences occur in transcription factors involved in the skewing towards different Th subsets ${ }^{124-126}$. Whereas in humans STAT4 is activated by IFN- $\alpha$ and is required for Th1 polarization, in mice INF- $\alpha$ does not lead to Th1 polarization ${ }^{127}$. Additionally, Th subtypes are responsible for clearance of the different pathogenic classes; the clearance of schistosomiasis caused by parasitic worms occurs by Th2 induction in humans, whereas in mice the activation of Th1 cells is crucial ${ }^{128,129}$. Thus, murine models are suboptimal to study all aspects of human $\mathrm{CD}^{+} \mathrm{T}$ cell polarization and there is need for valorisation of therapeutic interventions identified in murine models. This is strengthened by findings revealing that a cure identified in murine models was ineffective in humans ${ }^{130-132}$.

Considering the emerging complexity of the regulation of Th responses reveals the necessity for good, consistent tools and methods to study the $\mathrm{CD}^{+}{ }^{+} \mathrm{T}$ cell regulation in more depth. Currently available human in vitro assays to study APC-dependent initiation of naive CD4 ${ }^{+}$ $\mathrm{T}$ cell responses are limited. Despite the progress in understanding the processes involved in $\mathrm{CD}^{+}{ }^{+} \mathrm{T}$ cell polarization, the currently available methodologies limit the study of certain aspects of human $\mathrm{CD}^{+} \mathrm{T}$ cell immunity.

\section{IMMUNOMODULATORY ROLE OF NK CELLS}

NK cells were first described in the early seventies ${ }^{133-135}$ and are large granular lymphocytes arising from the same lymphoid progenitors as $\mathrm{T}$ and $\mathrm{B}$ lymphocytes. Different from $\mathrm{B}$ and T lymphocytes, NK cells are part of the innate immunity. More recently, they have been classified as being part of innate lymphoid cells (ILC), which are considered to be the innate counterpart of the adaptive Th cells. Conventional IFN- $\gamma$-producing NK cells are part of group I ILC ${ }^{136}$. Initially, NK cells were described as 'killers' having capacity to eliminate malignant cells without the need for priming. Up-to-date the functions ascribed to NK cells are extended: cytotoxicity and secretion of antimicrobial products, cytokine and chemokine secretion, contact-dependent co-stimulation and regulation of other immune cells ${ }^{137}$. 
Cellular cytotoxicity is mediated by a tight balance of NK cell inhibitory (several killer immunoglobulin receptors [KIRs], NKG2A/CD94) versus activating receptors (natural cytotoxicity receptors [NCR], NKG2D, DNAM-1) and their interaction with the respective ligands on the target cells. Ligands for inhibitory receptors are classical and non-classical MHC class I molecules. Abnormal cells are recognized by NK cells due to lack of MHC class I ligation to inhibitory NK cells receptors (known as missing self-recognition) or by the upregulation of stress ligands ligating activating receptors expressed on NK cells (known as stress-induced self-recognition) ${ }^{138}$ (Figure 3A). Additionally, NK cell licensing (also called NK cell education) prevents autoreactivity of NK cells. During functional maturation of NK cells, the cells need to engage self-MHC via their KIRs to acquire full effector function. $\mathrm{NK}$ cells that fail to engage the corresponding MHC class I molecules for the expressed KIR repertoire are hyporesponsive ${ }^{139}$. Upon contact of licensed NK cells with target cells triggering their activation (activating signals > inhibitory signals), lysosomes, containing perforin and granzymes, are transported to the membrane of NK cells and secreted into the immunological synapse inducing the lysis of target cells (granule exocytosis) ${ }^{140}$. Another mechanism of eliminating target cells is via death receptor pathway involving FasL, TRAIL and $\mathrm{TNF}_{-} \alpha{ }^{141}$. NK cells can recognize antibody-coated target cells via their Fc $\gamma \mathrm{RIII}$ (CD16) which can bind to the Fc portion of the antibody and mediate activation of NK cells and lysis of the target cell. This process is called antibody-dependent cell-mediated cytotoxicity (ADCC) ${ }^{142}$. Additionally, NK cells are potent cytokine producers; depending on their activation, NK cells secrete IFN- $\gamma$, TNF- $\alpha$, GM-CSF, IL-5, IL-13, CCL3, CCL4 and CCL5 ${ }^{143-145}$.

In peripheral blood two major NK cell subsets can be distinguished: $\mathrm{CD} 56^{\mathrm{dim}} \mathrm{CD} 16^{+}(90 \%)$ and $\mathrm{CD}_{5} 6^{\text {bright }} \mathrm{CD} 16^{-}(10 \%)$. In lymph nodes $(\mathrm{LN})$ this ratio is inversed. CD56 ${ }^{\mathrm{dim}} \mathrm{CD} 16^{+}$are commonly referred to as the cytotoxic subset, expressing KIRs and containing cytotoxic granules, whereas $\mathrm{CD} 56^{\text {bright }} \mathrm{CD} 16^{-} \mathrm{NK}$ cells are considered to be the major cytokine producers ${ }^{146}$. Nonetheless, reports on the IFN $\gamma$-secreting $\mathrm{NK}$ cell subpopulation are still controversial and both $\mathrm{CD} 56^{\text {bright }}$ and $\mathrm{CD} 56^{\mathrm{dim}}$ subsets have been shown to produce IFN- $\gamma^{147-149}$. Moreover, LN CD56 ${ }^{\text {bright }}$ CD16- NK cells upregulate CD16, KIR and NCR (NKp46 and NKp30) after encounter of $\mathrm{T}$ cells and IL-2, enabling them to kill their targets ${ }^{150,151}$. After acquisition of KIR expression and perforin, the expression of CD56 and CD16 is reported to be stable ${ }^{152}$. Possibly, CD56 ${ }^{\text {dim }}$ NK cells represent a subsequent stage of $\mathrm{CD}^{6} 6^{\text {bright }}$ cells and are more mature ${ }^{153}$. Furthermore, the classification of NK cell subsets can be refined by CD57 and CD27 expression pattern ${ }^{154-156}$. These two subsets express divergent chemokine receptor profiles. Resting $\mathrm{CD} 56^{\mathrm{dim}} \mathrm{CD} 16^{+}$express a variety of chemokine receptors, mainly CXCR1 and CX3CR1, and migrate upon CXCL12 and CXC3L1 towards peripheral sites of inflammation. In contrast, CD56 ${ }^{\text {bright }}$ CD16- express CCR5 and CCR7 allowing their migration to secondary lymphoid organs upon CCL19, 
CCL21, CXCL10, CXCL11, and CXCL12 ${ }^{145,153 .}$

\section{DC-induced NK cell responses}

DC have the capacity to activate NK cells by soluble as well as contact-dependent factors and thereby enhancing cytokine production, proliferation, survival, and cytotoxicity of NK cells as illustrated in Figure 4.

DC activate NK cells to produce cytokines (mainly TNF- $\alpha$ and IFN- $\gamma$ ), which is dependent on a two-signal activation by soluble or contact-dependent factors or a combination of both ${ }^{157-159}$. Depending on the encountered maturation stimuli, DC produce specific cytokines and upregulate $\mathrm{NK}$-cell activating surface molecules. DC-derived soluble factors, such as IL-12, IL-15, IL-18, IL-2, and IFN- $\alpha / \beta$ are highly efficient in activating NK cell responses ${ }^{160-167}$. The NK cell-activating capacity is confined to PRR-triggered DC ${ }^{160,168}$.

In addition to soluble factors, the activation of $\mathrm{NK}$ cells is enhanced by direct interaction with DC, suggesting that contact-dependent factors also play a role ${ }^{160}$. These factors include surface molecules expressed on DC that ligate with $\mathrm{NK}$ cell-activating receptors. One of these receptors is NKG2D, which is a C-type lectin co-activation receptor that binds to stress-inducible members of the polymorphic MHC class-I related chain A/B (MICA/B) family and ULBP ${ }^{169,170}$. Moreover, the activating NCR NKp30 and NKp46 are expressed by all NK cells and activate NK cells in the absence of additional stimuli ${ }^{171,172}$. They bind to currently unknown ligands expressed by DC ${ }^{173-175}$. The expression of a third NCR, NKp44, is restricted to activated NK cells ${ }^{176}$. A high expression of NCR on NK cells is correlated with high cytotoxic capacities ${ }^{171,172}$. Another contact-dependent interaction, ligation of CD48 by 2B4 receptor expressed on NK cells, is still promiscuous as the 2B4-pathway can be either activating or inhibitory ${ }^{177,178}$, depending on the maturation status and localization of the NK cell itself ${ }^{179}$. These stress-dependent factors can be upregulated during DC maturation and mediate danger signals to the surrounding tissue. The resulting cytokine release by NK cells can further amplify DC maturation or enhance Th1 responses in an IFN- $\gamma$-dependent manner (Figure 3B).

Besides enhanced NK cell cytokine production also NK cell cytotoxicity can be enhanced by DC-dependent mechanisms ${ }^{158,180}$. DC-derived cytokines IL-12, IL-2, and IL-15 or combination of diverse cytokines (e.g. IL-12, IL-15, and IL-18) as well as interaction with contact-dependent factors (e.g. NKp30, NKp46, NKG2D) have been shown to influence NK cell-mediated cytotoxicity ${ }^{174,181-183}$. These DC-induced cytolytic mechanisms include both perforin and granzyme B-pathways and FasL/Fas-based pathways ${ }^{184}$. 


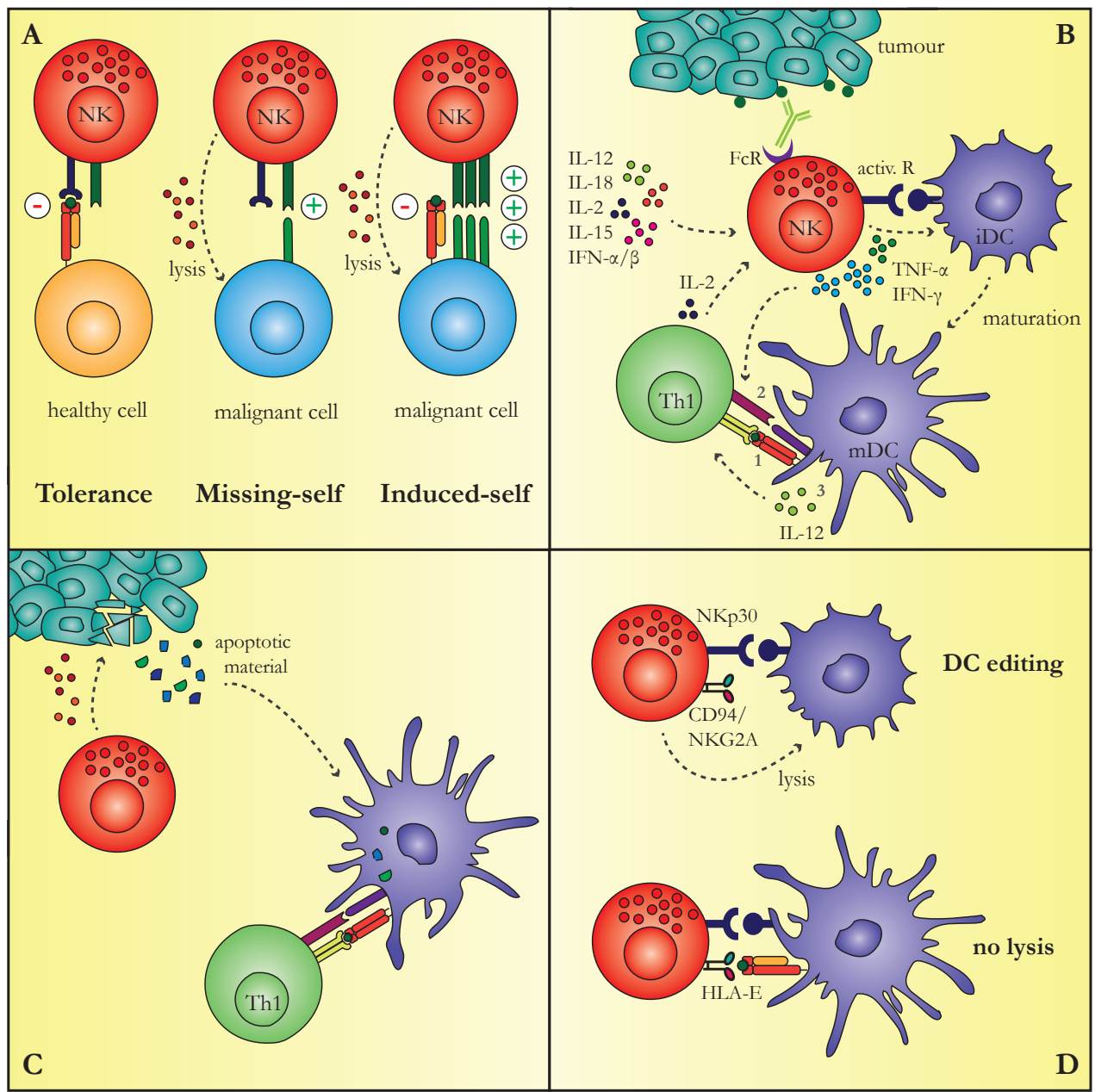

Figure 3 | Functions of NK cells. (A) Concept of tolerance, missing-self and induced-self regulating the cytolytic activity of NK cells. (B) Activated NK cells provide cytokines and contact-dependent activation factors for DC maturation. Moreover, NK cells provide IFN- $\gamma$ and co-stimulatory factors to enhance Th1 polarization. (C) Cytolytic activity of NK cells provides antigenic material for DC (cross-) presentation (D) NK cell-mediated editing of immature DC.

\section{NK cell-induced DC responses}

NK cells hold the capacity to control and enhance DC-induced immune responses, mainly by influencing the maturation of Th1-polarizing DC, providing antigenic material for presentation by DC, and killing of inappropriately matured or immature DC (DC editing) (Figure 3B-D). 
As NK cells have the natural capacity to kill virally infected or malignantly transformed cells ${ }^{138}$, they are not only involved in the direct elimination of these cells, but also provide (tumour-related) antigenic material facilitating the uptake, processing, and (cross-) presentation by DC ${ }^{185,186}$.

NK cells mediate immunoregulatory 'helper' functions. These helper cells are characterized as $\mathrm{CD} 83^{+} \mathrm{CCR} 7{ }^{+} \mathrm{CD} 56{ }^{\mathrm{dim}} \mathrm{NK}$ cells that possess DC-activating capacities ${ }^{148}$, which is mediated by both NK cell-derived soluble factors, mainly IFN- $\gamma$ and TNF- $\alpha{ }^{187,188}$, as well as ligation of surface receptors (e.g. CD40 ligation) ${ }^{189}$. NK-DC interaction results in the development of stable, type-1-polarized DC that produce high amounts of pro-inflammatory cytokines and, thereby, are able to enhance Th1 and CTL-mediated immunity against intracellular pathogens and cancer ${ }^{159,187,190,191}$. In the absence of NK cells, Th polarization is biased towards Th2 polarization, without induction of CTL ${ }^{192,193}$. NK cell-derived IFN- $\gamma$ induces upregulation of the Th1 lineage-specifying transcription factor T-bet and inhibition of the Th2 lineage-specifying transcription factor GATA-3 ${ }^{194}$. These 'helper' NK cells gained their function after activation by IL-12 or IL-18 ${ }^{148}$. Other pro-inflammatory cytokines (IL-2, IL-15, type-I IFNs: IFN- $\alpha / \beta)$, NK cell-sensitive tumour cell lines and opsonizing tumour-specific antibodies can synergize in a two-signal mechanism ${ }^{159,}, 190,195$.

NK cells also have the capacity to eliminate autologous and allogeneic iDC ${ }^{187,196}$. NKp30 has been shown to play a major role in iDC lysis and cooperates with DNAM-1. Because both mature as well as iDC express ligands for NKp30 and DNAM-1 ${ }^{197}$, an additional mechanism must be involved. Analysis of NK cell clones has revealed that killing of iDC was confined to NK cells that lack expression of inhibitory KIRs specific for self-HLA class I alleles, but do express the HLA-E-specific CD94/NKG2A inhibitory receptor ${ }^{198}$. iDC become susceptible to NK cell-mediated cytotoxicity due to low HLA-E expression irrespective of expression of other HLA molecules. In contrast, mDC upregulate HLA-E and are, therefore, kept untouched ${ }^{198,}{ }^{199}$. iDC have been implicated in tolerance and induction of regulatory $\mathrm{T}$ cells ${ }^{200}$. Thus, it can be hypothesized that by eliminating iDC, NK cells ensure activation of adaptive immune responses by preventing inadequately matured DC to interact with T cells ${ }^{196,201,202}$. Although in apparent paradox, NK cells can induce DC maturation as well lysis of iDC, which depends on the relative numbers of each cell type ${ }^{187}$.

The crosstalk of NK cells and DC can occur at multiple locations; NK-DC interaction takes place at the site of inflammation as well as in the lymph nodes ${ }^{203}$. During an inflammatory response, a burst of immunoactive molecules is secreted, including chemokines, resulting in immune cell recruitment. We and others have shown that upon maturation, TLR-triggered DC produce large amounts of many different chemokines 204, 205. Among these, NK cell-recruiting chemokines are produced, like CCL5, CXCL10, and CCL19. Different 


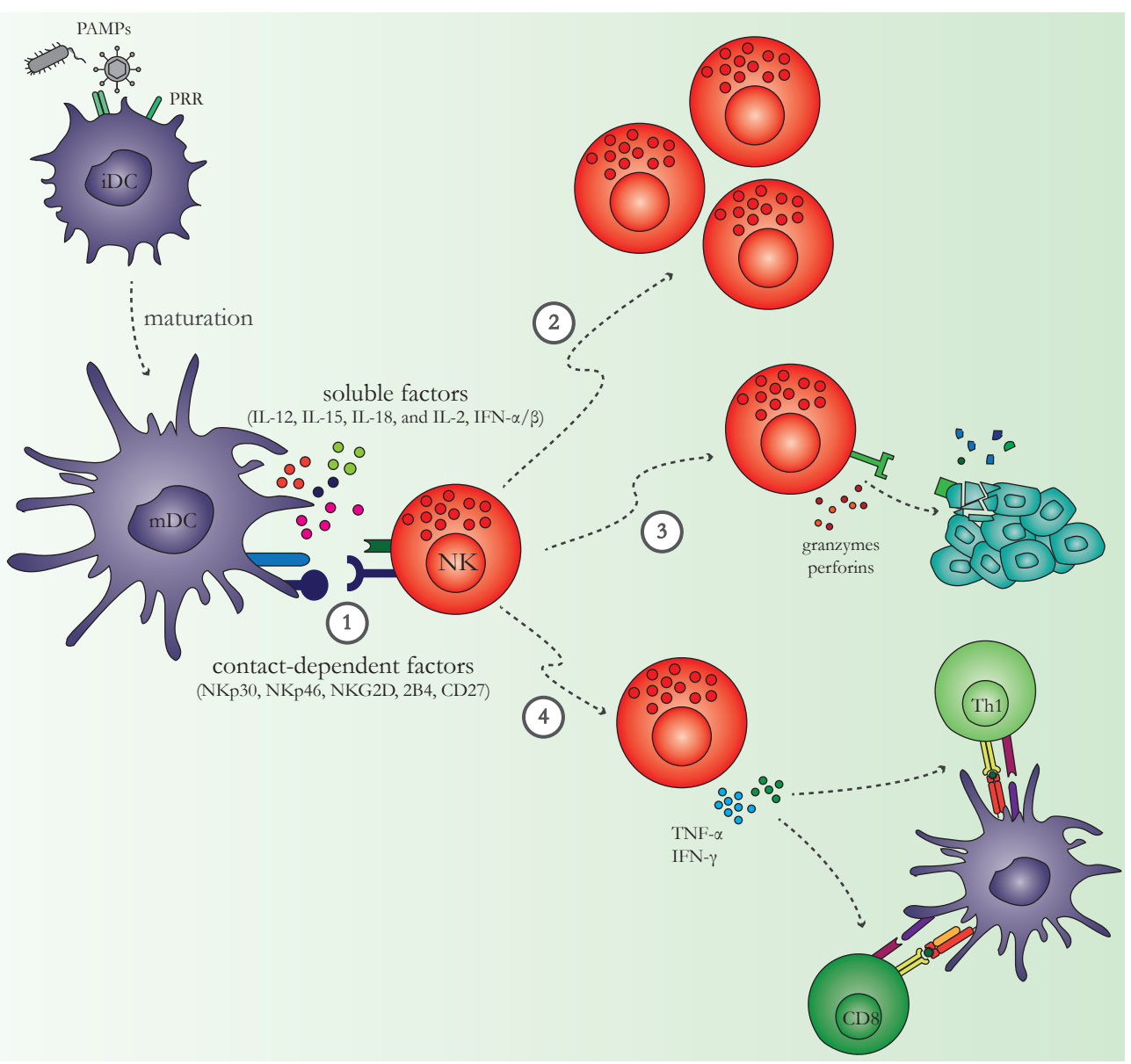

Figure 4 | DC-induced NK cell responses. (1) PAMP-matured DC activate NK cells via contactindependent and/or via contact-dependent factors by a two-signal activation. This leads to enhanced NK cell proliferation and survival (2), increased cytotoxic capacity of NK cells via granule exocytosis and death receptor pathway (3). Additionally, the NK-DC crosstalk enhances helper activity of NK cells by inducing the release of pro-inflammatory cytokines (mainly TNF- $\alpha$ and IFN- $\gamma$ ). These soluble factors enhance maturation of surrounding DC, Th1 polarization, and CTL activation (4).

chemokines and chemokine receptors have been shown to be involved in DC-mediated NK cell recruitment ${ }^{147,}{ }^{194}$. Because maturing DC migrate into the draining lymph nodes, chemokine production by mature DC is possibly also responsible for the recruitment of NK cells into the lymph node. In CXCR $3^{-/-}$mice, it has been shown that Th1 polarization was inhibited, due to impaired recruitment of NK cells into the lymph nodes ${ }^{194}$. In humans, however, additional NK cell-recruiting mechanisms have been proposed. NK cells are able to upregulate their CCR7 expression and subsequently their responsiveness to the lymph node-homing chemokine CCL19 upon activation with IL-18 and after NK-DC crosstalk $^{147,148}$. This would represent an additional mechanism by which DC induce NK cell 
migration into the draining lymph nodes. Given the heterogeneity of DC subsets and the location of NK cells at different sites of the body ${ }^{206}$, NK-DC crosstalk may have different functional consequences on the induced immune responses depending on the site of interaction. Likewise, BDCA- $1^{+}$DC, described as potent IL-12 producers ${ }^{207}$, could provide this cytokine in the secondary lymphoid organs to enhance the helper function mediated by NK cells via the release of IFN- $\gamma$ and stimulate the induction of potent T cell responses. On the other hand, BDCA- $3^{+}$cells located in inflamed tissue could be a source of IFN- $\alpha$, which enhances the cytolytic function of NK cells at the site of infection ${ }^{208}$. This bi-directional crosstalk between different human DC subsets and NK cells needs further investigation.

\section{NK cells and $T$ cell responses}

Another feature of NK-DC crosstalk is the $\mathrm{CD}^{+} \mathrm{T}$ cell-independent induction of CTL responses. Different studies established the need for proper NK cell function for the induction of CTL responses. Moreover, CTL induction was abolished after removal of NK cells. Thus, NK cells are important players of CTL initiation and persistence ${ }^{209-213}$. This function of NK cells is attributed to NK cell-secreted cytokines which are partly dependent on NK-DC crosstalk ${ }^{214}$. For example, IL-2 and IL-15-stimulated NK cells upregulate CD137 and via CD137 ligation NK cells produce IFN- $\gamma$ and proliferate, which is accompanied by expansion of activated $\mathrm{CD}^{+} \mathrm{T}$ cells in vitro ${ }^{215}$.

Besides providing IFN- $\gamma$ to enhance DC-induced Th1 polarization, NK cells may also directly interact with $\mathrm{CD}^{+}{ }^{+} \mathrm{T}$ cells. Activated $\mathrm{NK}$ cells can upregulate $\mathrm{MHC}$ class II and co-stimulatory molecules (e.g. CD80, CD86, CD70 OX40L) ${ }^{216,217}$ displaying APC-like properties with unique pathways for antigen uptake, presentation, and direct activation of $\mathrm{CD}^{+} \mathrm{T}$ cells ${ }^{217-219}$. This process may be locally limited to secondary lymphoid organs. Interestingly, NK cells present in human inflamed tonsils displayed higher MHC class II and co-stimulatory molecules expression ${ }^{217}$. The upregulating of co-stimulatory molecules is probably influenced by the local environment. Likewise, innate cytokines or crosslinking of various activating receptors were sufficient to upregulate CD86 expression on NK cells. However, the ligation of activating receptors (e.g. CD16, NKG2D) in combination with innate cytokines were required to induce OX40L. Crosstalk between activated NK cells and autologous $\mathrm{CD}^{+} \mathrm{T}$ cells induced proliferation and cytokines secretion of Th cells ${ }^{217,219,220}$.

\section{Direct recognition of pathogens}

The importance of NK cells in human host defence and control of infections is supported by several patients with NK cell deficiencies displaying an increased susceptibility to recurrent viral infections (mainly herpes- and papillomavirus) ${ }^{221-224}$. Besides the activation 
of NK cells via PAMP-sensing accessory cells (e.g. DC), NK cells have also been identified to express a repertoire of innate PRR, allowing a potential direct recognition of PAMPs. Until now the expression of TLR1-10 as well as RIG-I, NOD2, NRLP3, and MDA5 225-227 has been confirmed. Engagement of various TLR (TLR2, 3, 7, 8, and 9) has been shown to activate NK cells and enhance their proliferation, cytotoxicity against various tumour cell lines ${ }^{228-231}$ as well as increase their DC editing capacity ${ }^{231}$. Moreover, the activation of NK cells via MDP (NOD2 receptor ligand) enhanced cytokine production, but not cytotoxicity ${ }^{225}$. Whereas NK cells could recognize certain PAMPs directly, for others the presence of accessory cytokines was required for efficient sensing 229,232 . Further research is needed to reveal the exact role of triggering other PRR expressed by NK cells on their function as well as the role of PRR-triggering in the induction of their 'helper' properties.

\section{Regulatory functions of NK cells}

Besides all the immune stimulatory capacities assigned to NK cells, they can also act as immune regulators to keep immune homeostasis. This attributes an important function to NK cells in autoimmunity, pregnancy, tolerance, and organ transplantation. Several animal models revealed a progress of autoimmune disorders when NK cell were depleted. In this line, patients with diabetes, multiple sclerosis, or rheumatoid arthritis display reduced numbers and activity of NK cells ${ }^{233-235}$. The NK cell rheostat function can be mediated by direct elimination of overstimulated immune cells (e.g. activated T cells) or by secretion of inhibitory cytokines (e.g. IL-10 and TGF- $\beta$ ) blocking the activation and proliferation of $\mathrm{T}$ cells ${ }^{236-241}$. The precise functions and mechanisms of action of regulatory NK cells are currently being explored; definition of NK cell regulatory subsets and their induction as well as the influence of viral load on the mediated outcome are subject of investigation ${ }^{242}$.

\section{CANCER IMMUNOTHERAPY \& DC VACCINATION}

Besides the conventional cancer treatments such as surgery, radiation-, and chemotherapy, immunotherapy has been implemented into standard treatment regimens for certain types of cancer. The main goal of cancer immunotherapy is to stimulate and/or restore the patient's immune system to specifically attack and to reject the tumour. Different types of cancer immunotherapy exist, which can be divided into passive and active approaches as well as specific and non-specific mechanisms of action. Immunomodulatory agents (e.g. cytokines, adjuvants), monoclonal antibodies (mAb; e.g. rituximab), adoptive cell transfer or therapeutic vaccines are examples of cancer immunotherapy. In 1891, W. Coley applied the first form of cancer immunotherapy by treating cancer patients with bacterial injections ${ }^{243}$. In the mid 1980's, the first cytokine, IFN- $\alpha$, was approved by the FDA as cancer treatment. 
This was followed by approvals of other cytokines as well as the use of $\mathrm{mAb}$, the first one being rituximab in 1997 targeted against CD20 to treat B cell lymphomas. A breakthrough for active cancer immunotherapy occurred in 2010, with the FDA-approval of the first therapeutic cancer vaccine, sipuleucel-T $\left(\right.$ Provenge $\left.^{\circledR}\right){ }^{244}$ for the treatment of advanced prostate cancer resulting in a prolonged survival of patients by 4.1 months. This success was followed by the FDA-approval of the cytotoxic T-lymphocyte-associated protein 4 (CTLA4; ilipimumab), a checkpoint-inhibitor extending the survival of patients with metastatic melanoma. In 2014, mAb targeting another checkpoint, PD-1, have been approved, nivolumab and pembrolizumab, designated for the treatment metastatic melanoma and squamous non-small cell lung cancer. In the meanwhile, promising clinical trials with optimized or novel as well as combinatorial approaches of cancer immunotherapy are ongoing. One of these approaches is the chimeric antigen receptor (CAR) $T$ cell therapy. This approach applies genetically modified T cells from patient's body to target and specifically eliminate the cancer cells. Promising results have been shown in several clinical trials reaching $89-100 \%$ response rates ${ }^{245-247}$.

The approval of Provenge ${ }^{\circledR}$ by the FDA illustrates the potential of cell-based vaccines for anti-cancer immunotherapeutic treatments. DC are of particular interest in vaccination strategies since they are sentinel cells of the innate immune system and are the key regulators in linking the innate and adaptive immune system ${ }^{248}$. In patients with cancer DC display an increased immature phenotype, reduced stimulatory capacities, and an impaired induction of type-1 immune responses ${ }^{249,250}$, which are important to induce effective anti-tumour responses. Thus, one of the strategies to overcome the problem of dysfunctional DC in cancer patients is the injection of ex vivo-matured DC, which are capable of restoring the immunosuppressive balance. In contrast to endogenously developing DC, they are partially resistant to tumour-related suppressive factors ${ }^{77,251}$. The generation of new methods to isolate monocytes in large numbers from peripheral blood and culture them ex vivo into iDC ${ }^{252,253}$, opened new possibilities to apply these cells in vaccination strategies. The most commonly applied strategy to generate ex vivo DC is illustrated in Figure 5. In 1996, the results of the first clinical trial using antigen-pulsed iDC were published ${ }^{254}$. Initial studies applied iDC or partly matured DC, which only displayed limited T cell-stimulating activity and turned out to induce tolerogenic instead of immunogenic responses. The next generation of DC-based vaccines, which is by far the most common approach ${ }^{255}$, applied long-term IL-4/GMCSF-differentiated monocytes (5-7 days), which have been matured with a $\mathrm{PGE}_{2} / \mathrm{TNF}-$ $\alpha$-cocktail ( \pm IL-6/IL-1- $\beta$; often referred to as golden standard) ${ }^{256}$. These DC displayed a fully mature phenotype (high expression of MHC and costimulatory molecules), as well as enhanced in vitro migration and immune stimulation. However, the resulting $\mathrm{mDC}$ were lacking an immunostimulatory cytokine profile, mainly the production of IL-12p70, which turned out to be crucial for the efficacy of DC to induce type 1 immune responses ${ }^{257-260}$. 
Subsequent studies explored the addition of various cytokines and/or PRR-triggers as well as 'fast' differentiation/maturation protocols to enhance the immunostimulatory cytokine production. Defining an optimal combination of different factors to be included in the maturation cocktails is of relevance as it impacts the resulting DC phenotype, the amount, timing and duration of cytokine production and their trafficking properties ${ }^{261}$. Clinical trials applying this third generation of DC-based vaccines are still ongoing. Besides identifying the appropriate differentiation and maturation protocols for the use of moDC, current studies also investigate the effectiveness of using endogenous blood-circulating subsets in DC vaccination 262, 263. Moreover, crucial advances have been made in identifying optimal injection routes and regimens, and antigen-loading strategies. The combination of DCbased vaccines with other approaches, such as adjuvants or checkpoint inhibitors, are also currently explored.

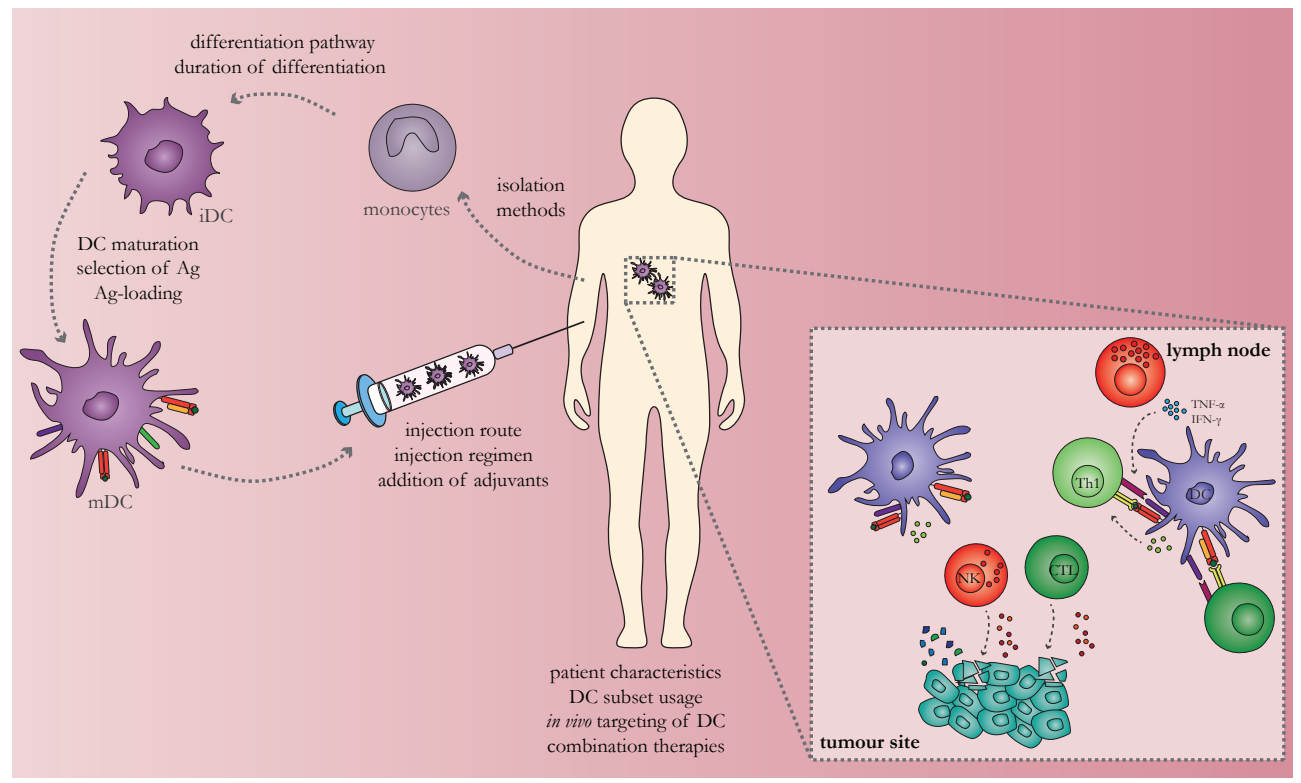

Figure 5 | DC-based vaccination. One of the most common methods to generate ex vivo-matured DC is shown. Monocytes are isolated from the patient's blood via leukapheresis, followed by elutriation. Monocytes are differentiated into iDC, which are matured and loaded with tumour-associated antigens. The obtained mature DC are re-injected into the patient where they possibly induce a type 1 immune response against the tumour including interaction of at least NK cells, CTL, and Th1 cells. Different intervention points to boost DC-based vaccines are indicated.

(C) T.H.P.M Habets

In general, many aspects need to be considered to design an optimal DC-based vaccine such as isolation methods of monocytes (or other DC subsets), differentiation pathways, maturation, choice and source of $\mathrm{Ag}$ and $\mathrm{Ag}$-loading, injection route and regimen, combination with 
adjuvants, and patient characteristics (e.g. host immunological competence, tumour size). DC used in clinical trials should ideally not be exhausted (still able to produce cytokines upon CD40 ligation), express high levels of costimulatory molecules (especially CD83), MHC class I and II molecules, and CCR7 (migration towards secondary lymphoid organs) and produce IL-12p70.

Besides the use of ex vivo-generated DC other approaches exist to manipulate and boost anti-cancer activities of DC, such as: endogenous vaccination (e.g. checkpoint blockade), reprogramming inflammation (e.g. blocking of cytokines), and the targeting antigens to DC subsets in vivo 264,265 . 


\section{SCOPE OF THE THESIS}

During a pathogenic insult, the efficient cooperation of innate and adaptive immunity is needed to eradicate the invader. PRR, expressed on various types of immune cells, are important components of the innate immunity and are responsible for sensing and instructing appropriate and coordinated immune responses. The main cell type expressing PRR and thus linking innate and adaptive immunity are APC, such as DC. Because of their importance and unique properties of instructing various immune effector cells, DC have been considered as promising targets in immunotherapeutic strategies against cancer.

Cancer immunotherapy aims to stimulate the patient's immune responses to eliminate the tumour cells. One approach of cellular immunotherapy are DC-based vaccines, which have been proven to be safe and non-toxic, however, overall clinical outcome is still limited. In 2010, the first DC-based vaccine against advanced prostate cancer, Provenge ${ }^{\circledR}$, has been approved by the FDA ${ }^{266}$. This vaccine prolonging the patient's life-time for several months (without eradicating the tumour) in combination with different ongoing clinical trials testing DC-based vaccination, exemplifies the potential role of DC-based vaccines in future standard anti-cancer treatments. Nonetheless, the limited overall positive clinical outcome monitored is indicative for the need of further optimizations. Initial studies focused on generating DC having the potential to efficiently induce anti-tumour CTL responses. However, increasing evidence indicates that the induction of more complete type 1 immune responses, including also Th1 and NK cells, is crucial for the induction of efficient anti-tumour responses.

The main aim of this thesis was to study the cellular interplay of DC, NK cells and T helper cells after PAMP encounter with main focus on type 1-induced helper responses (Figure 6). Identifying which signals induce and enhance the interaction of DC with different immune effector cells is important to increase the efficacy of DC vaccination strategies.

To study the crosstalk between DC, NK cells, and naive $\mathrm{CD}^{+}{ }^{+} \mathrm{T}$ cells and the influence of PAMPs on this cellular interplay, we started with setting up an assay allowing the study of naive $\mathrm{CD}^{+} \mathrm{T}$ cell polarization by autologous $\mathrm{DC}$ subsets in a human setting as described in chapter 2. Moreover, we applied the assay to evaluate the capacity of DC matured with various cocktails currently used in clinical trials to polarize naive $\mathrm{CD} 4^{+} \mathrm{T}$ cells. In chapter 3 , we studied the capacity of specific PAMP-matured DC to induce both NK helper cell activation and Th1 polarization. Additionally, we aimed to identify common soluble factors regulating this interaction. Moreover, in chapter 4, we aimed to study whether NK cells could be directly activated by different viral and bacterial PAMPs. We investigated whether these PAMP-activated NK cells could enhance the maturation of DC via the release of soluble factors. In the context of cancer, these cellular interactions are influenced by the 
presence of inhibitory factors released by tumor cells. In chapter 5, we studied the direct effect of such an immune suppressor, $\mathrm{PGE}_{2}$, on PAMP-induced DC maturation, NK cell activation, and on NK-DC crosstalk. This thesis concludes with a general discussion presented in chapter $\mathbf{6}$, reflecting the most important findings in the context of adjuvants for vaccination and the impact of helper cells in future DC vaccination strategies as well as the impact of tumour-derived suppressive factors on the efficacy of immunotherapy.

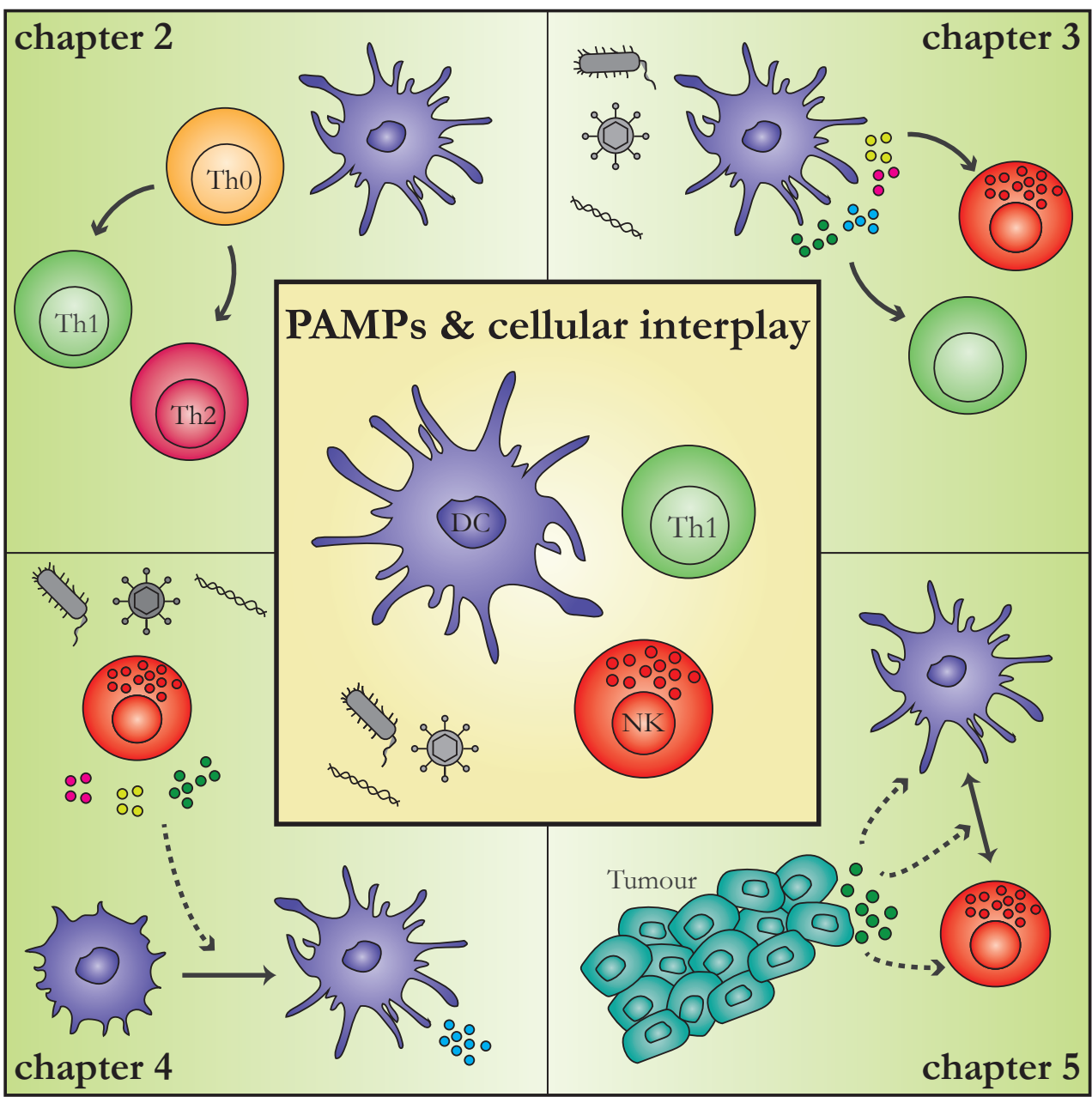

Figure 6 | Outline of the dissertation. The aim of the studies presented in this dissertation was to investigate how the cellular interplay between DC, NK cells and T helper cells could be influenced by various PAMPs. Chapter 2 describes the setting up of a human autologous naive $\mathrm{CD} 4^{+} \mathrm{T}$ cell polarization assay allowing to study the capacity of differently matured DC to polarize Th0 cells. In chapter 3 , we investigated the potential of PAMP-matured DC to activate both NK helper cell responses and Th1 cells. Chapter 4 describes the direct sensing of PAMPs by NK cells and how these cells can contribute to the activation of DC. In chapter 5, the influence of tumour-derived suppressive PGE 2 on NK-DC crosstalk was investigated. 


\section{REFERENCES}

1. Janeway CA, Jr., Medzhitov R. Innate immune recognition. Annu Rev Immunol. 2002;20:197-216.

2. Iwasaki A, Medzhitov R. Regulation of adaptive immunity by the innate immune system. Science. 2010;327(5963):291-295.

3. Medzhitov R. Toll-like receptors and innate immunity. Nature reviews Immunology. 2001;1(2):135145.

4. Palm NW, Medzhitov R. Pattern recognition receptors and control of adaptive immunity. Immunol Rev. 2009;227(1):221-233.

5. Bianchi ME. DAMPs, PAMPs and alarmins: all we need to know about danger. J Leukoc Biol. 2007;81(1):1-5.

6. Padovan E, Landmann RM, De Libero G. How pattern recognition receptor triggering influences T cell responses: a new look into the system. Trends Immunol. 2007;28(7):308-314.

7. Iwasaki A, Medzhitov R. Control of adaptive immunity by the innate immune system. Nat Immunol. 2015;16(4):343-353.

8. O’Neill LA, Golenbock D, Bowie AG. The history of Toll-like receptors - redefining innate immunity. Nat Rev Immunol. 2013;13(6):453-460.

9. Trinchieri G, Sher A. Cooperation of Toll-like receptor signals in innate immune defence. Nat Rev Immunol. 2007;7(3):179-190.

10. Chen G, Shaw MH, Kim YG, Nunez G. NOD-like receptors: role in innate immunity and inflammatory disease. Annu Rev Pathol. 2009;4:365-398.

11. Hoving JC, Wilson GJ, Brown GD. Signalling C-type lectin receptors, microbial recognition and immunity. Cell Microbiol. 2014;16(2):185-194.

12. Geijtenbeek TB, Gringhuis SI. Signalling through C-type lectin receptors: shaping immune responses. Nat Rev Immunol. 2009;9(7):465-479.

13. Loo YM, Gale M, Jr. Immune signaling by RIG-I-like receptors. Immunity. 2011;34(5):680-692.

14. Reikine S, Nguyen JB, Modis Y. Pattern Recognition and Signaling Mechanisms of RIG-I and MDA5. Front Immunol. 2014;5:342.

15. Brubaker SW, Bonham KS, Zanoni I, Kagan JC. Innate immune pattern recognition: a cell biological perspective. Annu Rev Immunol. 2015;33:257-290.

16. Hornung V, Rothenfusser S, Britsch S, et al. Quantitative expression of toll-like receptor 1-10 mRNA in cellular subsets of human peripheral blood mononuclear cells and sensitivity to CpG oligodeoxynucleotides. J Immunol. 2002;168(9):4531-4537.

17. Galluzzi L, Vacchelli E, Eggermont A, et al. Trial Watch: Experimental Toll-like receptor agonists for cancer therapy. Oncoimmunology. 2012;1(5):699-716.

18. Schreibelt G, Tel J, Sliepen KH, et al. Toll-like receptor expression and function in human dendritic cell subsets: implications for dendritic cell-based anti-cancer immunotherapy. Cancer Immunol Immunother. 2010;59(10):1573-1582.

19. Merad M, Sathe P, Helft J, Miller J, Mortha A. The dendritic cell lineage: ontogeny and function of dendritic cells and their subsets in the steady state and the inflamed setting. Annu Rev Immunol. 2013;31:563-604.

20. Kokkinopoulos I, Jordan WJ, Ritter MA. Toll-like receptor mRNA expression patterns in human dendritic cells and monocytes. Mol Immunol. 2005;42(8):957-968.

21. Kawai T, Akira S. Toll-like receptors and their crosstalk with other innate receptors in infection and immunity. Immunity. 2011;34(5):637-650.

22. Mogensen TH. Pathogen recognition and inflammatory signaling in innate immune defenses. Clin Microbiol Rev. 2009;22(2):240-273, Table of Contents.

23. Longhi MP, Trumpfheller C, Idoyaga J, et al. Dendritic cells require a systemic type I interferon response to mature and induce CD4+ Th1 immunity with poly IC as adjuvant. J Exp Med. 2009;206(7):1589- 
1602.

24. Misch EA, Hawn TR. Toll-like receptor polymorphisms and susceptibility to human disease. Clin Sci (Lond). 2008;114(5):347-360.

25. Netea MG, Wijmenga C, O’Neill LA. Genetic variation in Toll-like receptors and disease susceptibility. Nat Immunol. 2012;13(6):535-542.

26. Banchereau J, Steinman RM. Dendritic cells and the control of immunity. Nature. 1998;392(6673):245252.

27. Kapsenberg ML. Dendritic-cell control of pathogen-driven T-cell polarization. Nature reviews Immunology. 2003;3(12):984-993.

28. Fancke B, O'Keeffe M. Monitoring dendritic cell activation and maturation. Methods Mol Biol. 2013;960:359-370.

29. Banchereau J, Briere F, Caux C, et al. Immunobiology of dendritic cells. Annu Rev Immunol. 2000;18:767-811.

30. Kalantari T, Kamali-Sarvestani E, Ciric B, et al. Generation of immunogenic and tolerogenic clinicalgrade dendritic cells. Immunologic Research. 2011;51(2-3):153-160.

31. Gluckman JC, Canque B, Rosenzwajg M. Dendritic cells: A complex simplicity. Transplantation. 2002;73(1):S3-S6.

32. Collin M, McGovern N, Haniffa M. Human dendritic cell subsets. Immunology. 2013;140(1):22-30.

33. Dzionek A, Fuchs A, Schmidt P, et al. BDCA-2, BDCA-3, and BDCA-4: three markers for distinct subsets of dendritic cells in human peripheral blood. J Immunol. 2000;165(11):6037-6046.

34. Segura E, Valladeau-Guilemond J, Donnadieu MH, Sastre-Garau X, Soumelis V, Amigorena S. Characterization of resident and migratory dendritic cells in human lymph nodes. J Exp Med. 2012;209(4):653-660.

35. McIlroy D, Troadec C, Grassi F, et al. Investigation of human spleen dendritic cell phenotype and distribution reveals evidence of in vivo activation in a subset of organ donors. Blood. 2001;97(11):34703477.

36. Lindstedt M, Lundberg K, Borrebaeck CA. Gene family clustering identifies functionally associated subsets of human in vivo blood and tonsillar dendritic cells. J Immunol. 2005;175(8):4839-4846.

37. Robbins SH, Walzer T, Dembele D, et al. Novel insights into the relationships between dendritic cell subsets in human and mouse revealed by genome-wide expression profiling. Genome Biol. 2008;9(1):R17.

38. Ito $\mathrm{T}$, Inaba $\mathrm{M}$, Inaba $\mathrm{K}$, et al. A CD1a+/CD11c+ subset of human blood dendritic cells is a direct precursor of Langerhans cells. J Immunol. 1999;163(3):1409-1419.

39. MacDonald KP, Munster DJ, Clark GJ, Dzionek A, Schmitz J, Hart DN. Characterization of human blood dendritic cell subsets. Blood. 2002;100(13):4512-4520.

40. van der Aar AM, Sylva-Steenland RM, Bos JD, Kapsenberg ML, de Jong EC, Teunissen MB. Loss of TLR2, TLR4, and TLR5 on Langerhans cells abolishes bacterial recognition. J Immunol. 2007;178(4):1986-1990.

41. Lundberg K, Albrekt AS, Nelissen I, et al. Transcriptional profiling of human dendritic cell populations and models--unique profiles of in vitro dendritic cells and implications on functionality and applicability. PLoS One. 2013;8(1):e52875.

42. Harman AN, Bye CR, Nasr N, et al. Identification of lineage relationships and novel markers of blood and skin human dendritic cells. J Immunol. 2013;190(1):66-79.

43. Haniffa M, Shin A, Bigley V, et al. Human tissues contain CD141hi cross-presenting dendritic cells with functional homology to mouse CD103+ nonlymphoid dendritic cells. Immunity. 2012;37(1):6073.

44. Jongbloed SL, Kassianos AJ, McDonald KJ, et al. Human CD141+ (BDCA-3)+ dendritic cells (DCs) represent a unique myeloid DC subset that cross-presents necrotic cell antigens. J Exp Med. 2010;207(6):1247-1260.

45. Bachem A, Guttler S, Hartung E, et al. Superior antigen cross-presentation and XCR1 expression 
define human CD11c+CD141+ cells as homologues of mouse CD8+ dendritic cells. J Exp Med. 2010;207(6):1273-1281.

46. Joffre OP, Segura E, Savina A, Amigorena S. Cross-presentation by dendritic cells. Nat Rev Immunol. 2012;12(8):557-569.

47. Poulin LF, Salio M, Griessinger E, et al. Characterization of human DNGR-1+ BDCA3+ leukocytes as putative equivalents of mouse CD8alpha+ dendritic cells. J Exp Med. 2010;207(6):1261-1271.

48. Mittag D, Proietto AI, Loudovaris T, et al. Human dendritic cell subsets from spleen and blood are similar in phenotype and function but modified by donor health status. J Immunol. 2011;186(11):62076217.

49. Lauterbach H, Bathke B, Gilles S, et al. Mouse CD8alpha+ DCs and human BDCA3+ DCs are major producers of IFN-lambda in response to poly IC. J Exp Med. 2010;207(12):2703-2717.

50. Colonna M, Trinchieri G, Liu YJ. Plasmacytoid dendritic cells in immunity. Nat Immunol. 2004;5(12):1219-1226.

51. Liu YJ. IPC: professional type 1 interferon-producing cells and plasmacytoid dendritic cell precursors. Annu Rev Immunol. 2005;23:275-306.

52. Cox K, North M, Burke M, et al. Plasmacytoid dendritic cells (PDC) are the major DC subset innately producing cytokines in human lymph nodes. J Leukoc Biol. 2005;78(5):1142-1152.

53. Grouard G, Rissoan MC, Filgueira L, Durand I, Banchereau J, Liu YJ. The enigmatic plasmacytoid T cells develop into dendritic cells with interleukin (IL)-3 and CD40-ligand. J Exp Med. 1997;185(6):11011111.

54. Siegal FP, Kadowaki N, Shodell M, et al. The nature of the principal type 1 interferon-producing cells in human blood. Science. 1999;284(5421):1835-1837.

55. O'Doherty U, Peng M, Gezelter S, et al. Human blood contains two subsets of dendritic cells, one immunologically mature and the other immature. Immunology. 1994;82(3):487-493.

56. Marrack P, Kappler J, Mitchell T. Type I interferons keep activated T cells alive. J Exp Med. 1999;189(3):521-530.

57. Villadangos JA, Young L. Antigen-presentation properties of plasmacytoid dendritic cells. Immunity. 2008;29(3):352-361.

58. Lui G, Manches O, Angel J, Molens JP, Chaperot L, Plumas J. Plasmacytoid dendritic cells capture and cross-present viral antigens from influenza-virus exposed cells. PLoS One. 2009;4(9):e7111.

59. Segura E, Durand M, Amigorena S. Similar antigen cross-presentation capacity and phagocytic functions in all freshly isolated human lymphoid organ-resident dendritic cells. J Exp Med. 2013;210(5):1035-1047.

60. Romagnani C, Della Chiesa M, Kohler S, et al. Activation of human NK cells by plasmacytoid dendritic cells and its modulation by CD4+ T helper cells and CD4+ CD25hi T regulatory cells. Eur J Immunol. 2005;35(8):2452-2458.

61. Gerosa F, Gobbi A, Zorzi P, et al. The reciprocal interaction of NK cells with plasmacytoid or myeloid dendritic cells profoundly affects innate resistance functions. J Immunol. 2005;174(2):727-734.

62. Segura E, Amigorena S. Inflammatory dendritic cells in mice and humans. Trends Immunol. 2013;34(9):440-445.

63. Ebner S, Ratzinger G, Krosbacher B, et al. Production of IL-12 by human monocyte-derived dendritic cells is optimal when the stimulus is given at the onset of maturation, and is further enhanced by IL-4. J Immunol. 2001;166(1):633-641.

64. Banchereau J, Palucka AK. Dendritic cells as therapeutic vaccines against cancer. Nat Rev Immunol. 2005;5(4):296-306.

65. Dalod M, Chelbi R, Malissen B, Lawrence T. Dendritic cell maturation: functional specialization through signaling specificity and transcriptional programming. EMBO J. 2014;33(10):1104-1116.

66. Itoh T, Ueda Y, Okugawa K, et al. Streptococcal preparation OK432 promotes functional maturation of human monocyte-derived dendritic cells. Cancer Immunol Immunother. 2003;52(4):207-214.

67. Boltjes A, van Wijk F. Human dendritic cell functional specialization in steady-state and inflammation. 
Front Immunol. 2014;5:131.

68. Dzopalic T, Rajkovic I, Dragicevic A, Colic M. The response of human dendritic cells to co-ligation of pattern-recognition receptors. Immunol Res. 2012;52(1-2):20-33.

69. Annunziato F, Romagnani C, Romagnani S. The 3 major types of innate and adaptive cell-mediated effector immunity. J Allergy Clin Immunol. 2015;135(3):626-635.

70. Kuchroo VK, Ohashi PS, Sartor RB, Vinuesa CG. Dysregulation of immune homeostasis in autoimmune diseases. Nat Med. 2012;18(1):42-47.

71. Clement LT. Isoforms of the CD45 common leukocyte antigen family: markers for human T-cell differentiation. J Clin Immunol. 1992;12(1):1-10.

72. Forster R, Schubel A, Breitfeld D, et al. CCR7 coordinates the primary immune response by establishing functional microenvironments in secondary lymphoid organs. Cell. 1999;99(1):23-33.

73. Palm NW, Rosenstein RK, Medzhitov R. Allergic host defences. Nature. 2012;484(7395):465-472.

74. Lassmann H, Ransohoff RM. The CD4-Th1 model for multiple sclerosis: a critical [correction of crucial] re-appraisal. Trends Immunol. 2004;25(3):132-137.

75. Korn T, Bettelli E, Oukka M, Kuchroo VK. IL-17 and Th17 Cells. Annu Rev Immunol. 2009;27:485517.

76. Rissoan MC, Soumelis V, Kadowaki N, et al. Reciprocal control of T helper cell and dendritic cell differentiation. Science. 1999;283(5405):1183-1186.

77. Vieira PL, de Jong EC, Wierenga EA, Kapsenberg ML, Kalinski P. Development of Th1-inducing capacity in myeloid dendritic cells requires environmental instruction. Journal of immunology. 2000;164(9):4507-4512.

78. Kalinski P, Hilkens CM, Wierenga EA, Kapsenberg ML. T-cell priming by type-1 and type-2 polarized dendritic cells: the concept of a third signal. Immunology today. 1999;20(12):561-567.

79. Kalinski P. Dendritic cells in immunotherapy of established cancer: Roles of signals 1, 2, 3 and 4. Curr Opin Investig Drugs. 2009;10(6):526-535.

80. Kalinski P, Edington H, Zeh HJ, et al. Dendritic cells in cancer immunotherapy: vaccines or autologous transplants? Immunol Res. 2011;50(2-3):235-247.

81. Mosmann TR, Coffman RL. TH1 and TH2 cells: different patterns of lymphokine secretion lead to different functional properties. Annu Rev Immunol. 1989;7:145-173.

82. Romagnani S. Human TH1 and TH2 subsets: doubt no more. Immunol Today. 1991;12(8):256-257.

83. Korn T, Oukka M, Kuchroo V, Bettelli E. Th17 cells: effector T cells with inflammatory properties. Semin Immunol. 2007;19(6):362-371.

84. Geginat J, Paroni M, Facciotti F, et al. The CD4-centered universe of human T cell subsets. Semin Immunol. 2013;25(4):252-262.

85. Mosmann TR, Cherwinski H, Bond MW, Giedlin MA, Coffman RL. Two types of murine helper T cell clone. I. Definition according to profiles of lymphokine activities and secreted proteins. Journal of immunology. 1986;136(7):2348-2357.

86. Harrington LE, Hatton RD, Mangan PR, et al. Interleukin 17-producing CD4+ effector T cells develop via a lineage distinct from the T helper type 1 and 2 lineages. Nat Immunol. 2005;6(11):11231132.

87. Park H, Li Z, Yang XO, et al. A distinct lineage of CD4 T cells regulates tissue inflammation by producing interleukin 17. Nat Immunol. 2005;6(11):1133-1141.

88. Hirahara K, Poholek A, Vahedi G, et al. Mechanisms underlying helper T-cell plasticity: implications for immune-mediated disease. J Allergy Clin Immunol. 2013;131(5):1276-1287.

89. Lord GM, Rao RM, Choe H, et al. T-bet is required for optimal proinflammatory CD4+ T-cell trafficking. Blood. 2005;106(10):3432-3439.

90. Cosmi L, Annunziato F, Galli MIG, Maggi RME, Nagata K, Romagnani S. CRTH2 is the most reliable marker for the detection of circulating human type $2 \mathrm{Th}$ and type $2 \mathrm{~T}$ cytotoxic cells in health and disease. Eur J Immunol. 2000;30(10):2972-2979.

91. De Fanis U, Mori F, Kurnat RJ, et al. GATA3 up-regulation associated with surface expression of 
CD294/CRTH2: a unique feature of human Th cells. Blood. 2007;109(10):4343-4350.

92. Zheng W, Flavell RA. The transcription factor GATA-3 is necessary and sufficient for Th2 cytokine gene expression in CD4 T cells. Cell. 1997;89(4):587-596.

93. Lantelme E, Mantovani S, Palermo B, Campanelli R, Sallusto F, Giachino C. Kinetics of GATA-3 gene expression in early polarizing and committed human T cells. Immunology. 2001;102(2):123-130.

94. Annunziato F, Cosmi L, Santarlasci V, et al. Phenotypic and functional features of human Th17 cells. J Exp Med. 2007;204(8):1849-1861.

95. Wilson NJ, Boniface K, Chan JR, et al. Development, cytokine profile and function of human interleukin 17-producing helper T cells. Nat Immunol. 2007;8(9):950-957.

96. Schutyser E, Struyf S, Van Damme J. The CC chemokine CCL20 and its receptor CCR6. Cytokine Growth Factor Rev. 2003;14(5):409-426.

97. Romagnani S. Regulation of the development of type 2 T-helper cells in allergy. Curr Opin Immunol. 1994;6(6):838-846.

98. Gazzinelli RT, Wysocka M, Hieny S, et al. In the absence of endogenous IL-10, mice acutely infected with Toxoplasma gondii succumb to a lethal immune response dependent on CD4+ T cells and accompanied by overproduction of IL-12, IFN-gamma and TNF-alpha. J Immunol. 1996;157(2):798805.

99. Zhu J, Paul WE. CD4 T cells: fates, functions, and faults. Blood. 2008;112(5):1557-1569.

100. Oestreich KJ, Weinmann AS. Transcriptional mechanisms that regulate T helper 1 cell differentiation. Current opinion in immunology. 2012;24(2):191-195.

101. Vahedi G, Takahashi H, Nakayamada S, et al. STATs shape the active enhancer landscape of T cell populations. Cell. 2012;151(5):981-993.

102. Josefowicz SZ. Regulators of chromatin state and transcription in CD4 T-cell polarization. Immunology. 2013;139(3):299-308.

103. Nakayamada S, Takahashi H, Kanno Y, O’Shea JJ. Helper T cell diversity and plasticity. Current opinion in immunology. 2012;24(3):297-302.

104. Messi M, Giacchetto I, Nagata K, Lanzavecchia A, Natoli G, Sallusto F. Memory and flexibility of cytokine gene expression as separable properties of human $\mathrm{T}(\mathrm{H}) 1$ and $\mathrm{T}(\mathrm{H}) 2$ lymphocytes. Nat Immunol. 2003;4(1):78-86.

105. Cosmi L, Cimaz R, Maggi L, et al. Evidence of the transient nature of the Th17 phenotype of CD4+CD161+ T cells in the synovial fluid of patients with juvenile idiopathic arthritis. Arthritis Rheum. 2011;63(8):2504-2515.

106. Hirota K, Duarte JH, Veldhoen M, et al. Fate mapping of IL-17-producing T cells in inflammatory responses. Nat Immunol. 2011;12(3):255-263.

107. Kebir H, Ifergan I, Alvarez JI, et al. Preferential recruitment of interferon-gamma-expressing TH17 cells in multiple sclerosis. Ann Neurol. 2009;66(3):390-402.

108. Veldhoen M, Uyttenhove C, van Snick J, et al. Transforming growth factor-beta 'reprograms' the differentiation of $\mathrm{T}$ helper 2 cells and promotes an interleukin 9-producing subset. Nat Immunol. 2008;9(12):1341-1346.

109. Duhen T, Geiger R, Jarrossay D, Lanzavecchia A, Sallusto F. Production of interleukin 22 but not interleukin 17 by a subset of human skin-homing memory T cells. Nat Immunol. 2009;10(8):857-863.

110. Trifari S, Kaplan CD, Tran EH, Crellin NK, Spits H. Identification of a human helper T cell population that has abundant production of interleukin 22 and is distinct from $\mathrm{T}(\mathrm{H})-17, \mathrm{~T}(\mathrm{H}) 1$ and $\mathrm{T}(\mathrm{H}) 2$ cells. Nat Immunol. 2009;10(8):864-871.

111. Mucida D, Husain MM, Muroi S, et al. Transcriptional reprogramming of mature CD4(+) helper'T cells generates distinct MHC class II-restricted cytotoxic T lymphocytes. Nat Immunol. 2013;14(3):281289.

112. Reis BS, Rogoz A, Costa-Pinto FA, Taniuchi I, Mucida D. Mutual expression of the transcription factors Runx3 and ThPOK regulates intestinal CD4(+) T cell immunity. Nat Immunol. 2013;14(3):271-280.

113. Cheroutre H, Husain MM. CD4 CTL: living up to the challenge. Semin Immunol. 2013;25(4):273-281. 
114. Thieu VT, Yu Q, Chang HC, et al. Signal transducer and activator of transcription 4 is required for the transcription factor T-bet to promote T helper 1 cell-fate determination. Immunity. 2008;29(5):679690.

115. Mestas J, Hughes CC. Of mice and not men: differences between mouse and human immunology. J Immunol. 2004;172(5):2731-2738.

116. Crozat K, Guiton R, Guilliams M, et al. Comparative genomics as a tool to reveal functional equivalences between human and mouse dendritic cell subsets. Immunological reviews. 2010;234(1):177-198.

117. Bryant CE, Monie TP. Mice, men and the relatives: cross-species studies underpin innate immunity. Open biology. 2012;2(4):120015.

118. Kawai T, Akira S. The role of pattern-recognition receptors in innate immunity: update on Toll-like receptors. Nature immunology. 2010;11(5):373-384.

119. Boonstra A, Asselin-Paturel C, Gilliet M, et al. Flexibility of mouse classical and plasmacytoid-derived dendritic cells in directing $T$ helper type 1 and 2 cell development: dependency on antigen dose and differential toll-like receptor ligation. The Journal of experimental medicine. 2003;197(1):101-109.

120. Edwards AD, Diebold SS, Slack EM, et al. Toll-like receptor expression in murine DC subsets: lack of TLR7 expression by CD8 alpha+ DC correlates with unresponsiveness to imidazoquinolines. European journal of immunology. 2003;33(4):827-833.

121. Schreibelt G, Tel J, Sliepen KH, et al. Toll-like receptor expression and function in human dendritic cell subsets: implications for dendritic cell-based anti-cancer immunotherapy. Cancer immunology, immunotherapy : CII. 2010;59(10):1573-1582.

122. Kadowaki N, Ho S, Antonenko S, et al. Subsets of human dendritic cell precursors express different toll-like receptors and respond to different microbial antigens. The Journal of experimental medicine. 2001;194(6):863-869.

123. Bauer S, Kirschning CJ, Hacker H, et al. Human TLR9 confers responsiveness to bacterial DNA via species-specific CpG motif recognition. Proceedings of the National Academy of Sciences of the United States of America. 2001;98(16):9237-9242.

124. Ziegler SF. FOXP3: of mice and men. Annual review of immunology. 2006;24:209-226.

125. Farrar JD, Smith JD, Murphy TL, Leung S, Stark GR, Murphy KM. Selective loss of type I interferoninduced STAT4 activation caused by a minisatellite insertion in mouse Stat2. Nature immunology. 2000;1(1):65-69.

126. Rogge L, D'Ambrosio D, Biffi M, et al. The role of Stat4 in species-specific regulation of Th cell development by type I IFNs. Journal of immunology. 1998;161(12):6567-6574.

127. Farrar JD, Smith JD, Murphy TL, Leung S, Stark GR, Murphy KM. Selective loss of type I interferoninduced STAT4 activation caused by a minisatellite insertion in mouse Stat2. Nat Immunol. 2000;1(1):65-69.

128. Hagan P. IgE and protective immunity to helminth infections. Parasite Immunol. 1993;15(1):1-4.

129. Pearce EJ, Sher A. Functional dichotomy in the CD4+ T cell response to Schistosoma mansoni. Exp Parasitol. 1991;73(1):110-116.

130. Hayday AC, Peakman M. The habitual, diverse and surmountable obstacles to human immunology research. Nat Immunol. 2008;9(6):575-580.

131. Hackam DG, Redelmeier DA. Translation of research evidence from animals to humans. JAMA. 2006;296(14):1731-1732.

132. Pound P, Ebrahim S, Sandercock P, Bracken MB, Roberts I, Reviewing Animal Trials Systematically G. Where is the evidence that animal research benefits humans? BMJ. 2004;328(7438):514-517.

133. Greenberg AH, Hudson L, Shen L, Roitt IM. Antibody-dependent cell-mediated cytotoxicity due to a "null" lymphoid cell. Nat New Biol. 1973;242(117):111-113.

134. Herberman RB, Nunn ME, Lavrin DH. Natural cytotoxic reactivity of mouse lymphoid cells against syngeneic acid allogeneic tumors. I. Distribution of reactivity and specificity. Int J Cancer. 1975;16(2):216-229.

135. Rosenberg EB, Herberman RB, Levine PH, Halterman RH, McCoy JL, Wunderlich JR. Lymphocyte 
cytotoxicity reactions to leukemia-associated antigens in identical twins. Int J Cancer. 1972;9(3):648658.

136. Cella M, Miller H, Song C. Beyond NK cells: the expanding universe of innate lymphoid cells. Front Immunol. 2014;5:282.

137. Vivier E, Tomasello E, Baratin M, Walzer T, Ugolini S. Functions of natural killer cells. Nat Immunol. 2008;9(5):503-510.

138. Raulet DH, Vance RE. Self-tolerance of natural killer cells. Nat Rev Immunol. 2006;6(7):520-531.

139. Jonsson AH, Yokoyama WM. Natural killer cell tolerance licensing and other mechanisms. Adv Immunol. 2009;101:27-79.

140. Trapani JA, Smyth MJ. Functional significance of the perforin/granzyme cell death pathway. Nat Rev Immunol. 2002;2(10):735-747.

141. Wallin RP, Screpanti V, Michaelsson J, Grandien A, Ljunggren HG. Regulation of perforin-independent NK cell-mediated cytotoxicity. Eur J Immunol. 2003;33(10):2727-2735.

142. Mandelboim O, Malik P, Davis DM, Jo CH, Boyson JE, Strominger JL. Human CD16 as a lysis receptor mediating direct natural killer cell cytotoxicity. Proc Natl Acad Sci U S A. 1999;96(10):56405644.

143. Fauriat C, Long EO, Ljunggren HG, Bryceson YT. Regulation of human NK-cell cytokine and chemokine production by target cell recognition. Blood. 2010;115(11):2167-2176.

144. Loza MJ, Zamai L, Azzoni L, Rosati E, Perussia B. Expression of type 1 (interferon gamma) and type 2 (interleukin-13, interleukin-5) cytokines at distinct stages of natural killer cell differentiation from progenitor cells. Blood. 2002;99(4):1273-1281.

145. Robertson MJ. Role of chemokines in the biology of natural killer cells. J Leukoc Biol. 2002;71(2):173183.

146. Cooper MA, Fehniger TA, Caligiuri MA. The biology of human natural killer-cell subsets. Trends Immunol. 2001;22(11):633-640.

147. Van Elssen CH, Vanderlocht J, Frings PW, et al. Klebsiella pneumoniae-triggered DC recruit human NK cells in a CCR5-dependent manner leading to increased CCL19-responsiveness and activation of NK cells. Eur J Immunol. 2010;40(11):3138-3149.

148. Mailliard RB, Alber SM, Shen H, et al. IL-18-induced CD83+CCR7+ NK helper cells. J Exp Med. 2005;202(7):941-953.

149. De Maria A, Bozzano F, Cantoni C, Moretta L. Revisiting human natural killer cell subset function revealed cytolytic CD56(dim)CD16 + NK cells as rapid producers of abundant IFN-gamma on activation. Proc Natl Acad Sci U S A. 2011;108(2):728-732.

150. Ferlazzo G, Thomas D, Lin SL, et al. The abundant NK cells in human secondary lymphoid tissues require activation to express killer cell Ig-like receptors and become cytolytic. J Immunol. 2004;172(3):1455-1462.

151. Nielsen N, Odum N, Urso B, Lanier LL, Spee P. Cytotoxicity of CD56(bright) NK cells towards autologous activated CD4+ T cells is mediated through NKG2D, LFA-1 and TRAIL and dampened via CD94/NKG2A. PLoS One. 2012;7(2):e31959.

152. Romagnani C, Juelke K, Falco M, et al. CD56brightCD16- killer Ig-like receptor- NK cells display longer telomeres and acquire features of CD56dim NK cells upon activation. J Immunol. 2007;178(8):4947-4955.

153. Poli A, Michel T, Theresine M, Andres E, Hentges F, Zimmer J. CD56bright natural killer (NK) cells: an important NK cell subset. Immunology. 2009;126(4):458-465.

154. Hayakawa Y, Smyth MJ. CD27 dissects mature NK cells into two subsets with distinct responsiveness and migratory capacity. J Immunol. 2006;176(3):1517-1524.

155. Lopez-Verges S, Milush JM, Pandey S, et al. CD57 defines a functionally distinct population of mature NK cells in the human CD56dimCD16+ NK-cell subset. Blood. 2010;116(19):3865-3874.

156. Nielsen CM, White MJ, Goodier MR, Riley EM. Functional Significance of CD57 Expression on Human NK Cells and Relevance to Disease. Front Immunol. 2013;4:422. 
157. Andrews DM, Scalzo AA, Yokoyama WM, Smyth MJ, Degli-Esposti MA. Functional interactions between dendritic cells and NK cells during viral infection. Nat Immunol. 2003;4(2):175-181.

158. Fernandez NC, Lozier A, Flament C, et al. Dendritic cells directly trigger NK cell functions: cross-talk relevant in innate anti-tumor immune responses in vivo. Nat Med. 1999;5(4):405-411.

159. Mailliard RB, Son YI, Redlinger R, et al. Dendritic cells mediate NK cell help for Th1 and CTL responses: two-signal requirement for the induction of $\mathrm{NK}$ cell helper function. J Immunol. 2003;171(5):2366-2373.

160. Van Elssen CH, Vanderlocht J, Frings PW, et al. Klebsiella pneumoniae-triggered DC recruit human NK cells in a CCR5-dependent manner leading to increased CCL19-responsiveness and activation of NK cells. European journal of immunology. 2010;40(11):3138-3149.

161. Granucci F, Zanoni I, Pavelka N, et al. A contribution of mouse dendritic cell-derived IL-2 for NK cell activation. J Exp Med. 2004;200(3):287-295.

162. Feau S, Facchinetti V, Granucci F, et al. Dendritic cell-derived IL-2 production is regulated by IL-15 in humans and in mice. Blood. 2005;105(2):697-702.

163. Mortier E, Woo T, Advincula R, Gozalo S, Ma A. IL-15Ralpha chaperones IL-15 to stable dendritic cell membrane complexes that activate NK cells via trans presentation. J Exp Med. 2008;205(5):12131225.

164. Viaud S, Terme M, Flament C, et al. Dendritic cell-derived exosomes promote natural killer cell activation and proliferation: a role for NKG2D ligands and IL-15Ralpha. PLoS One. 2009;4(3):e4942.

165. Ferlazzo G, Pack M, Thomas D, et al. Distinct roles of IL-12 and IL-15 in human natural killer cell activation by dendritic cells from secondary lymphoid organs. Proc Natl Acad Sci U S A. 2004;101(47):16606-16611.

166. Brilot F, Strowig T, Roberts SM, Arrey F, Munz C. NK cell survival mediated through the regulatory synapse with human DCs requires IL-15Ralpha. J Clin Invest. 2007;117(11):3316-3329.

167. Strengell M, Matikainen S, Siren J, et al. IL-21 in synergy with IL-15 or IL-18 enhances IFN-gamma production in human NK and T cells. J Immunol. 2003;170(11):5464-5469.

168. Gustafsson K, Ingelsten M, Bergqvist L, Nystrom J, Andersson B, Karlsson-Parra A. Recruitment and activation of natural killer cells in vitro by a human dendritic cell vaccine. Cancer Res. 2008;68(14):59655971.

169. Qiao Y, Liu B, Li Z. Activation of NK cells by extracellular heat shock protein 70 through induction of NKG2D ligands on dendritic cells. Cancer Immun. 2008;8:12.

170. Jinushi M, Takehara T, Kanto T, et al. Critical role of MHC class I-related chain A and B expression on IFN-alpha-stimulated dendritic cells in NK cell activation: impairment in chronic hepatitis $\mathrm{C}$ virus infection. J Immunol. 2003;170(3):1249-1256.

171. Pende D, Parolini S, Pessino A, et al. Identification and molecular characterization of NKp30, a novel triggering receptor involved in natural cytotoxicity mediated by human natural killer cells. J Exp Med. 1999;190(10):1505-1516.

172. Sivori S, Pende D, Bottino C, et al. NKp46 is the major triggering receptor involved in the natural cytotoxicity of fresh or cultured human NK cells. Correlation between surface density of NKp46 and natural cytotoxicity against autologous, allogeneic or xenogeneic target cells. Eur J Immunol. 1999;29(5):1656-1666.

173. Ferlazzo G, Tsang ML, Moretta L, Melioli G, Steinman RM, Munz C. Human dendritic cells activate resting natural killer $(\mathrm{NK})$ cells and are recognized via the NKp30 receptor by activated NK cells. J Exp Med. 2002;195(3):343-351.

174. Wai LE, Garcia JA, Martinez OM, Krams SM. Distinct roles for the NK cell-activating receptors in mediating interactions with dendritic cells and tumor cells. J Immunol. 2011;186(1):222-229.

175. Draghi M, Pashine A, Sanjanwala B, et al. NKp46 and NKG2D recognition of infected dendritic cells is necessary for NK cell activation in the human response to influenza infection. J Immunol. 2007;178(5):2688-2698.

176. Cantoni C, Bottino C, Vitale M, et al. NKp44, a triggering receptor involved in tumor cell lysis by 
activated human natural killer cells, is a novel member of the immunoglobulin superfamily. J Exp Med. 1999;189(5):787-796.

177. Chuang SS, Kumaresan PR, Mathew PA. 2 B4 (CD244)-mediated activation of cytotoxicity and IFNgamma release in human NK cells involves distinct pathways. J Immunol. 2001;167(11):6210-6216.

178. Sivori S, Parolini S, Falco M, et al. 2B4 functions as a co-receptor in human NK cell activation. Eur J Immunol. 2000;30(3):787-793.

179. Sivori S, Falco M, Marcenaro E, et al. Early expression of triggering receptors and regulatory role of 2B4 in human natural killer cell precursors undergoing in vitro differentiation. Proc Natl Acad Sci U S A. 2002;99(7):4526-4531.

180. Gerosa F, Baldani-Guerra B, Nisii C, Marchesini V, Carra G, Trinchieri G. Reciprocal activating interaction between natural killer cells and dendritic cells. J Exp Med. 2002;195(3):327-333.

181. Ni J, Miller M, Stojanovic A, Garbi N, Cerwenka A. Sustained effector function of IL-12/15/18preactivated NK cells against established tumors. J Exp Med. 2012;209(13):2351-2365.

182. Leong JW, Chase JM, Romee R, et al. Preactivation with IL-12, IL-15, and IL-18 induces CD25 and a functional high-affinity IL-2 receptor on human cytokine-induced memory-like natural killer cells. Biol Blood Marrow Transplant. 2014;20(4):463-473.

183. Nishioka Y, Nishimura N, Suzuki Y, Sone S. Human monocyte-derived and CD $83(+)$ blood dendritic cells enhance NK cell-mediated cytotoxicity. Eur J Immunol. 2001;31(9):2633-2641.

184. Yu Y, Hagihara M, Ando K, et al. Enhancement of human cord blood CD34+ cell-derived NK cell cytotoxicity by dendritic cells. J Immunol. 2001;166(3):1590-1600.

185. Galetto A, Buttiglieri S, Forno S, Moro F, Mussa A, Matera L. Drug- and cell-mediated antitumor cytotoxicities modulate cross-presentation of tumor antigens by myeloid dendritic cells. Anticancer Drugs. 2003;14(10):833-843.

186. Albert ML, Sauter B, Bhardwaj N. Dendritic cells acquire antigen from apoptotic cells and induce class I-restricted CTLs. Nature. 1998;392(6671):86-89.

187. Piccioli D, Sbrana S, Melandri E, Valiante NM. Contact-dependent stimulation and inhibition of dendritic cells by natural killer cells. J Exp Med. 2002;195(3):335-341.

188. Nagasaki E, Takahara A, Koido S, et al. Combined treatment with dendritic cells and 5-fluorouracil elicits augmented NK cell-mediated antitumor activity through the tumor necrosis factor-alpha pathway. J Immunother. 2010;33(5):467-474.

189. Zhang AL, Colmenero P, Purath U, et al. Natural killer cells trigger differentiation of monocytes into dendritic cells. Blood. 2007;110(7):2484-2493.

190. Wong JL, Mailliard RB, Moschos SJ, et al. Helper activity of natural killer cells during the dendritic cell-mediated induction of melanoma-specific cytotoxic T cells. J Immunother. 2011;34(3):270-278.

191. Kalinski P, Giermasz A, Nakamura Y, et al. Helper role of NK cells during the induction of anticancer responses by dendritic cells. Mol Immunol. 2005;42(4):535-539.

192. Coudert JD, Coureau C, Guery JC. Preventing NK cell activation by donor dendritic cells enhances allospecific CD4 $\mathrm{T}$ cell priming and promotes Th type 2 responses to transplantation antigens. J Immunol. 2002;169(6):2979-2987.

193. Byrne P, McGuirk P, Todryk S, Mills KH. Depletion of NK cells results in disseminating lethal infection with Bordetella pertussis associated with a reduction of antigen-specific Th1 and enhancement of Th2, but not Tr1 cells. Eur J Immunol. 2004;34(9):2579-2588.

194. Martin-Fontecha A, Thomsen LL, Brett S, et al. Induced recruitment of NK cells to lymph nodes provides IFN-gamma for T(H)1 priming. Nat Immunol. 2004;5(12):1260-1265.

195. Fehniger TA, Cooper MA, Nuovo GJ, et al. CD56bright natural killer cells are present in human lymph nodes and are activated by T cell-derived IL-2: a potential new link between adaptive and innate immunity. Blood. 2003;101(8):3052-3057.

196. Ferlazzo G. In vivo evidence for dendritic cell lysis by NK cells: Hints on improving cancer vaccines by targeting NK cell activation. Oncoimmunology. 2012;1(9):1635-1636.

197. Pende D, Castriconi R, Romagnani P, et al. Expression of the DNAM-1 ligands, Nectin-2 (CD112) and 
poliovirus receptor (CD155), on dendritic cells: relevance for natural killer-dendritic cell interaction. Blood. 2006;107(5):2030-2036.

198. Della Chiesa M, Vitale M, Carlomagno S, Ferlazzo G, Moretta L, Moretta A. The natural killer cellmediated killing of autologous dendritic cells is confined to a cell subset expressing CD94/NKG2A, but lacking inhibitory killer Ig-like receptors. Eur J Immunol. 2003;33(6):1657-1666.

199. Ferlazzo G, Morandi B, D’Agostino A, et al. The interaction between NK cells and dendritic cells in bacterial infections results in rapid induction of $\mathrm{NK}$ cell activation and in the lysis of uninfected dendritic cells. Eur J Immunol. 2003;33(2):306-313.

200. Steinman RM, Hawiger D, Nussenzweig MC. Tolerogenic dendritic cells. Annu Rev Immunol. 2003;21:685-711.

201. Ferlazzo G, Munz C. NK cell compartments and their activation by dendritic cells. J Immunol. 2004;172(3):1333-1339.

202. Morandi B, Mortara L, Chiossone L, et al. Dendritic cell editing by activated natural killer cells results in a more protective cancer-specific immune response. PLoS One. 2012;7(6):e39170.

203. Moretta A. Natural killer cells and dendritic cells: rendezvous in abused tissues. Nat Rev Immunol. 2002;2(12):957-964.

204. Hansen M, Hjorto GM, Donia M, et al. Comparison of clinical grade type 1 polarized and standard matured dendritic cells for cancer immunotherapy. Vaccine. 2013;31(4):639-646.

205. Vanderlocht J, Van Elssen CH, Senden-Gijsbers BL, et al. Increased tumor-specific CD8+ T cell induction by dendritic cells matured with a clinical grade TLR-agonist in combination with IFNgamma. Int J Immunopathol Pharmacol. 2010;23(1):35-50.

206. Carrega P, Ferlazzo G. Natural killer cell distribution and trafficking in human tissues. Front Immunol. 2012;3:347.

207. Nizzoli G, Krietsch J, Weick A, et al. Human CD1c+ dendritic cells secrete high levels of IL-12 and potently prime cytotoxic T-cell responses. Blood. 2013;122(6):932-942.

208. Ferlazzo G, Morandi B. Cross-Talks between Natural Killer Cells and Distinct Subsets of Dendritic Cells. Front Immunol. 2014;5:159.

209. Kos FJ, Engleman EG. Requirement for natural killer cells in the induction of cytotoxic T cells. J Immunol. 1995;155(2):578-584.

210. Kos FJ, Engleman EG. Role of natural killer cells in the generation of influenza virus-specific cytotoxic T cells. Cell Immunol. 1996;173(1):1-6.

211. Adam C, King S, Allgeier T, et al. DC-NK cell cross talk as a novel CD4+ T-cell-independent pathway for antitumor CTL induction. Blood. 2005;106(1):338-344.

212. Geldhof AB, Van Ginderachter JA, Liu Y, Noel W, Raes G, De Baetselier P. Antagonistic effect of NK cells on alternatively activated monocytes: a contribution of NK cells to CTL generation. Blood. 2002;100(12):4049-4058.

213. Combe CL, Curiel TJ, Moretto MM, Khan IA. NK cells help to induce CD8(+)-T-cell immunity against Toxoplasma gondii in the absence of CD4(+) T cells. Infect Immun. 2005;73(8):4913-4921.

214. Hardy MY, Kassianos AJ, Vulink A, et al. NK cells enhance the induction of CTL responses by IL-15 monocyte-derived dendritic cells. Immunol Cell Biol. 2009;87(8):606-614.

215. Wilcox RA, Tamada K, Strome SE, Chen L. Signaling through NK cell-associated CD137 promotes both helper function for CD8+ cytolytic T cells and responsiveness to IL-2 but not cytolytic activity. J Immunol. 2002;169(8):4230-4236.

216. Phillips JH, Le AM, Lanier LL. Natural killer cells activated in a human mixed lymphocyte response culture identified by expression of Leu-11 and class II histocompatibility antigens. J Exp Med. 1984;159(4):993-1008.

217. Hanna J, Gonen-Gross T, Fitchett J, et al. Novel APC-like properties of human NK cells directly regulate T cell activation. J Clin Invest. 2004;114(11):1612-1623.

218. Roncarolo MG, Bigler M, Haanen JB, et al. Natural killer cell clones can efficiently process and present protein antigens. J Immunol. 1991;147(3):781-787. 
219. Zingoni A, Sornasse T, Cocks BG, Tanaka Y, Santoni A, Lanier LL. NK cell regulation of T cellmediated responses. Mol Immunol. 2005;42(4):451-454.

220. Zingoni A, Sornasse T, Cocks BG, Tanaka Y, Santoni A, Lanier LL. Cross-talk between activated human NK cells and CD4+ T cells via OX40-OX40 ligand interactions. J Immunol. 2004;173(6):37163724.

221. Biron CA, Byron KS, Sullivan JL. Severe herpesvirus infections in an adolescent without natural killer cells. N Engl J Med. 1989;320(26):1731-1735.

222. Orange JS. Human natural killer cell deficiencies and susceptibility to infection. Microbes Infect. 2002;4(15):1545-1558.

223. Orange JS. Human natural killer cell deficiencies. Curr Opin Allergy Clin Immunol. 2006;6(6):399409.

224. Orange JS, Ballas ZK. Natural killer cells in human health and disease. Clin Immunol. 2006;118(1):110.

225. Athie-Morales V, O'Connor GM, Gardiner CM. Activation of human NK cells by the bacterial pathogen-associated molecular pattern muramyl dipeptide. J Immunol. 2008;180(6):4082-4089.

226. Perrot I, Deauvieau F, Massacrier C, et al. TLR3 and Rig-like receptor on myeloid dendritic cells and Rig-like receptor on human NK cells are both mandatory for production of IFN-gamma in response to double-stranded RNA. J Immunol. 2010;185(4):2080-2088.

227. Duluc D, Tan F, Scotet M, et al. PolyI:C plus IL-2 or IL-12 induce IFN-gamma production by human NK cells via autocrine IFN-beta. Eur J Immunol. 2009;39(10):2877-2884.

228. Girart MV, Fuertes MB, Domaica CI, Rossi LE, Zwirner NW. Engagement of TLR3, TLR7, and NKG2D regulate IFN-gamma secretion but not NKG2D-mediated cytotoxicity by human NK cells stimulated with suboptimal doses of IL-12. J Immunol. 2007;179(6):3472-3479.

229. Hart OM, Athie-Morales V, O'Connor GM, Gardiner CM. TLR7/8-mediated activation of human NK cells results in accessory cell-dependent IFN-gamma production. J Immunol. 2005;175(3):16361642 .

230. Sivori S, Carlomagno S, Moretta L, Moretta A. Comparison of different CpG oligodeoxynucleotide classes for their capability to stimulate human NK cells. Eur J Immunol. 2006;36(4):961-967.

231. Sivori S, Falco M, Della Chiesa M, et al. CpG and double-stranded RNA trigger human NK cells by Toll-like receptors: induction of cytokine release and cytotoxicity against tumors and dendritic cells. Proc Natl Acad Sci U S A. 2004;101(27):10116-10121.

232. O'Connor GM, Hart OM, Gardiner CM. Putting the natural killer cell in its place. Immunology. 2006;117(1):1-10.

233. French AR, Yokoyama WM. Natural killer cells and autoimmunity. Arthritis Res Ther. 2004;6(1):8-14.

234. Lunemann JD, Munz C. Do natural killer cells accelerate or prevent autoimmunity in multiple sclerosis? Brain. 2008;131(Pt 7):1681-1683.

235. Rodacki M, Svoren B, Butty V, et al. Altered natural killer cells in type 1 diabetic patients. Diabetes. 2007;56(1):177-185.

236. Dowdell KC, Cua DJ, Kirkman E, Stohlman SA. NK cells regulate CD4 responses prior to antigen encounter. J Immunol. 2003;171(1):234-239.

237. Li MO, Wan YY, Sanjabi S, Robertson AK, Flavell RA. Transforming growth factor-beta regulation of immune responses. Annu Rev Immunol. 2006;24:99-146.

238. Rabinovich BA, Li J, Shannon J, et al. Activated, but not resting, T cells can be recognized and killed by syngeneic NK cells. J Immunol. 2003;170(7):3572-3576.

239. Schott E, Bonasio R, Ploegh HL. Elimination in vivo of developing T cells by natural killer cells. J Exp Med. 2003;198(8):1213-1224.

240. Cerboni C, Zingoni A, Cippitelli M, Piccoli M, Frati L, Santoni A. Antigen-activated human T lymphocytes express cell-surface NKG2D ligands via an ATM/ATR-dependent mechanism and become susceptible to autologous NK-cell lysis. Blood. 2007;110(2):606-615.

241. Trivedi PP, Roberts PC, Wolf NA, Swanborg RH. NK cells inhibit T cell proliferation via p21- 
mediated cell cycle arrest. J Immunol. 2005;174(8):4590-4597.

242. Waggoner SN, Cornberg M, Selin LK, Welsh RM. Natural killer cells act as rheostats modulating antiviral T cells. Nature. 2012;481(7381):394-398.

243. Coley WB. II. Contribution to the Knowledge of Sarcoma. Ann Surg. 1891;14(3):199-220.

244. Kantoff PW, Higano CS, Shore ND, et al. Sipuleucel-T immunotherapy for castration-resistant prostate cancer. N Engl J Med. 2010;363(5):411-422.

245. Grupp SA, Kalos M, Barrett D, et al. Chimeric antigen receptor-modified T cells for acute lymphoid leukemia. N Engl J Med. 2013;368(16):1509-1518.

246. Brentjens RJ, Davila ML, Riviere I, et al. CD19-targeted T cells rapidly induce molecular remissions in adults with chemotherapy-refractory acute lymphoblastic leukemia. Sci Transl Med. 2013;5(177):177ra138.

247. Kochenderfer JN, Dudley ME, Kassim SH, et al. Chemotherapy-refractory diffuse large B-cell lymphoma and indolent B-cell malignancies can be effectively treated with autologous $\mathrm{T}$ cells expressing an anti-CD19 chimeric antigen receptor. J Clin Oncol. 2015;33(6):540-549.

248. Sousa CRE. Activation of dendritic cells: translating innate into adaptive immunity. Current Opinion in Immunology. 2004;16(1):21-25.

249. Pinzon-Charry A, Maxwell T, Lopez JA. Dendritic cell dysfunction in cancer: a mechanism for immunosuppression. Immunology and cell biology. 2005;83(5):451-461.

250. Yang L, Carbone DP. Tumor-host immune interactions and dendritic cell dysfunction. Advances in cancer research. 2004;92:13-27.

251. Kalinski P, Schuitemaker JH, Hilkens CM, Kapsenberg ML. Prostaglandin E2 induces the final maturation of IL-12-deficient CD1a+CD83 + dendritic cells: the levels of IL-12 are determined during the final dendritic cell maturation and are resistant to further modulation. Journal of immunology. 1998;161(6):2804-2809.

252. Markowicz S, Engleman EG. Granulocyte-macrophage colony-stimulating factor promotes differentiation and survival of human peripheral blood dendritic cells in vitro. J Clin Invest. 1990;85(3):955-961.

253. Sallusto F, Lanzavecchia A. Efficient presentation of soluble antigen by cultured human dendritic cells is maintained by granulocyte/macrophage colony-stimulating factor plus interleukin 4 and downregulated by tumor necrosis factor alpha. J Exp Med. 1994;179(4):1109-1118.

254. Hsu FJ, Benike C, Fagnoni F, et al. Vaccination of patients with B-cell lymphoma using autologous antigen-pulsed dendritic cells. Nat Med. 1996;2(1):52-58.

255. Anguille S, Smits EL, Lion E, van Tendeloo VF, Berneman ZN. Clinical use of dendritic cells for cancer therapy. Lancet Oncol. 2014;15(7):e257-267.

256. Jonuleit H, Kuhn U, Muller G, et al. Pro-inflammatory cytokines and prostaglandins induce maturation of potent immunostimulatory dendritic cells under fetal calf serum-free conditions. Eur J Immunol. 1997;27(12):3135-3142.

257. Trinchieri G. Interleukin-12 and the regulation of innate resistance and adaptive immunity. Nat Rev Immunol. 2003;3(2):133-146.

258. Athie-Morales V, Smits HH, Cantrell DA, Hilkens CM. Sustained IL-12 signaling is required for Th1 development. J Immunol. 2004;172(1):61-69.

259. Okada H, Kalinski P, Ueda R, et al. Induction of CD8+ T-cell responses against novel gliomaassociated antigen peptides and clinical activity by vaccinations with \{alpha $\}$-type 1 polarized dendritic cells and polyinosinic-polycytidylic acid stabilized by lysine and carboxymethylcellulose in patients with recurrent malignant glioma. J Clin Oncol. 2011;29(3):330-336.

260. Carreno BM, Becker-Hapak M, Huang A, et al. IL-12p70-producing patient DC vaccine elicits Tc1polarized immunity. J Clin Invest. 2013;123(8):3383-3394.

261. Mailliard RB, Wankowicz-Kalinska A, Cai Q, et al. alpha-type-1 polarized dendritic cells: a novel immunization tool with optimized CTL-inducing activity. Cancer Res. 2004;64(17):5934-5937.

262. Bol KF, Tel J, de Vries IJ, Figdor CG. Naturally circulating dendritic cells to vaccinate cancer patients. 
Oncoimmunology. 2013;2(3):e23431.

263. Tel J, Aarntzen EH, Baba T, et al. Natural human plasmacytoid dendritic cells induce antigen-specific T-cell responses in melanoma patients. Cancer Res. 2013;73(3):1063-1075.

264. Palucka K, Banchereau J. Cancer immunotherapy via dendritic cells. Nat Rev Cancer. 2012;12(4):265277.

265. Kreutz M, Tacken PJ, Figdor CG. Targeting dendritic cells--why bother? Blood. 2013;121(15):28362844.

266. Patel PH, Kockler DR. Sipuleucel-T: a vaccine for metastatic, asymptomatic, androgen-independent prostate cancer. Ann Pharmacother. 2008;42(1):91-98. 


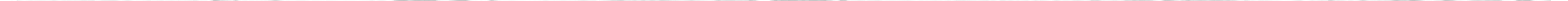




\section{Monitoring the initiation and}

kinetics of human dendritic cell-induced polarization of autologous naive $\mathrm{CD} 4^{+} \mathrm{T}$ cells

Oth T. ${ }^{1}$

Schnijderberg M.C.A. ${ }^{1}$ Senden-Gijsbers B.L.M.G. ${ }^{1}$ Germeraad W.T.V. ${ }^{1}$ Bos G.M.J. ${ }^{1}$ Vanderlocht J. ${ }^{2}$

${ }^{1}$ Division of Haematology, Department of Internal Medicine, MUMC+, Maastricht ${ }^{2}$ Tissue Typing Laboratory, Department of Transplantation Immunology, MUMC+, Maastricht 


\begin{abstract}
A crucial step in generating de novo immune responses is the polarization of naive cognate $\mathrm{CD}^{+}{ }^{+} \mathrm{T}$ cells by pathogen-triggered dendritic cells (DC). In the human setting, standardized DC-dependent systems are lacking to study molecular events during the initiation of a naive $\mathrm{CD}^{+}{ }^{+} \mathrm{T}$ cell response.
\end{abstract}

We developed a TCR-restricted assay to compare different pathogen-triggered human DC for their capacities to instruct functional differentiation of autologous, naive $\mathrm{CD} 4^{+} \mathrm{T}$ cells. We demonstrated that this methodology can be applied to compare differently matured $\mathrm{DC}$ in terms of kinetics, direction, and magnitude of the naive $\mathrm{CD} 4^{+} \mathrm{T}$ cell response. Furthermore, we showed the applicability of this assay to study the $\mathrm{T}$ cell-polarizing capacity of low-frequency blood-derived DC populations directly isolated ex vivo.

This methodology for addressing APC-dependent instruction of naive $\mathrm{CD}^{+}{ }^{+} \mathrm{T}$ cells in a human autologous setting will provide researchers with a valuable tool to gain more insight into molecular mechanisms occurring in the early phase of T cell polarization. In addition, it may also allow the study of pharmacological agents on DC-dependent $\mathrm{T}$ cell polarization in the human system. 


\section{INTRODUCTION}

Since the first description of two different subsets of activated murine T helper (Th) cells ${ }^{1}$, the understanding on induction, phenotypic discrimination, and functional consequences of the different Th lineages has enormously expanded. The polarization of naive $\mathrm{CD}^{+}{ }^{+} \mathrm{T}$ cells into different Th subtypes is a tightly controlled and regulated process, which is induced by the interaction of $\mathrm{CD}^{+} \mathrm{T}$ cells with pathogen-triggered antigen-presenting cells (APC), such as dendritic cells (DC). This interaction consists of antigen-specific, co-stimulatory, and polarizing signals ${ }^{2,3}$. Th lineage specialization is induced according to the nature of the pathogenic insult ${ }^{2,4-6}$ and the different Th lineages are defined by the expression of various transcription factors and cytokines. Uncontrolled activation and dysregulation of this process is associated with immune-related diseases ${ }^{7-9}$. It is of crucial importance to get more insight into initiating pathways and regulating networks involved in human $\mathrm{CD}^{+} \mathrm{T}$ cell polarization to identify potential intervention points for therapy and to improve diagnostics.

Over the last decade, it has become clear that the functional differentiation of Th cells is a complex process in terms of lineages, involvement of transcription factors, plasticity, and epigenetic imprinting. Whereas lineage-specifying factors, e.g. T-bet for Th1 ${ }^{10}$, were initially considered as being both required and sufficient to determine the Th phenotype, recent research revealed their possible co-expression and interplay in one particular Th subtype ${ }^{11,12}$. Moreover, the transcriptional programming during the initiation of $\mathrm{CD}^{+}{ }^{+} \mathrm{T}$ cell responses has been shown to be imprinted only to a limited extend by these Th lineagespecifying factors and instead by cytokine-regulated environmental response factors, such as signal transducers and activators of transcription (STATs) ${ }^{3,14}$. Furthermore, it has been shown that polarized Th subsets are not terminally differentiated and retain a certain degree of flexibility and plasticity; they are able to respond and adapt their phenotype to changing environmental cues ${ }^{15}$. These environmental changes, e.g. invasion of pathogens causing cell damage or inflammation, are sensed by DC and translated into an appropriate immune response ${ }^{6}$. The concentration as well as the nature of these 'danger' signals influence the expression of co-stimulatory molecules and the cytokine profile of DC ${ }^{16-22}$ and thereby indirectly the $\mathrm{T}$ cell priming. It is important to study naive $\mathrm{CD}^{+} \mathrm{T}$ cell polarization in an APC-dependent manner to better understand how different pathogens induce specific Th responses and to take into account the complex network of soluble and membrane-bound factors presented by DC.

Up-to-date the majority of knowledge on Th cell differentiation was generated using murine models, such as the OT-II system or knockout models lacking specific genes involved in T cell skewing. However, murine and human immune systems display some crucial differences. This makes the extrapolation of data generated from these models in the context of human 
Th cell polarization challenging. Murine and human DC subsets display divergences in terms of cytokine profiles ${ }^{23}$, pattern recognition receptor (PRR) expression patterns ${ }^{24-29}$, and ligand recognition ${ }^{30}$. In addition, $\mathrm{CD}^{+}{ }^{+} \mathrm{T}$ cells show interspecies heterogeneity in terms of cytokine secretion by the different Th subtypes ${ }^{31,32}$ and the involvement of lineage-specifying transcription factors ${ }^{33-35}$. These divergences illustrate that the mechanisms and therapeutic interventions identified in murine models require confirmation in human in vitro systems before their translation into clinical trials. This need of valorisation is underscored by studies revealing the possibility to cure mice but not humans with a similar treatment ${ }^{36-38}$. However, human in vitro assays to study the APC-dependent initiation of naive $\mathrm{CD} 4^{+} \mathrm{T}$ cell polarization are still limited.

Importantly, efforts were undertaken to study the kinetics of the in vitro programming of human naive $\mathrm{CD}^{+}{ }^{+} \mathrm{T}$ cells using high-throughput genome-wide microarrays ${ }^{39,40}$. The advantage of this approach is gaining insight into the kinetics of the individual molecular events and pathways during the differentiation of naive $\mathrm{T}$ cells into specific lineages, which may result in the identification of therapeutic targets; the limitation is the APC-independent setup. Even though this approach can be used as complementary method to study the involvement of single or multiple soluble factors in the initiation of a $\mathrm{T}$ cell response, the contribution of DC-derived contact-dependent factors is ignored. Their importance for the induction of a proper Th response has been shown ${ }^{4}$ and thus it is important to study the early molecular events during the differentiation of naive $\mathrm{CD}^{+} \mathrm{T}$ cells in an APC-dependent manner. In current APC-dependent assays many confounders exist: medium usage, source and purity of cells, restimulation, ratio of effector:target cells, time point of measurement, culture density and the use of superantigens ${ }^{4,6,41-46}$. Most importantly, these current approaches do not address the initiation phase of naive DC-induced CD4 ${ }^{+}$ $\mathrm{T}$ cell responses without adding supplemental environmental or blocking factors to the co-cultures. Furthermore, the monitoring of a broader range of the induced responses is limited.

We set up a system to study the initiation phase of autologous naive $\mathrm{CD}^{+}{ }^{+} \mathrm{T}$ cell polarization in an APC-dependent and TCR-restricted manner. This system allows studying the effect of different PRR stimuli on DC-mediated direction, potency, and kinetics of Th cell differentiation. It takes into account how DC-derived soluble factors interact together with co-stimulatory molecules during priming of naive $\mathrm{CD} 4^{+} \mathrm{T}$ cell responses without additional artificial stimulation of the co-culture, e.g. addition of Th cell-polarizing cytokines. It allows the comparison of differently matured DC as well as different DC subsets and has the possibility to monitor the kinetics and magnitude of the lineage-specifying transcription factors of the different Th lineages and their cytokine profiles in parallel in a small-scale, serum-free setup. 


\section{MATERIALS AND METHODS}

\section{Generation of dendritic cells}

\section{Monocyte-derived DC}

Leukapheresis products obtained from healthy volunteers were used to isolate the monocytes; this study was approved by the local Medical Ethics Committee of Maastricht University Medical Center, the Netherlands (MEC azM/UM; MEC 08-2-120) and written informed consent was obtained from all participating healthy volunteers. Enrichment of monocytes from leukapheresis products was achieved by counterflow centrifugal elutriation using the Elutra ${ }^{\circledR}$ Cell Separation System monocyte enrichment application (Elutra, Terumo BCT Inc., Lakewood, CO, USA). Purity of enriched monocyte fractions was $87.9 \% \pm 5.2$ as assessed by flow cytometry with an average yield of $1.74 \times 10^{9}$ monocytes \pm 0.96 per leukapheresis. Characterization of contaminating cells revealed presence of B cells, NK cells, granulocytes, and $\mathrm{T}$ cells. The latter counted up for $0.77 \% \pm 0.22$. Monocytes were frozen at $50 \times 10^{6}$ cells per vial in $1 \mathrm{ml}$ freeze medium: $86 \%$ autologous plasma $+10 \%$ DMSO (WAK Chemie, Steinbach/Ts. Germany) + 4\% Glucose (50\% Glucose; B. Braun Melsungen AG, Melsungen, Germany). Upon thawing, monocytes were differentiated in serum-free AIM-V ${ }^{\circledR}$ medium (Invitrogen, Carlsbad, CA, USA) supplemented with GM-CSF (400 U/ml; Berlex Laboratories Inc., Montville, NJ, USA) and IL-4 (2000U/ml; Strathmann Biotech AG, Hamburg, Germany) at a density of 2x10 cells $/ \mathrm{ml}$. After 7 days, iDC were harvested and processed in the DC-T cell co-culture experiments. Unless differently stated, monocyte-derived (moDC) were used.

\section{Plasmacytoid DC}

For the isolation of plasmacytoid DC (pDC), 500ml of fresh heparin-anticoagulated peripheral blood was used as starting material, because of the low frequency of CD304 cells in the blood, allowing the separation of up to $2.5 \times 10^{6}$ cells. Blood was obtained from Sanquin blood bank Maastricht, the Netherlands (project 2000-03AZM) from healthy donors who agreed to donate their blood for research purposes and signed an informed consent. Peripheral blood mononuclear cells (PBMC) of healthy donors were isolated by density gradient centrifugation using lymphoprep ${ }^{\text {TM }}$ (Axis-Shield PoC AS, Oslo, Norway). pDC were isolated by positive immunomagnetic cell separation using a CD304 enrichment kit (Miltenyi Biotec GmbH, Bergisch Gladbach, Germany) according to manufacturer's instructions. Purity of enriched pDC fractions exceeded $85 \%$ as assessed by flow cytometry, with contaminating $\mathrm{CD} 4{ }^{+} \mathrm{CD} 45 \mathrm{RO}^{+}$cells $<0.5 \%$ of all living cells. pDC were further processed in the DC-T cell co-culture experiments. The remaining PBMC fraction (flow-through) was resuspended in serum-free AIM-V ${ }^{\circledR}$ medium at a concentration of $15 \times 10^{6}$ cells $/ \mathrm{ml}$ and incubated overnight at $37^{\circ} \mathrm{C}$ and $5 \% \mathrm{CO}_{2}$. This suspension was used as 
a starting material to isolate naive $\mathrm{CD}^{+} \mathrm{CD}^{+} 5 \mathrm{RA}^{+} \mathrm{T}$ cells.

\section{$T$ helper cell isolation}

Autologous total $\mathrm{CD}^{+}{ }^{-} \mathrm{T}$ cells, $\mathrm{CD} 4^{+} \mathrm{CD} 45 \mathrm{RA}^{+}, \mathrm{CD}^{+} \mathrm{CD}^{2} 5 \mathrm{RO}^{+}$were isolated from $500 \mathrm{ml}$ of fresh heparin-anticoagulated peripheral blood. PBMC were obtained by density gradient centrifugation and further processed by negative immunomagnetic separation using a total $\mathrm{CD}^{+}$or $\mathrm{CD}^{+} \mathrm{CD} 45 \mathrm{RO}^{+}$isolation kit (Miltenyi Biotec) following the manufacturer's instructions. Purities of the different $\mathrm{T}$ cell subsets exceeded 95\%. The isolation of untouched $\mathrm{CD}^{+} \mathrm{CD}^{+} 5 \mathrm{RA}^{+} \mathrm{T}$ cells was optimized as illustrated in Figure S1. The negative immunomagnetic separation procedure was performed twice as the isolation of these highly pure naive $\mathrm{CD}^{+} \mathrm{T}$ cells required two consecutive rounds of separation. The highest purity $\left(\geq 99.8 \%\right.$ with $\leq 0.1 \% \mathrm{CD}^{+} \mathrm{CD} 45 \mathrm{RO}^{+}$) was achieved by incubating the flow-through of the first separation round a second time with the combination of antibody-mix and beads. A limitation of this second isolation procedure is the accompanied cell loss of $30-60 \%$. The yield of isolated naive $\mathrm{CD} 4{ }^{+} \mathrm{T}$ cells was donor-dependent. Autologous $\mathrm{CD}^{+} \mathrm{CD} 45 \mathrm{RA}^{+} \mathrm{T}$ cells for the pDC-T cell co-cultures were isolated from the remaining fraction obtained after positive $\mathrm{pDC}$ selection, which has been incubated overnight at $37^{\circ} \mathrm{C}, 5 \% \mathrm{CO}_{2}$ at $15 \times 10^{6}$ cells $/ \mathrm{ml}$ in serum-free AIM- ${ }^{\circledR}$ medium.

\section{$T$ cell polarization assays}

\section{APC-dependent assay}

iDC were matured in round-bottom 96 -well plates $\left(0.2 \times 10^{5} \mathrm{moDC} /\right.$ well or $0.1 \times 10^{5}$ pDC/well) with different maturation cocktails: PGE $2(18 \mu \mathrm{g} / \mathrm{ml}$; Sigma-Aldrich, St. Louis, MO, USA) and TNF- $\alpha(1000 \mathrm{U} / \mathrm{ml}$; Biosource International, Camarillo, CA, USA); FMKp $(10 \mu \mathrm{g} / \mathrm{ml}$; Pierre Fabre Laboratories, Boulogne-Billancourt, France) and IFN- $\gamma$ (500U/ml; R\&D systems, Minneapolis, MN, USA); LPS (200U/ml; USP, Rockville, MD, USA) and IFN- $\gamma(1000 \mathrm{U} / \mathrm{ml})$; HKLM ( $10^{\circ} \mathrm{cells} / \mathrm{ml}$; InvivoGen, Toulouse, France $)$ and IFN- $\gamma$ $(500 \mathrm{U} / \mathrm{ml})$; or ODN2216 $(10 \mu \mathrm{M} / \mathrm{ml}$; InvivoGen). For moDC all cocktails were supplemented with IL-4 $(500 \mathrm{U} / \mathrm{ml})$ and GM-CSF $(500 \mathrm{U} / \mathrm{ml})$ and for pDC with IL-3 (100ng/ml; Miltenyi Biotec). The optimal moDC-T cell co-culture ratios were determined by culturing increasing numbers of $24 \mathrm{~h}$-matured FMKp/IFN- $\gamma$-moDC $\left(0.1,0.2,0.5 \times 10^{5}\right)$ with $0.5 \times 10^{5}$ autologous naive $\mathrm{CD}^{+} \mathrm{T}$ cells (Figure S2). To this end, 24h-matured DC were harvested, washed and transferred at different ratios into round-bottom 96-well plates together with an equal amount of pooled supernatant of $24 \mathrm{~h}$-matured DC. Because of their higher $\mathrm{T}$ cell stimulatory capacity in a pilot experiment (data not shown), we co-cultured pDC and naive T cells at a ratio of 1:5. In the condition with 'washed FMKp/IFN- $\gamma$-DC', the maturation stimuli were removed $6 \mathrm{~h}$ after the induction of maturation by washing the 
DC three times with medium and adding $50 \mu \mathrm{l}$ of fresh serum-free medium. After $24 \mathrm{~h}$ of maturation, DC were loaded with $50 \mu \mathrm{g} / \mathrm{ml}$ of a pan HLA-DR binding peptide (PADRE; AGVAAWTLKAAA) that binds all groups of HLA-DR variants and leads to a polyclonal TCR-restricted T cell stimulation ${ }^{47}$. After $1 \mathrm{~h}$ of incubation, $0.5 \times 10^{5}$ autologous $\mathrm{T}$ cells were added in $25 \mu \mathrm{l}$ to the different wells. As a negative control, T cells were cultured in serum-free medium in the absence of DC. During the 7-day co-culture, samples were collected by harvesting each day individual wells of the different conditions. Supernatant was harvested and frozen for cytokine determination, whereas the cell pellets were lysed in RLT buffer (Qiagen, Alameda, CA, USA) containing 1\% 2-mercaptoethanol (Sigma-Aldrich) and stored at $-80^{\circ} \mathrm{C}$ for gene expression analyses. Furthermore, supplementary wells were cultured to study surface activation markers, as well as to determine the presence of intracellular IFN- $\gamma$ on day 7 of the co-culture. GolgiStop ${ }^{\mathrm{TM}}$ and GolgiPlug ${ }^{\mathrm{TM}}$ (both BD Biosciences, Franklin Lakes, NJ, USA) were added to the latter wells and cells were incubated overnight in absence or presence of PMA $(0.25 \mu \mathrm{g} / \mathrm{ml})$ and ionomycin $(0.5 \mu \mathrm{g} / \mathrm{ml}$; both Sigma-Aldrich).

\section{APC-independent assay}

Round-bottom 96-well plates were coated overnight with $0.25 \mu \mathrm{g} / \mathrm{ml}$ anti-CD3 (clone 2G3, kind gift from Prof. Dr. N. Hellings, Biomedical Research Institute, Diepenbeek, Belgium). After extensive washing of the plates, $0.5 \times 10^{5}$ pure $\mathrm{CD} 4^{+} \mathrm{CD} 45 \mathrm{RA}^{+} \mathrm{T}$ cells were cultured in serum-free medium in absence or presence of DC supernatant. This supernatant was generated by maturing iDC at a density of $5 \times 10^{5} / \mathrm{ml}$ for $6 \mathrm{~h}$ in the presence of IL-4 (500U/ $\mathrm{ml})$, GM-CSF (400U/ml), IFN- $\gamma(500 \mathrm{U} / \mathrm{ml})$ and FMKp $(10 \mu \mathrm{g} / \mathrm{ml})$. After the induction of maturation, adherent cells were washed three times to remove the maturation stimuli and fresh medium was added. After a total of 48h, DC supernatants were collected. During the 5-day co-culture, each day the culture supernatant was harvested and frozen at $-20^{\circ} \mathrm{C}$ for cytokine determination. Cells were harvested and lysed in RLT buffer supplemented with $1 \% 2$-mercaptoethanol and frozen at $-80^{\circ} \mathrm{C}$ for gene expression analyses.

\section{Flow cytometry}

All flow cytometry antibodies used to determine $\mathrm{DC}$ and $\mathrm{T}$ cell purities as well as Th cell surface marker expression were purchased from BD Biosciences, except for BDCA-2 (Miltenyi Biotec). Antibodies were used at the proper concentrations either as fluorescein isothiocyanate, phycoerythrin, peridinin chlorophyll protein, allophyocyanin, allophyocyanin-H7, Horizon 450, Horizon 500, Alexa Fluor 488 or Pe-Cy7. Intracellular IFN- $\gamma$ staining was performed as described previously ${ }^{48}$. Analyses were performed with BD FACS Canto II and analysed by BD FACSDiva Software v6.1.2 (BD Biosciences). 


\section{qPCR}

Total cellular RNA was isolated from lysed T cells using RNeasy Mini kit (Qiagen) according to manufacturer's instructions. Genomic DNA was removed by DNase I (Invitrogen) treatment followed by reverse transcription using random hexamer primers (Invitrogen) and Superscript III Reverse Transcriptase (Invitrogen) according to the standard procedures. Primers for quantitative PCR analysis were generated using primerBLAST software (NCBI). All primers were selected to span exon-exon boundaries with a maximal amplification length of $300 \mathrm{bp}$. Primer specificity was tested by melting curve analyses, product size confirmation by gel-based PCR analyses and bidirectional sequencing of amplified products after subcloning in plasmids (Topo TA cloning, Invitrogen). Relative quantification was done by generating a standard curve of a reference sample (cDNA of total T cell fraction). Real-time PCR was done with SYBR green detection (SensiMix SYBR \& Fluorescein Kit, both from Bioline Reagents Ltd., London, United Kingdom) using an iCycler iQ (Biorad Laboratories Inc., Hercules, CA, USA) and primers (10pmol) specific for the different Th lineages (listed in Table S1). The PCR program consisted of $10 \mathrm{~min}$ initial heating at $95^{\circ} \mathrm{C}$ (hot start polymerase), followed by 35 cycles amplification $\left(30 \mathrm{~s}\right.$ at $95^{\circ} \mathrm{C}$, $20 \mathrm{~s}$ at the optimized annealing temperature and $20 \mathrm{~s}$ at $72^{\circ} \mathrm{C}$ ) and a final heating up to $92^{\circ} \mathrm{C}$ (increasing $0.5^{\circ} \mathrm{C} / 7 \mathrm{~s}$ ) for the generation of a melting curve. Each data point of the graphs was generated by determining expression of the gene of interest on the different days in duplicate and normalizing these data to the corresponding expression of CD $3 \varepsilon$ used as housekeeping gene in our assay.

\section{T helper cell cytokine detection}

Quantification of Th-specific cytokines (IFN- $\gamma$, IL-4, IL-5, IL-13, IL-17, IL-10) in the supernatant of the DC-T cell co-cultures on day 1, 3, 5 and 7 (day 1, 3 and 5 for the antiCD3 culture) was performed by CBA flex set assay (BD Biosciences) according to the manufacturer's instructions. Measurements were performed with BD FACS Canto II and analysed by BD FACSDiva Software v6.1.2 and FCAP array analysis software (version 1.0.1; Soft Flow Inc., St. Louis Park, Minnesota, USA).

\section{Statistical analyses}

Statistical analyses were performed by Wilcoxon matched pairs test and the correlation was tested by nonparametric Spearman correlation; $P$ values $<0.05$ were regarded as significant. Data was analysed using Prism Software (version 6; GraphPad Software, San Diego, CA, USA). 

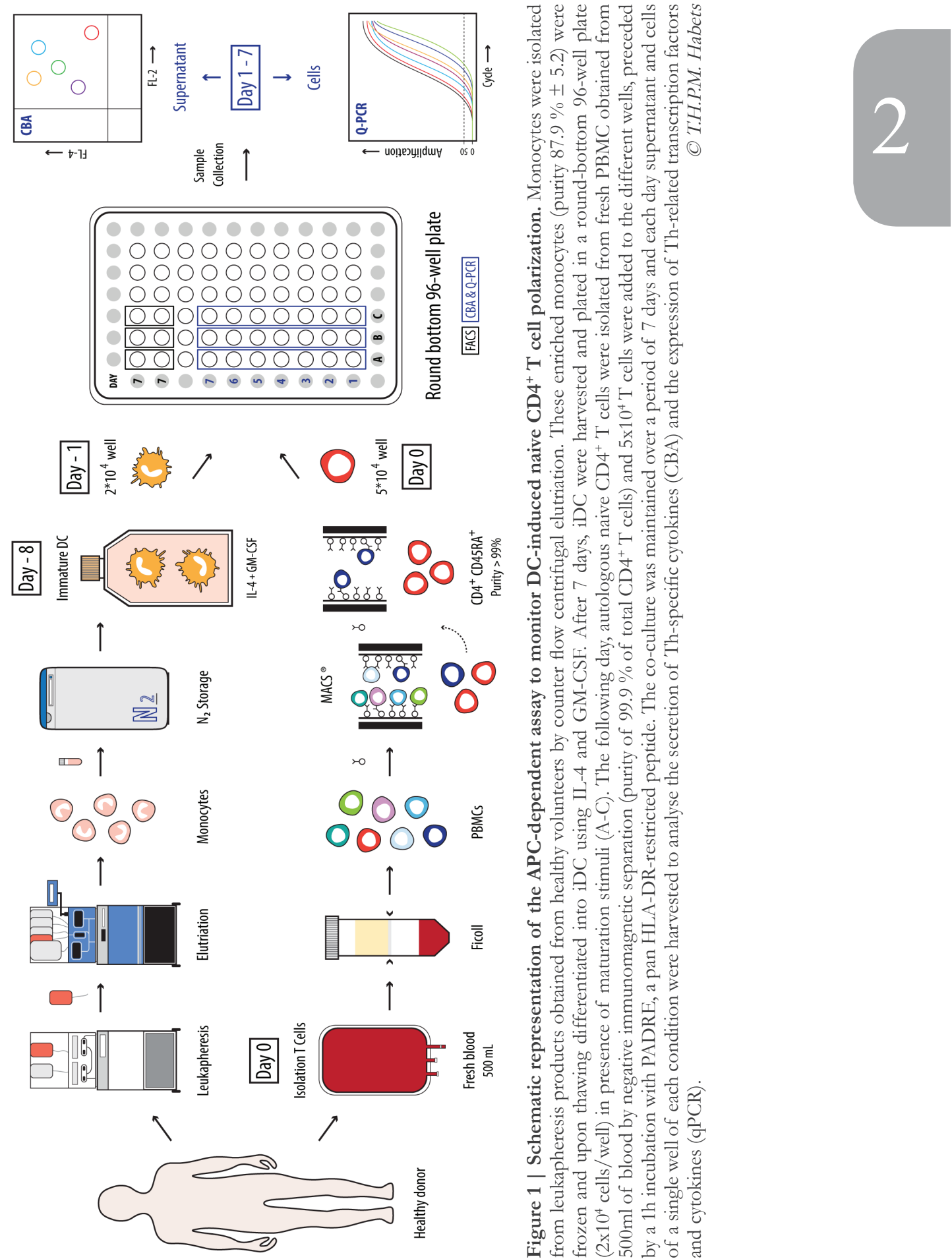

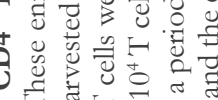

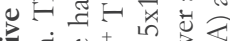

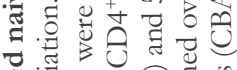

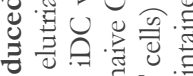
है $=$

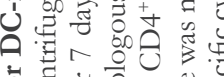

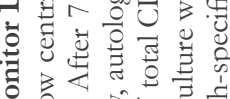

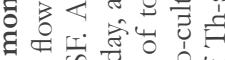
苞茠

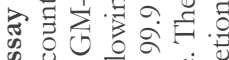

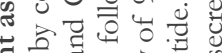

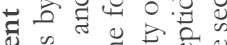

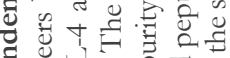
过 $\dot{0} \overrightarrow{0}$ उं

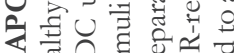
ฮำ छี.

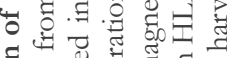

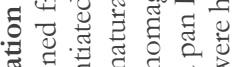
击

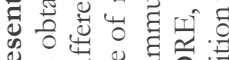

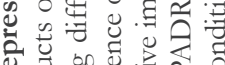
प्ञ

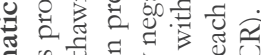
द्वृ

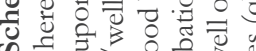
क त्वित

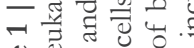
은

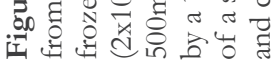




\section{RESULTS}

\section{Development and setup of an APC-dependent, TCR-restricted naive $C D 4^{+} \mathrm{T}$ cell polarization assay}

We set out to develop a TCR-restricted, human autologous assay which allows the comparison of the $\mathrm{CD}^{+} \mathrm{T}$ cell polarizing capacity of differently matured DC using primary cells. In order to develop such an APC-dependent system a number of prerequisites need to be considered. These include e.g. the selection of an appropriate polyclonal antigen, isolation of pure cells, and determining appropriate cell ratios. A schematic overview of the optimized assay is represented in Figure 1. In the following sections more details about the assay development will be provided.

\section{Antigen selection}

The human precursor frequencies of epitope-specific naive $\mathrm{CD}^{+} \mathrm{T}$ cells, counting up to at most 100 cells $/ 10^{6}$ naive $T$ cells ${ }^{49}$, limited the development of small-scale 96 -well format assay for the comparison of human naive cognate $\mathrm{CD} 4^{+} \mathrm{T}$ cell responses. To circumvent this, we used a pan HLA-DR-restricted peptide, named PADRE, which polyclonaly activates a subset of $\mathrm{T}$ cells ${ }^{47}$. PADRE differs from superantigens as it binds inside the peptide-binding groove of HLA-DR. PADRE has the advantage of binding to all major groups of HLA-DR-restricted variants, which makes it a TCR-restricted peptide for the study of $\mathrm{CD}^{+} \mathrm{T}$ cell responses in the majority of individuals.

\section{Co-culture ratios}

To determine the optimal DC:T cell ratio, we co-cultured different concentrations of DC with a constant number of $\mathrm{CD} 4^{+} \mathrm{CD} 45 \mathrm{RA}^{+} \mathrm{T}$ cells $\left(5 \times 10^{4} /\right.$ well). To exclude the influence of different concentrations of DC-derived factors on the initiation of the T cell response, DC were washed after $24 \mathrm{~h}$ of maturation prior to their addition to the co-culture. Additionally, all the co-cultures were supplemented with the same amount of pooled 24h-matured DC-derived supernatant. Based on these experiments (Figure S2), we selected a DC:T cell ratio of 2:5 to perform the co-culture experiments, as the amount of T cell-derived IFN- $\gamma$ in these Th1-polarizing conditions was shown to be the highest.

\section{Setup of the co-culture}

Summarizing, the ultimate setup of the assay is as follows (Figure 1): to maximize the priming efficiency of DC ${ }^{43}$, iDC were matured in a round-bottom 96-well plate in serum-free AIM- $V^{\circledR}$-medium supplemented with different maturation stimuli. The next day, naive $\mathrm{CD}^{+} \mathrm{CD}^{+} 5 \mathrm{RA}^{+} \mathrm{T}$ cells were isolated from fresh PBMC and added to the 24h-matured DC preceding a $1 \mathrm{~h}$-incubation with PADRE. During a 7-day co-culture, each 
day supernatant and cells were harvested from a single well to determine Th cytokines and Th lineage-specifying transcription factors by CBA and qPCR, respectively.

\section{Monitoring the initiation of Th1 responses}

In our search for a DC maturation stimulus capable of polarizing naive $\mathrm{CD} 4^{+} \mathrm{T}$ cells towards a Th1 phenotype, we used a combination of FMKp and IFN- $\gamma$ as maturation cocktail. This selection was based on previous demonstrations that FMKp/IFN- $\gamma$-matured DC were able to produce high IL-12 levels ${ }^{48,50,51}$, a cytokine which is crucial for Th1 responses ${ }^{52,53}$. Furthermore, these DC were shown to be potent inducers of CTL responses ${ }^{50}$.

To study the initiation of a Th1 response, we compared the polarizing capacities of iDC and FMKp/IFN- $\gamma$-matured DC (Figure 2). FMKp/IFN- $\gamma$-matured DC induced the lineage-specifying transcription factor T-bet (gene name TBX21) and IFN- $\gamma$ mRNA levels already after $24 \mathrm{~h}$ and were peaking on day 3 (30 resp. 90 -fold increase in mRNA levels compared with $\mathrm{T}$ cells on day 0$)$. IFN- $\gamma$ mRNA induction was associated with
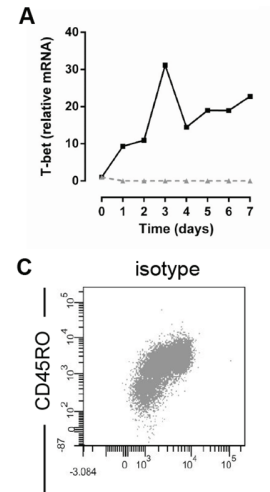
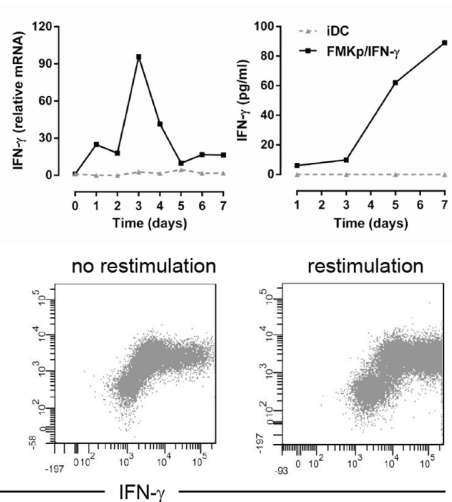

B
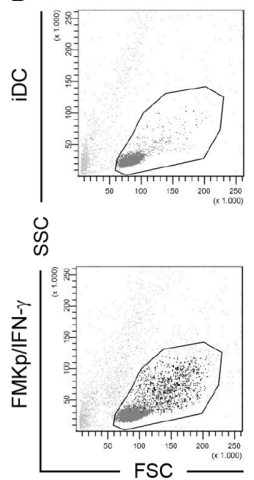

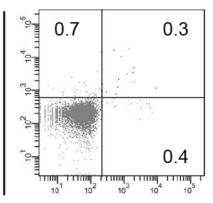

กับ

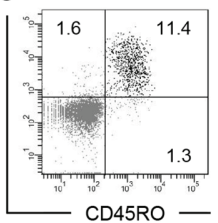

Figure 2 | FMKp/IFN- $\gamma$-matured DC polarize a subpopulation of naive $\mathbf{T}$ cells into the Th1 lineage. iDC or FMKp/IFN- $\gamma$-matured DC were pulsed with PADRE for $1 \mathrm{~h}$ before the addition of autologous $\mathrm{CD}^{+} \mathrm{CD}^{+} \mathrm{RA}^{+} \mathrm{T}$ cells to the 7 -day co-culture. (A) Expression of T-bet and IFN- $\gamma$ and IFN- $\gamma$ production of naive $\mathrm{CD}^{+}{ }^{+} \mathrm{T}$ cells co-cultured with iDC $(\boldsymbol{\Delta})$ or FMKp/IFN- $\gamma$-matured DC (ם) are compared. CD3 $\varepsilon$ was used as housekeeping gene and the expression data were normalized to the relative mRNA content of naive $\mathrm{T}$ cells on day 0 . IFN- $\gamma$ production by naive $\mathrm{T}$ cells co-cultured with differently matured DC was determined in the supernatant of the co-culture on day 1, 3, 5 and 7 by CBA. Graphs are representative of 11 independent experiments. (B) On day 7, T cells were stained for expression of CD45RO and CD25 and analysed by flow cytometry. Cells are gated in FSC/SSC on lymphocyte gate, excluding dead cells and doublets (light grey dots), and selected for $\mathrm{CD}^{+}{ }^{+}$cells (dark grey and black dots). Percentages of CD45RO and CD25 positive populations are indicated in the plots. Dot plots are representative of 5 independent experiments. (C) On day 6 of the co-culture, GolgiPlug TM and GolgiStop ${ }^{\mathrm{TM}}$ were added to $\mathrm{T}$ cells with or without PMA/ionomycin restimulation. The next day, intracellular IFN- $\gamma$ staining was performed and cells were analysed by flow cytometry. Representative dot plots of CD45RO and IFN- $\gamma$ expression of $\mathrm{CD}^{+}{ }^{+} \mathrm{T}$ cells co-cultured with FMKp/IFN- $\gamma$-matured DC are shown.Data are representative of 5 independent experiments. 
IFN- $\gamma$ cytokine production as evidenced by CBA. T cells co-cultured with iDC only showed minor upregulation of T-bet levels (up to 5-fold) and no upregulation of IFN- $\gamma$ levels (Figure 2A). Additionally, T cells of the two co-cultures were stained on day 7 for different activation markers and analysed by flow cytometry. Of the $T$ cells co-cultured with FMKp/IFN- $\gamma$-matured DC, 11.4\% were double positive for CD25 and CD45RO (Figure 2B) compared with $0.3 \%$ in the co-culture with iDC. In addition, these double positive cells were enlarged in the FSC/SSC compared with the double negative ones.

We performed an intracellular IFN- $\gamma$ staining to identify whether or not the amount of IFN- $\gamma$ secreted on day 7 of the co-culture was derived from a few high-producing cells. Protein transport inhibitors were added on day 6 of the co-culture and the cells were incubated overnight. To enhance the cytokine secretion of all Th1-committed cells, we performed an additional intracellular cytokine staining on restimulated cells. The percentage of IFN- $\gamma^{+}-\mathrm{T}$ cells was higher in the co-culture of FMKp/IFN- $\gamma$-matured DC compared with iDC (data not shown). This corresponds to the higher total IFN- $\gamma$ levels detected in the supernatant of this condition. Even though restimulation of the cells for $16 \mathrm{~h}$ with PMA/ionomycin was not required to detect the accumulation of intracellular IFN- $\gamma$ in $\mathrm{CD}^{+}{ }^{+} \mathrm{T}$ cells, more $\mathrm{Th} 1$-committed $\mathrm{CD}^{+}{ }^{+} \mathrm{T}$ cells were detected in the restimulated condition on day 7 of the co-culture (Figure 2C). This indicates that restimulation is required for estimating the total size of the Th1-committed subpopulation.

Taken together, these data indicate that PADRE-loaded FMKp/IFN- $\gamma$-matured moDC are capable of polarizing a subset of naive $\mathrm{CD}^{+} \mathrm{T}$ cells into the Th1 lineage as evidenced by their upregulation of T-bet and IFN- $\gamma$ mRNA levels, their expression of CD25 and CD45RO, and the secretion of IFN- $\gamma$.

\section{Th1 polarization is not a direct effect of the maturation stimuli on $T$ cells}

We performed washing experiments to exclude that $T$ cells are polarized in response to the DC maturation stimuli instead of their interaction with matured DC and their released cytokines. Previously, we and others ${ }^{6,48,54}$ have shown that an imprinting of the DC maturation of $6 \mathrm{~h}$ is sufficient to trigger the DC maturation programme. We compared $\mathrm{CD}^{+} \mathrm{T}$ cell polarizing capacity of FMKp/IFN- $\gamma$-matured DC incubated for $24 \mathrm{~h}$ with maturation stimuli with those of $6 \mathrm{~h}$ after induction of maturation extensively washed FMKp/IFN- $\gamma$-matured DC. Both washed and non-washed FMKp/IFN- $\gamma$-matured DC induced the expression of T-bet and IFN- $\gamma$ following the same pattern, as well as comparable levels of IFN- $\gamma$ after 7 days of co-culture (Figure 3A). These data confirm that the Th1 polarization seen by co-culturing FMKp/IFN- $\gamma$-matured DC with naive $\mathrm{CD}^{+}{ }^{+} \mathrm{T}$ cells is APC-dependent and is not a consequence of direct influence of the DC maturation stimuli on the $\mathrm{T}$ cells. 

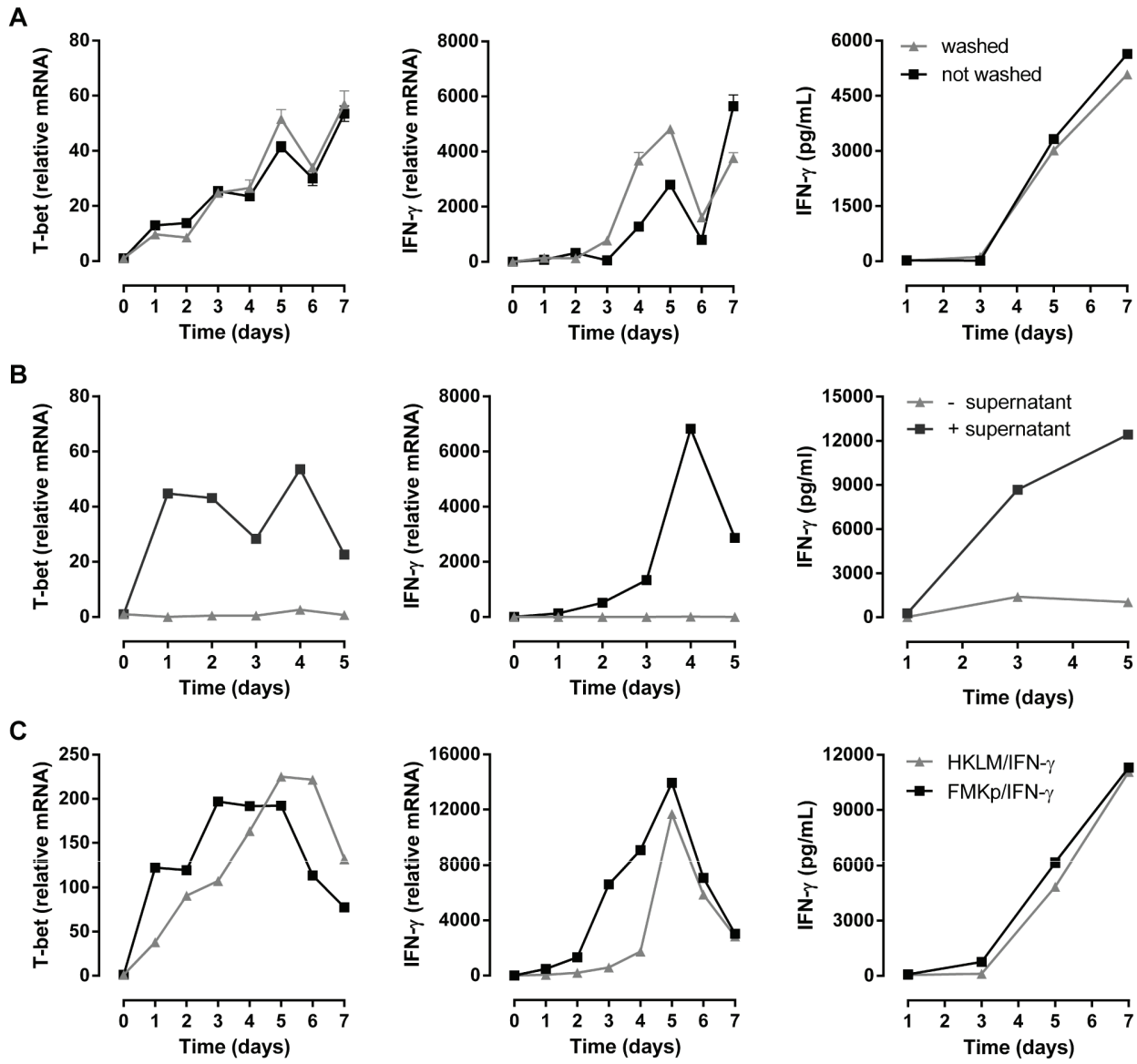

Figure 3 | Dependency of DC-induced Th1 polarization on DC-derived soluble factors. (A) FMKp/IFN- $\gamma$-matured DC were either extensively washed $(\mathbf{\Delta})$ or not (- $6 \mathrm{~h}$ after induction of maturation and co-cultured for 7 days with autologous $\mathrm{CD}^{+} \mathrm{CD}^{2} 5 \mathrm{RA}^{+} \mathrm{T}$ cells. Expression of T-bet and IFN $-\gamma$ and total IFN- $\gamma$ production are shown. Graphs are representative of 5 independent experiments. (B) APC-independent assay using immobilized anti-CD3 allows studying the influence of DC-derived soluble factors on $\mathrm{T}$ cell polarization. $5 \times 10^{4}$ cells $\mathrm{CD}^{+} \mathrm{CD}^{+} 5 \mathrm{RA} \mathrm{A}^{+} \mathrm{T}$ cells were cultured for 5 days without $(\boldsymbol{\Delta})$ or with (-) washed FMKp/IFN- $\gamma$-matured DC-derived supernatant in presence of plate-bound anti-CD3 $(0.25 \mu \mathrm{g} / \mathrm{ml})$ in a round-bottom $96-$ well plate. Transcriptional induction of T-bet and IFN- $\gamma$ and secretion of IFN- $\gamma$ were determined. Data shown are representative data of 3 independent experiments. (C) FMKp/IFN- $\gamma$ - and HKLM/IFN- $\gamma$-matured DC induce Th1 polarization. iDC were matured with $\mathrm{HKLM} / \mathrm{IFN}-\gamma(\boldsymbol{\Delta})$ or FMKp/IFN- $\gamma(\boldsymbol{\bullet})$ and co-cultured with $\mathrm{CD}^{+}{ }^{+} \mathrm{CD} 45 \mathrm{RA}^{+} \mathrm{T}$ cells. Expression of T-bet and IFN- $\gamma$ and total IFN- $\gamma$ production are shown. Data are representative of 4 independent experiments.

\section{Effect of FMKp/IFN $\gamma$-derived cytokines on Th1 polarization}

To further investigate the contribution and importance of the DC-derived soluble factors on T cell polarization, an APC-independent approach can be used as complementary tool to study their influence independently of the co-stimulatory and other membrane-bound 
factors. To this end, we cultured naive $\mathrm{CD}^{+} \mathrm{T}$ cells for 5 days on immobilized anti-CD3 in the absence or presence of FMKp/IFN- $\gamma$-DC-derived supernatant. To compare results obtained by this assay with our APC-dependent assay and to avoid the direct polarizing effect of the immobilized anti-CD3, we titrated down anti-CD3 to such an extent that it gave a similar proliferative response as observed in the APC-dependent assay (data not shown). The influence of DC-derived soluble factors on naive $\mathrm{T}$ cells was tested with supernatant derived from 24h-matured FMKp/IFN- $\gamma$-DC, which were extensively washed $6 \mathrm{~h}$ after induction of maturation. As shown in Figure 3B , in the presence of FMKp/IFN- $\gamma$-DC-derived supernatant the expression of both T-bet and IFN- $\gamma$ was induced and IFN- $\gamma$ was detected in the culture supernatant as evidenced by CBA. These data illustrate that APC-independent systems are complementary to our APC-dependent system allowing the discovery of the causative factors without interference of contactdependent stimuli (e.g. co-stimulatory molecules).

\section{Commercially available DC maturation stimuli inducing Th1 polarization}

To investigate whether or not a commercially available DC maturation stimulus shows similar effects on the T cell polarization as FMKp, we screened different PRRtriggers in combination with IFN- $\gamma$ (data not shown). Among all the triggers we tested, HKLM/IFN- $\gamma$-matured DC had the most potent capacity to induce Th1 polarization. As shown in Figure 3C, a similar expression pattern of T-bet and IFN- $\gamma$ was observed, with FMKp/IFN- $\gamma$-DC leading to faster induction of these factors in the T cells. The level of IFN- $\gamma$ secretion over time of the co-culture was not significantly different.

\section{Influence of memory $\mathrm{CD}^{+} \mathrm{T}$ cell contamination}

A disadvantage of using an HLA-DR-restricted polyclonal peptide in this assay is the activation of memory $\mathrm{CD}^{+} \mathrm{T}$ cells. They do not require a differentiation phase and thereby readily produce cytokines upon TCR-triggering. To evaluate to what extent the purity of naive $\mathrm{CD}^{+}{ }^{+} \mathrm{T}$ cells influences our read-out parameters, we first compared Th1-inducing potential of different $\mathrm{CD}^{+}{ }^{+} \mathrm{T}$ cell fractions. The different $\mathrm{CD}^{+} \mathrm{T}$ cell fractions - total $\mathrm{CD}^{+}, \mathrm{CD}^{+} \mathrm{CD} 45 \mathrm{RA}^{+}$and $\mathrm{CD}^{+}{ }^{+} \mathrm{CD} 45 \mathrm{RO}^{+} \mathrm{T}$ cells - were co-cultured for 5 days with FMKp/IFN- $\gamma$-matured, PADRE-pulsed DC and supernatants were harvested each day. The purities of the different $\mathrm{CD}^{+} \mathrm{T}$ cell fractions were analysed with flow cytometry (Figure S3). On day 5 of the co-culture, memory $\mathrm{CD}^{+} \mathrm{CD}^{2} 5 \mathrm{RO}^{+} \mathrm{T}$ cells produced as much IFN- $\gamma$ as the total $\mathrm{CD}^{+} \mathrm{T}$ cell fraction; whereas naive $\mathrm{CD} 4^{+} \mathrm{CD} 45 \mathrm{RA}{ }^{+} \mathrm{T}$ cells produced 10 times less IFN- $\gamma$ after 5 days of co-culture (Figure 4A).

Compared with a naive response, the magnitude of the cytokine response is 10 -fold increased for the memory $\mathrm{CD}^{+} \mathrm{T}$ cells and they are the main contributors of IFN- $\gamma$ secretion after 5 days of co-culture with moDC. We performed a spiking experiment to 
evaluate to what extent a contamination with memory $\mathrm{T}$ cells during the co-culture with $\mathrm{CD}^{+} \mathrm{CD}_{45 \mathrm{RA}^{+}}$will influence the read-out parameters of our PADRE-peptide-based assay. Increasing numbers of $\mathrm{CD}^{+} \mathrm{CD} 45 \mathrm{RO}^{+}$cells were added to a $\mathrm{DC}-\mathrm{CD} 4^{+} \mathrm{CD} 45 \mathrm{RA}^{+}$ co-culture (up to $10 \%$ memory spike) and IFN- $\gamma$ secretion on day 3 and day 5 of the coculture was determined. On day 3 , no differences between pure $\mathrm{CD}^{+} \mathrm{CD}_{4} 5 \mathrm{RA}^{+}$co-culture and up to $5 \%$ spiking with $\mathrm{CD} 4^{+} \mathrm{CD} 45 \mathrm{RO}^{+}$were observed, whereas the IFN- $\gamma$ production of the condition with $10 \% \mathrm{CD}^{+} \mathrm{CD}^{2} 5 \mathrm{RO}^{+}$cells was twice as high compared with the other conditions (Figure 4B). On day 5, a 2 -fold difference in IFN- $\gamma$ production was detectable with $5 \%$ spiking and even 3 -fold with $10 \%$ spiking compared with the pure $\mathrm{CD}^{+} \mathrm{CD} 45 \mathrm{RA}{ }^{+}$ fraction. Taking into account that with our procedure it is possible to isolate highly pure $\mathrm{CD}^{+} \mathrm{CD} 45 \mathrm{RA}^{+} \mathrm{T}$ cells (Figure S1) and that the contamination with $\mathrm{CD}^{+} \mathrm{CD}^{+} 5 \mathrm{RO}^{+}$cells is below $0.1 \%$, the read-out parameters of our assay are only to a minute extent biased by memory $\mathrm{CD}^{+} \mathrm{T}$ cell contamination.

A

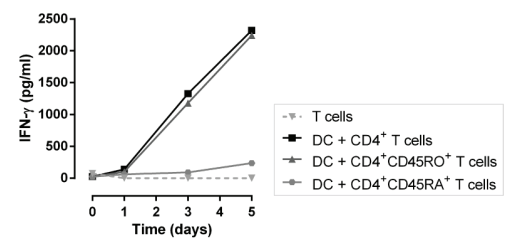

B

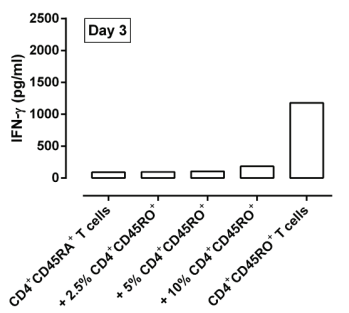

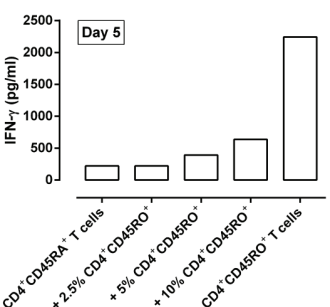

Figure 4 Presence of $\mathrm{CD}^{+} \mathrm{CD}^{2} 5 \mathrm{RO}^{+} \mathrm{T}$ cells in the $\mathrm{DC}-\mathrm{CD} 4{ }^{+} \mathrm{CD} 45 \mathrm{RA}^{+} \mathrm{T}$ cell co-culture influences Th1 read-out parameters. $(\mathbf{A}) \mathrm{CD}^{+}, \mathrm{CD}^{+} \mathrm{CD} 45 \mathrm{RO}^{+}, \mathrm{CD}^{+} \mathrm{CD} 45 \mathrm{RA}^{+}$populations were isolated by negative immunomagnetic separation from freshly isolated PBMC. IFN- $\gamma$ production of total $\mathrm{CD}^{+}(\boldsymbol{\bullet}), \mathrm{CD}^{+} \mathrm{CD}_{4} 5 \mathrm{RA}^{+}(\bullet)$, and $\mathrm{CD} 4{ }^{+} \mathrm{CD}_{4} 5 \mathrm{RO}^{+}(\boldsymbol{\Delta})$ T cells co-cultured with FMKp/IFN- $\gamma$-matured DC for 7 days as measured by CBA. (B) Contribution of contaminating $\mathrm{CD}^{+} \mathrm{CD}_{4} 5 \mathrm{RO}^{+} \mathrm{T}$ cells $(2.5,5$

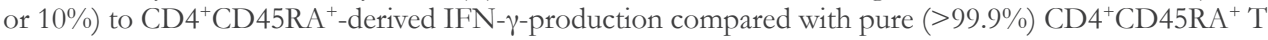
cell populations. Data shown are representative of 2 independent experiments.

\section{Differential Th cell-polarizing capacity of DC}

\section{Induction of Th1 and Th2 polarization by moDC}

The current system allows the comparison of the $T$ cell polarizing capacity of differently matured DC in terms of kinetics and magnitude of Th1 responses. We show the example of the capacity of 3 different (pre-) clinical DC maturation cocktails - $\mathrm{PGE}_{2} / \mathrm{TNF}-\alpha$, LPS/IFN- $\gamma$ or FMKp/IFN- $\gamma$ - used for the generation of ex vivo matured DC for DCbased vaccines and their capacity to polarize naive $\mathrm{CD}^{+} \mathrm{T}$ cells into Th1 cells (Figure 5). Both, in T cells co-cultured with LPS/IFN- $\gamma$ and FMKp/IFN- $\gamma$-matured DC, the mRNA levels of T-bet were induced over time, being higher in the FMKp/IFN- $\gamma$-DC co-culture. 

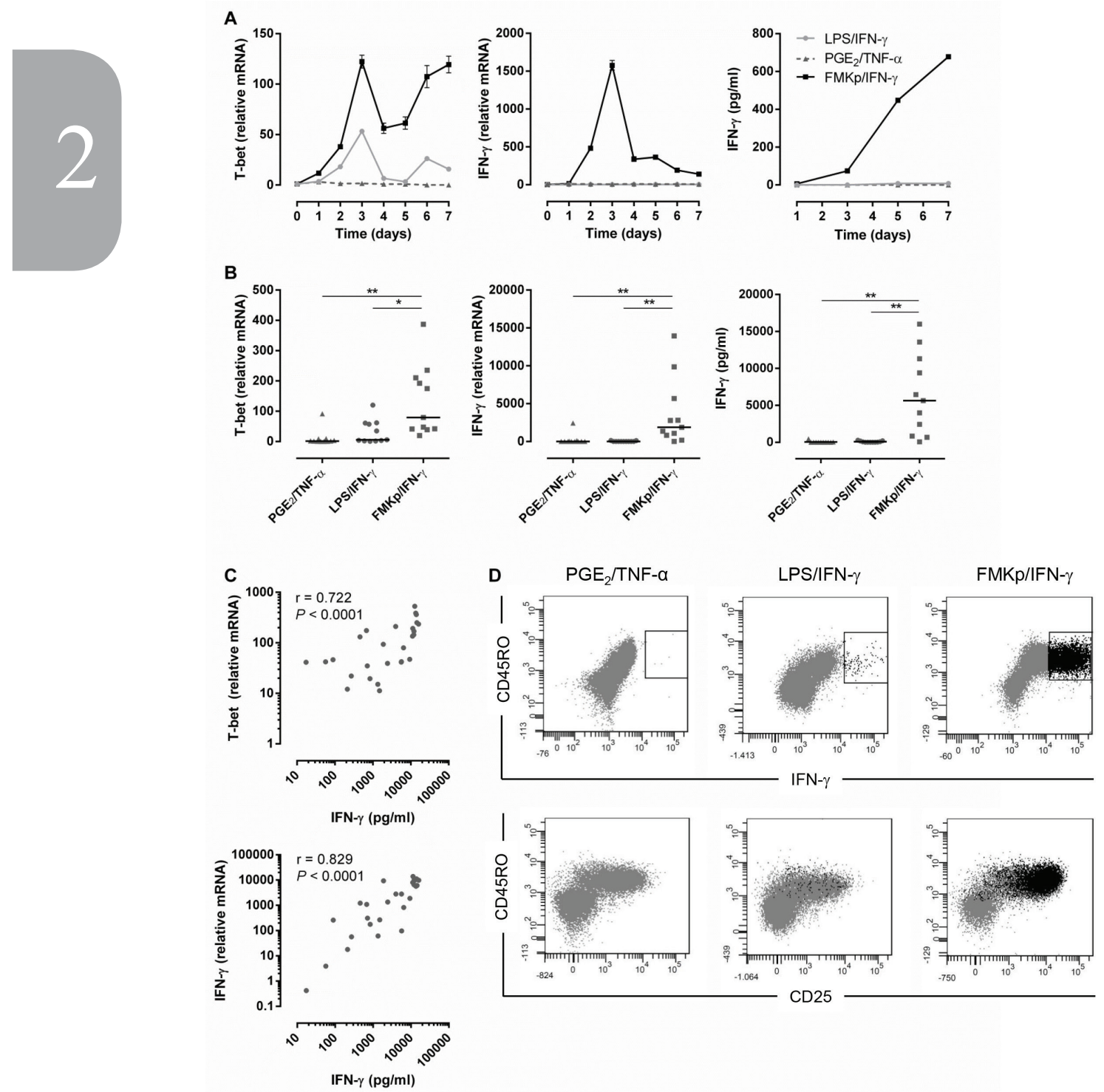

Figure 5 | Differential Th1-polarizing capacity of differently matured DC. Naive CD4 ${ }^{+} \mathrm{T}$ cells were co-cultured for 7 days with PGE $2 /$ TNF- $\alpha(\boldsymbol{\Delta})$, LPS/IFN- $\gamma(\bullet)$ or FMKp/IFN- $\gamma-(\boldsymbol{\bullet})$ matured DC. (A) Expression of T-bet and IFN- $\gamma$ and production of IFN- $\gamma$ were monitored. Graphs are representative of 11 independent experiments. (B) Comparison of the expression of T-bet and IFN- $\gamma$ on day 5 and IFN- $\gamma$ production on day 7 of differently matured $\mathrm{DC}$ cultured with naive $\mathrm{CD} 4^{+} \mathrm{T}$ cells. 11 independent experiments and their median levels are shown. Wilcoxon signed-rank test significance, ${ }^{* *} P \leq 0.01$, ${ }^{* * *} P<0.001$ (C) Correlation between T-bet and IFN- $\gamma$ expression on day 5 and IFN- $\gamma$ secretion on day 7 of FMKp/IFN- $\gamma$-matured DC in co-culture with naive $\mathrm{CD}^{+}{ }^{+} \mathrm{T}$ cells. Nonparametric Spearman correlation test significance indicated in the graphs. (D) Expression of CD45RO, CD25, and intracellular IFN- $\gamma$ of naive $\mathrm{CD} 4^{+} \mathrm{T}$ cells cultured for 7 days with differently matured $\mathrm{DC}$ as indicated above the graphs. On day 6, GolgiPlug ${ }^{\mathrm{TM}}$ and GolgiStop ${ }^{\mathrm{TM}}$ were added to the co-culture and the staining was performed on day 7. Cells shown in the plots represent living singlet cells gated on $\mathrm{CD}^{+} \mathrm{CD}^{+}$(dark grey population). T cells positive for IFN- $\gamma$ are shown in black. Dot plots are representative graphs of 3 independent experiments. 
mRNA levels and secretion of IFN- $\gamma$ could only be detected in the co-cultures of T cells with FMKp/IFN- $\gamma$-matured DC (Figure 5A). In Figure 5B the average expression of T-bet and IFN- $\gamma$ on day 5 of the co-cultures of these three different conditions as well as the total IFN- $\gamma$ production detected in the supernatant of the co-cultures on day 7 are combined. In line with the graphs of Figure 5A, both T cells cultured with LPS/IFN- $\gamma$ and FMKp/IFN- $\gamma$-matured DC showed increased levels of T-bet (up-regulated median levels of 5.6 vs. 79.5 compared with $\mathrm{T}$ cells alone), but the mRNA levels and secretion of IFN- $\gamma$ was limited to naive T cells cultured with FMKp/IFN- $\gamma$-matured DC. There was a significant correlation of both T-bet and IFN- $\gamma$ mRNA levels on day 5 of the FMKp/IFN- $\gamma$-mDC co-cultured $T$ cells with the accumulated IFN- $\gamma$ secretion on day 7 (Figure 5C). Additionally, $\mathrm{T}$ cells of the different conditions were stained for CD45RO and CD25 as well as for intracellular IFN- $\gamma$. In all three conditions T cells up-regulated the expression of CD25 and CD45RO upon the 'antigen'-encounter. Only in the FMKp/IFN- $\gamma$ conditions, part of these cells was also positive for IFN- $\gamma$, which corresponds to data shown in Figure 5A, B.
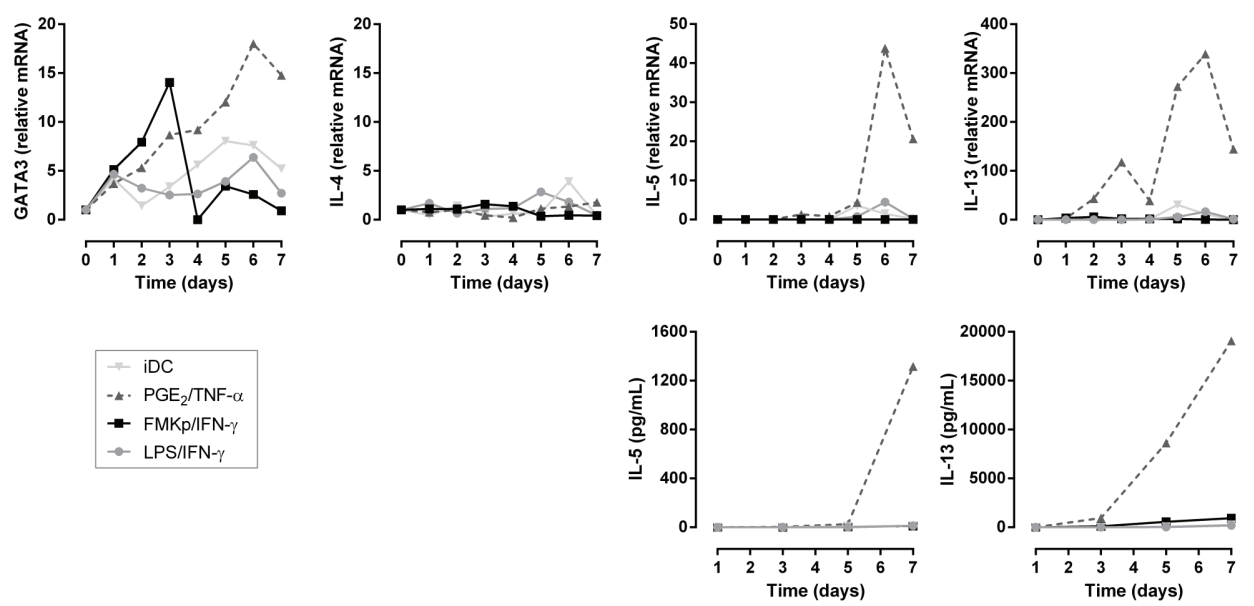

Figure 6 | Differential Th2-polarizing capacities of differently matured moDC. Naive $\mathrm{CD}^{+} \mathrm{T}$ cells were co-cultured for 7 days with PGE 2 /TNF- $\alpha(\boldsymbol{\Delta})$, LPS/IFN- $\gamma(\bullet)$ or FMKp/IFN- $\gamma-(\boldsymbol{\bullet})$ matured DC. Expression of GATA3, IL-4, IL-5, and IL-13 and production of IL-5 and IL-13 were monitored. IL-5 and IL-13 protein production by naive T cells co-cultured with differently matured DC was determined in the supernatant of the co-culture. Graphs are representative of 5 independent experiments.

In parallel, we studied the capacity of these differently matured DC to induce Th2 polarization, as illustrated in Figure 6. In all the DC-T cell co-cultures, a transient up-regulation of GATA3 mRNA levels, the lineage-specifying transcription factor of Th2 cells, was observed. Only $\mathrm{PGE}_{2} / \mathrm{TNF}-\alpha$-DC led to a constantly increasing expression of GATA3 in the T cells. In addition, the expression of IL-4, IL-5, and IL-13, the signature 
cytokines of the Th2 lineage, was monitored. IL-5 and IL-13 expression was only detectable in the $\mathrm{PGE}_{2} / \mathrm{TNF} \alpha$ condition, which paralleled the cytokine secretion profile; only $\mathrm{T}$ cells of the $\mathrm{PGE}_{2} / \mathrm{TNF}-\alpha$ condition secreted IL-5 and IL-13. This is in line with our previous demonstration of $\mathrm{CRTH}_{2}{ }^{+} \mathrm{CD}^{+}{ }^{+} \mathrm{T}$ cells in a co-culture of $\mathrm{PGE}_{2} / \mathrm{TNF}-\alpha$-matured $\mathrm{DC}$ in a total $\mathrm{T}$ cell pool ${ }^{50}$. IL-4 was not expressed nor secreted in any of the conditions. Thus, $\mathrm{PGE}_{2} / \mathrm{TNF}-\alpha$-matured DC can be used as a positive control for IL-5/IL-13-secreting Th2 cells. Unexpectedly, the Th1-inducing FMKp/IFN- $\gamma$-DC induced a transient expression of GATA3, but did not lead to any secretion of Th2 cytokines, supporting the recently published studies about co-expression of different transcription factors ${ }^{11,12}$.

\section{Induction of Th1 polarization by $\mathrm{pDC}$}

To investigate whether or not the small-scale setup of the assay allows the study of a more infrequent blood DC subset, we studied the applicability of this system to pDC, which is illustrated in Figure 7. Unstimulated and ODN2216-triggered pDC, a microbial stimulus known to trigger $\mathrm{pDC}$ via TLR9 ${ }^{55}$, were co-cultured with naive $\mathrm{T}$ cells during 7 days in absence or presence of IL-3. Naive $\mathrm{CD}^{+}{ }^{+} \mathrm{T}$ cells co-cultured with unstimulated pDC up-regulated T-bet and IFN- $\gamma$ mRNA and produced minor levels of IFN- $\gamma$ (Figure 7A). IL-3 stimulation of $\mathrm{pDC}$ increased the magnitude of T-bet expression, induced faster kinetics and led to substantially higher levels of IFN- $\gamma$ secretion $(117 \mathrm{vs} .3026 \mathrm{pg} / \mathrm{ml}$ on day 7). T cells cultured with ODN2216-stimulated pDC, showed a delayed but overall increased T-bet expression compared with pDC alone or $\mathrm{pDC}+\mathrm{IL}-3$. The combination of ODN2216 and IL-3-stimulated pDC led to faster T-bet expression and both a faster and a higher IFN- $\gamma$ expression, which was also reflected on the cytokine level. These data illustrate that IL-3 is not only an important survival factor for $\mathrm{pDC}{ }^{56}$, but it also influences the kinetics and the magnitude of pDC-induced T cell differentiation. ODN2216-stimulated pDC can be used as a positive control to study the effect of differently stimulated pDC on naive $\mathrm{CD}^{+} \mathrm{T}$ cell polarization.

To investigate whether or not different DC subsets translate a challenge by a particular PRR trigger into similar Th cell responses, we tested in the same experiment the influence of differently matured $\mathrm{pDC}$ on naive $\mathrm{CD}^{+}{ }^{+} \mathrm{T}$ cell polarization (Figure $7 \mathbf{B}$ ), comparing the maturation cocktails described in Figure $\mathbf{5}$ in the presence of IL-3. Naive T cells cocultured with these three differently stimulated $\mathrm{pDC}$ all expressed T-bet. IFN- $\gamma$ was mainly expressed by $\mathrm{T}$ cells in culture with FMKp/IFN- $\gamma$-pDC, which was also reflected by the highest IFN- $\gamma$ levels produced over 7 days. Even though LPS/IFN- $\gamma$-pDC showed the fastest kinetics, FMKp/IFN- $\gamma$-pDC showed 3-fold higher IFN- $\gamma$ levels and even 10-fold compared with $\mathrm{PGE}_{2} / \mathrm{TNF}-\alpha-\mathrm{pDC}$ on day 7 of the co-culture.

We illustrated that this APC-dependent system allows the comparison of the T cell-polarizing 
capacity of differently matured DC in terms of kinetics, magnitude and direction. Moreover, the system can be applied for functional studies with multiple DC subsets.
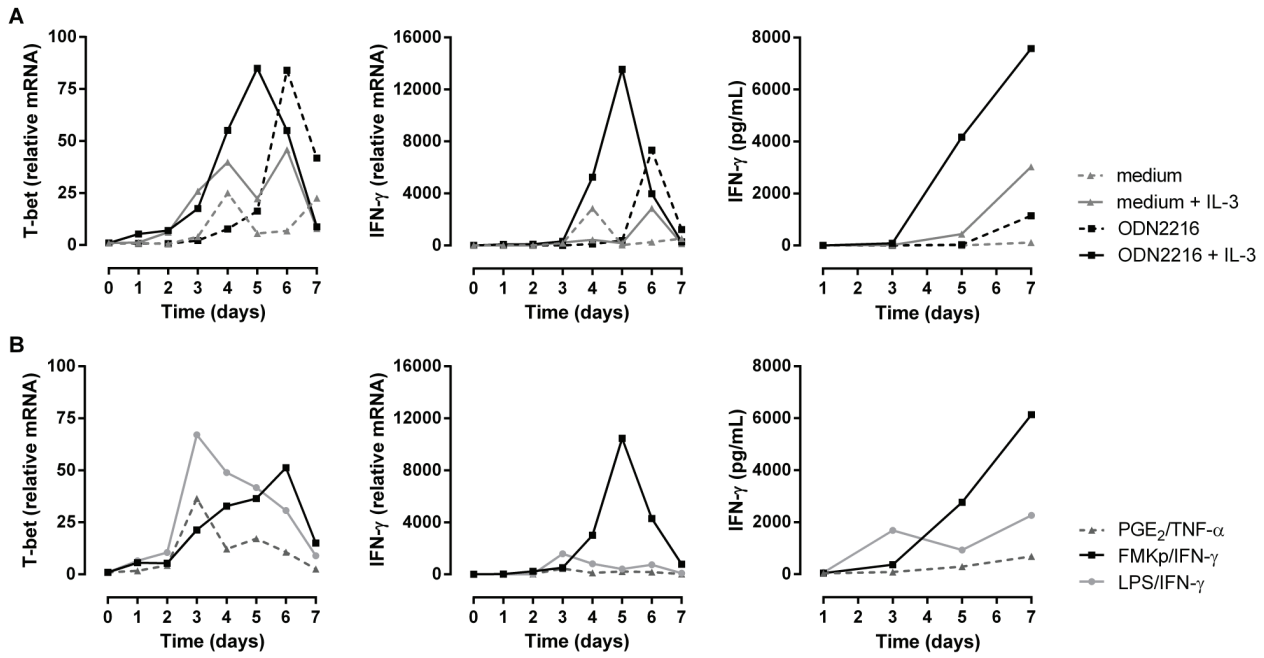

Figure 7 | Differential Th1-polarizing capacity of differently matured plasmacytoid DC. pDC, isolated from fresh blood, were stimulated overnight with different cocktails and $24 \mathrm{~h}$ later autologous naive $\mathrm{CD}^{+}{ }^{+} \mathrm{T}$ cells were added and the expression of T-bet and IFN- $\gamma$, and secretion of IFN- $\gamma$ were monitored during 7 days. (A) pDC were stimulated overnight with IL-3 (full grey line), ODN2216 (dashed black line) or with a combination of both (full black line). (B) Comparison of the capacity of differently matured pDC to induce Th1 polarization. pDC were incubated with PGE $_{2} / \mathrm{TNF}-\alpha(\boldsymbol{\Delta}), \mathrm{LPS} / \mathrm{IFN}-\gamma(\bullet)$ or FMKp/ IFN- $\gamma(\boldsymbol{\square})$ cocktail in the presence of IL-3. Representative data from 2 independent experiments are shown.

\section{DISCUSSION}

In terms of human $\mathrm{T}$ cell differentiation, fundamental tools to study the initiation of APC-dependent naive $\mathrm{CD}^{+} \mathrm{T}$ cell polarization are lacking. However, a dysregulation in human $\mathrm{CD}^{+} \mathrm{T}$ cell polarization is associated with a variety of diseases, such as cancer, autoimmunity, and allergies ${ }^{7,9}$. Due to interspecies discrepancies, data generated from murine models on e.g. the positive effect of medication on T cell-mediated diseases awaits confirmation in human in vitro assays. In this paper, we have described a standardized methodology to study the priming of human naive $\mathrm{CD}^{+} \mathrm{T}$ cells by differently matured DC. This in vitro system consists of a multi-faceted read-out tool that allows the monitoring of transcriptional events associated with $\mathrm{T}$ cell polarization and matching them to a $\mathrm{Th}$ cytokine secretion profile using a protein-multiplexing platform.

Inherent to the aim of setting up a small-scale (96-well format) assay to study $\mathrm{CD} 4^{+} \mathrm{T}$ cell polarization in the human system is that it does not allow antigen-specificity, because of 
the low precursor frequencies of epitope-specific naive $\mathrm{CD} 4^{+} \mathrm{T}$ cells in humans ${ }^{49}$. As a consequence the assay is performed in an antigen-independent but TCR-restricted manner using the HLA-DR-restricted peptide PADRE. In initial experiments, we observed that memory $\mathrm{CD}^{+}{ }^{+} \mathrm{T}$ cells were rapidly activated in this system and that they secreted cytokines upon TCR-triggering without the need of a programming phase. A memory contamination of more than $5 \%$ in the DC-T cell co-culture contributed to at least $50 \%$ of the Th1-derived IFN- $\gamma$ secretion after 5 days. In addition, memory contamination induced a faster response compared with a co-culture of highly pure naive $\mathrm{CD}^{+} \mathrm{T}$ cells (data not shown), indicating the importance of using pure naive $\mathrm{CD}^{+}{ }^{+} \mathrm{T}$ cells in a polyclonally activated system. We have shown that these highly pure $\mathrm{CD} 4^{+} \mathrm{CD} 45 \mathrm{RA}^{+} \mathrm{T}$ cells $\left(>99.9 \% \mathrm{CD}^{+} \mathrm{CD} 45 \mathrm{RA}^{+}\right.$and $<0.1 \% \mathrm{CD}^{+} \mathrm{CD}_{45 \mathrm{RO}^{+}}$) can be obtained using a simple immunomagnetic bead isolation kit without the need of a high-end flow-sorting methodology confirming previous findings ${ }^{57}$.

Most existing assays aim to demonstrate the ultimate fate of the polarized $T$ cell and not the initial priming phase of a naive $\mathrm{CD}^{+}{ }^{+} \mathrm{T}$ cell response. Moser et al. ${ }^{42}$ introduced a DC-based system to study the in vitro priming of naive $\mathrm{T}$ cell responses aiming to predict vaccine efficacies. Even though this assay has the advantage of monitoring antigen-specific $\mathrm{T}$ cell responses, the co-culture period over 14 days with restimulation by fresh antigen-pulsed $\mathrm{DC}$ only detects late stage responses of the naive $\mathrm{CD}^{+} \mathrm{T}$ cell polarization. However, it is possible that differently matured DC do not differ in the magnitude nor in the direction of the induced $\mathrm{T}$ cell response but that they lead to a faster induction. This knowledge can be of importance in pharmacological studies and may create valuable insight for designing vaccines. With our system, we provide a complementary tool to study the acute phase and evaluate the kinetics during the initiation of a naive $\mathrm{CD}^{+} \mathrm{T}$ cell response.

The vast majority of in vitro assays studying human $\mathrm{CD}^{+} \mathrm{T}$ cell polarization in an APC-dependent manner focus on moDC. An important disadvantage of this DC population is that these cells show more similarity with monocytes than with human subsets of lymphoid-tissue-resident DC: pDC and cDC (BDCA- $1^{+}$and BDCA- $\left.3^{+}\right)^{23}$. Nevertheless, it is generally accepted that moDC are good surrogates to study inflammatory DC and we optimized our assay using moDC as source of APC. In addition, we demonstrated that because of the small-scale assay setup, our findings can be translated to other in vivo and low-frequent blood-derived DC subsets. Out of $500 \mathrm{ml}$ fresh blood we could obtain between $1-2.5 \times 10^{6} \mathrm{pDC}$, which allows studying the capacity of at least 14 differently stimulated pDC to prime $\mathrm{CD}^{+} \mathrm{T}$ cells. This opens new perspectives to study the human counterparts of the mouse $\mathrm{pDC}, \mathrm{CD} 8 \alpha^{+} \mathrm{cDC}$ and $\mathrm{CD}_{11} \mathrm{~b}^{+} \mathrm{cDC}$ despite their very low blood frequencies. In addition, because of the low-scale setup of this assay, we foresee that this co-culture system may also be applied to study primary tissue-resident DC subsets. 
Previous studies focusing on the differentiation requirements of mouse and human Th17 cells showed serum to be a confounder influencing the outcome of $\mathrm{T}$ cell polarization. Initially, it was claimed that the requirements differ between these two species and that for human Th17 differentiation TGF- $\beta$ would be a dispensable factor ${ }^{58,59}$. However, follow-up experiments in serum-free medium revealed that TGF- $\beta$ is also required for human Th17 polarization and that the serum was probably contaminated with platelets that are a source of TGF- $\beta^{60}$. Since serum is a considerable source of artefacts due to lot-to-lot variability and variable protein contents, we established the assay in serum-free AIM-V ${ }^{\circledR}$ medium.

As a proof of concept that our assay can be applied to address biological questions, we have shown that DC triggered with various bacterial compounds have different capacities to induce Th1 polarization. This illustrates that, indeed, the environmental DC instruction influences the fate of the $\mathrm{CD}^{+}{ }^{+} \mathrm{T}$ cells. We demonstrated a profound difference in the Th1-polarizing capacity of different bacterial fragments, with LPS being at least 100-fold less potent to induce IFN- $\gamma$ secretion compared with the bacterial lysates FMKp and HKLM. Importantly, we also showed qualitative differences in capacity of different DC subsets to induce Th1 responses upon a particular PRR stimulus. Whereas LPS maturation of moDC did not result in high IFN- $\gamma$ secretion in naive T cells, LPS-triggered $\mathrm{pDC}$ did respond with a pronounced transcriptional induction of T-bet and IFN- $\gamma$ and the secretion of IFN- $\gamma$ by $\mathrm{T}$ cells after 7 days of co-culture. Moreover, we showed that PGE $2 / T N F-\alpha$-matured moDC did not lead to Th1 induction but instead to Th2 cells. This finding is consistent with previous studies ${ }^{3,61}$. In contrast to de Jong et al. ${ }^{4}$, we showed that this Th2 induction was independent of IL-4, as we neither detected IL-4 mRNA levels nor the secretion of the protein. Findings of other groups did show the possibility for IL-4 independent Th2 induction by $\mathrm{pDC}^{62}$.

Complementary APC-independent tools, mimicking the APC by replacing it e.g. by anti-CD3 ( \pm anti-CD28) or by feeder cells, represent a good approach to study the involvement of soluble DC-derived factors. However, anti-CD3 and anti-CD28 exert polarizing capacities on their own; this may vary depending on which clones of anti-CD 3 or anti-CD28 antibodies are used. It has been shown that triggering of murine $\mathrm{CD}^{+}{ }^{+} \mathrm{T}$ cells, in vitro and in vivo, by antiCD28 led to the induction of GATA3 and to the secretion of Th2-specifying cytokines ${ }^{63}$. Additionally, the presence as well as the strength of TCR-signaling influences the fate of a naive $\mathrm{CD}^{+}{ }^{+} \mathrm{T}$ cells independently of the cytokine milieu ${ }^{64-66}$. Strong TCR-signaling induces Th1 cells, whereas weak TCR-stimulation favours Th2 responses ${ }^{67}$. We tried to titrate down anti-CD3 to such an extent that it resulted in similar proliferative responses as observed in the co-culture experiments. We also observed that high concentrations of immobilized anti$\mathrm{CD} 3$ induced the polarization of naive $\mathrm{CD}^{+} \mathrm{T}$ cells in the absence of polarizing signals. 
We propose a new combination of tools to study human DC-induced naive $\mathrm{CD}^{+}{ }^{+} \mathrm{T}$ cell polarization in a small-scale, autologous setup. The assay combines both analyses on transcriptional and protein levels. It allows comparing the magnitude, kinetics, and direction of a naive $\mathrm{CD}^{+} \mathrm{T}$ cell response after interaction with different PRR-experienced DC. The combination of monitoring simultaneously the expression kinetics of the different Th subset-related transcription factors and their cytokine release in one culture condition offers new perspectives on studying the priming phase of $\mathrm{CD}^{+} \mathrm{T}$ cells. The continuous monitoring of transcription factor expression over time allows studying differences in the kinetics of transcriptional induction by different DC and whether or not transient expression of transcription factors is responsible for functional subset specialization. Furthermore, this system can be of great value to investigate the influence of immunomodulating drugs or environmental factors on the initiation of human $T$ cell responses and Th cell fates. The most effective moments of drug administration can be revealed and factors on which they eventually have a direct influence may be identified. In addition, it is possible to study epigenetic changes related to the priming phase of a $\mathrm{T}$ cell response, in an APC-dependent manner, such as the regulation of Th-specific enhancers.

Overall, this standardized assay will allow a more straightforward comparison of results obtained by different groups and will help to further extend our knowledge on the initiation of human naive $\mathrm{CD} 4^{+} \mathrm{T}$ cell responses. 


\section{ACKNOWLEDGEMENTS}

The authors thank T.H.P.M. Habets for graphical support.

\section{REFERENCES}

1. Mosmann TR, Cherwinski H, Bond MW, Giedlin MA, Coffman RL. Two types of murine helper T cell clone. I. Definition according to profiles of lymphokine activities and secreted proteins. Journal of immunology. 1986;136(7):2348-2357.

2. Kapsenberg ML. Dendritic-cell control of pathogen-driven T-cell polarization. Nature reviews Immunology. 2003;3(12):984-993.

3. Kalinski P, Hilkens CM, Wierenga EA, Kapsenberg ML. T-cell priming by type-1 and type-2 polarized dendritic cells: the concept of a third signal. Immunol Today. 1999;20(12):561-567.

4. de Jong EC, Vieira PL, Kalinski P, et al. Microbial compounds selectively induce Th1 cell-promoting or Th2 cell-promoting dendritic cells in vitro with diverse th cell-polarizing signals. Journal of immunology. 2002;168(4):1704-1709.

5. Medzhitov R. Toll-like receptors and innate immunity. Nature reviews Immunology. 2001;1(2):135145.

6. Vieira PL, de Jong EC, Wierenga EA, Kapsenberg ML, Kalinski P. Development of Th1-inducing capacity in myeloid dendritic cells requires environmental instruction. Journal of immunology. 2000;164(9):4507-4512.

7. Palm NW, Rosenstein RK, Medzhitov R. Allergic host defences. Nature. 2012;484(7395):465-472.

8. Lassmann H, Ransohoff RM. The CD4-Th1 model for multiple sclerosis: a critical re-appraisal. Trends in immunology. 2004;25(3):132-137.

9. Korn T, Bettelli E, Oukka M, Kuchroo VK. IL-17 and Th17 Cells. Annual review of immunology. 2009;27:485-517.

10. Szabo SJ, Kim ST, Costa GL, Zhang X, Fathman CG, Glimcher LH. A novel transcription factor, T-bet, directs Th1 lineage commitment. Cell. 2000;100(6):655-669.

11. Evans CM, Jenner RG. Transcription factor interplay in T helper cell differentiation. Briefings in functional genomics. 2013;12(6):499-511.

12. Oestreich KJ, Weinmann AS. Master regulators or lineage-specifying? Changing views on CD4+ T cell transcription factors. Nature reviews Immunology. 2012;12(11):799-804.

13. Vahedi G, Takahashi H, Nakayamada S, et al. STATs shape the active enhancer landscape of T cell populations. Cell. 2012;151(5):981-993.

14. Josefowicz SZ. Regulators of chromatin state and transcription in CD4 T-cell polarization. Immunology. 2013;139(3):299-308.

15. Nakayamada S, Takahashi H, Kanno Y, O’Shea JJ. Helper T cell diversity and plasticity. Current opinion in immunology. 2012;24(3):297-302.

16. Scott K, Manunta M, Germain C, et al. Qualitatively distinct patterns of cytokines are released by human dendritic cells in response to different pathogens. Immunology. 2005;116(2):245-254.

17. Peters M, Dudziak K, Stiehm M, Bufe A. T-cell polarization depends on concentration of the danger signal used to activate dendritic cells. Immunology and cell biology. 2010;88(5):537-544.

18. Warger T, Osterloh P, Rechtsteiner G, et al. Synergistic activation of dendritic cells by combined Tolllike receptor ligation induces superior CTL responses in vivo. Blood. 2006;108(2):544-550.

19. Dzopalic T, Rajkovic I, Dragicevic A, Colic M. The response of human dendritic cells to co-ligation of pattern-recognition receptors. Immunologic research. 2012;52(1-2):20-33.

20. Padovan E, Landmann RM, De Libero G. How pattern recognition receptor triggering influences T 
cell responses: a new look into the system. Trends in immunology. 2007;28(7):308-314.

21. Reis e Sousa C. Toll-like receptors and dendritic cells: for whom the bug tolls. Seminars in immunology. 2004;16(1):27-34.

22. de Jong EC, Smits HH, Kapsenberg ML. Dendritic cell-mediated T cell polarization. Springer seminars in immunopathology. 2005;26(3):289-307.

23. Crozat K, Guiton R, Guilliams M, et al. Comparative genomics as a tool to reveal functional equivalences between human and mouse dendritic cell subsets. Immunological reviews. 2010;234(1):177-198.

24. Bryant CE, Monie TP. Mice, men and the relatives: cross-species studies underpin innate immunity. Open biology. 2012;2(4):120015.

25. Kawai T, Akira S. The role of pattern-recognition receptors in innate immunity: update on Toll-like receptors. Nature immunology. 2010;11(5):373-384.

26. Boonstra A, Asselin-Paturel C, Gilliet M, et al. Flexibility of mouse classical and plasmacytoid-derived dendritic cells in directing $T$ helper type 1 and 2 cell development: dependency on antigen dose and differential toll-like receptor ligation. The Journal of experimental medicine. 2003;197(1):101-109.

27. Edwards AD, Diebold SS, Slack EM, et al. Toll-like receptor expression in murine DC subsets: lack of TLR7 expression by CD8 alpha+ DC correlates with unresponsiveness to imidazoquinolines. European journal of immunology. 2003;33(4):827-833.

28. Schreibelt G, Tel J, Sliepen KH, et al. Toll-like receptor expression and function in human dendritic cell subsets: implications for dendritic cell-based anti-cancer immunotherapy. Cancer immunology, immunotherapy : CII. 2010;59(10):1573-1582.

29. Kadowaki N, Ho S, Antonenko S, et al. Subsets of human dendritic cell precursors express different toll-like receptors and respond to different microbial antigens. The Journal of experimental medicine. 2001;194(6):863-869.

30. Bauer S, Kirschning CJ, Hacker H, et al. Human TLR9 confers responsiveness to bacterial DNA via species-specific CPG motif recognition. Proceedings of the National Academy of Sciences of the United States of America. 2001;98(16):9237-9242.

31. Donnelly RP, Sheikh F, Dickensheets H, Savan R, Young HA, Walter MR. Interleukin-26: an IL-10-related cytokine produced by Th17 cells. Cytokine \& growth factor reviews. 2010;21(5):393-401.

32. Del Prete G, De Carli M, Almerigogna F, Giudizi MG, Biagiotti R, Romagnani S. Human IL-10 is produced by both type 1 helper (Th1) and type 2 helper (Th2) T cell clones and inhibits their antigen-specific proliferation and cytokine production. Journal of immunology. 1993;150(2):353-360.

33. Ziegler SF. FOXP3: of mice and men. Annual review of immunology. 2006;24:209-226.

34. Farrar JD, Smith JD, Murphy TL, Leung S, Stark GR, Murphy KM. Selective loss of type I interferon-induced STAT4 activation caused by a minisatellite insertion in mouse Stat2. Nature immunology. 2000;1(1):65-69.

35. Rogge L, D'Ambrosio D, Biffi M, et al. The role of Stat4 in species-specific regulation of Th cell development by type I IFNs. Journal of immunology. 1998;161(12):6567-6574.

36. Hayday AC, Peakman M. The habitual, diverse and surmountable obstacles to human immunology research. Nature immunology. 2008;9(6):575-580.

37. Hackam DG, Redelmeier DA. Translation of research evidence from animals to humans. JAMA : the journal of the American Medical Association. 2006;296(14):1731-1732.

38. Pound P, Ebrahim S, Sandercock P, Bracken MB, Roberts I, Reviewing Animal Trials Systematically G. Where is the evidence that animal research benefits humans? BMJ. 2004;328(7438):514-517.

39. Hawkins RD, Larjo A, Tripathi SK, et al. Global chromatin state analysis reveals lineage-specific enhancers during the initiation of human $\mathrm{T}$ helper 1 and $\mathrm{T}$ helper 2 cell polarization. Immunity. 2013;38(6):1271-1284.

40. Tuomela S, Salo V, Tripathi SK, et al. Identification of early gene expression changes during human Th17 cell differentiation. Blood. 2012;119(23):e151-160.

41. Bellanger AP, Pallandre JR, Borg C, Loeffert S, Gbaguidi-Haore H, Millon L. Human monocyte-derived dendritic cells exposed to microorganisms involved in hypersensitivity pneumonitis induce a 
Th1-polarized immune response. Clin Vaccine Immunol. 2013;20(8):1133-1142.

42. Moser JM, Sassano ER, Leistritz del C, et al. Optimization of a dendritic cell-based assay for the in vitro priming of naive human CD4+ T cells. Journal of immunological methods. 2010;353(1-2):8-19.

43. Langenkamp A, Casorati G, Garavaglia C, Dellabona P, Lanzavecchia A, Sallusto F. T cell priming by dendritic cells: thresholds for proliferation, differentiation and death and intraclonal functional diversification. European journal of immunology. 2002;32(7):2046-2054.

44. Lombardi V, Van Overtvelt L, Horiot S, Moingeon P. Human dendritic cells stimulated via TLR7 and/ or TLR8 induce the sequential production of Il-10, IFN-gamma, and IL-17A by naive CD4+ T cells. Journal of immunology. 2009;182(6):3372-3379.

45. Napolitani G, Rinaldi A, Bertoni F, Sallusto F, Lanzavecchia A. Selected Toll-like receptor agonist combinations synergistically trigger a $\mathrm{T}$ helper type 1-polarizing program in dendritic cells. Nat Immunol. 2005;6(8):769-776.

46. O'Garra A, Gabrysova L, Spits H. Quantitative events determine the differentiation and function of helper T cells. Nature immunology. 2011;12(4):288-294.

47. Alexander J, Sidney J, Southwood S, et al. Development of high potency universal DR-restricted helper epitopes by modification of high affinity DR-blocking peptides. Immunity. 1994;1 (9):751-761.

48. Van Elssen CH, Vanderlocht J, Frings PW, et al. Klebsiella pneumoniae-triggered DC recruit human NK cells in a CCR5-dependent manner leading to increased CCL19-responsiveness and activation of NK cells. European journal of immunology. 2010;40(11):3138-3149.

49. Jenkins MK, Chu HH, McLachlan JB, Moon JJ. On the composition of the preimmune repertoire of T cells specific for Peptide-major histocompatibility complex ligands. Annual review of immunology. 2010;28:275-294.

50. Vanderlocht J, Van Elssen CH, Senden-Gijsbers BL, et al. Increased tumor-specific CD8+ T cell induction by dendritic cells matured with a clinical grade TLR-agonist in combination with IFN-gamma. International journal of immunopathology and pharmacology. 2010;23(1):35-50.

51. Frasca L, Nasso M, Spensieri F, et al. IFN-gamma arms human dendritic cells to perform multiple effector functions. Journal of immunology. 2008;180(3):1471-1481.

52. Athie-Morales V, Smits HH, Cantrell DA, Hilkens CM. Sustained IL-12 signaling is required for Th1 development. Journal of immunology. 2004;172(1):61-69.

53. Macatonia SE, Hosken NA, Litton M, et al. Dendritic cells produce IL-12 and direct the development of Th1 cells from naive CD4+ T cells. Journal of immunology. 1995;154(10):5071-5079.

54. Luger R, Valookaran S, Knapp N, Vizzardelli C, Dohnal AM, Felzmann T. Toll-like receptor 4 engagement drives differentiation of human and murine dendritic cells from a pro- into an anti-inflammatory mode. PLoS One. 2013;8(2):e54879.

55. Krug A, Towarowski A, Britsch S, et al. Toll-like receptor expression reveals CpG DNA as a unique microbial stimulus for plasmacytoid dendritic cells which synergizes with CD40 ligand to induce high amounts of IL-12. European journal of immunology. 2001;31(10):3026-3037.

56. Grouard G, Rissoan MC, Filgueira L, Durand I, Banchereau J, Liu YJ. The enigmatic plasmacytoid T cells develop into dendritic cells with interleukin (IL)-3 and CD40-ligand. The Journal of experimental medicine. 1997;185(6):1101-1111.

57. Blom L, Poulsen LK. In vitro Th1 and Th2 cell polarization is severely influenced by the initial ratio of naive and memory CD4+ T cells. Journal of immunological methods. 2013.

58. Acosta-Rodriguez EV, Napolitani G, Lanzavecchia A, Sallusto F. Interleukins 1 beta and 6 but not transforming growth factor-beta are essential for the differentiation of interleukin 17-producing human T helper cells. Nat Immunol. 2007;8(9):942-949.

59. Wilson NJ, Boniface K, Chan JR, et al. Development, cytokine profile and function of human interleukin 17-producing helper T cells. Nat Immunol. 2007;8(9):950-957.

60. Miossec P, Korn T, Kuchroo VK. Interleukin-17 and type 17 helper T cells. The New England journal of medicine. 2009;361(9):888-898.

61. Kalinski P. Regulation of immune responses by prostaglandin E2. J Immunol. 2012;188(1):21-28. 
62. Ouyang W, Lohning M, Gao Z, et al. Stat6-independent GATA-3 autoactivation directs IL-4-independent Th2 development and commitment. Immunity. 2000;12(1):27-37.

63. Rodriguez-Palmero M, Hara T, Thumbs A, Hunig T. Triggering of T cell proliferation through CD28 induces GATA-3 and promotes T helper type 2 differentiation in vitro and in vivo. European journal of immunology. 1999;29(12):3914-3924.

64. Purvis HA, Stoop JN, Mann J, et al. Low-strength T-cell activation promotes Th17 responses. Blood. 2010;116(23):4829-4837.

65. Nembrini C, Abel B, Kopf M, Marsland BJ. Strong TCR signaling, TLR ligands, and cytokine redundancies ensure robust development of type 1 effector T cells. Journal of immunology. 2006;176(12):71807188.

66. Placek K, Gasparian S, Coffre M, et al. Integration of distinct intracellular signaling pathways at distal regulatory elements directs T-bet expression in human CD4+ T cells. Journal of immunology. 2009;183(12):7743-7751.

67. Leitenberg D, Bottomly K. Regulation of naive $\mathrm{T}$ cell differentiation by varying the potency of TCR signal transduction. Semin Immunol. 1999;11(4):283-292. 


\section{SUPPORTING INFORMATION}

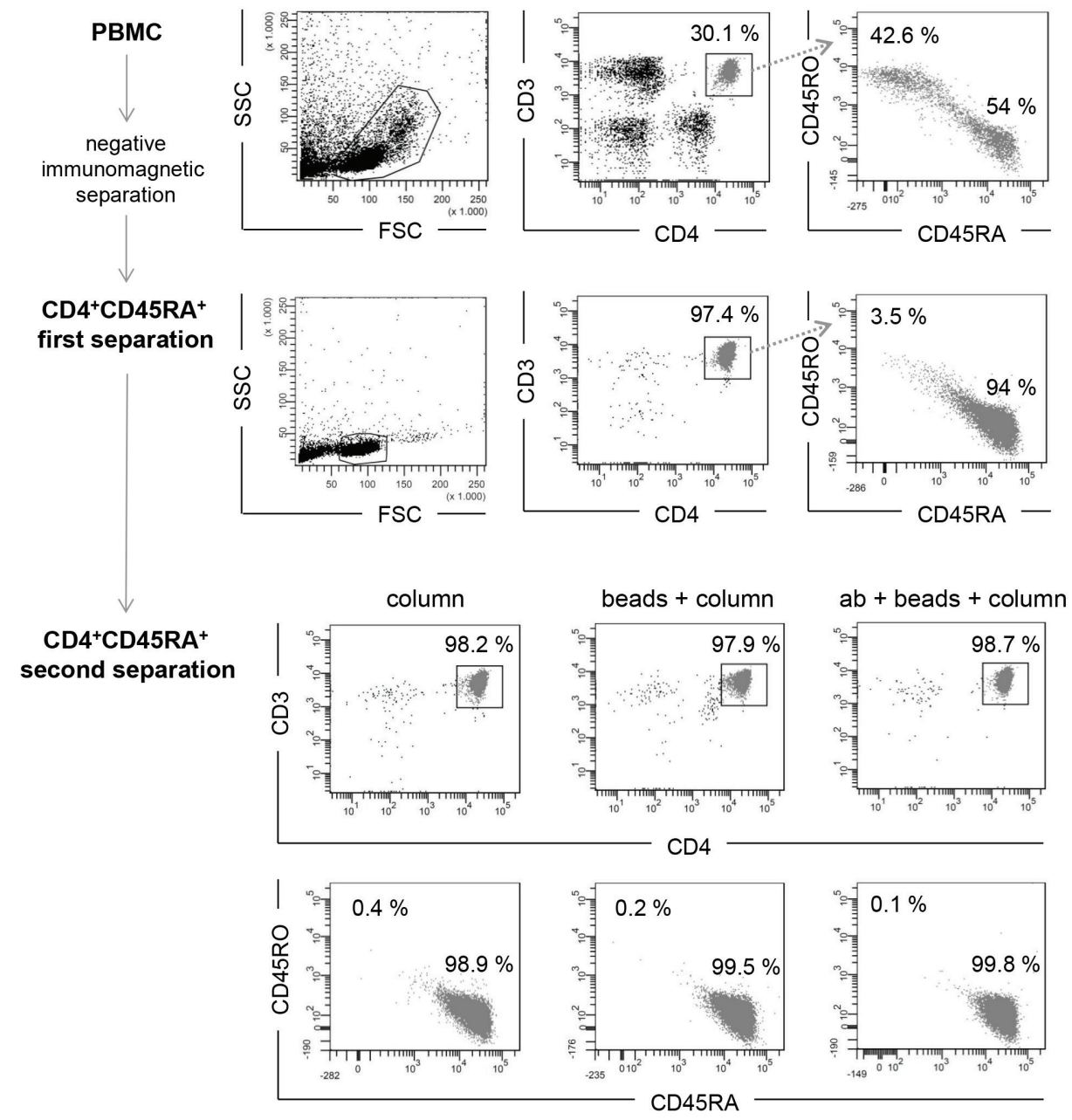

Supplementary Figure S1 | Optimization of $\mathrm{CD}^{+} \mathrm{CD}^{2} 5 \mathrm{RA}^{+} \mathrm{T}$ cell isolation using immunomagnetic beads. PBMC were isolated from whole blood by density centrifugation. $\mathrm{CD}^{+} \mathrm{CD} 45 \mathrm{RA}^{+} \mathrm{T}$ cells were isolated by negative immunomagnetic separation according to the manufacturer's instructions. To achieve highly pure naive $\mathrm{CD}^{+} \mathrm{T}$ cells, $\mathrm{CD} 4^{+} \mathrm{CD} 45 \mathrm{RA}^{+} \mathrm{T}$ cells were purified a second time. The purification protocol was optimized by using the flow-through from the first separation followed by another round over a column, incubation with beads and purification over a second column or incubating with antibody-mix and beads and running it over a column. Purity staining of PBMC, first separation of $\mathrm{CD}^{+} \mathrm{CD}^{+} 5 \mathrm{RA}{ }^{+} \mathrm{T}$ cells and of different second separations of CD $4^{+} \mathrm{CD} 45 \mathrm{RA}^{+}$cell populations were performed and analysed by flow cytometry. Cells were gated on lymphocytes in FSC/SSC and on the living cells (7-AAD-negative) and set as $100 \%$. CD $4^{+} \mathrm{T}$ cells were gated on $\mathrm{CD}^{+} / \mathrm{CD}^{+}$cells and furthermore discriminated between $\mathrm{CD}_{45 \mathrm{RO}^{+}}$and CD45RA ${ }^{+}$. Percentages of the different populations are indicated in the dot plots. 

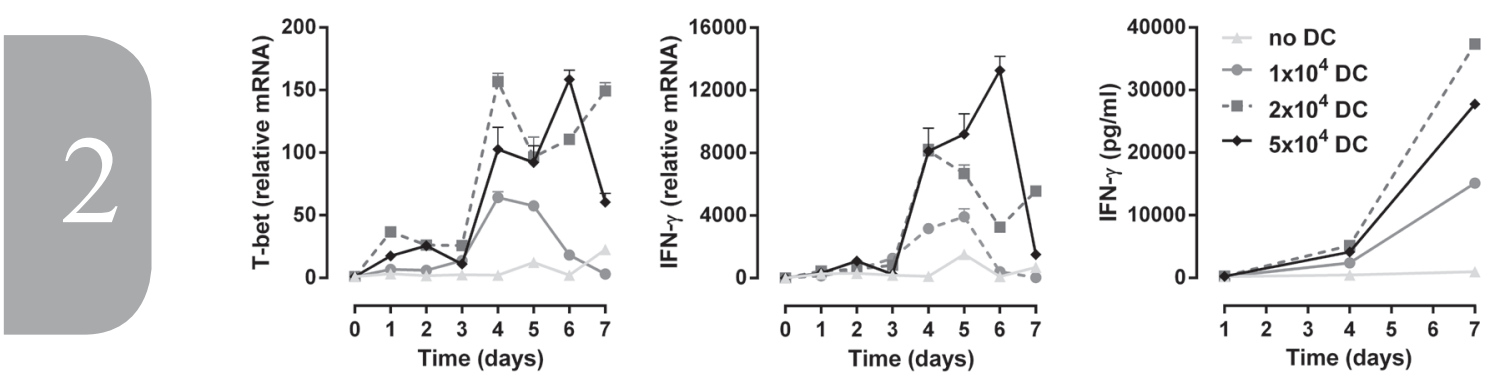

Supplementary Figure S2 | Optimization of DC:T cell ratios. 24h-matured FMKp/IFN- $\gamma$ DC were washed and added at different concentrations to a round-bottom 96-well plate: $1 \times 10^{4}(\bullet), 2 \times 10^{4}(\boldsymbol{\bullet})$ or $5 \times 10^{4}$ ( ) and co-cultured with $5 \times 10^{4}$ naive $\mathrm{CD}^{+} \mathrm{T}$ cells for 7 days in the presence of $24 \mathrm{~h}-\mathrm{FMKp} / \mathrm{IFN}-\gamma$-matured DC-derived supernatant. Transcriptional induction of T-bet and IFN- $\gamma$ as well as secretion of IFN- $\gamma$ were determined. Data shown are representative of 4 independent experiments.

A

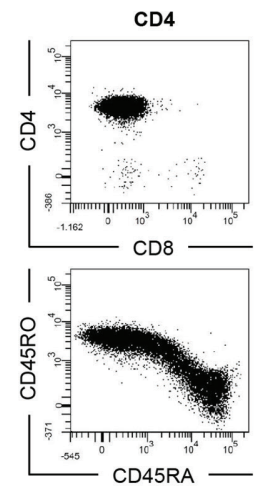

CD4CD45RO

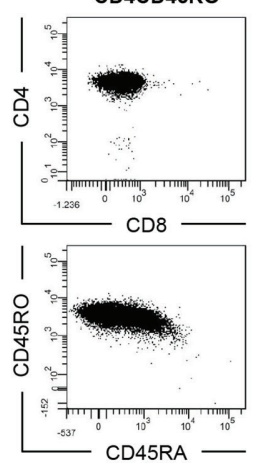

\begin{tabular}{|l|r|}
\hline CD3 & $99.4 \%$ \\
\hline CD4 & $99.3 \%$ \\
\hline CD4CD45RA & $0.1 \%$ \\
\hline CD4CD45RO & $99.2 \%$ \\
\hline
\end{tabular}
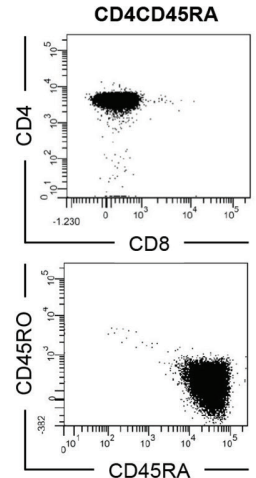

CD45RA -

\begin{tabular}{|l|r|}
\hline CD3 & $99.6 \%$ \\
\hline CD4 & $99.3 \%$ \\
\hline CD4CD45RA & $99.7 \%$ \\
\hline CD4CD45RO & $0.1 \%$ \\
\hline
\end{tabular}

B
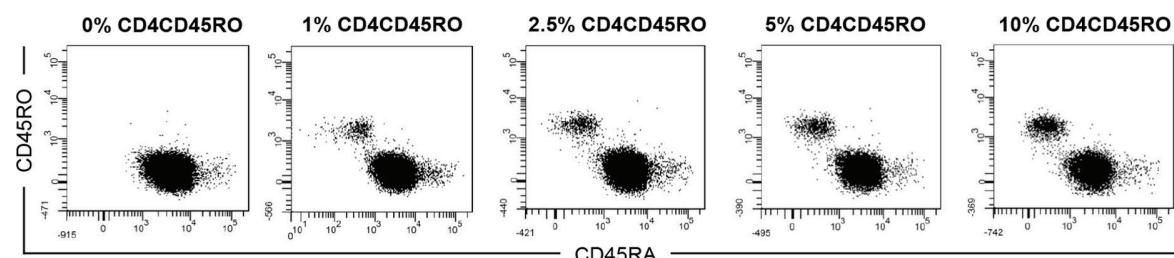

Supplementary Figure S3 | Purities of differently isolated $\mathrm{CD}^{+}{ }^{+} \mathrm{T}$ cell populations. (A) Purity staining of total $\mathrm{CD}^{+}, \mathrm{CD}^{+} \mathrm{CD}_{4} 5 \mathrm{RA}^{+}$, and $\mathrm{CD}^{+} \mathrm{CD} 45 \mathrm{RO}^{+} \mathrm{T}$ cells after negative immunomagnetic isolation from freshly isolated PBMC. Percentage of $\mathrm{CD}^{+}$cells is expressed as percentage of total living singlet cells. Percentages of $\mathrm{CD}^{+}$cells are expressed related to total $\mathrm{CD}^{+}$cells and those of $\mathrm{CD}^{+} 5 \mathrm{RA}^{+}$and $\mathrm{CD}^{2} 4 \mathrm{RO}^{+}$cells are related to $\mathrm{CD} 4^{+} \mathrm{T}$ cell population. $(\mathbf{B})$ Increasing percentages $(0-10 \%)$ of $\mathrm{CD}^{2} 5 \mathrm{RO}^{+}$ contamination into pure $\mathrm{CD} 4^{+} \mathrm{CD} 45 \mathrm{RA}^{+} \mathrm{T}$ cell population. 


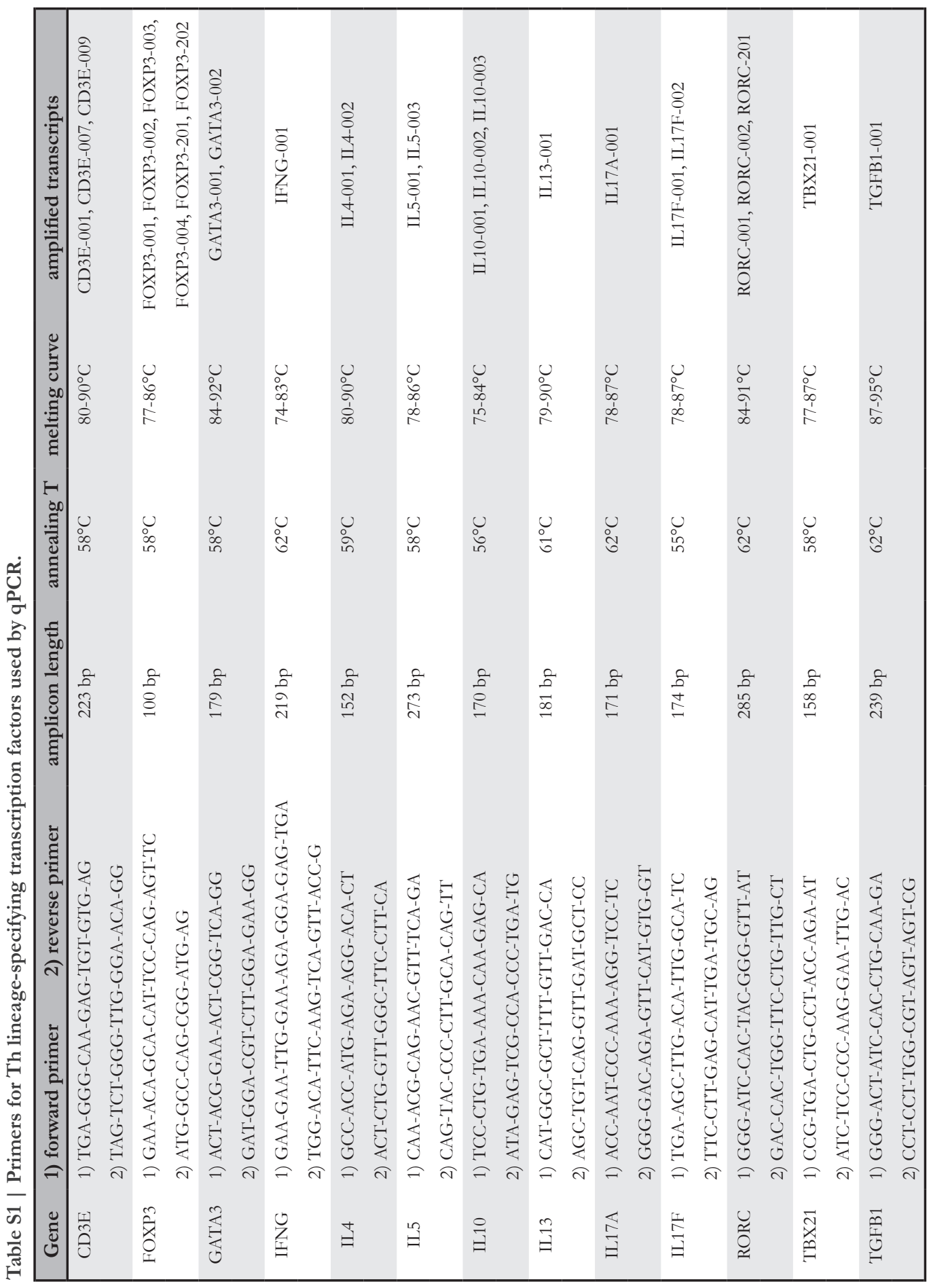




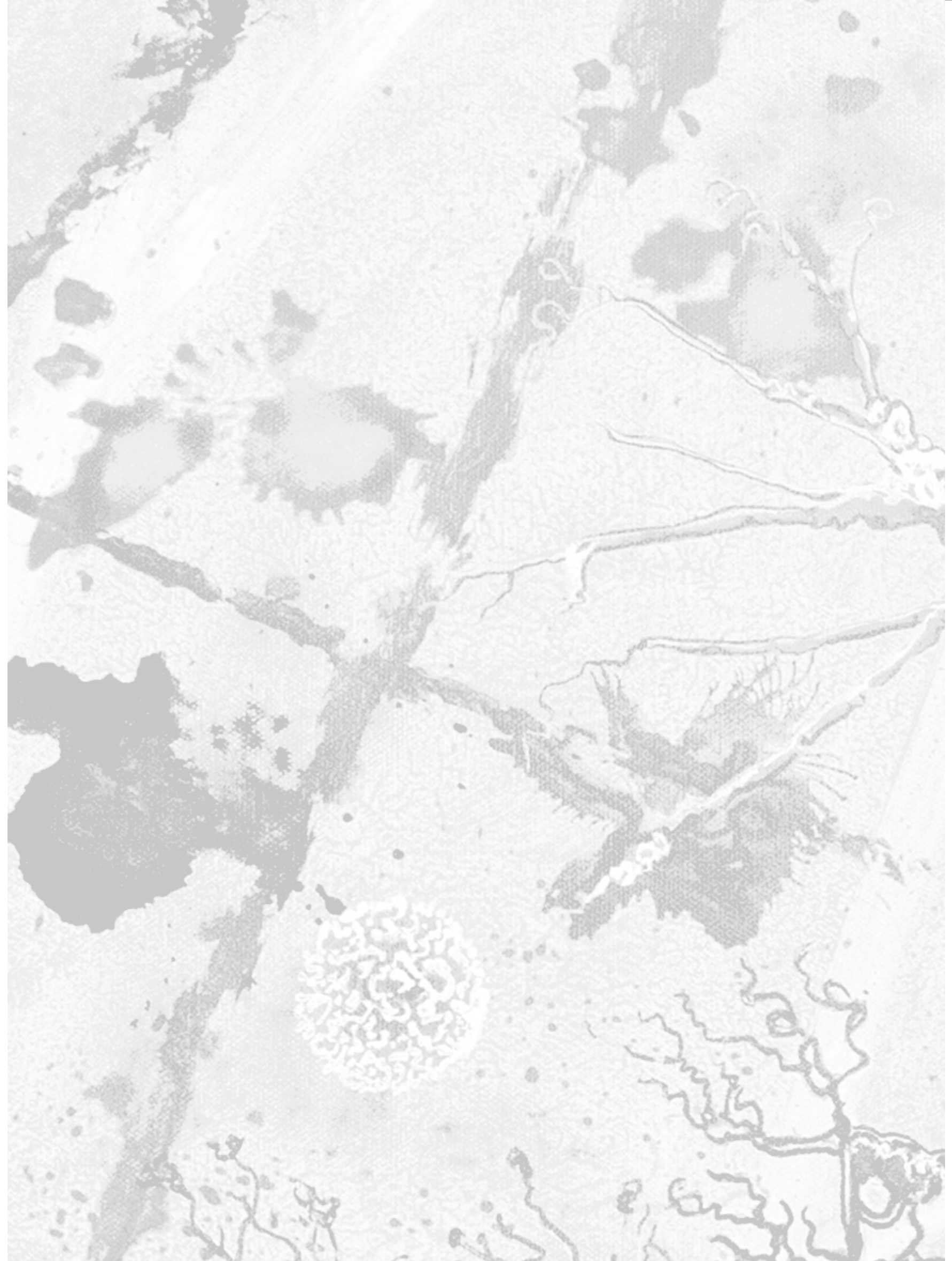




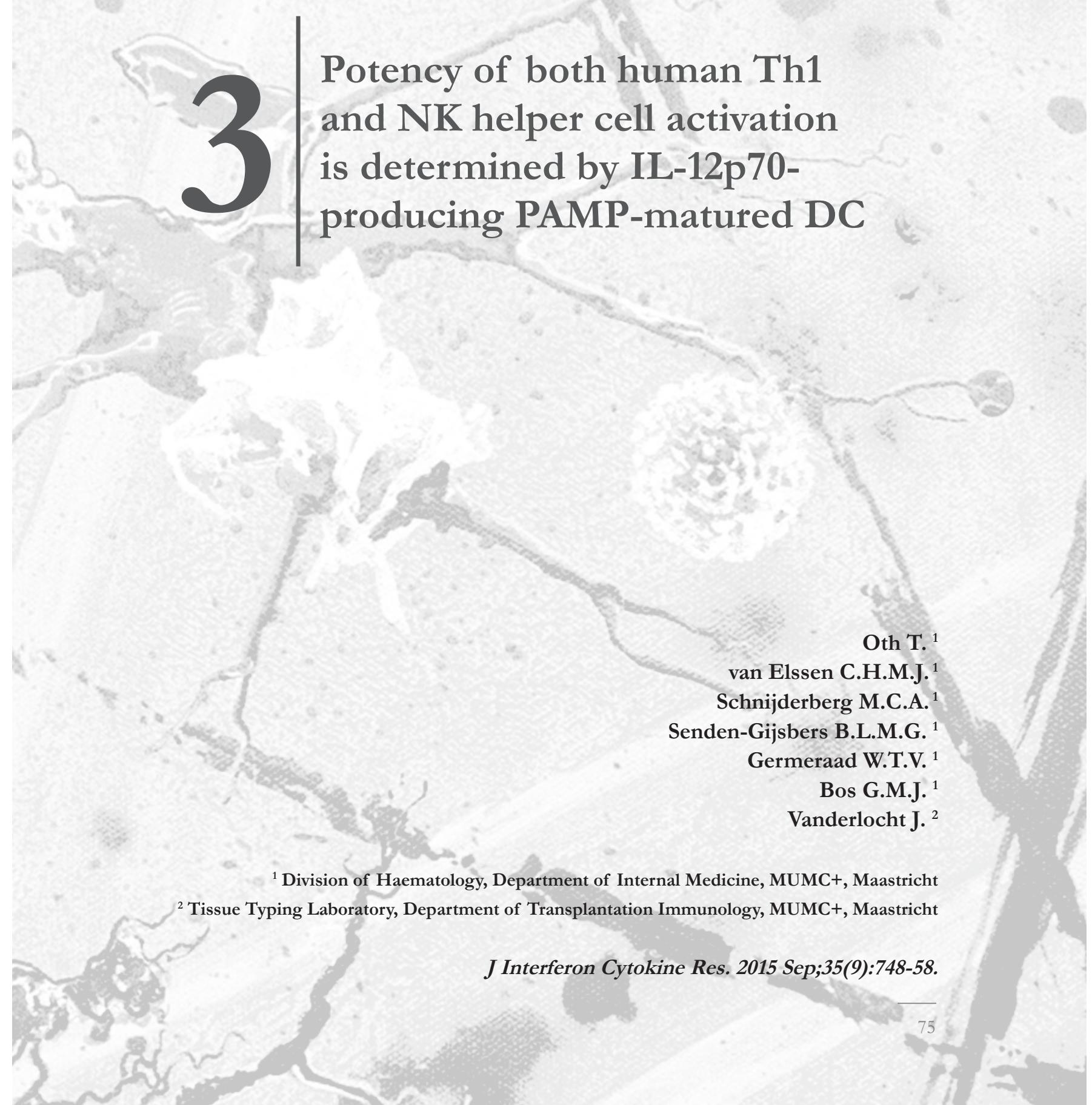




\begin{abstract}
Besides T helper (Th) cells also natural killer (NK) cells have been described to participate in the shaping of dendritic cell (DC)-mediated adaptive immune responses. At present, it remains unclear to what extent the induction of these NK helper cell immune mechanisms is coupled with Th cell responses and whether both helper immune responses are induced by the same DC upon specific pathogen recognition receptor (PRR) stimulation.

Here we demonstrate that maturation of DC with a cocktail containing FMKp (membrane fragments of $K$. pneumoniae) mounts both Th cell and NK cell helper responses in a PRR trigger dose-dependent manner as determined by the capacity of the helper cells to produce IFN- $\gamma$. Furthermore, by triggering an additional PRR-pathway (FMKp in combination with poly(I:C) lyovec) we reveal that both approaches modulate the amount of DC-derived IL-12p70 and that this cytokine is the key determinant of the DC-induced Th1 and NK cell helper responses. Moreover, all PRR triggers able to induce IL-12-producing mature DC are sufficient to induce these helper responses.
\end{abstract}

We propose the existence of a single programme used by DC to induce potent cellular immune responses by stimulating both Th and NK cell helper processes. This knowledge can help to select the proper PRR triggers in preventive and therapeutic vaccine design. 


\section{INTRODUCTION}

Dendritic cells (DC) are key regulators in shaping and linking innate and adaptive immune responses. Depending on the environmental stimuli DC encounter, they transmit signals to immune effector cells inducing immunogenic or tolerogenic immune responses ${ }^{1},{ }^{2}$. Therefore, DC represent a crucial target of vaccine adjuvants, both in preventive and therapeutic vaccination. In particular the latter type of vaccines requires further improvement. Elucidating the mechanisms by which danger signals induce and enhance the interaction of DC with different immune effector cells will reveal new insights to increase the efficacy of vaccination strategies.

One of the crucial mechanisms by which these DC mount appropriate and potent immune responses is by activating helper immune cells. In recent years it has become clear that these helper immune cells are not limited to $\mathrm{CD}^{+}{ }^{+} \mathrm{T}$ cells, but also include innate lymphoid cells (e.g. natural killer (NK) cells). Despite these novel insights, the polarization of naive $\mathrm{CD} 4^{+}$ $\mathrm{T}$ cells into different $\mathrm{T}$ helper $(\mathrm{Th})$ lineages is still considered a decisive event to induce de novo immune responses ${ }^{3}$. The DC modulate this response by co-stimulatory molecules and cytokines, which are controlled by the nature of the pathogenic insult. The priming of Th1 cells is crucial for the generation and expansion of cytotoxic T lymphocytes (CTL) and survival of $\mathrm{CD}^{+}$memory $\mathrm{T}$ cells, which are in turn able to kill infected or cancer cells ${ }^{4}$.

NK cells also serve an important role in regulating DC-mediated adaptive immune responses ${ }^{5-7}$. Classically, NK cells are involved in the direct early control of viral infections and tumour immunosurveillance ${ }^{8-10}$, but NK cells also indirectly provide help by interacting with DC at the site of inflammation or in the lymph nodes ${ }^{11}$. Upon their encounter NK cells can become activated via a two-signal requirement provided by soluble factors (such as IL-12, IL-18, IL-15, IL-21 and IFN- $\alpha$ ) or by cell-contact dependent pathways ${ }^{12,13,14}$. Once activated, NK cells enhance the maturation and antigen presentation of DC ${ }^{15-17}$ and gain the capacity to edit the DC repertoire ${ }^{18}$. Additionally, activated 'helper' NK cells secrete pro-inflammatory cytokines, mainly IFN- $\gamma$ and $\mathrm{TNF}-\alpha$, which facilitate Th1 responses, and which are further stimulated by the expression of co-stimulatory molecules on $\mathrm{NK}$ cells ${ }^{19-22}$. Moreover, NK cells were shown to enhance anti-tumour CTL responses without the induction of $\mathrm{CD}^{+}{ }^{+} \mathrm{T}$ cells ${ }^{23,24}$.

The recognition of a pathogenic insult via pattern recognition receptors (PRR) has been shown to influence the DC cytokine profile and consequently the fate of naive CD4 ${ }^{+}$ T cells ${ }^{25-27}$. Furthermore, NK cell activation is confined to PRR-triggered DC and the nature of the PRR stimulus determines the degree of activation by influencing the release of NK cell-activating factors and the expression of surface molecules ${ }^{28,29}$. Even though it is 
plausible that during the mounting of an immune response multiple helper subsets including NK cells participate in concert, there is limited experimental proof of this cellular interplay in humans. It remains to be established whether both helper mechanisms get enhanced by the same PRR-triggered DC or whether the source of PRR-triggering directs either Th or $\mathrm{NK}$ cell helper responses. In the current study, we investigated whether the capacity of DC to enhance both Th1 polarization and to promote NK cell helper responses is triggered by the same PRR agonist in a dose-dependent manner or by triggering multiple PRR during DC maturation. Furthermore, we examined if common soluble factors are involved in the activation of both helper responses.

\section{MATERIALS AND METHODS}

\section{Generation of DC}

Monocytes were generated as previously described ${ }^{30}$ and differentiated in serum-free AIM-V ${ }^{\circledR}$ medium (Life technologies, Carlsbad, CA, USA) supplemented with GM-CSF (400U/ml; Berlex Laboratories Inc., Montville, NJ, USA) and IL-4 (2000U/ml; Miltenyi Biotec GmbH, Bergisch Gladbach, Germany) at a density of 2 × $10^{6}$ cells $/ \mathrm{ml}$. After 7 days, immature DC (iDC) were harvested and frozen or immediately processed in the DC-T cell co-cultures or NK cell activation assays.

To study quantitative PRR-triggering, iDC were matured with either IFN- $\gamma(500 \mathrm{U} / \mathrm{ml}$; R\&D systems, Minneapolis, MN, USA) or the combination of IFN- $\gamma$ and FMKp (Pierre Fabre Laboratories, Boulogne-Billancourt, France) at different concentrations (1 or $10 \mu \mathrm{g} /$ $\mathrm{ml})$. Cooperative PRR-triggering was performed by maturing iDC with IFN- $\gamma$ and poly(I:C) lyovec $(1 \mu \mathrm{g} / \mathrm{ml}$; InvivoGen, Toulouse, France) in the presence or absence of FMKp $(1 \mu \mathrm{g} / \mathrm{ml})$. All maturation cocktails were supplemented with IL-4 $(500 \mathrm{U} / \mathrm{ml})$ and GM-CSF $(500 \mathrm{U} / \mathrm{ml})$.

Washed DC supernatants used to activate NK cells were generated by maturing iDC $\left(0.5 \times 10^{6}\right.$ cells $\left./ \mathrm{ml}\right)$ in 24 -well plates with the different cocktails described previously in this section. DC were washed $6 \mathrm{~h}$ after the induction of maturation to remove all the maturation stimuli and cultured for a total of $48 \mathrm{~h}$ in serum-free in AIM- $\mathrm{V}^{\circledR}$ medium. We and others have previously demonstrated that this shortened incubation with the maturation stimuli irreversibly triggers DC maturation ${ }^{31-34}$. Cell-free supernatants were harvested and stored at $-20^{\circ} \mathrm{C}$ until further use.

To generate differently matured DC as depicted in the correlation graphs, iDC were matured 
with various pathogen-associated molecular patterns (PAMPs): TLR1/2 (Pam3CSK4), TLR2 (HKLM), TLR3 (poly(I:C) LMW/HMW, poly(A:U)), TLR4 (LPS E. coli K12), TLR5 (flagellin), TLR 6/2 (FSL-1), TLR7 (imiquimod, gardiquimod), TLR7/8 (R848, CL075), TLR8 (ssRNA40, sspolyU, E. coli RNA) TLR9)(ODN2006, ODN2216, ODN2395, E. coli ssDNA), RIG-I/MDA-5 (poly(I :C) lyovec), NOD1 (tri-DAP), NOD2 (MDP), Dectin-1 ( $\beta$-glucan) in the presence of IFN- $\gamma$, IL-4 and GM-CSF. DC were matured with single PAMPs or in combination with FMKp. All PAMPs were purchased from InvivoGen. In addition, iDC were matured with $\mathrm{PGE}_{2} / \mathrm{TNF}-\alpha(+\mathrm{IL}-6 / \mathrm{IL} 1-\beta)$ or TNF $\alpha / \mathrm{IL}-1 \beta / \mathrm{IFN}-\gamma /$ $\operatorname{poly}(\mathrm{I}: \mathrm{C}) / \mathrm{IFN} \alpha$.

\section{T helper cell isolation}

Autologous $\mathrm{CD}^{+} \mathrm{CD}^{+} 5 \mathrm{RA}^{+} \mathrm{T}$ cells were isolated by negative immunomagnetic separation (Miltenyi Biotec) as described previously ${ }^{30}$. Purity of the naive $\mathrm{CD}^{+}{ }^{+} \mathrm{T}$ cells was $\geq 99.8 \%$ containing $0 \% \mathrm{CD}^{+} \mathrm{CD} 45 \mathrm{RO}^{+}$cells.

\section{NK cell isolation}

NK cells were isolated from buffy coats or fresh peripheral blood-derived mononuclear cells (PBMC) by negative immunomagnetic cell separation (Miltenyi Biotec) according to the manufacturer's instructions. Blood was obtained from Sanquin blood bank Maastricht, the Netherlands (project 2000-03AZM) from healthy donors after informed consent. NK cell purity routinely exceeded $95 \% \mathrm{CD}^{\circ} 6^{+} \mathrm{CD}^{-}$as assessed by flow cytometry.

\section{T helper cell polarization assays}

APC-dependent $T$ cell polarization assays were performed as previously described ${ }^{30}$. The IL-12 supplementation experiments were performed with mature FMKp/IFN- $\boldsymbol{\gamma}$-DC. iDC were matured in 6-well plates at $1 \times 10^{6}$ cells/ml with IL-4, GM-CSF, IFN- $\gamma$ and FMKp $(10 \mu \mathrm{g} / \mathrm{ml})$. After extensive washing, 2x10 $24 \mathrm{~h}-\mathrm{FMKp} / \mathrm{IFN}-\gamma$-matured DC/well were cultured in serum-free medium in presence of different concentrations of rhIL-12 $\left(0-10.000 \mathrm{pg} / \mathrm{ml} ; \mathrm{R} \& \mathrm{D}\right.$ systems) and $5 \times 10^{4}$ naive $\mathrm{T}$ cells. In addition to collecting supernatant and storing the cells in RTL buffer for gene expression analyses, the cells were counted on day 5 using a coulter counter ${ }^{\circledR}$ (Z1; Beckman Coulter Inc., Brea, CA, USA) and analysed by flow cytometry. 


\section{NK cell activation assays}

Enriched NK cells were cultured in round-bottom 96-well plates $\left(10^{5}\right.$ cells/well) in the presence of washed cell-free supernatants of differently matured DC. After $16 \mathrm{~h}$ of incubation, supernatant was harvested to determine NK cell-derived IFN- $\gamma$ secretion and the cells were analysed by flow cytometry for the expression of different activation markers. NK cell activation with rhIL-12 (100ng/ml) and/or rhIL-18 (1000ng/ml; R\&D systems) was performed in AIM-V ${ }^{\circledR}$ medium or washed FMKp/IFN- $\gamma$-DC supernatant as indicated in the figure legends.

\section{Flow cytometry}

All antibodies used to determine DC, T cell and NK cell purities as well as their surface marker expression were purchased from BD Biosciences (Franklin Lakes, NJ, USA). Antibodies were used, titrated to their optimal concentration, either as fluorescein isothiocyanate (FITC), phycoerythrin (PE), peridinin chlorophyll protein (PerCP), allophyocyanin (APC), allophyocyanin H7 (APC-H7), Horizon 450, Horizon 500, Alexa Fluor 488 or PeCy7. Analyses were performed with BD FACS Canto II and analysed by BD FACSDiva Software v6.1.2 (BD Biosciences).

\section{qPCR}

qPCR was performed as previously described ${ }^{30}$. Primers for the Th1 lineage were used: T-bet (F: CCG-TGA-CTG-CCT-ACC-AGA-AT, R: ATC-TCC-CCC-AAG-GAA-TTGAC) and IFN- $\gamma$ (F: GAA-GAA-T'TG-GAA-AGA-GGA-GAG-TGA, R: TGG-ACA-TTCAAG-TCA-GTT-ACC-G) at their optimized annealing temperature (T-bet: $58^{\circ} \mathrm{C}$; IFN- $\gamma$ : $62^{\circ} \mathrm{C}$ ). Relative quantification was done by generating a standard curve of a reference sample (cDNA of total $\mathrm{T}$ cells). Each data point of the graphs was generated by determining expression of the gene of interest on the different days in duplicate and normalizing these data to the corresponding expression of $\mathrm{CD} 3 \varepsilon$ used as housekeeping gene in our assay.

\section{Cytokine detection}

Quantification of the Th1-specific cytokine IFN- $\gamma$ in the supernatant of the DC-T cell co-cultures on day 1, 3, 5 and 7 (day 1, 3 and 5 for the anti-CD3 culture) as well as NK cell-derived IFN- $\gamma$ after overnight activation and the determination of IL-12p70 in the supernatant of differently matured DC were performed by cytometric bead arrays (CBA; BD Biosciences) according to the manufacturer's instructions. Measurements were performed with BD FACS Canto II and analysed by BD FACSDiva Software v6.1.2 and 
FCAP array analysis software (version 1.0.1; Soft Flow Inc., St. Louis Park, MN, USA). Quantification of IL-18 in DC-derived supernatants was performed by ELISA (MBL International Corporation, Woburn, MA, USA).

\section{Statistical analyses}

Statistical analyses were determined by Wilcoxon matched pairs test or by Mann-Whitney $\mathrm{U}$ test and the correlation was tested by nonparametric Spearman correlation; ${ }^{*} P<0.05,{ }^{* *}$ $P<0.01,{ }^{* * *} P<0.001,{ }^{* * * *} P<0.0001$. Data were analysed using GraphPad Prism Software (version 6; GraphPad Software, San Diego, CA, USA).

\section{RESULTS}

Quantitative PRR-triggering during DC maturation enhances DC-induced Th1 and NK cell helper responses

We previously revealed that FMKp/IFN- $\boldsymbol{\gamma}$-matured DC have the capacity to activate NK cells ${ }^{31}$ and to polarize naive $\mathrm{CD}^{+}{ }^{+} \mathrm{T}$ cells towards Th1 cells ${ }^{30,35}$. To address the question whether quantitative PRR-triggering enhances the capacity of $\mathrm{DC}$ to polarize naive $\mathrm{CD} 4^{+} \mathrm{T}$ cells towards Th1 cells, we matured DC with two different concentrations of FMKp (1 and $10 \mu \mathrm{g} / \mathrm{ml}$; referred to as FI 1 and FI 10) using this established DC maturation protocol.

The maturation of DC with different concentrations of FMKp did not have an influence on the expression of DC maturation markers and co-stimulatory molecules HLA-ABC, HLA-DR, CD80, CD83, and CD86 (data not shown). In Figure 1A the expression of T-bet (gene name TBX21) and IFN- $\gamma$ as well as the IFN- $\gamma$ secretion of a 7-day co-culture is shown. DC matured with a higher dose of the bacterial trigger induced a 4-fold higher T-bet mRNA and a 16-fold higher IFN- $\gamma$ mRNA expression compared with the low dose. Additionally, changes in Th1 gene expression were observed at earlier time points indicating faster kinetics in the presence of a higher dose of FMKp. This was confirmed on the cytokine level; on day 7, T cells co-cultured with high dose FMKp-matured DC induced a 7 -fold increase in IFN- $\gamma$ levels compared with low dose FMKp-matured DC. Levels of IFN- $\gamma$ secretion at day 7 of the co-culture were significantly different between naive T cells cultured with different concentrations of FMKp (Figure 1B). T cells of donors having a moderate Th1 response with low dose FMKp-matured DC showed an increased IFN- $\gamma$ secretion with high dose FMKp matured-DC.

Because we previously showed that NK cells facilitate Th1 polarization by providing an 
early source of IFN- $\gamma^{31}$, we investigated the effect of quantitative PRR-triggering on NK cell activation. NK cells were activated overnight in washed cell-free DC supernatants. We analysed the expression of the activation markers CD69 and CD25, as well as CD83, a phenotype marker for 'helper' $\mathrm{NK}$ cells ${ }^{21}$, and NKp30, an activating receptor being involved in DC editing and maturation ${ }^{16,36}$.

NK cells activated in high-dose FMKp/IFN- $\gamma$-DC-derived supernatant showed the highest median expression of CD69 compared with IFN- $\gamma$ and FI1. Moreover, the percentages of $\mathrm{CD}_{25} 5^{+}$and $\mathrm{CD} 83^{+} \mathrm{NK}$ cells were significantly increased when $\mathrm{NK}$ cells were treated with FI 10-matured DC supernatant (2.5 and 2.4-fold compared with FI 1-matured DC supernatant) (Figure 1C, S1). No differences were detected in the expression of NKp30 (Figure S1). In addition, we determined the NK cell-derived IFN- $\gamma$ secretion after overnight incubation, which was significantly higher by NK cells activated in FI 10-DC supernatant compared with IFN- $\gamma$ and FI 1-DC supernatant (Figure 1D).
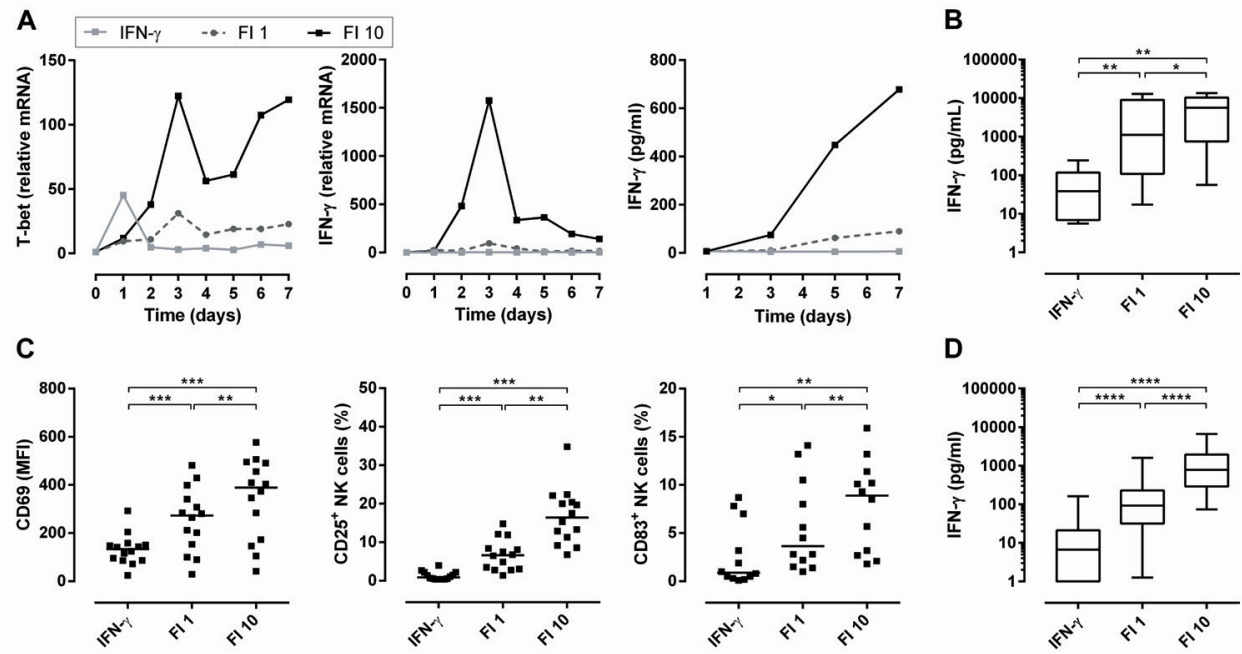

Figure 1 | PRR-triggering during DC maturation enhances both Th1 polarization and NK cell helper activation. (A) Th1-polarizing capacity of IFN- $\gamma-(\mathbf{\bullet})$, FMKp $(1 \mu \mathrm{g} / \mathrm{ml}) / \mathrm{IFN}-\gamma(\mathrm{FI} 1)-(\bullet)$ and FI 10-(ם) matured DC during a 7-day co-culture with autologous naive $\mathrm{CD}^{+} \mathrm{CD} 45 \mathrm{RA}^{+} \mathrm{T}$ cells at a ratio of $2: 5$ is shown by means of T-bet and IFN- $\gamma$ expression. IFN- $\gamma$ production by naive $T$ cells co-cultured with differently matured DC was determined in the supernatant of the co-culture on day 1, 3, 5 and 7 by CBA. Representative data of one out of 9 independent experiments are shown. (B) Combined IFN- $\gamma$ secretion of $\mathrm{T}$ cells at day 7 of the co-culture of 9 independent experiments. (C, D) NK cells were activated overnight in washed DC-derived cell-free supernatants. Supernatant was generated by maturing iDC with IFN- $\gamma$, FI 1 or FI 10. (C) Flow cytometric evaluation of CD69, CD25 and CD83 surface expression of differently activated NK cells. NK cells were gated on FSC/SSC on lymphocyte gate, excluding dead cells and doublets and selected for $\mathrm{CD} 56^{+} \mathrm{CD} 3$ cells. MFI of total NK cells for CD 69 respectively percentages of $\mathrm{CD}_{2} 5^{+} \mathrm{NK}$ cells of 14 independent experiments are shown including the median. Percentages of $\mathrm{CD} 83^{+} \mathrm{NK}$ cells of 12 independent experiments are shown. (D) NK cell-derived IFN- $\gamma$ production measured in the culture supernatant by CBA. Combination of 12 independent experiments is shown. Wilcoxon signed-rank test significance ${ }^{*} P<0.05 ;{ }^{* *} P<0.01 ;{ }^{* * *} P<0.001 ;{ }^{* * * *} P<0.0001$. 


\section{Cooperative PRR-triggering during DC maturation enhances Th1 polarizing and NK cell activating capacities of $D C$}

Previously it has been shown that triggering of multiple PRR-signalling cascades influences the DC cytokine profile and enables DC to modify their interaction with helper cells ${ }^{25-27,31}$. As FMKp contains only bacterial PAMPs, we addressed the question whether the combination with a viral PAMP would lead to DC being more potent in inducing both Th1 and NK 'helper' cell responses.

Poly(I:C) lyovec (further on described as poly(I:C)), a RIG-1/MDA-5 receptor complex trigger, was added to the FI-cocktail and first the effect of this combined viral and bacterial triggering during DC maturation was studied on the Th cell polarizing capacities. T cells

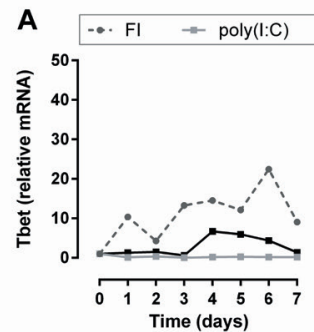

C

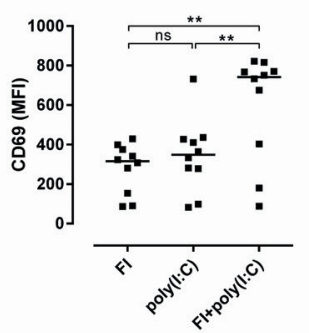

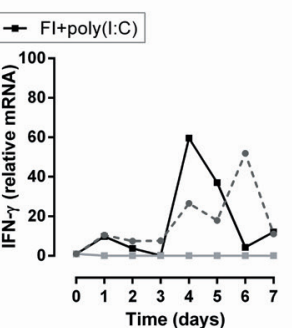

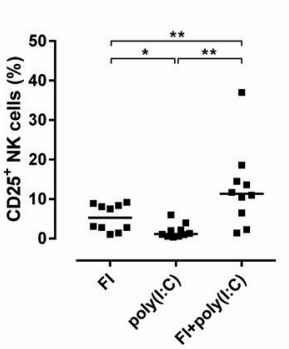

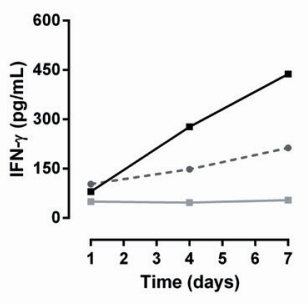

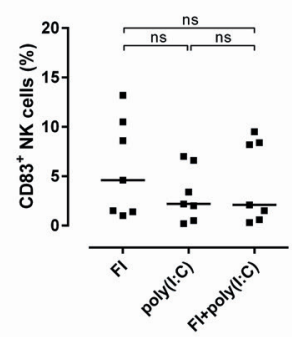

B
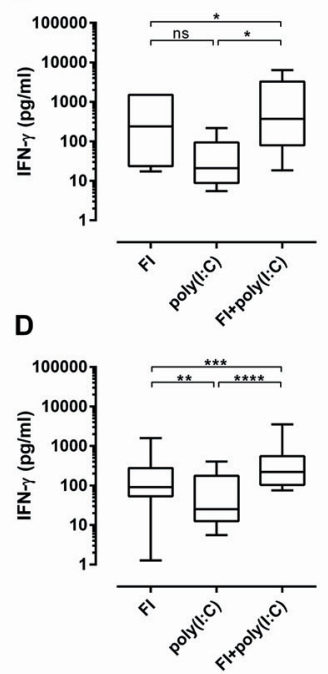

Figure 2 | Impact of cooperative PRR-triggering during DC maturation on DC-induced Th1 polarization and NK cell activation. (A, B) Monocyte-derived iDC were matured with FMKp/ IFN- $\gamma(\mathrm{FI})$, poly(I:C) lyovec (poly(:C)) or the combination of both (FI+poly(I:C)). 24h-matured DC were co-cultured with autologous naive $\mathrm{CD}^{+}{ }^{+} \mathrm{CD} 45 \mathrm{RA}^{+} \mathrm{T}$ cells and the expression of $\mathrm{T}$-bet and IFN- $\gamma$ as well as the IFN- $\gamma$ production were monitored during 7 days. (A) Th1-polarizing capacity of FI- $(\bullet)$, poly(I:C)-(- and FI+poly(I:C)-(- matured DC of one out of 6 representative experiments are shown by means of T-bet and IFN- $\gamma$ expression as well as IFN- $\gamma$ secretion. (B) Average IFN- $\gamma$ secretion of T cells at day 7 of the different co-cultures $(n=6)$. (C, D ) NK cells were activated overnight in washed DC-derived cell-free supernatants. (C) Flow cytometric evaluation of CD69, CD25 and CD83 surface expression of differently activated NK cells. NK cells were gated in FSC/SSC on lymphocyte gate, excluding dead cells and doublets and selected for $\mathrm{CD} 56^{+} \mathrm{CD} 3$ cells. MFI of total NK cells for $\mathrm{CD} 69$ respectively percentages of CD25+ NK cells of 10 experiments are shown. Percentages of CD83 NK cells of 7 experiments are shown. (D) NK cell-derived IFN- $\gamma$ production measured by CBA in the culture supernatant. Combination of 16 experiments is shown. Wilcoxon signed-rank test significance ${ }^{*} P<0.05 ;{ }^{* *} P<0.01 ;{ }^{* * *} P<0.001 ;{ }^{* * * * *}$ $P<0.0001$. 
co-cultured with FI+poly(I:C)-DC displayed an earlier transcriptional induction of IFN- $\gamma$ (day 4 vs. day 6 for FI-DC-T cell co-culture) and in line with this, a significantly higher secretion of IFN- $\gamma$ on day 7 (Figure $2 \mathrm{~A}, \mathbf{B}$ ).

Next, we studied the effect of cooperative PRR-triggering on NK cell activation. Both the expression of CD 69 on NK cells and the percentage of CD $25^{+} \mathrm{NK}$ cells were increased by activation with FI+poly(I:C)-DC supernatant (Figure 2C). In contrast, the percentage of $\mathrm{CD} 83^{+} \mathrm{NK}$ cells was not significantly different between the groups. NK cells activated by both the bacterial and viral trigger showed significant increased IFN- $\gamma$ secretion compared with those triggered by either of the individual ligands in combination with IFN- $\gamma$ (Figure 2D).

\section{IL-12p70, the common factor of quantitative and cooperative PRR-triggering}

Both quantitative and cooperative PRR-triggering positively influenced the capacities of DC to interact with Th and NK cells. Since the NK cells were activated in a cell-cell contact-independent milieu, we addressed the question whether a common soluble factor was responsible for the observed effects. We tested whether the amount of IL-12p70 was the common factor up-regulated, as previous reports demonstrated the necessity of this cytokine for both Th1 and NK cell responses ${ }^{31,37,38}$.

A

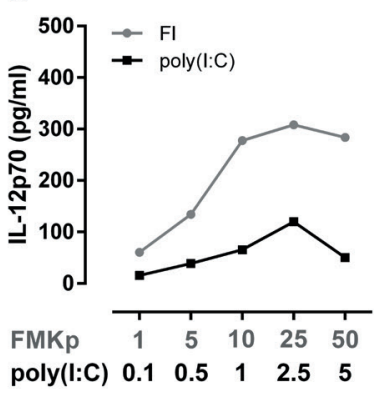

B

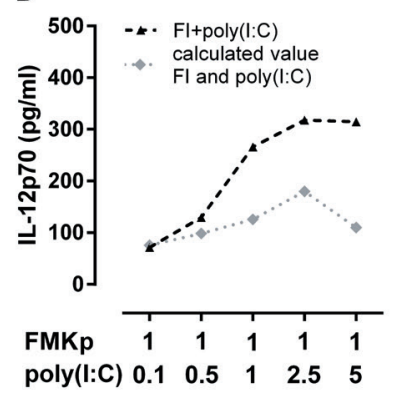

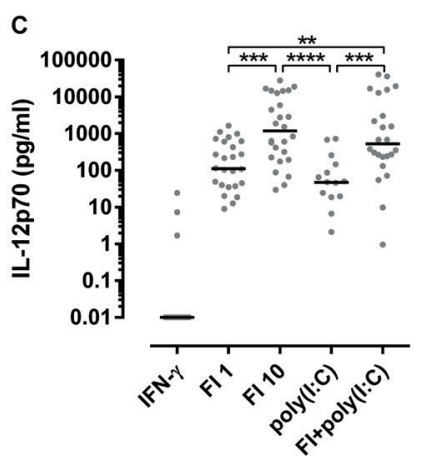

Figure 3 | IL-12p70 production is influenced by quantitative PRR-triggering. IL-12p70 secretion by differently matured DC measured by CBA. iDC were matured for $48 \mathrm{~h}$ with different cocktails at a density of $0.5 \times 10^{6}$ cells $/ \mathrm{ml}$ in 24-well plates. (A) iDC were matured with different concentrations of FMKp $(1-50 \mathrm{ug} / \mathrm{ml})(\bullet)$ or poly (I:C) $(0.1-5 \mathrm{ug} / \mathrm{ml})(\mathbf{\square})$ in presence of IFN- $\gamma$. Representative data of 3 independent experiments are shown. (B) IL-12p70 values of a titration curve with FI 1 plus increasing concentrations of poly(I:C) $(0.1-5 \mathrm{ug} / \mathrm{ml})(\boldsymbol{\Delta})$. Dotted grey line $(\downarrow)$ represents theoretical calculated IL-12p70 value by summing up the IL-12p70 concentration of FI 1 with the different IL-12p70 concentrations of poly(I:C) $0.1-5 \mathrm{ug} / \mathrm{ml}$ conditions. (C) Individual and median IL-12p70 secretion of IFN- $\gamma$, FI 1, FI 10, poly(I:C), and FI+ poly(I:C)-matured DC is shown. Mann-Whitney U test ${ }^{* *} P<0.01 .^{* * *} P<0.001 ;^{* * * *} P<0.0001$. 
Maturing iDC with increasing concentrations of FMKp or poly(I:C) led to increased IL-12 secretion with an optimum at $25 \mu \mathrm{g} / \mathrm{ml}$ FMKp and $2.5 \mu \mathrm{g} / \mathrm{ml}$ poly(I:C). Thus, in both cases quantitative PRR-triggering (with either FMKp or poly(I:C)), positively influences the IL-12 production by DC (Figure 3A). The combination of FMKp and poly(I:C) generated DC producing up to 3-fold more IL-12 compared with DC matured with the respective theoretical concentrations of the triggers alone (Figure 3B). In addition, supernatants of the differently matured DC used to perform the above described experiments indeed showed differences in IL-12 levels. The median IL-12 levels of FI 10-DC was 10.6-fold and the one of FI+poly(I:C) 4.7-fold higher compared with FI 1-DC (Figure 3C).

\section{IL-12p70 is sufficient to induce Th1 polarization but not NK cell activation}

Since we showed that IL-12p70 is a factor that is influenced by quantitative and cooperative PRR-triggering, we investigated whether IL-12p70 is the common factor predicting Th1 polarization and NK cell activation. Therefore, we studied whether the dose of IL-12 has a positive influence on the magnitude and/or kinetics of Th1 polarization and NK cell activation.

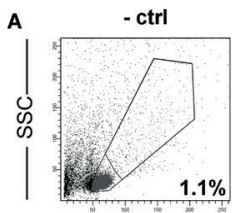

$0 \mathrm{pg} / \mathrm{ml} \mathrm{IL-12}$

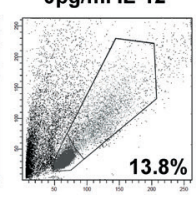

$10 \mathrm{pg} / \mathrm{ml} \mathrm{IL-12}$

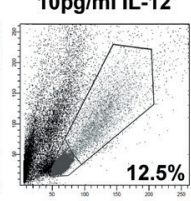

$100 \mathrm{pg} / \mathrm{ml} \mathrm{IL-12}$

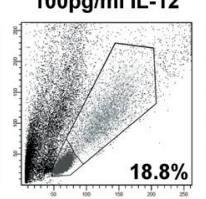

FSC
$1000 \mathrm{pg} / \mathrm{ml} \mathrm{IL-12} 10000 \mathrm{pg} / \mathrm{ml} \mathrm{IL-12}$
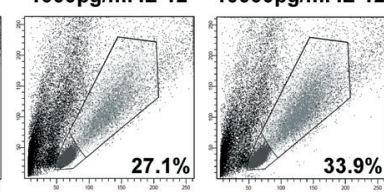

$33.9 \%$

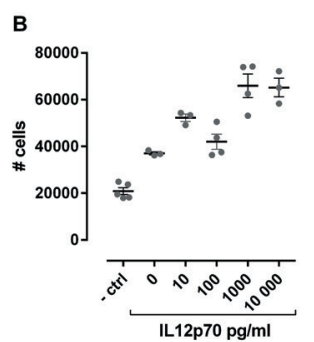

Figure 4 | The quantity of rhIL-12p70 positively influences the magnitude of Th1 polarization. FMKp $/ \mathrm{IFN}-\gamma$ (FI)-matured DC were washed after $24 \mathrm{~h}$ and co-cultured with naive $\mathrm{CD} 4^{+} \mathrm{CD} 45 \mathrm{RA}^{+} \mathrm{T}$ cells during 7 days in the presence of different concentrations of rhIL-12p70. (A) Flow cytometric evaluation of T cells on day 5 of the co-culture. FSC/SSC of the different co-cultures are shown and the percentages of enlarged $\mathrm{CD}^{+} \mathrm{T}$ cells are indicated in the plots. (B) The number of total cells present in the co-cultures on day 5 as measured by coulter counter. (C) Expression of T-bet and IFN- $\gamma$ and total IFN- $\gamma$ production by naive $\mathrm{CD} 4^{+} \mathrm{T}$ cells co-cultured with FI-matured DC in presence of different concentrations of rhIL-12 are shown. Gradient from low to high IL-12 concentrations is illustrated as a colour gradient from light grey to black lines. 
First, we supplemented a DC-T cell co-culture with different concentrations of recombinant human (rh) IL-12p70. Increasing doses of IL-12 administered to the co-cultures correlated with higher percentages of enlarged $\mathrm{CD}^{+}{ }^{+} \mathrm{T}$ cells as depicted in FSC/SCC after flow cytometric analyses on day 5 of the co-culture (Figure 4A). Additionally, we observed an increased number of $\mathrm{T}$ cells in the conditions with higher doses of IL-12 (Figure 4B), which was also observed in the culture wells (data not shown). Furthermore, the height and kinetics of T-bet mRNA expression were not influenced by the amount of rhIL-12 supplemented to the co-cultures. T-bet mRNA expression was even induced without the addition of rhIL-12 (Figure 4C). However, IL-12 levels dose-dependently correlated with IFN- $\gamma$ mRNA expression and IFN- $\gamma$ secretion. This could also be observed in an APC-independent assay, in which we cultured naive $\mathrm{CD}^{+}{ }^{+} \mathrm{T}$ cells on anti-CD3-coated plates in the presence of different concentrations of rhIL-12 (Figure S2). As observed in the autologous co-culture, TCR-triggering and IL-12 administration were sufficient to induce Th1 polarization.

Second, to address the question whether IL-12p70 is a sufficient factor for the activation of NK cells, we performed NK cell activation assays in which we activated enriched NK cells overnight with different concentrations of rhIL-12 (Figure 5A). Concentrations of $1000 \mathrm{pg} / \mathrm{ml}$ IL-12 and higher led to a minor IFN- $\gamma$ production by NK cells. Increasing doses of rhIL-12 had a positive effect on the expression of CD69 and NKp30 of CD56 ${ }^{+}$CD 3 $\mathrm{NK}$ cells and also led to an increased $\mathrm{CD}_{2} 5^{+}$subpopulation in the presence of rhIL-12 above $100 \mathrm{pg} / \mathrm{ml}$. No effect was observed on the expression of CD83. We observed a more prominent expression of activation markers as well as higher NK cell-derived IFN- $\gamma$ secretion when NK cells were activated with FI-DC-derived supernatant compared with IL-12-activated NK cells (Figure 2C, D).

Considering these observations together with previously published data on the necessity of a two-signal requirement for $\mathrm{NK}$ cell activation ${ }^{12}$, we further studied whether the supplementation of rhIL-12 to FI-DC supernatant, containing more soluble factors than only IL-12, would increase the NK cell activation potential. We observed that all the analysed parameters were increased compared with NK cells activated with the corresponding dose of rhIL-12 alone (Figure 5A). The increasing dose of IL-12 supplemented into the FI-supernatant led to a dose-dependent increase of the $\mathrm{CD} 25^{+} \mathrm{NK}$ cell population. Additionally, NK cell-derived IFN- $\gamma$ secretion was positively influenced by the dose of IL-12. Thus, IL-12 had a superior potential to activate NK cells when combined with other soluble DC-derived factors.

Another cytokine which has been shown by our group and others ${ }^{21,31}$ to be important for NK cell activation is IL-18. Since this cytokine is released in the synaptic cleft during 
the NK-DC interaction, it is present in minor concentrations in the DC supernatant. In our supernatants the levels of IL-18 were all below the ELISA detection limit of $12.5 \mathrm{pg} / \mathrm{ml}$ (data not shown). Nevertheless, we tested the influence of rhIL-18 on the potential of rhIL-12 to activate NK cells (Figure 5B). NKp30 as well as NK cell-derived IFN- $\gamma$ secretion were up-regulated by adding IL-12 as single factor, whereas IL-18 as single factor was able to induce expression of CD69 on total NK cells and to induce CD25 $5^{+}$and $\mathrm{CD} 3^{+}$subpopulations. For NK cells activated by the combination of IL-12 and IL-18, a synergistic effect was observed for IFN- $\gamma$ secretion and all the phenotypic markers except for NKp30 when comparing to single-cytokine activated NK cells.

A
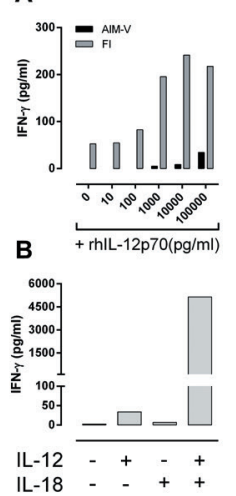

NK cell surface marker expression
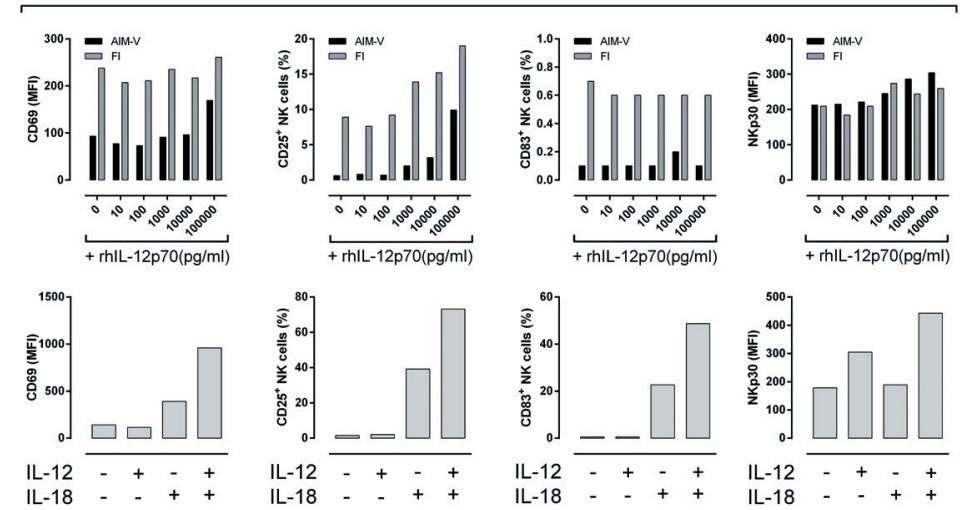

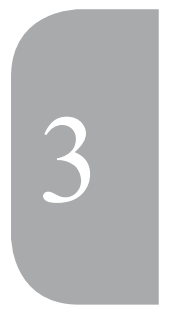

Figure 5 | The quantity of rhIL-12p70 positively influences NK-cell derived IFN- $\gamma$ production. (A) Freshly isolated NK cells from PBMC were incubated overnight in a round-bottom 96-well plate with increasing concentrations of rhIL-12p70 $(0-100 \mathrm{ng} / \mathrm{ml})$ in serum-free AIM- ${ }^{\circledR}$ medium (black bars) or FMKp/IFN- $\gamma$-DC-derived (grey bars) cell-free supernatant. NK cell-derived IFN- $\gamma$ production was measured by CBA in the culture supernatants. Flow cytometric evaluation of CD69, CD25, CD83, and NKp30 surface expression of the differently activated NK cells is shown. NK cells were gated in FSC/ SSC on lymphocyte gate, excluding dead cells and doublets and selected for $\mathrm{CD} 56^{+} \mathrm{CD} 3$ cells. MFI of total NK cells for CD 69 and NKp30 and percentages of $\mathrm{CD} 25^{+}$and $\mathrm{CD} 83^{+} \mathrm{NK}$ cells are shown, respectively. Graphs are representative of 3 independent experiments. (B) NK cells were incubated overnight in serum-free medium in presence of $100 \mathrm{ng} / \mathrm{ml} \mathrm{IL}-12$ or $1000 \mathrm{ng} / \mathrm{ml} \mathrm{IL-18}$ or the combination of both. NK cell-derived IFN- $\gamma$ production was measured by CBA in the culture supernatant. Flow cytometric evaluation of CD69, CD25, CD83, and NKp30 surface expression of the differently activated NK cells of one out of 3 representative experiments is shown.

\section{The quantity of IL-12p70 secretion by differently matured DC predicts the magnitude of NK cell and Th1 helper responses}

We observed quantitative differences among donors in the IL-12-producing capacity (Figure 3C). To study whether this cytokine-producing capacity correlates with their capacity to induce Th1 and NK cell helper activation, we correlated IL-12 levels of FMKp-matured DC of different donors against their corresponding Th1- and NK cell-derived IFN- $\gamma$ 
levels (Figure 6A). For both Th1 polarization and NK cell activation, a significant positive correlation was observed between IL-12 secretion and IFN- $\gamma$ production. This indicates that the inter-individual difference in the capacity to produce IL-12 by monocyte-derived (mo)DC is correlated with the magnitude of induced NK cell and $\mathrm{CD}^{+}{ }^{+} \mathrm{T}$ cell helper responses.
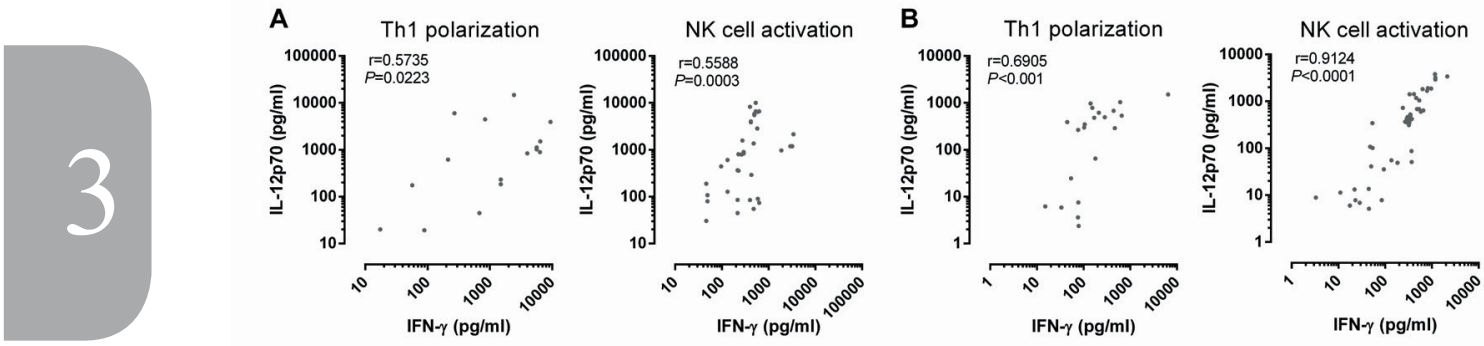

Figure 6 IL-12p70 correlates with the magnitude of Th1 polarization and the degree of NK helper cell activation. (A) IL-12p70 production of DC matured with different concentrations of FI (1 and $10 \mu \mathrm{g} / \mathrm{ml}$ ) were correlated with corresponding IFN- $\gamma$ values of day 7 of the DC-T cell co-culture or the NK cell-derived IFN- $\gamma$ levels after overnight incubation in the FI-DC supernatants. (B) DC-derived IL-12p70 of differently matured DC (each dot represents a different maturation cocktail) were correlated with the corresponding IFN- $\gamma$ value of day 7 of the DC-T cell co-culture or the NK cell-derived IFN- $\gamma$ levels after overnight incubation in the FI-DC supernatants. Spearman correlation test significance: $P$ values are indicated in the graphs.

We further aimed to prove that IL-12 can serve as a possible marker to predict the capacity of differently matured DC to interact with Th1 and NK cells. To this end, we correlated the IL-12 levels of differently matured DC with their corresponding Th1- and NK cell-derived IFN- $\gamma$ levels (Figure 6B). Both graphs show a highly significant correlation between these two factors, illustrating the importance of programming DC to produce IL-12p70.

\section{DISCUSSION}

In the current study, we set out to investigate whether and how PAMP-matured moDC activate both NK helper cells and Th1 cells. We showed the existence of at least one programme used by DC to induce potent cellular immune responses by stimulating both helper processes. The increased capacity of DC to mount the helper responses appeared in absence of up-regulation of HLA- and co-stimulatory molecules; instead it was paralleled with the production of IL-12p70. PRR-triggering can modulate the capacity of DC to produce IL-12p70 and the amount of IL-12 produced is important for the strength of NK cell activation and the magnitude of Th1 polarization. In addition, among the PRR-agonists we tested, the bacterial or viral triggers by which DC are programmed to produce IL-12 seem to be of minor importance. If DC get programmed to produce IL-12, they will most 
probably be able to interact efficiently with both Th1 and NK helper cells. We manipulated the IL-12 production of the DC in a range that was relevant for an increased interaction with Th1 and NK cells.

IL-12 being an important factor for Th1 polarization and NK cell-derived IFN- $\gamma$ production is well known. Previous work by our group ${ }^{31}$ and others ${ }^{39,40}$ has shown that NK cell-derived IFN- $\gamma$ secretion is abrogated when blocking IL-12, suggesting that IL-12 is indispensable for eliciting NK cell helper responses. Furthermore, a study of Athie-Morales et al. ${ }^{37}$ showed that sustained IL-12-signalling was necessary to induce efficient Th1 polarization of naive $\mathrm{CD}^{+}{ }^{+} \mathrm{T}$ cells and neutralization of IL-12 in co-cultures of differently matured DC with naive $\mathrm{CD}^{+}{ }^{+} \mathrm{T}$ cells resulted in a reduced percentage of $\mathrm{IFN}-\gamma^{+}$cells combined with a shift towards IL- $4^{+}$Th2 cells ${ }^{25}$. However, until now it has been unclear to what extent IL-12 is a quantitative requirement for human cells. We extended these findings with exogenous supplementation studies and demonstrated that indeed the requirement of IL-12p70 for both for Th1 polarization and NK cell derived-IFN- $\gamma$ production is quantitative in a range in which it was also possible to manipulate the DC by using bacterial and viral PAMPs in maturation cocktails. In presence of TCR-triggering, IL-12p70 is sufficient to induce Th1 polarization in naive $\mathrm{CD}^{+} \mathrm{T}$ cells both in an APC-dependent and -independent cultures. Notably, we observed that a higher dose of IL-12 increased the IFN- $\gamma$ expression and secretion by Th cells, however, the expression of T-bet mRNA remained unchanged for all the conditions. Since we observed this phenomenon in both an APC-dependent and independent culture systems, we can exclude that contaminating DC are responsible for the detected T-bet expression levels. Even though T-bet expression is necessary for optimal Th1 induction ${ }^{41,42}$, our findings are in line with a previous study reporting that the T-bet expression did not correlate with IFN- $\gamma$ secretion ${ }^{43}$. Additionally, we previously showed that the expression of T-bet is not necessarily associated with the induction of IFN $-\gamma^{30}$. Moreover, we showed that increasing doses of IL-12 had a positive effect on $\mathrm{T}$ cell proliferation. We cannot exclude that the positive effect of increasing IL-12p70 concentrations on the total number of cells is influenced by endogenous IL-2 production. However, an IL-2-independent, but IL-12p70-dependent proliferation was previously shown for Th cell clones ${ }^{44}$. On NK cells, the expression of CD25 and the IFN- $\gamma$ production was induced by adding rhIL-12p70, but to a lesser extent when compared with the two-signal activation of the NK cells. These findings are in line with previous studies showing a twosignal requirement for both cytokine and chemokine production by NK cells ${ }^{12,45}$.

Our demonstration that DC are capable to influence the magnitude of the NK cell helper response by virtue of their IL-12 secretion taken together with recent data in literature provide a more comprehensive view on the importance of the IL-12p70-pathway for NK cell responses. Besides their enhanced capacity to assist in $\mathrm{T}$ cell priming ${ }^{31,46}$ and 
to induce effector cell recruiting chemokines ${ }^{47}$, NK cells which have been activated ex vivo in the presence of IL-12 show enhanced cytokine production and cytolytic activity as well as antibody-dependent cellular cytotoxicity ${ }^{38}$. Helper NK cells possess the capacity to induce additional IL-12 production in $\mathrm{DC}^{7}$ which suggests the existence of an additional positive feedback loop by which NK cells potentiate the ability of DC to mount both $\mathrm{CD}^{+}$and $\mathrm{CD}^{+} \mathrm{T}$ cell responses. Furthermore, in animal models DC-NK interactions were shown to synergize for CTL induction ${ }^{23}$, and for homing of $\mathrm{T}$ cells to the tumour microenvironment ${ }^{45,48,49}$. At this point it remains to be established to what extent NK cells contribute to human adaptive immunity. However, the existence of the helper pathway of NK cells, the observations that its regulation is paralleled by Th1 induction and that it is conserved between human and mice ${ }^{50}$ may point towards a similar role as previously demonstrated in mice ${ }^{51}$. Furthermore, pathogen-recognizing APC attract NK cells to lymphoid organs where they serve as editors of the DC repertoire ${ }^{52,53}$. In murine models it was shown that this editing by NK cells was required for the induction of a potent anti-cancer immune responses ${ }^{54}$.

Since the maturation of DC by different PAMPs induces a unique cytokine and chemokine profile, the question arises whether the observed effects are the result of IL-12p70 alone or of a co-factor being regulated in parallel. For NK cells, two-signal activation is required for efficient activation ${ }^{12}$. We previously showed that blocking of IL-12p70 inhibited the production of NK cell-derived IFN- $\gamma^{31}$. Kalinski et al. demonstrated the importance of IL-18 in the priming of NK helper cells ${ }^{21,45}$, which facilitates DC maturation, DC-mediated Th1 polarization, and recruitment of effector $\mathrm{CD}^{+} \mathrm{T}$ cells. Whereas IL-18 is able to upregulate activation markers such as CD69 and CD25 on a subpopulation of NK cells, IL-18-conditioned NK cells only produced marginal IFN- $\gamma$ levels as shown in this study and by others ${ }^{17,22,55,56}$. In addition, blocking IL-18 in DC supernatant conditioned NK cells only had marginal effect on NK-cell derived IFN- $\gamma$ secretion ${ }^{31}$, postulating that IL-12p70 is the necessary factor for this response. For Th cells, our data showed that IL-12 in combination with TCR-signalling is sufficient to induce Th1 polarization. Murine studies revealed that a possible co-factor IL-18 was not able to polarize naive $\mathrm{CD}^{+}{ }^{+} \mathrm{T}$ cell into Th1 cells, but the enhancing effect was mainly exerted on already primed Th1 cells ${ }^{57}$, which has been confirmed in human in vitro blocking studies ${ }^{58}$. Thus, in vivo, the contribution of other cytokines as possible co-factors to further enhance IL-12-induced type 1 immune responses cannot be excluded. However, our data together with previous studies strengthen the fact that IL-12 plays a crucial role as primary signal in the activation of both helper responses irrespective of the nature of the pathogenic stimulus.

The optimization and implementation of more powerful therapeutic DC-mediated vaccines requires more insight into the interaction of DC with other immune effector cells. Besides 
the activation of CTL, also helper cell activation is important for an effective anti-tumour response ${ }^{14,18,54}$. Because of the crucial role of the dose of DC-derived IL-12p70 for the induction of helper responses, we anticipate that screening DC for IL-12-producing capacities will contribute to vaccine design, screening of adjuvants and thus provide additional rational for the optimization of cellular vaccines. The profound effect of IL-12p70 together with the large variation of DC from different healthy individuals to produce IL-12p70 may suggest an underlying additional reason for the poor clinical outcome observed so far in DC-based vaccines in clinical trials. It should be noted that the range in which we were able to manipulate the IL-12 production by different maturation stimuli in this study had a clear biological effect. This study illustrates that reaching superior IL-12 levels is desirable for the design of DC-mediated vaccines. Recent studies by Okada et al. ${ }^{59}$ and Carreno et al. ${ }^{60}$ showed that the capacity of DC to produce IL-12p70 correlated positively with time to progression in patients with recurrent malignant glioma and patients with melanoma and strengthens the importance of high IL-12p70-producing DC. Thus, besides identifying potent IL-12-inducing maturation factors, an improvement of DC-based vaccine strategies may also be achieved by engineering DC to express IL-12. Such an approach showed promising results in a murine liver cancer model ${ }^{61}$.

Taken together, we revealed that moDC programmed by the selection of PRR triggers tested in this study have the capacity to promote both NK cell and Th1 helper responses and that IL-12p70 is the key factor determining the magnitude of these helper responses. Furthermore, we strengthened the findings on the importance of IL-12p70 in the DC-mediated induction of Th1 and NK helper cells responses. This knowledge may be of importance to design and evaluate a new generation of DC-based vaccines against cancer and infectious diseases and for the in vivo activation of DC.

\section{ACKNOWLEDGEMENTS}

We would like to thank Fraukje Mulders, Elsbeth Pekelharing, and Marijke I. Zonneveld for technical assistance. This work was supported by the 'Fonds National de la Recherche', Luxembourg (project 1039369; T.O.). The funders had no role in study design, data collection and analyses, decision to publish, or preparation of the manuscript. 


\section{REFERENCES}

1. Kalantari T, Kamali-Sarvestani E, Ciric B, et al. Generation of immunogenic and tolerogenic clinicalgrade dendritic cells. Immunologic Research. 2011;51(2-3):153-160.

2. Gluckman JC, Canque B, Rosenzwajg M. Dendritic cells: A complex simplicity. Transplantation. 2002;73(1):S3-S6.

3. Kapsenberg ML. Dendritic-cell control of pathogen-driven T-cell polarization. Nature reviews Immunology. 2003;3(12):984-993.

4. Kennedy R, Celis E. Multiple roles for CD4+ T cells in anti-tumor immune responses. Immunol Rev. 2008;222:129-144.

5. Marcenaro E, Dondero A, Moretta A. Multi-directional cross-regulation of NK cell function during innate immune responses. Transpl Immunol. 2006;17(1):16-19.

6. Welsh RM, Waggoner SN. NK cells controlling virus-specific T cells: Rheostats for acute vs. persistent infections. Virology. 2013;435(1):37-45.

7. Kalinski P, Giermasz A, Nakamura Y, et al. Helper role of NK cells during the induction of anticancer responses by dendritic cells. Mol Immunol. 2005;42(4):535-539.

8. Andrews DM, Scalzo AA, Yokoyama WM, Smyth MJ, Degli-Esposti MA. Functional interactions between dendritic cells and NK cells during viral infection. Nat Immunol. 2003;4(2):175-181.

9. Smyth MJ, Hayakawa Y, Takeda K, Yagita H. New aspects of natural-killer-cell surveillance and therapy of cancer. Nat Rev Cancer. 2002;2(11):850-861.

10. Lee SH, Miyagi T, Biron CA. Keeping NK cells in highly regulated antiviral warfare. Trends Immunol. 2007;28(6):252-259.

11. Moretta A. Natural killer cells and dendritic cells: rendezvous in abused tissues. Nat Rev Immunol. 2002;2(12):957-964.

12. Mailliard RB, Son YI, Redlinger R, et al. Dendritic cells mediate NK cell help for Th1 and CTL responses: two-signal requirement for the induction of NK cell helper function. J Immunol. 2003;171(5):2366-2373.

13. Strengell M, Matikainen S, Siren J, et al. IL-21 in synergy with IL-15 or IL-18 enhances IFN-gamma production in human NK and T cells. J Immunol. 2003;170(11):5464-5469.

14. Van Elssen CH, Oth T, Germeraad WT, Bos GM, Vanderlocht J. Natural killer cells: the secret weapon in dendritic cell vaccination strategies. Clin Cancer Res. 2014;20(5):1095-1103.

15. Kalinski P, Mailliard RB, Giermasz A, et al. Natural killer-dendritic cell cross-talk in cancer immunotherapy. Expert Opin Biol Ther. 2005;5(10):1303-1315.

16. Vitale M, Della Chiesa M, Carlomagno S, et al. NK-dependent DC maturation is mediated by TNFalpha and IFNgamma released upon engagement of the NKp30 triggering receptor. Blood. 2005;106(2):566-571.

17. Srivastava S, Pelloso D, Feng H, et al. Effects of interleukin-18 on natural killer cells: costimulation of activation through Fc receptors for immunoglobulin. Cancer Immunol Immunother. 2013;62(6):10731082.

18. Ferlazzo G, Moretta L. Dendritic cell editing by natural killer cells. Crit Rev Oncog. 2014;19(1-2):6775.

19. Hanna J, Gonen-Gross T, Fitchett J, et al. Novel APC-like properties of human NK cells directly regulate T cell activation. J Clin Invest. 2004;114(11):1612-1623.

20. Zingoni A, Sornasse T, Cocks BG, Tanaka Y, Santoni A, Lanier LL. Cross-talk between activated human NK cells and CD4+ T cells via OX40-OX40 ligand interactions. J Immunol. 2004;173(6):37163724.

21. Mailliard RB, Alber SM, Shen H, et al. IL-18-induced CD83+CCR7+ NK helper cells. J Exp Med. 2005;202(7):941-953.

22. Agaugue S, Marcenaro E, Ferranti B, Moretta L, Moretta A. Human natural killer cells exposed to IL2, IL-12, IL-18, or IL-4 differently modulate priming of naive T cells by monocyte-derived dendritic 
cells. Blood. 2008;112(5):1776-1783.

23. Adam C, King S, Allgeier T, et al. DC-NK cell cross talk as a novel CD4+ T-cell-independent pathway for antitumor CTL induction. Blood. 2005;106(1):338-344.

24. Hardy MY, Kassianos AJ, Vulink A, et al. NK cells enhance the induction of CTL responses by IL-15 monocyte-derived dendritic cells. Immunol Cell Biol. 2009;87(8):606-614.

25. de Jong EC, Vieira PL, Kalinski P, et al. Microbial compounds selectively induce Th1 cell-promoting or Th2 cell-promoting dendritic cells in vitro with diverse th cell-polarizing signals. Journal of immunology. 2002;168(4):1704-1709.

26. Spranger S, Javorovic M, Burdek M, et al. Generation of Th1-polarizing dendritic cells using the TLR7/8 agonist CL075. J Immunol. 2010;185(1):738-747.

27. Walsh KP, Mills KH. Dendritic cells and other innate determinants of $\mathrm{T}$ helper cell polarisation. Trends Immunol. 2013;34(11):521-530.

28. Re F, Strominger JL. Toll-like receptor 2 (TLR2) and TLR4 differentially activate human dendritic cells. J Biol Chem. 2001;276(40):37692-37699.

29. Ozinsky A, Underhill DM, Fontenot JD, et al. The repertoire for pattern recognition of pathogens by the innate immune system is defined by cooperation between toll-like receptors. Proc Natl Acad Sci U S A. 2000;97(25):13766-13771.

30. Oth T, Schnijderberg MC, Senden-Gijsbers BL, Germeraad WT, Bos GM, Vanderlocht J. Monitoring the initiation and kinetics of human dendritic cell-induced polarization of autologous naive CD4+ $\mathrm{T}$ cells. PLoS One. 2014;9(8):e103725.

31. Van Elssen CH, Vanderlocht J, Frings PW, et al. Klebsiella pneumoniae-triggered DC recruit human NK cells in a CCR5-dependent manner leading to increased CCL19-responsiveness and activation of NK cells. European journal of immunology. 2010;40(11):3138-3149.

32. Van Elssen CH, Vanderlocht J, Oth T, Senden-Gijsbers BL, Germeraad WT, Bos GM. Inflammationrestraining effects of prostaglandin E2 on natural killer-dendritic cell (NK-DC) interaction are imprinted during DC maturation. Blood. 2011;118(9):2473-2482.

33. Luger R, Valookaran S, Knapp N, Vizzardelli C, Dohnal AM, Felzmann T. Toll-like receptor 4 engagement drives differentiation of human and murine dendritic cells from a pro- into an antiinflammatory mode. PLoS One. 2013;8(2):e54879.

34. Vieira PL, de Jong EC, Wierenga EA, Kapsenberg ML, Kalinski P. Development of Th1-inducing capacity in myeloid dendritic cells requires environmental instruction. Journal of immunology. 2000;164(9):4507-4512.

35. Vanderlocht J, Van Elssen CH, Senden-Gijsbers BL, et al. Increased tumor-specific CD8+ T cell induction by dendritic cells matured with a clinical grade TLR-agonist in combination with IFNgamma. Int J Immunopathol Pharmacol. 2010;23(1):35-50.

36. Ferlazzo G, Tsang ML, Moretta L, Melioli G, Steinman RM, Munz C. Human dendritic cells activate resting natural killer $(\mathrm{NK})$ cells and are recognized via the NKp30 receptor by activated NK cells. J Exp Med. 2002;195(3):343-351.

37. Athie-Morales V, Smits HH, Cantrell DA, Hilkens CM. Sustained IL-12 signaling is required for Th1 development. Journal of immunology. 2004;172(1):61-69.

38. Lehmann D, Spanholtz J, Sturtzel C, et al. IL-12 directs further maturation of ex vivo differentiated NK cells with improved therapeutic potential. PLoS One. 2014;9(1):e87131.

39. Ferlazzo G, Pack M, Thomas D, et al. Distinct roles of IL-12 and IL-15 in human natural killer cell activation by dendritic cells from secondary lymphoid organs. Proc Natl Acad Sci U S A. 2004;101(47):16606-16611.

40. Borg C, Jalil A, Laderach D, et al. NK cell activation by dendritic cells (DCs) requires the formation of a synapse leading to IL-12 polarization in DCs. Blood. 2004;104(10):3267-3275.

41. Kanhere A, Hertweck A, Bhatia U, et al. T-bet and GATA3 orchestrate Th1 and Th2 differentiation through lineage-specific targeting of distal regulatory elements. Nat Commun. 2012;3:1268.

42. Szabo SJ, Kim ST, Costa GL, Zhang X, Fathman CG, Glimcher LH. A novel transcription factor, 
T-bet, directs Th1 lineage commitment. Cell. 2000;100(6):655-669.

43. Ylikoski E, Lund R, Kylaniemi M, et al. IL-12 up-regulates T-bet independently of IFN-gamma in human CD4+ T cells. Eur J Immunol. 2005;35(11):3297-3306.

44. Maruo S, Toyo-oka K, Oh-hora M, et al. IL-12 produced by antigen-presenting cells induces IL-2independent proliferation of T helper cell clones. J Immunol. 1996;156(5):1748-1755.

45. Wong JL, Berk E, Edwards RP, Kalinski P. IL-18-primed helper NK cells collaborate with dendritic cells to promote recruitment of effector CD8+ $\mathrm{T}$ cells to the tumor microenvironment. Cancer research. 2013;73(15):4653-4662.

46. Morandi B, Bougras G, Muller WA, Ferlazzo G, Munz C. NK cells of human secondary lymphoid tissues enhance T cell polarization via IFN-gamma secretion. Eur J Immunol. 2006;36(9):2394-2400.

47. Robertson MJ. Role of chemokines in the biology of natural killer cells. J Leukoc Biol. 2002;71(2):173183.

48. Wong JL, Mailliard RB, Moschos SJ, et al. Helper activity of natural killer cells during the dendritic cell-mediated induction of melanoma-specific cytotoxic $\mathrm{T}$ cells. Journal of immunotherapy. 2011;34(3):270-278.

49. Mailliard RB, Wankowicz-Kalinska A, Cai Q, et al. alpha-type-1 polarized dendritic cells: a novel immunization tool with optimized CTL-inducing activity. Cancer research. 2004;64(17):5934-5937.

50. Colucci F, Di Santo JP, Leibson PJ. Natural killer cell activation in mice and men: different triggers for similar weapons? Nat Immunol. 2002;3(9):807-813.

51. Martin-Fontecha A, Thomsen LL, Brett S, et al. Induced recruitment of NK cells to lymph nodes provides IFN-gamma for T(H)1 priming. Nat Immunol. 2004;5(12):1260-1265.

52. Della Chiesa M, Vitale M, Carlomagno S, Ferlazzo G, Moretta L, Moretta A. The natural killer cellmediated killing of autologous dendritic cells is confined to a cell subset expressing CD94/NKG2A, but lacking inhibitory killer Ig-like receptors. Eur J Immunol. 2003;33(6):1657-1666.

53. Wilson JL, Heffler LC, Charo J, Scheynius A, Bejarano MT, Ljunggren HG. Targeting of human dendritic cells by autologous NK cells. J Immunol. 1999;163(12):6365-6370.

54. Morandi B, Mortara L, Chiossone L, et al. Dendritic cell editing by activated natural killer cells results in a more protective cancer-specific immune response. PLoS One. 2012;7(6):e39170.

55. Matikainen S, Paananen A, Miettinen M, et al. IFN-alpha and IL-18 synergistically enhance IFNgamma production in human NK cells: differential regulation of Stat4 activation and IFN-gamma gene expression by IFN-alpha and IL-12. Eur J Immunol. 2001;31(7):2236-2245.

56. Leong JW, Chase JM, Romee R, et al. Preactivation with IL-12, IL-15, and IL-18 induces CD25 and a functional high-affinity IL-2 receptor on human cytokine-induced memory-like natural killer cells. Biol Blood Marrow Transplant. 2014;20(4):463-473.

57. Stoll S, Jonuleit H, Schmitt E, et al. Production of functional IL-18 by different subtypes of murine and human dendritic cells (DC): DC-derived IL-18 enhances IL-12-dependent Th1 development. Eur J Immunol. 1998;28(10):3231-3239.

58. de Jong EC, Vieira PL, Kalinski P, et al. Microbial compounds selectively induce Th1 cell-promoting or Th2 cell-promoting dendritic cells in vitro with diverse th cell-polarizing signals. J Immunol. 2002;168(4):1704-1709.

59. Okada H, Kalinski P, Ueda R, et al. Induction of CD8+ T-cell responses against novel gliomaassociated antigen peptides and clinical activity by vaccinations with \{alpha\}-type 1 polarized dendritic cells and polyinosinic-polycytidylic acid stabilized by lysine and carboxymethylcellulose in patients with recurrent malignant glioma. J Clin Oncol. 2011;29(3):330-336.

60. Carreno BM, Becker-Hapak M, Huang A, et al. IL-12p70-producing patient DC vaccine elicits Tc1polarized immunity. J Clin Invest. 2013;123(8):3383-3394.

61. Vogt A, Sievers E, Lukacs-Kornek V, et al. Improving immunotherapy of hepatocellular carcinoma (HCC) using dendritic cells (DC) engineered to express IL-12 in vivo. Liver Int. 2013. 


\section{SUPPORTING INFORMATION}

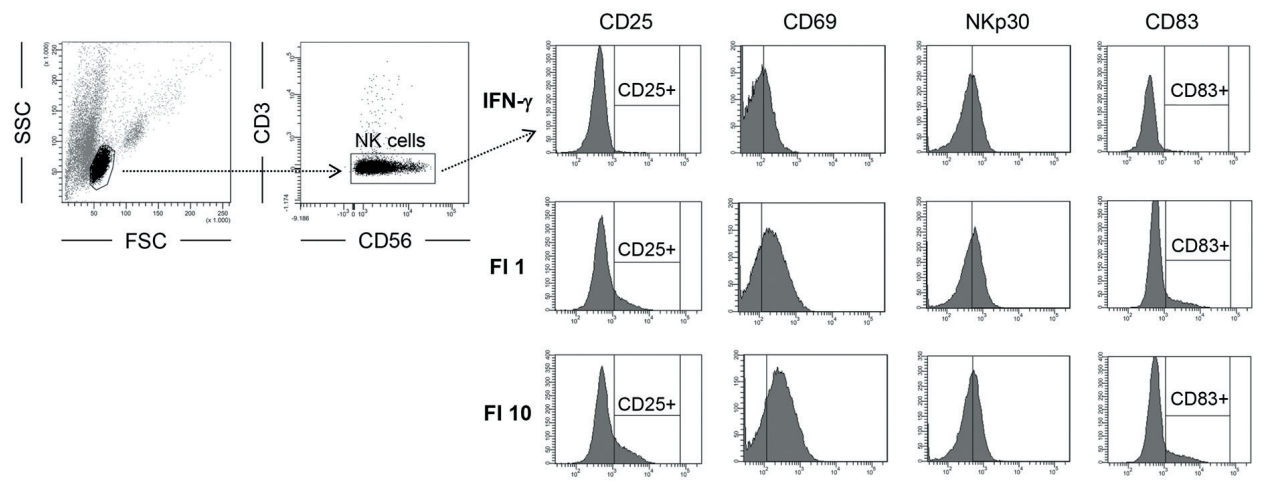

Supplementary Figure S1 | Flow cytometric analyses of DC supernatant-induced NK cell activation. NK cells were incubated overnight in washed supernatant of differently matured DC and stained for CD25, CD69, NKp30 and CD83. NK cells were gated in the FSC/SCC on the lymphocyte gate and further selected on $\mathrm{CD} 56^{+} \mathrm{CD} 3-$ cells. Expression of the different markers is shown in histograms for NK cells activated with IFN- $\gamma$, FI 1 and FI 10-DC supernatants. CD25 and CD83 showed a shift of a part of the NK cell population and results were depicted as percentages in figure 1, 2, and 5. CD69 was upregulated on the entire NK population and was shown as mean fluorescence intensity (MFI) in Figure 1, 2, and 5. The expression of NKp30 was not affected by activating NK cells in different DC supernatants.
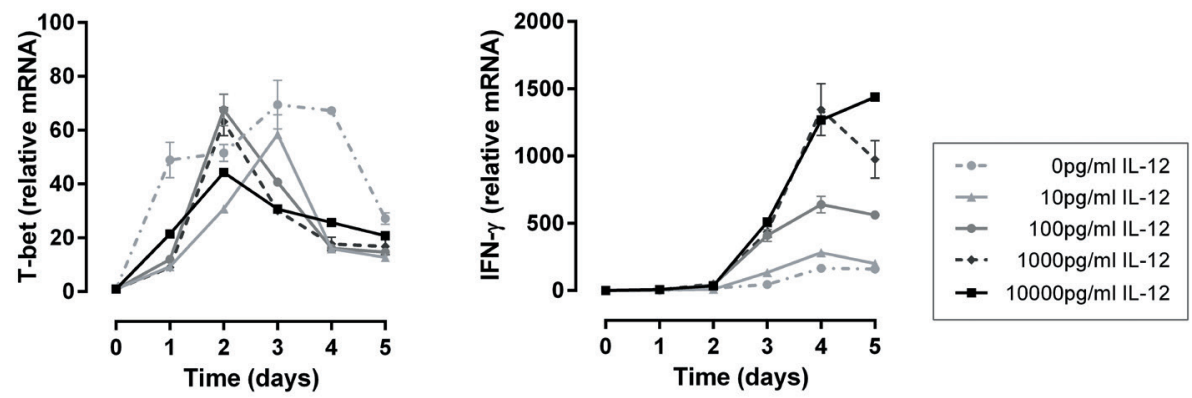

Supplementary Figure S2 | IL-12p70 is sufficient to induce Th1 polarization in an APC-independent setup. $5 \times 10^{4}$ naive $\mathrm{CD}^{+} \mathrm{CD} 45 \mathrm{RA}^{+} \mathrm{T}$ cells were cultured in round-bottom 96-well plates on immobilized anti-CD3 $(1 \mu \mathrm{g} / \mathrm{ml})$ for 5 days in the presence of different rhIL-12p70 concentrations $(0-10000 \mathrm{pg} / \mathrm{ml})$. Transcriptional induction of T-bet and IFN- $\gamma$ was determined over time. 


\section{Fie Pathogen recognition by NK cells amplifies the pro-inflammatory cytokine production of monocyte- derived DC via IFN- $\gamma$ but not TNF- $\alpha$}

Oth T. ${ }^{1}$

Germeraad W.T.V. ${ }^{1}$

Zonneveld M.I. ${ }^{2}$

Bos G.M.J. ${ }^{1}$

Vanderlocht J. ${ }^{3}$

${ }^{1}$ Division of Haematology, Department of Internal Medicine, MUMC+, Maastricht

${ }^{2}$ Division of Pharmacology, Department of Pharmaceutical Sciences, Utrecht University, Utrecht

${ }^{3}$ Tissue Typing Laboratory, Department of Transplantation Immunology, MUMC+, Maastricht

Under revision. 


\begin{abstract}
Natural killer $(\mathrm{NK})$ cells play a crucial role in host defense by eliminating infected or malignantly transformed cells. Moreover, NK cells serve as modulators of adaptive immune responses. Because NK cells express various pattern recognition receptors (PRR), we investigated whether direct sensing of viral and bacterial motifs contributes to the response of inflammatory dendritic cells (DC) against the same pathogenic stimuli.
\end{abstract}

We demonstrated that direct sensing of pathogens by NK cells augments the pro-inflammatory cytokine profile of DC via NK cell-derived soluble factors. Among viral motifs, the enhancement of DC-derived IL-12p70 secretion was observed by TLR3, TLR7/8, and TLR8-activated NK cells. TLR8-triggering ligands showed different results; sensing of ssRNA40 amplified the DC cytokine profile, whereas ssPolyU did not. TLR7 agonists only induced a marginal activation of NK cells. Additionally, we demonstrated that NK cells amplify the DC-derived IL-12p70 production upon recognition of bacterial motifs, including TLR1/2, TLR2, TLR2/6, TLR4, and TLR5 triggers. DC-derived secretion of IL-1 $\beta$, IL-6, CXCL9, and CXCL10 was also influenced in the presence of NK cell-derived soluble factors. Notably, this amplification was dependent on the cytokine environment in which NK cells recognized the pathogen indicating the importance of accessory cell activation for this mechanism. Furthermore, we showed that NK cells amplify the DC cytokine profile via a TNF- $\alpha$-independent mechanism and relying on IFN- $\gamma$.

These findings display an important level of interaction between different PRR-expressing immune cells. This is of interest to modulate immune responses, for example for the selection of adjuvants for vaccination strategies. 


\section{INTRODUCTION}

Natural killer $(\mathrm{NK})$ cells are important players of the innate immune system and are well described for their role in controlling viral infections and limiting tumour outgrowth by recognizing and eliminating altered self-cells ${ }^{1-3}$. The activation of NK cells is controlled by a tight balance of activating and inhibitory receptors between the interacting cells according to 'missing-self' or 'stress-induced self-recognition'-principle ${ }^{4}$ and/or by the surrounding cytokine milieu ${ }^{5,6}$. The importance of NK cells in host defence and control of infections is supported by several studies with NK cell-deficient mice or mice having an impaired NK cell function, in which infections cause an increased viral load and lead to a higher mortality as compared to control animals ${ }^{7}$. Moreover, patients with NK cell deficiencies have an increased susceptibility to recurrent viral infections (mainly herpes- and papillomavirus) ${ }^{8-11}$. Interestingly, NK cell-deficient mice also displayed a higher bacterial load ${ }^{12-14}$.

The presence of viral or bacterial pathogens is sensed by pattern recognition receptors (PRR). These receptors recognize conserved microbial structures, the so-called pathogen-associated molecular patterns (PAMPs). A variety of immune cells, such as antigen-presenting cells (e.g. dendritic cells; DC) express a specific repertoire of these PRR allowing a coordinated response of the different immune effectors cells against a particular pathogen ${ }^{15-17}$. Likewise, PAMP-matured DC have the capacity to activate NK cells by soluble as well as contact-dependent factors. This indirect sensing of pathogens includes enhancement of proliferation and survival as well as increased cytotoxic potential and cytokine secretion ${ }^{18-21}$. Moreover, several studies revealed that NK cells also express a diverse repertoire of PRR potentially allowing direct sensing of pathogens. This repertoire includes expression of Toll-like receptors (TLR) 1-9 $9^{22-25}$ as well as members of other PRR families: RIG-I, NOD-2, NRLP3, and MDA-5 26-28. Various authors showed the functional importance of PAMP recognition with respect to the induction of cytotoxicity. Triggering of TLR2, 7, 8, and 9 enhances NK cell cytolytic potential against various tumour cell lines ${ }^{22,29-31}$. Furthermore, TLR ligation can also influence the capacity of NK cells to edit the DC repertoire by eliminating suppressive immature DC (iDC) ${ }^{31}$. Thus, direct PAMP-sensing by NK cells is not only influencing direct elimination of altered cells but can also modulate adaptive immune responses.

In recent years, another mechanism has been described by which NK cells can modulate immune responses. Besides their important cytotoxic role, NK cells have also been ascribed a helper function. These helper NK cells have a DC-activating capacity and induce type-1-polarizing DC. These DC are in turn able to produce high amounts of pro-inflammatory cytokines and to enhance Th1 and CTL responses ${ }^{20,21,32,33}$. Thus far, the induction of these NK helper cells in vitro has been achieved by pro-inflammatory 
cytokines. Whether the helper activity of NK cells gets also induced upon direct sensing of pathogen remains understudied. A recent study by Wong et al. ${ }^{34}$ showed that the addition of a TLR3 trigger to a NK-DC co-culture led to an enhanced DC maturation with respect to co-stimulatory molecule expression and IL-12p70 as well as melanoma-specific CTL responses. It remains unclear whether this effect is influenced by the NK-DC crosstalk and whether the engagement of other PRR can induce this response. Further investigation on the role of PRR engagement by NK cells as an alternative activation pathway on the onset of an immune response is needed.

In the current study we aimed to investigate whether the recognition of specific viral and bacterial PAMPs contributes to an increased activation of monocyte-derived (mo)DC exposed to the same trigger. Therefore, we first studied the capacity of NK cells to respond towards diverse viral and bacterial PAMPs. Furthermore, we aimed at identifying by virtue of which cytokines NK cells induce increased DC cytokine secretion and whether this mechanism differs between viral and bacterial activated NK cells.

\section{MATERIAL AND METHODS}

\section{Generation of DC}

Monocytes were generated as previously described ${ }^{35}$ and differentiated in serum-free AIM-V ${ }^{\circledR}$ medium (Life technologies, Carlsbad, CA, USA) supplemented with GM-CSF (400U/ml; Berlex Laboratories Inc., Montville, NJ, USA) and IL-4 (2000U/ml; Miltenyi Biotec GmbH, Bergisch Gladbach, Germany) at a density of $2 \times 10^{6}$ cells $/ \mathrm{ml}$. After 7 days, iDC were harvested and frozen or immediately processed in $N K$ cell-induced $D C$ maturation assays.

\section{NK cell isolation}

NK cells were isolated from buffy coats or fresh peripheral blood-derived PBMC by negative immunomagnetic cell separation (Miltenyi Biotec) according to the manufacturer's instructions. Blood was obtained from Sanquin blood bank Maastricht, the Netherlands (project 2000-03AZM) from healthy donors after informed consent. Isolated NK cells were $\geq 95 \% \mathrm{CD}^{2} 6^{+} \mathrm{CD}^{-}$(containing $0 \% \mathrm{CD} 4^{+}$cells) as assessed by flow cytometry.

\section{Activation of NK cells}

Freshly isolated NK cells were activated overnight in round-bottom 96-well plates 
$\left(2.5 \times 10^{5}\right.$ cells/well $)$ in serum-free AIM- ${ }^{\circledR}$ medium supplemented with various PAMPs and if indicated in the figure legends supplemented with different combinations of cytokines: IL-2 (1000U/ml; Proleukin, Novartis, Basel, Switzerland); IL-2 and IL-18 (100ng/ml; MBL International cooperation, Woburn, MA, USA); IL-12 (10ng/ml; R\&D systems, Minneapolis, MN, USA), IL-15 (20ng/ml; R\&D systems) and IL-18. The following PAMPs were used in this study: poly(I:C)HMW $(50 \mu \mathrm{g} / \mathrm{ml})$, poly(I:C)LMW $(100 \mu \mathrm{g} / \mathrm{ml})$, imiquimod $(5 \mu \mathrm{g} /$ $\mathrm{ml})$, gardiquimod $(5 \mu \mathrm{g} / \mathrm{ml})$, CL075 $(5 \mu \mathrm{g} / \mathrm{ml}), \mathrm{R} 848(5 \mu \mathrm{g} / \mathrm{ml})$, ssPolyU $(5 \mu \mathrm{g} / \mathrm{ml})$, ssRNA40 $(5 \mu \mathrm{g} / \mathrm{ml})$, Pam3CSK4 $(5 \mu \mathrm{g} / \mathrm{ml})$, HKLM $\left(10^{8} \mathrm{cells} / \mathrm{ml}\right)$, FSL-1 $(1 \mu \mathrm{g} / \mathrm{ml})$, LPS $(20 \mu \mathrm{g} / \mathrm{ml})$, flagellin $(10 \mu \mathrm{g} / \mathrm{ml}$; all purchased from InvivoGen, Toulouse, France), and FMKp $(10 \mu \mathrm{g} /$ ml; Pierre Fabre Laboratories, Boulogne-Billancourt, France). As controls, additional wells on the same plate containing medium and PAMPs with or without cytokine cocktails were incubated overnight. After 16-18h of incubation, cell-free supernatants and control wells were harvested and used to mature iDC. Additionally, NK cell-derived cytokine and chemokine profile was determined. The remaining cells were stained for various cell surface markers and were analysed by flow cytometry. If indicated, the supernatant of washed NK cells was used. For this purpose NK cells were first activated for 4h with PAMPs and then extensively washed, followed by additional incubation for a total of $16-18 \mathrm{~h}$ in fresh serumfree medium at $37^{\circ} \mathrm{C} / 5 \% \mathrm{CO}_{2}$.

\section{NK cell-induced DC maturation}

Supernatants of activated NK cells and control supernatants (medium containing PAMPs with or without cytokines stored overnight in the incubator without the presence of $\mathrm{NK}$ cells) were transferred into flat-bottom 96-well plates supplemented with IL-4 (500U/ml) and GM-CSF $(500 \mathrm{U} / \mathrm{ml})$. To each well, $2.5 \times 10^{5}$ iDC were added. After $48 \mathrm{~h}$ of maturation, the supernatant was harvested and analysed for DC-derived cytokines and chemokines. Additionally, DC were harvested, stained for phenotypic surface markers and analysed by flow cytometry.

\section{Blocking studies}

Blocking studies were performed with cell-free supernatants obtained from freshly isolated $\mathrm{NK}$ cells activated overnight in serum-free AIM-V ${ }^{\circledR}$ medium and IL-2 $(1.000 \mathrm{U} / \mathrm{ml})$ supplemented with FMKp $(10 \mu \mathrm{g} / \mathrm{ml})$ or poly(I:C)HMW $(50 \mu \mathrm{g} / \mathrm{ml})$. The receptor-blocking was performed by pre-incubating iDC with blocking antibodies for $20 \mathrm{~min}$ before their addition into flat-bottom 96-well plates containing the cell-free NK cell supernatant supplemented with IL-4 $(500 \mathrm{U} / \mathrm{ml})$ and GM-CSF $(500 \mathrm{U} / \mathrm{ml})$. The following receptor blocking antibodies were used: IFNGR1 $(20 \mu \mathrm{g} / \mathrm{ml})$, TNFR1 $(20 \mu \mathrm{g} / \mathrm{ml})$, TNFR2 $(20 \mu \mathrm{g} / \mathrm{ml})$, or isotype control (all purchased from R\&D systems). The blocking of the 
cytokines (IFN- $\gamma$ and TNF- $\alpha$ ) in the NK cell-derived supernatants was performed by preincubating the supernatants with anti-TNF- $\alpha(20 \mu \mathrm{g} / \mathrm{ml}$; BD) or anti-IFN- $\gamma(10 \mu \mathrm{g} / \mathrm{ml}$; BD) before adding the iDC. As reference value, iDC were incubated with NK cell-derived supernatant in absence of blocking agents. As a negative control, iDC were incubated with medium supplemented with FMKp or poly(I:C) and IL-2. After 48h of maturation, the supernatant was harvested to determine the DC cytokine and chemokine profile.

\section{Supplementation studies}

iDC were matured in 48 well plates $\left(2.5 \times 10^{5}\right.$ cells / well $)$ in serum-free AIM-V ${ }^{\circledR}$ in the presence of IL-4 $(500 \mathrm{U} / \mathrm{ml})$ and GM-CSF $(500 \mathrm{U} / \mathrm{ml})$ supplemented with different concentrations of rhIFN- $\gamma$ (0-50.000U/ml; R\&D systems) or rhTNF- $\alpha$ (0-10.000U/ml; Life Technologies). The supernatant was harvested after $48 \mathrm{~h}$ of maturation and cytokines were analysed by cytometric bead array (CBA; see below).

\section{Flow cytometry}

All antibodies used to determine NK cell purities as well as the surface marker expression of NK cells and DC were purchased from BD Biosciences (Franklin Lakes, NJ, USA). Antibodies were used, titrated to their optimal concentration, either as fluorescein isothiocyanate (FITC), phycoerythrin (PE), peridinin chlorophyll protein (PerCP), allophyocyanin (APC), allophyocyanin H7 (APC-H7), Horizon 450 or PeCy7. Discrimination between dead and living cells was made based on LIVE/DEAD ${ }^{\circledR}$ Fixable Dead Cell staining (Aqua stain; Life Technologies). Analysis were performed with BD FACS Canto II and analysed by BD FACS Diva Software v6.1.2 (BD Biosciences).

\section{Cytokine detection}

Quantification of DC- and NK cell-derived pro-inflammatory cytokine and chemokine profiles were performed by CBA flex set assay (BD Biosciences) according to the manufacturer's instructions. Measurements were performed with BD FACS Canto II and analysed by BD FACS Diva Software v6.1.2 and FCAP array analysis software (version 1.0.1; Soft Flow Inc., St. Louis Park, MN, USA).

\section{Statistical analyses}

Statistical analyses were determined by Kruskal-Wallis (NK cell analyses) or by MannWhitney $\mathrm{U}$ test (DC analyses) and the correlation was tested by nonparametric Spearman correlation; * $P \leq 0.05,{ }^{* *} P \leq 0.01,{ }^{* * *} P \leq 0.001,{ }^{* * * *} P \leq 0.0001$. Data were analysed using GraphPad Prism Software (version 6; GraphPad Software, San Diego, CA, USA). 


\section{RESULTS}

\section{Viral PAMP recognition by NK cells induces activation in the presence of IL-2}

To evaluate whether NK cells recognize and get activated after engagement of different viral PAMPs (triggering various TLR), we incubated NK cells with different viral TLR ligands: poly(I:C) (TLR3), gardiquimod (TLR7), CL075 and R848 (both TLR7/8), ssRNA40 and sspolyU (both TLR8). The production of NK helper cell-derived regulatory cytokines, IFN- $\gamma$ and TNF- $\alpha$, was minimal after viral TLR ligation and did not differ between the different viral PAMPs. Furthermore, we determined the production of the chemokines involved in attraction and enhanced cytotoxity of NK cells ${ }^{36,37}$ as well as in the recruitment of iDC ${ }^{33}$ : CCL3 and CCL5. The chemokine production was low and no differences were observed between the different triggers (Figure 1A). The expression of activation markers CD69 and CD25 was upregulated by NK cells activated with the TLR3 trigger poly(I:C) and TLR7/ 8 trigger R848 (Figure 1B).

Since it has been previously reported that NK cells get more efficiently activated by the combination of two signals ${ }^{32}$, we investigated whether the addition of IL-2 to the viral PAMPs during overnight incubation enhances PAMP-induced NK cell activation. The presence of IL-2 led to an increase in CCL3, CD69, and CD25 in the control condition. By adding IL-2, we also observed differences in the ability of NK cells to sense viral PAMPs and to induce cytokine and chemokine secretion as well as upregulation of cell surface markers. Only triggering TLR3 by poly(I:C) in combination with IL-2 enhanced all the analysed parameters and was superior in cytokine secretion and surface marker expression compared to all the other triggers. R848 and ssRNA40 induced a significant increase in NK cell-derived IFN- $\gamma$ (Figure 1A, B). The limited response towards TLR7 trigger gardiquimod was observed as well as for another TLR7 PAMP, imiquimod. Notably, whereas of the two TLR8 triggers ssRNA40 and ssPolyU, only ssRN40 induced IFN- $\gamma$ production by NK cells, the induction of the other parameters was comparable between these two PAMPs.

These data show that NK cells are able to respond to different viral triggers, however, for efficient sensing NK cells require a pro-inflammatory environment (e.g. IL-2) to induce potent cytokine secretion. Additionally, we observed that the different TLR-triggering PAMPs, but also PAMPs triggering the same TLR (e.g. TLR8) differ in their potency to induce an NK cell response. So not only TLR3 triggers showed an NK cell stimulatory effect, but also other viral TLR triggers did, where TLR7/8 triggers induced cytokine production by NK cells most efficiently. 

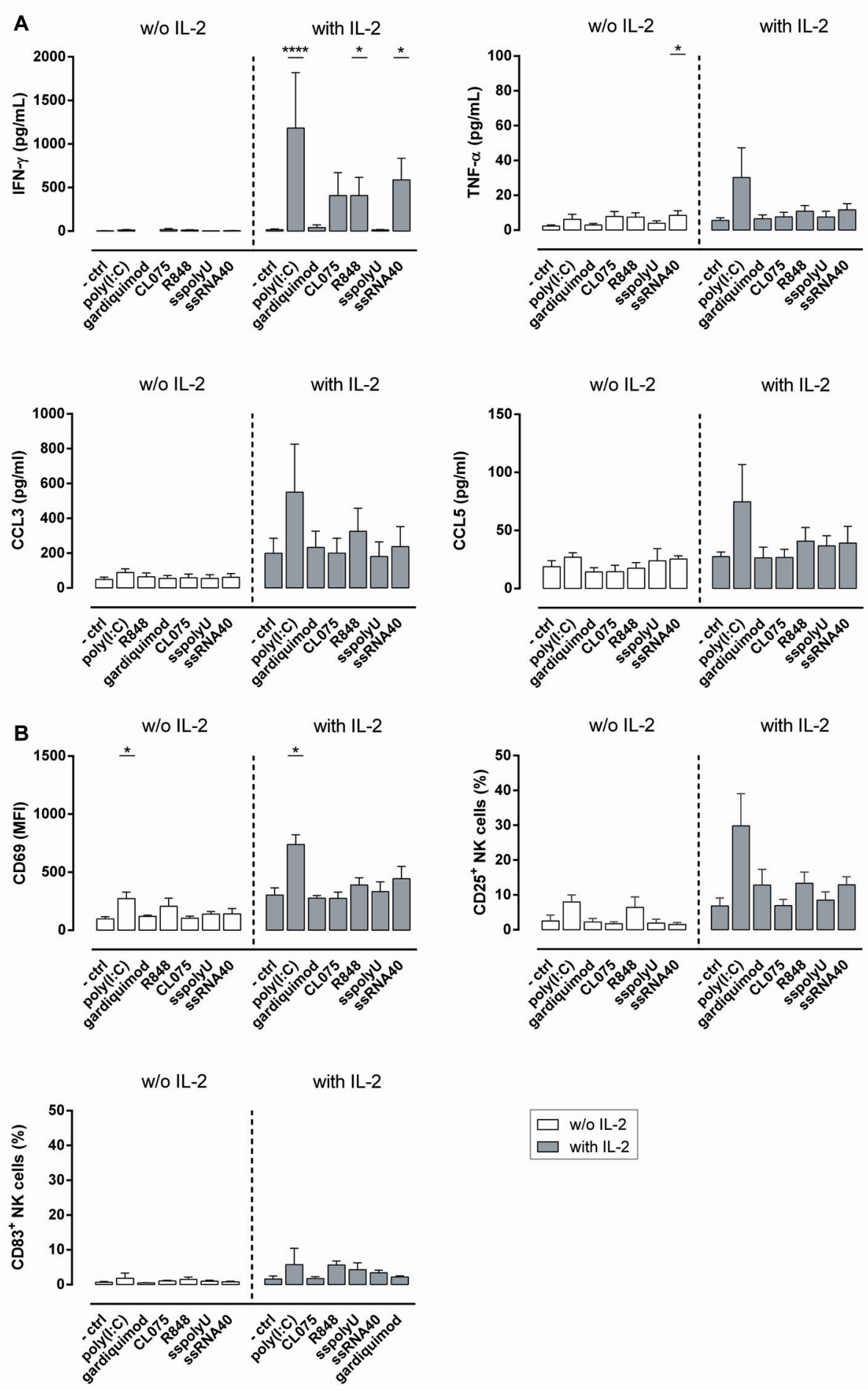
Figure 1 | Sensing of viral PAMP triggers NK cell activation and cytokine secretion. NK cells were activated overnight in round-bottom 96 -well plates $\left(2.5 \times 10^{5}\right.$ cells/well $)$ with viral PAMPs in the absence (white bars) or presence (grey bars) of IL-2 in serum-free medium. As a negative control NK cells were incubated with medium alone. (A) After 16-18h of incubation and IFN- $\gamma$, TNF- $\alpha$, CCL 3 and CCL5 were determined in the culture supernatant by CBA. (B) After 16-18h of incubation cells were harvested and stained for CD69, CD25 and CD83. Expression of these markers was analysed by flow cytometry. All data are presented as mean + SEM and are representative of at least 4 independent experiments. KruskalWallis test significance as compared to negative control with and without IL-2, respectively. ${ }^{*} P \leq 0.05$, ${ }^{* * * * *} P \leq 0.0001$

\section{Bacterial PAMP recognition by NK cells induces activation in the presence of IL-2}

In addition to viral PRR, NK cells are also equipped with TLR sensing bacterial PAMPs. Therefore, we investigated whether bacterial triggers activate and induce cytokine production by NK cells. We incubated NK cells with various bacterial PAMPs triggering diverse TLR: Pam3CSK4 (TLR1/2), HKLM (TLR2), FSL-1 (TLR2/6), LPS (TLR4), flagellin (TLR5), and FMKp (a lysate containing membrane fragments of Klebsiella pneumoniae, triggering multiple PRR). In the absence of IL-2, only FMKp-activated NK cells showed significant increased IFN- $\gamma$ secretion levels as compared to control. This was even further increased in the presence of IL-2 (Figure 2A). In the presence of IL-2, also all other bacterial PAMPs induced superior IFN- $\gamma$ secretion levels as compared to the control. Overall, the TNF- $\alpha$ secretion was low; HKLM and FMKp-triggered NK cells showed the highest secretion in absence of IL-2. TNF- $\alpha$ secretion was enhanced in the presence of IL-2 for all the triggers, except for HKLM. Moreover, bacterial TLR-triggering induced NK cell-derived chemokine production CCL3 and CCL5 in all the conditions. The addition of IL-2 did not substantially enhance the production of CCL5 (Figure 2A). In addition, we analysed surface marker expression of the differently activated NK cells. Cell surface markers were increased by all bacterial PAMPs in the presence of IL-2 as compared to the control. FMKp-activated NK cells showed the highest expression of the activation marker CD69 and an increased $\mathrm{CD}_{25}{ }^{+}$and $\mathrm{CD}_{8} 3^{+}$subpopulation in absence or presence of IL-2 (Figure 2B). FSL-1 in presence or absence of IL-2 induced as well a high percentage of $\mathrm{CD} 25^{+}$and $\mathrm{CD} 83^{+} \mathrm{NK}$ cells, comparable to FMKp-activated NK cells.

Thus, NK cells are able to respond to different bacterial triggers, which requires similarly as for viral stimuli an additional pro-inflammatory environment for efficient sensing by NK cells.

\section{PAMP-activated NK cells provide help for DC maturation}

We showed that NK cells get activated by both viral and bacterial PAMPs triggering diverse TLR in the presence of IL-2. Next, we studied whether these PAMP-activated NK cells 

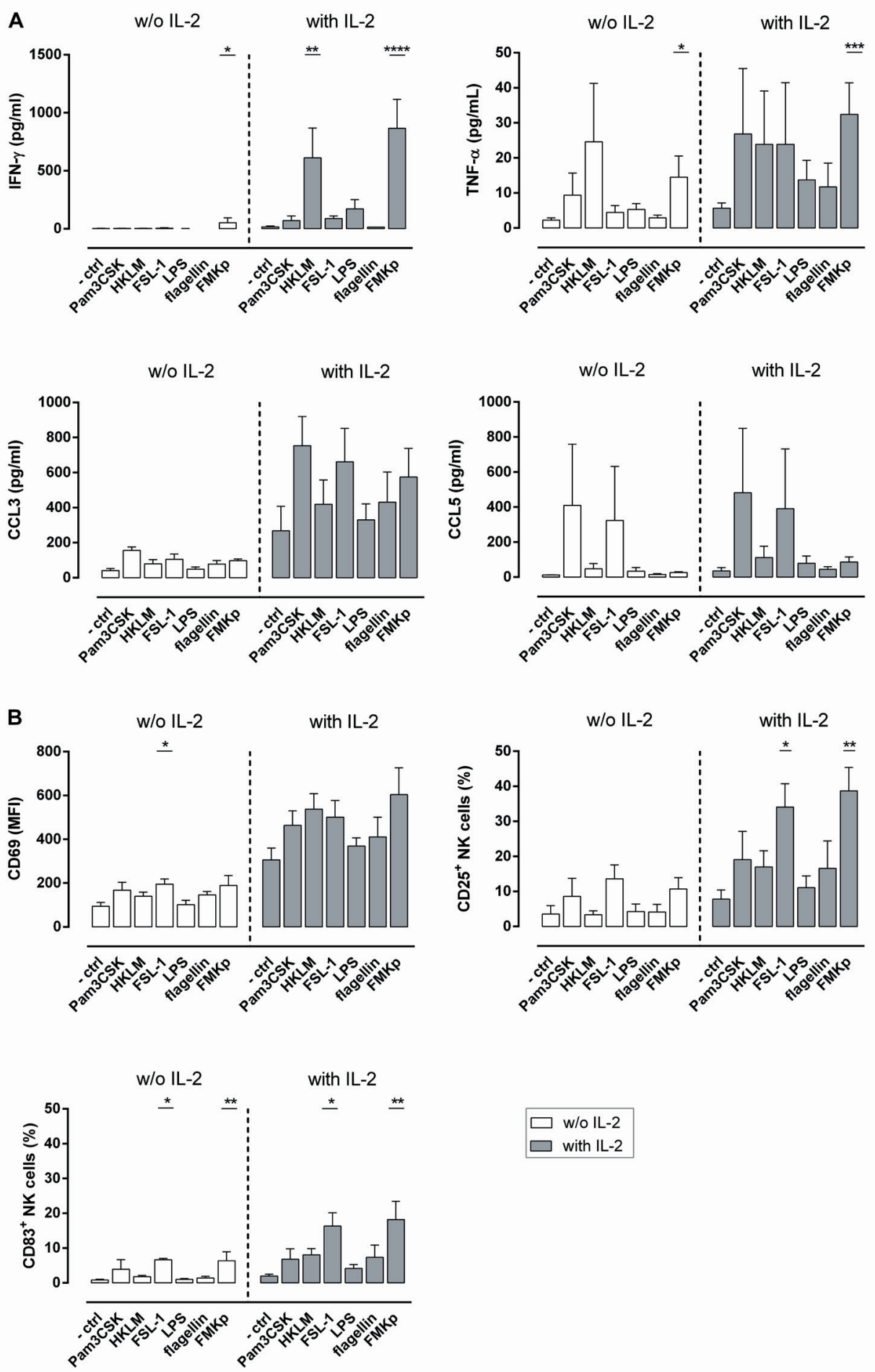
Figure 2 | Sensing of bacterial PAMP triggers NK cell activation and cytokine secretion. NK cells $\left(2.5 \times 10^{5}\right.$ cells/well) were activated overnight in round-bottom 96 -well plates with various bacterial PAMPs in the absence (white bars) or presence (grey bars) of IL-2 in serum-free medium. As a negative control NK cells were incubated with medium alone. (A) After 16-18h of incubation and IFN- $\gamma$, TNF- $\alpha$, CCL3 and CCL5 were determined in the culture supernatant by CBA. (B) After 16-18h of incubation cells were harvested and stained for CD69, CD25 and CD83. Expression of these markers was analysed by flow cytometry. All data are presented as mean + SEM and are representative of at least 4 independent experiments. Kruskal-Wallis test significance as compared to negative control with and without IL-2, respectively. ${ }^{*} P \leq 0.05,{ }^{* *} P \leq 0.01,{ }^{* * *} P \leq 0.001,{ }^{* * * *} P \leq 0.0001$.

can modulate immune responses by providing help for DC maturation. To this end, we investigated whether $\mathrm{NK}$-cell derived soluble factors are facilitating DC pro-inflammatory cytokine responses. iDC were matured in the absence or presence of NK cell-conditioned medium derived from NK cells activated with various PAMPs in the presence of IL-2.

In a previous study, we showed that DC-derived IL-12p70 production positively correlates with their capacity to activate NK cells and to induce Th1 responses ${ }^{38}$ and thus playing a crucial role in coordinating potent type 1 immune responses. Therefore, we first analysed the capacity of NK cells to enhance DC-derived IL-12 production. DC matured with the viral TLR3 and 7/8 triggers displayed enhanced IL-12p70 production in the presence of NK cell supernatant. A marginal effect was observed with TLR7 triggers gardiquimod (Figure 3A) and imiquimod (data not shown). Notably, only after stimulation with one of the two TLR8 triggers, ssRNA40, the DC-derived IL-12p70 production was enhanced in the presence of NK cell-conditioned medium. DC matured in the presence of conditioned medium derived from bacterial PAMP-triggered NK cells displayed all an enhanced capacity to produce IL-12p70 as compared to DC matured with the respective PAMPs alone; the highest increase was observed with FMKp (Figure 3A).

We further analysed the capacity of DC to produce IL-1 $\beta$ (Figure $3 \mathbf{B}$ ). The production was enhanced for both viral TLR7/8 triggers, CL075 and R848, and ssRNA40 in the presence of NK cell-derived supernatant. The secretion of IL-1 $\beta$ was enhanced in all the conditions for the bacterial PAMPs, however, the production levels were low compared to FMKp (Figure 3B). The secretion of IL-6 was enhanced in all conditions in the presence of NK cell conditioned medium (Figure 3C). The IL-10-producing capacity of DC was not influenced by the presence of NK cell-conditioned medium (data not shown).

We next determined the secretion of the chemokine CCL5 and of the two CD ${ }^{+} \mathrm{T}$ cellrecruiting chemokines CXCL9 and CXCL10. In the absence of NK cell-derived cytokines, FMKp, LPS, flagellin and poly(I:C) did induce CCL5 secretion (Figure 4A). The production of CCL5 was enhanced for all viral triggers in the presence of NK cell supernatant except poly (I:C) and for the bacterial triggers HKLM, LPS, and FMKp. Both virally and bacterially activated NK cell supernatants enhanced the capacity of DC to produce CXCL9 and 
CXCL10 (Figure 4 B, C). In the absence of NK cell supernatant only some of the viral triggers (poly(I:C), ssPolyU, and ssRNA40) directly induced CXCL10 production by DC (Figure 4C).

viral PAMPs

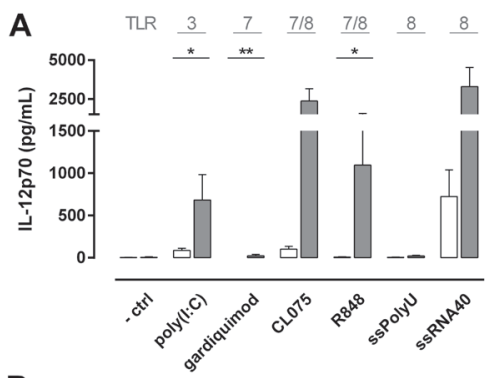

B

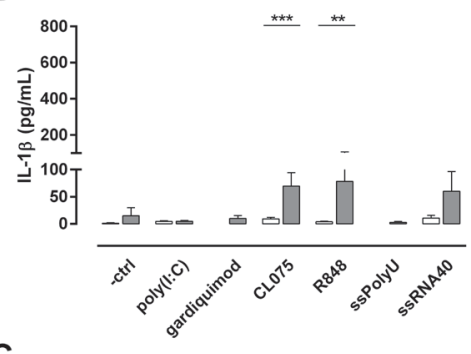

C

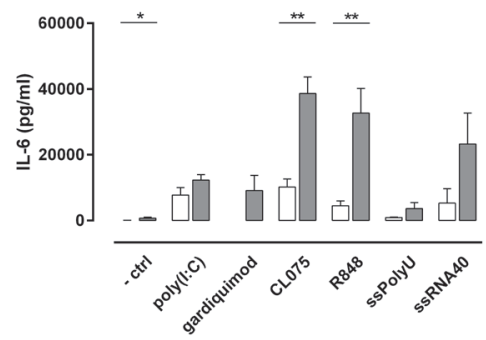

bacterial PAMPs
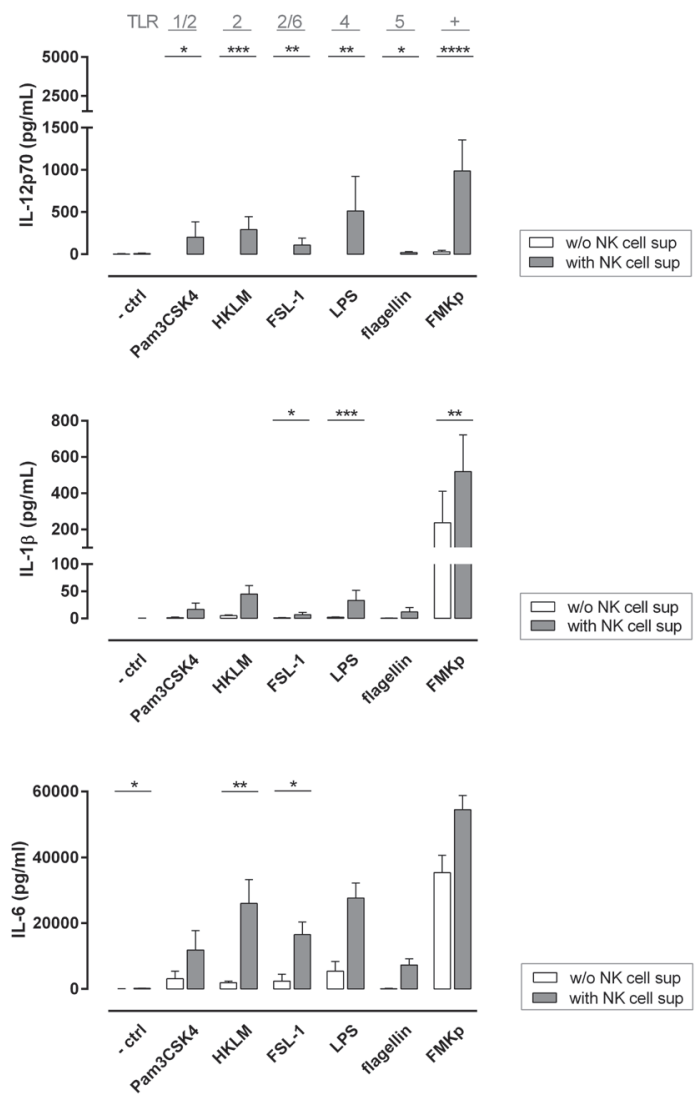

Figure 3 | Soluble factors derived from viral and bacterial-triggered NK cells help to increase the pro-inflammatory cytokine profile of DC. NK cells $\left(2.5 \times 10^{5}\right.$ cells/well $)$ were activated overnight in round-bottom 96-well plates with various viral and bacterial PAMPs (indicated on $x$-axis) in the presence of IL-2. As control viral and bacterial PAMPs were stored overnight in the incubator without the presence of NK cells. iDC were matured in these cell-free NK cell-derived supernatants (grey bars) or control supernatants (white bars) supplemented with IL-4 (500U/ml) and GM-CSF (500U/ml). After 48h, DC-derived cytokines were determined in the culture supernatant by CBA (A) IL-12p70 production. Mean + SEM of $n \geq 9$ independent experiments is shown. (B) IL-1 $\beta$ production. Mean + SEM of $n \geq 7$ independent experiments is shown. (C) IL-6 production. Mean + SEM of $n \geq 3$ independent experiments is shown. Mann-Whitney $\mathrm{U}$ test comparing absence and presence of NK cell-derived supernatant (white vs. grey bars). ${ }^{*} P \leq 0.05,{ }^{* *} P \leq 0.01,{ }^{* * *} P \leq 0.001,{ }^{* * * *} P \leq 0.0001$. 
viral PAMPs

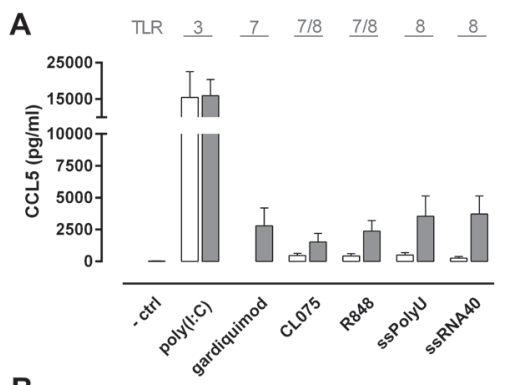

B

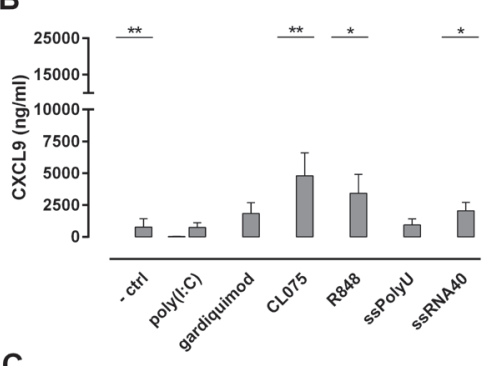

C

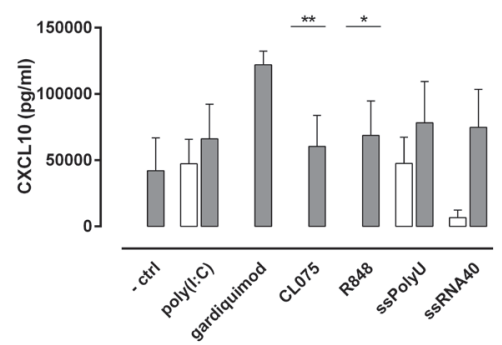

bacterial PAMPs
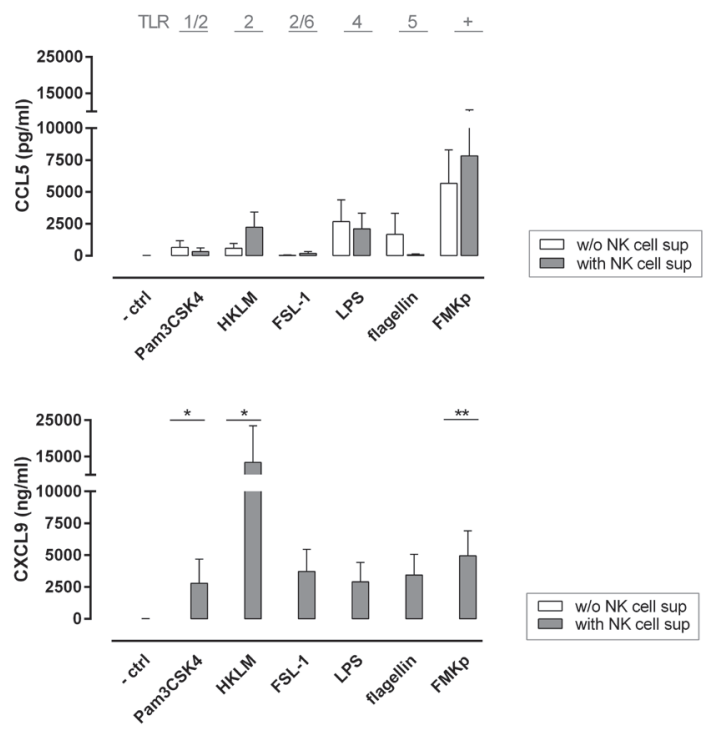

$\square$ w/o NK cell sup with NK cell sup

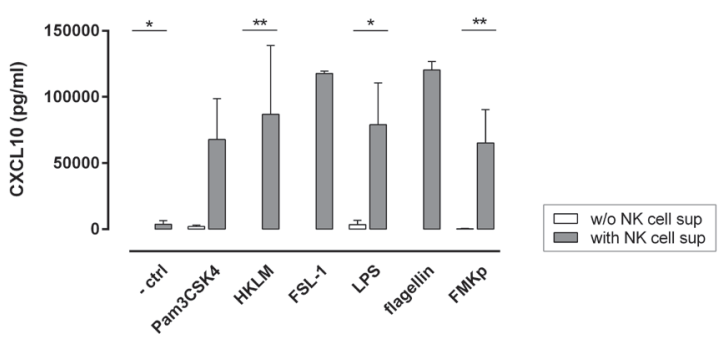

Figure 4 | Soluble factors derived from viral and bacterial-triggered NK cells help to increase the pro-inflammatory chemokine profile of DC. NK cells $\left(2.5 \times 10^{5}\right.$ cells/well $)$ were activated overnight in round-bottom 96-well plates with various viral and bacterial PAMPs (indicated on $x$-axis) in the presence of IL-2. As control, viral and bacterial PAMPs were stored overnight in the incubator without the presence of NK cells. iDC were matured in these cell-free NK cell-derived supernatants (grey bars) or control supernatants (white bars) supplemented with IL-4 (500U/ml) and GM-CSF (500U/ml). After 48h, DC-derived chemokines were determined in the culture supernatant by CBA. (A) CCL5 production. (B) CXCL9 production. (C) CXCL10 production. Mean + SEM of $\mathrm{n} \geq 3$ independent experiments is shown. Mann-Whitney U test comparing absence and presence of NK cell-derived supernatant (white vs. grey bars). ${ }^{*} P \leq 0.05,{ }^{* *} P \leq 0.01$.

The potency of the NK cell accessory effect after pathogen-sensing is determined by the cytokine milieu

It is well established that the activation of NK cells is influenced by the local cytokine 
environment ${ }^{5,21,39}$. We studied whether the cytokine milieu in which NK cells recognize the different PAMPs would also enhance the capacity of NK cells to amplify the pro-inflammatory cytokine profile of DC. We studied the effect of cytokine environment with a bacterial trigger. To this end, we activated NK cells in the presence of FMKp and different combinations of cytokine cocktails, previously shown to be efficient inducers of NK cell activation on their own ${ }^{21,40,41}$.

The DC-derived secretion of IL-12p70 was enhanced by the cytokine milieu in which NK cells encountered FMKp; in presence of IL-2 and IL-18 the secretion of IL-12p70 was significantly increased compared with control in the presence of NK cell-conditioned medium. This was even further increased when NK cells encountered FMKp in the presence of IL-12, IL-15, and IL-18. Additionally, also the production of IL12-p40 and the T cell-attracting chemokines CXCL9 and CXCL10 was enhanced in the presence of NK cell-conditioned medium. No additive effect was observed for the secretion of IL-6 and CCL5 (Figure 5). It should be noted, that as seen in Figure 3C and 4A, FMKp-matured DC secreted IL-6 and CCL5 in the absence of NK cell-conditioned medium and cytokines, and this did not further increase with NK cell help.

\section{Accessory help for DC maturation of PAMP-activated NK cells is not confined to the recognition of the same microbial trigger}

We showed that NK cells are able to amplify DC maturation against the same encountered PAMP via the release of soluble factors. Next, we studied whether soluble factors derived from bacterial or viral PAMP-activated NK cells have the capacity to enhance the maturation of DC which encountered a different pathogen. For this purpose, we activated NK cells in the presence of IL-2 and various PAMPs and washed the triggers away after 4h. NK cells were incubated for an additional 12h, allowing cytokine and chemokine production. iDC were matured with the bacterial trigger FMKp in the presence of the different washed NK cell-derived supernatants. IL-12p70 production by DC is depicted in Figure 6A. Not only soluble factors derived from NK cells activated by FMKp did enhance IL-12p70 production, but also NK cells activated by LPS, another bacterial trigger, as well as viral PAMP-activated NK cells. The latter differed in their capacities to induce IL-12p70 production with poly(I:C) showing best response followed by R848, CL075, and gardiquimod-activated NK cells.

\section{IFN- $\gamma$-mediated NK cell help for enhanced DC cytokine and chemokine secretion}

Next, we wanted to identify which common soluble factors are responsible for the mediated help. Therefore, we first correlated the amount of pro-inflammatory cytokine IFN- $\gamma$ produced by the differently activated NK cells with their respective DC-derived IL-12p70 

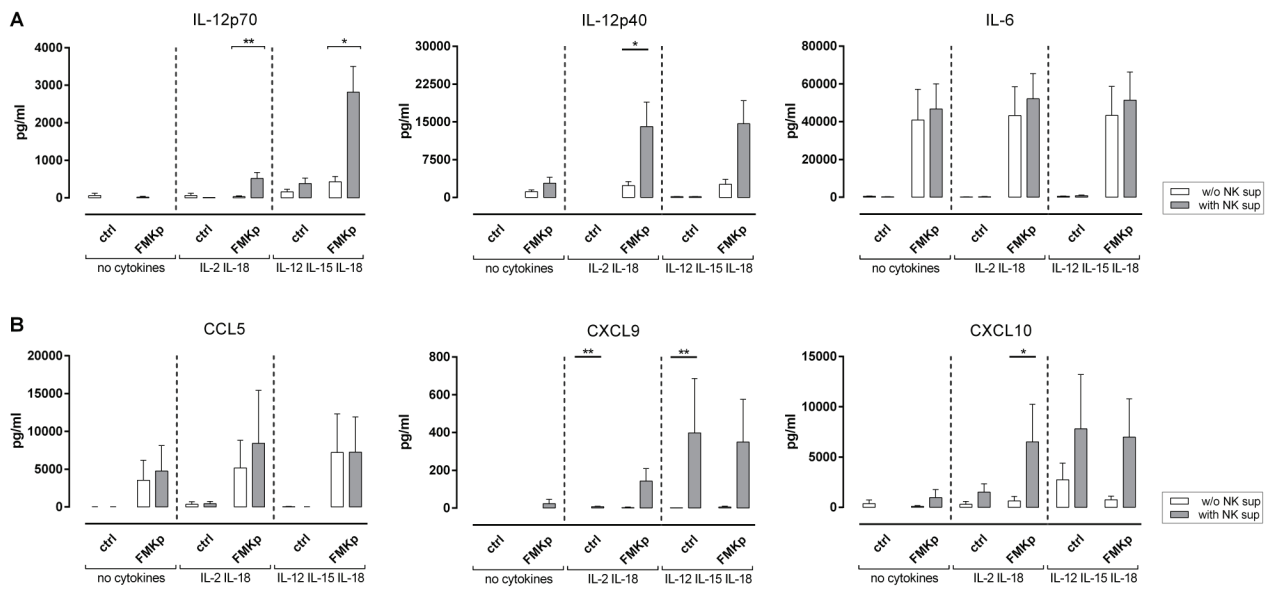

Figure 5 | Influence of cytokine milieu. NK cells were activated overnight in serum-free medium in the absence or presence of FMKp with or without different cytokine combinations (no cytokines; IL-2/IL18; IL-12/IL-15/IL-18). iDC were matured in presence or absence of these NK cell-derived supernatants for $48 \mathrm{~h}$. DC-derived cytokine and chemokine secretion was determined in cell-free supernatants by CBA. (A) Cytokine profile. (B) Chemokine profile. Data are shown as mean + SEM of $n \geq 4$ independent experiments. Mann-Whitney $\mathrm{U}$ test comparing absence and presence of $\mathrm{NK}$ cell-derived supernatant (white vs. grey bars). ${ }^{*} P \leq 0.05,{ }^{* *} P \leq 0.01$.

levels and showed a significant positive correlation (Figure 6B). Furthermore, besides IFN- $\gamma$ also TNF- $\alpha$ has been described as a factor involved in DC maturation ${ }^{42}$. By correlating the secretion of NK cell-derived IFN- $\gamma$ and $\mathrm{TNF}-\alpha$, we observed that the secretion of TNF- $\alpha$ and IFN- $\gamma$ was regulated in parallel (Figure 6B). To elucidate whether both NK-derived IFN- $\gamma$ and TNF- $\alpha$ play a role in the mediated effect on DC maturation, we performed supplementation studies with rhIFN- $\gamma$ and rhTNF- $\alpha$. The addition of increasing doses of IFN- $\gamma$ to iDC in the presence of FMKp led to increased production of IL-12p70, IL-12p40, CXCL9 and CXCL10 by DC (Figure 6C). In contrast, the effect of supplementation on IL-6, IL-1 $\beta$ and CCL5 production was marginal. The secretion of the anti-inflammatory cytokine IL-10 was not influenced (data not shown). Furthermore, the supplementation of IFN- $\gamma$ to poly(I:C)-matured DC showed similar results as FMKp-matured DC (Figure S1). However, no effect was observed by supplementing rhTNF- $\alpha$ during DC maturation (Figure S2).

To confirm these findings, we performed blocking studies. The supernatant of FMKp and IL-2-activated NK cells was added to iDC in the absence or presence of anti-IFN- $\gamma$ or anti-TNF- $\alpha$ or presence of receptor blockers (anti-IFNGR1, anti-TNFR1, or anti-TNFR2). Blocking of IFN- $\boldsymbol{\gamma}$ by either capturing IFN- $\boldsymbol{\gamma}$ in the supernatant or IFNGR1 on the surface of iDC dramatically reduced the capacity of DC to produce IL-12p70 (remaining capacity by blocking with anti-IFN- $\gamma: 1.67 \% \pm 1.11)$, IL-12p40 (5.79\% \pm 2.09$)$, CXCL9 $(0.09 \% \pm$ 
A
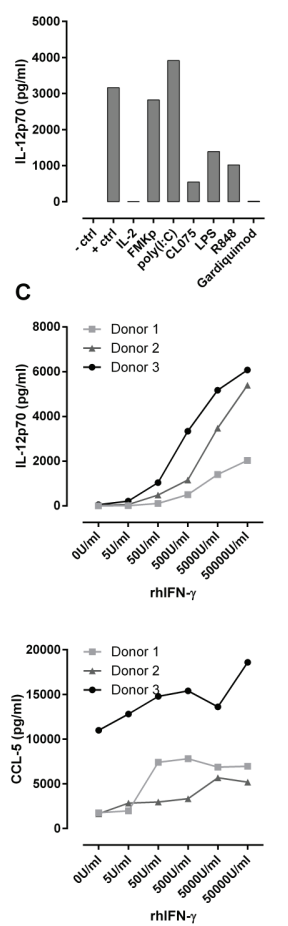

D
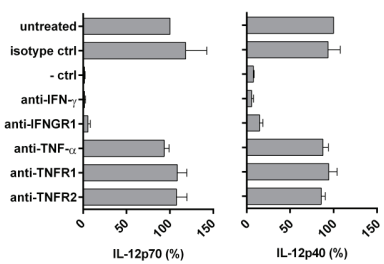

B
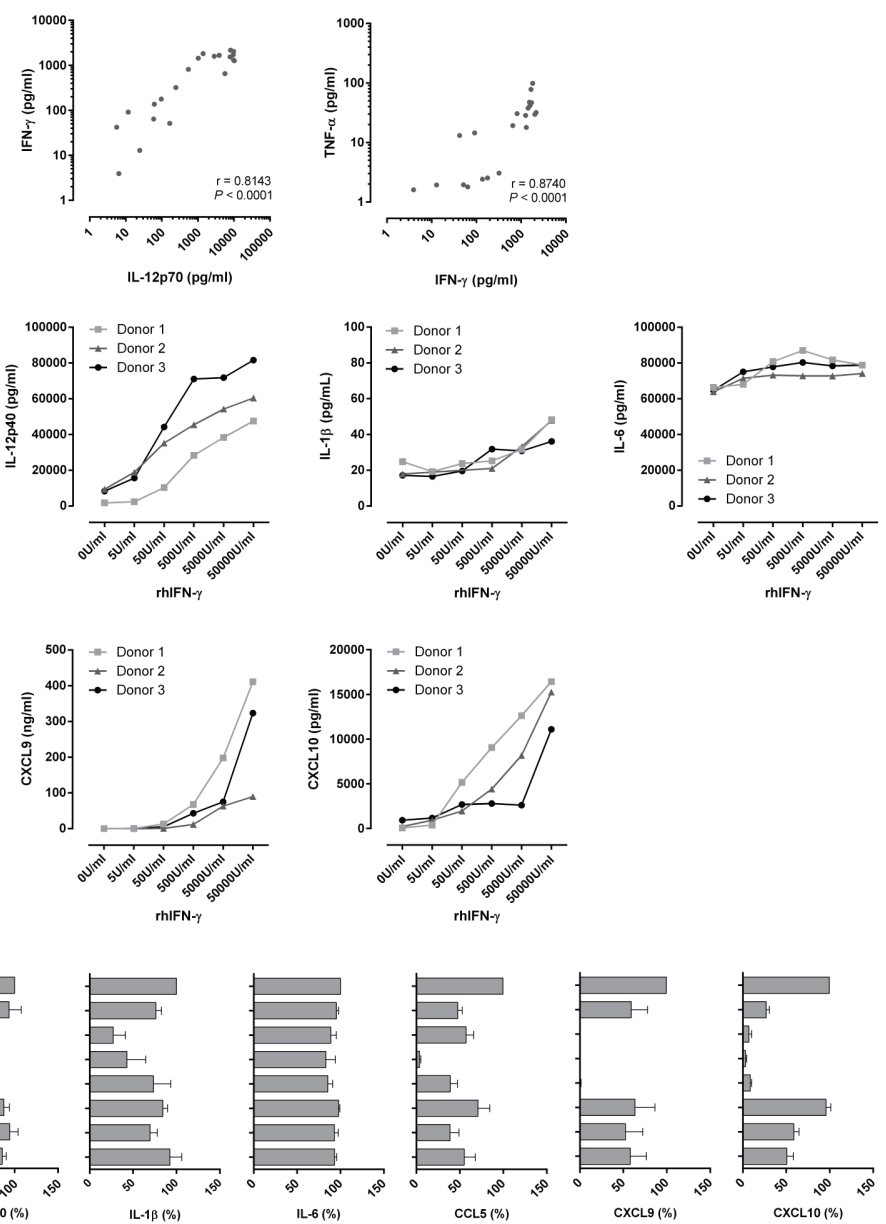

Figure 6 | NK cell-derived IFN- $\gamma$ but not TNF- $\alpha$ is necessary to modulate the pro-inflammatory cytokine profile of DC. (A) IL-12p70 secretion by FMKp-matured DC in the presence of differently activated NK cell-derived supernatants. iDC were matured in a flat-bottom 96-well plate $\left(2.5 \times 10^{5} /\right.$ well $)$ with washed NK cell-derived supernatant supplemented with FMKp, IL-4 (500U/ml), and GM-CSF $(500 \mathrm{U} / \mathrm{ml})$. Washed NK cell-derived supernatant was generated by activating NK cells with various PAMPs (indicated on $x$-axis). After $4 \mathrm{~h}$ of activation NK cells were extensively washed and activated for a total of 16-18h before harvesting of the supernatant. As a negative control iDC were incubated without any NK cell supernatant and as positive control iDC were matured in the presence of FMKp, IL-4, GM-CSF and rhIFN- $\gamma(500 \mathrm{U} / \mathrm{ml})$. After $48 \mathrm{~h}$ of maturation, the DC culture supernatant was harvested and IL-12p70 was quantified by CBA. Representative graph out of 3 independent experiments is shown. (B) Correlation between NK cell-derived IFN- $\gamma$, respectively, TNF- $\alpha$ secretion (washed after $4 \mathrm{~h}$ ) and the corresponding DC-derived IL-12p70. Dots represent IFN- $\gamma$ and TNF- $\alpha$ values of NK cells activated by various PAMPs ( $x$-axis panel A) and their corresponding DC-derived IL-12p70 values of 3 independent combined experiments. (C) Supplementation of rhIFN- $\gamma$ during DC maturation and its effect on cytokine and chemokine secretion is shown. iDC were matured in serum-free medium supplemented with FMKp, IL-4 and GM-CSF in the presence of increasing concentrations of rhIFN- $\gamma$. Cytokine and chemokine profiles were determined in the culture supernatants after $48 \mathrm{~h}$ of maturation by CBA. The individual donors are shown. (D) Blocking of IFN- $\gamma$ and TNF- $\alpha$ during DC maturation and its effect on cytokine 
and chemokine secretion is shown. iDC were matured in the cell-free supernatant derived from FMKpactivated NK cells in the presence of IL-2. As indicated on the $y$-axis various blocking antibodies were added: anti-IFN- $\gamma$, anti-IFNGR1, anti-TNF- $\alpha$, anti-TNFR1, and anti-TNFR2. iDC matured with NK cell-derived supernatant in the absence of blocking antibodies (untreated) were used as reference value and set at $100 \%$ capacity to produce a cytokine/chemokine ( $x$-axis). The negative control represents the capacity of DC to produce the indicated cytokine upon maturation with FMKp in absence of NK cell-derived supernatant. Mean + SEM of 3 independent experiments is shown.

$0.07)$ and CXCL10 $(3.12 \% \pm 1.39)$ as compared to untreated DC matured in the presence of NK cell-conditioned medium (Figure 6D). In line with the supplementation of rhIFN- $\gamma$, marginal or no effect was observed on the capacities of DC to secrete IL-1 $\beta$, IL-6 and CCL5. Furthermore, blocking of TNF- $\alpha$ did not influence the cytokine secretion by DC. The same effect was observed for DC which have been matured in the presence of poly(I:C)-activated NK cell-derived supernatant and blocking antibodies (data not shown).

\section{DISCUSSION}

In the current study, we set out to investigate whether the direct sensing of viral and bacterial pathogens would not only increase their cytotoxic potential as previously shown ${ }^{22,29-31}$, but also induce helper responses for DC maturation. We identified several viral and bacterial PAMPs able to induce functional activation of NK cells (TLR1/2, TLR2, TLR2/6, TLR3, TLR4, TLR7/8, and TLR8 triggers) with respect to pro-inflammatory cytokine secretion (IFN- $\gamma$, TNF- $\alpha$, CCL3, CCL5) and upregulation of activation markers (CD69, CD25, CD83). We demonstrated that NK cells only showed limited responses towards TLR7 triggers imiquimod and gardiquimod. The soluble factors released by these PAMP-triggered NK cells amplified the pro-inflammatory cytokine response of moDC. This amplification of DC responsiveness was dependent on the local cytokine environment in which the NK cells encountered the pathogen. Moreover, we demonstrated that NK cells mediated this helper activity via the release of IFN- $\gamma$.

Previously, a study of Wong et al. ${ }^{34}$ addressed the effect of poly(I:C) on DC maturation during NK-DC co-culture. Here, we were interested in studying the contribution of TLR-triggered NK cells on DC maturation, rather than studying the effect of TLR triggers on NK-DC crosstalk. We revealed that the helper activity of both viral- and bacterialtriggered NK cells on DC cytokine production, namely IL-12p70, IL-12p40, CXCL9, and CXCL10 was dependent on IFN- $\gamma$ and not on TNF- $\alpha$. The secretion of IL-6, IL-1 $\beta$ and CCL5 was independent of both cytokines. Previous studies postulated the importance of TNF- $\alpha$ for DC maturation. Vitale et al. ${ }^{42}$ showed that TNF- $\alpha$ was necessary for the upregulation of CD83 on DC in a cell-cell contact-dependent setup. However, in our study no positive effect of TNF- $\alpha$ was associated with the enhanced pro-inflammatory cytokine 
profile of DC. An inhibitory role of $\mathrm{TNF}-\alpha$ on IL-12p70 production has previously been shown for mouse macrophages ${ }^{43}$. It seems that TNF- $\alpha$ has a role in upregulating phenotype markers during DC maturation, but that IFN- $\gamma$ is an essential factor controlling the pro-inflammatory cytokine release, mainly IL-12p70. Further studies are needed to reveal whether in a cell-cell contact-dependent setting, the helper activity of NK cells is solely dependent on IFN- $\gamma$. The engagement of TLR by NK cells and accessory cells can be accompanied by expression changes, such as the upregulation of activating receptors and ligands ${ }^{44}$, which could additionally boost NK cell responses in a contact-dependent manner.

Moreover, the influence of the cytokine milieu on the strength of PRR-induced NK cell activation and the resulting helper properties suggest that the coordinated immune response induced by a particular pathogen can be influenced by all PRR-expressing immune cells. As such, an accessory cell can be triggered by a specific PAMP to release a defined set of pro-inflammatory cytokines. In turn, these cytokines, e.g. IL-12, lead to an enhanced PAMP recognition by NK cells and their activation. Activated NK cells control the immune response by direct killing of infected cells, Treg or by DC editing as well as providing cytokines and chemokines. TLR-activated NK cells are able to secrete CCL3, CCL4 and CCL5 to recruit iDC ${ }^{33}$ as well as IFN- $\gamma$ by which the DC maturation and Th1 polarization are further enhanced. Furthermore, those NK cells induce CXCL10 and CXCL9-producing $\mathrm{CD}^{+} \mathrm{T}$ effector cell-recruiting DC, which has been previously only observed with IL-18 primed NK cells ${ }^{33}$. The specific response against a pathogenic insult has thus different checkpoints, which act as regulators or amplifiers. We and others ${ }^{22,}{ }^{27}$ have shown that the recognition of individual TLR by NK cells as well as the subsequent NK cell helper activity mostly requires the presence of accessory cytokines. Thus, we propose that the direct sensing of pathogens by NK cells functions as an amplifier of the initiated immune responses, rather than initiator of pathogen-specific immune responses. The accessory cells determine the local cytokine milieu and thus regulate the strength of NK cell activation and subsequently the kinetics of the NK helper cell-mediated augmentation of immune responses.

The presence of accessory cytokines was of crucial importance for an optimal sensing of both bacterial and viral PAMPs and induction of NK helper cell properties. Here we show that the addition of IL-2, the combination of IL-18 and IL-2, or IL-12, IL-15 and IL-18 influence the activation of NK cells and their helper activities, which were marginal in the absence of these cytokines. NK cells briefly pre-activated by this combination of cytokines (IL-12, IL-15 and IL-18) were previously shown to have a sustained effector function in tumour mouse models and an enhanced proliferative capacity as well as increased IFN- $\gamma$ response over time in human in vitro studies ${ }^{40,41}$. We show that by adding FMKp, the helper capacity of these NK cells to induce DC maturation can be further improved (up to 12-fold 
increase in IL-12p70 secretion).

We previously showed that DC-derived IL-12p70 was positively correlated with the capacity of DC to induce Th1 responses and activate IFN- $\gamma$-producing NK helper cells ${ }^{38}$. $\mathrm{NK}$ cell-derived IFN- $\gamma$ production induced by DC-derived soluble factors was dependent on IL-12p70 ${ }^{20}$. Here, we showed that IFN- $\gamma$-producing $\mathrm{NK}$ helper cells can also be generated in the presence of a TLR trigger and an accessory cell-derived cytokine, e.g. IL-2. This offers the possibility that cell-independent NK helper cell activation in vivo may occur via two different mechanisms, one being dependent on two signals of which IL-12 is indispensable in the presence of only soluble factors and the other independent of IL-12 in the presence of pathogenic triggers.

Among the different viral triggers tested in this study, poly(I:C) (TLR3 trigger), R848 and CL075 (both TLR7 / 8 triggers) activated NK cells most efficiently including the induction of helper properties. Previous studies showed that sensing of these triggers stimulated cytolytic capacities ${ }^{22,31}$. Thus, sensing of these PAMPs potentially induces both the helper and killer capacities of NK cells. Nonetheless, the extent of the induction of both programmes may be dependent on the local cytokine environment in vivo. Notably, whereas both TLR7/8 triggers induce NK helper properties, this effect was only observed for one of the two TLR 8 triggers and for none of the TLR7 triggers. Even though, ssPolyU and ssRNA both induced NK cell activation to a similar extent (activation marker upregulation and chemokine secretion), ssPolyU failed at inducing IFN- $\gamma$ production explaining the differences observed in providing help for DC-induced cytokine production. Activating human NK cells with imiquimod has previously been shown to enhance cytotoxicity of NK cells, but not IFN- $\gamma$ secretion ${ }^{25}$. Furthermore, another study showed that both gardiquimod and imiquimod could enhance NK cell proliferation as well as cytotoxicity in mice ${ }^{45}$. Yet another study observed enhanced IFN- $\gamma$ secretion after activation of NK cells with the TLR7 trigger loxoribine ${ }^{29}$. Different from gardiquimod and imiquimod, which are both imidazoquinoline compounds, loxorobine is a guanosine analogue. Arguably, depending on the choice of compound to trigger TLR7, the NK helper programme will or will not get induced.

Previously, we showed indirect activation of NK cells via DC that were matured in the presence of bacterial pathogens ${ }^{20}$. The current study confirms the findings of other groups that NK cells have the capacity to directly respond to bacterial pathogens. In addition to these studies, we showed that the direct sensing of bacterial pathogens by NK cells also enhances NK cell-mediated help for DC maturation and is not only limited to the induction of their cytotoxic capacity. All the bacterial PAMP-triggered NK cells enhanced DC-derived IL-12 production. Possibly, the helper function may be a more important mechanism in response against bacterial pathogens than cytotoxic function. The strongest response 
against bacterial PAMPs was induced by FMKp. In a previous study, we observed IL-18 production by FMKp-matured DC ${ }^{20}$. Together with the highest IL-1 $\beta$ production detected in the current study, this suggests the involvement of inflammasome activation. Hence, a stronger response may be linked to simultaneous engagement of multiple PRR, as the bacterial lysate FMKp possibly triggers a range of different PRR. Arguably, autonomous activation of NK cells by PRR occurs more easily upon multiple receptor stimulation as e.g. shown for HCMV infection or tuberculosis ${ }^{46,47}$.

Notably, we observed a large donor variation in response to the different triggers. Whereas some donors produced very high amounts of IFN- $\gamma$ after poly(I:C) stimulation, other donors hardly showed response. This is in line with previous work by our group revealing a large donor variation of DC against a particular PRR trigger ${ }^{38}$. Even though PRR are evolutionary conserved receptors, their expression levels vary substantially between different donors. Sivori et al. ${ }^{48}$ and Marcenaro et al. ${ }^{23}$ described varied expression levels of TLR3, respectively TLR2, on NK cells from different individuals being a possible explanation between the heterogeneous responses observed. At this point it remains to be established whether or not other immune cell subsets of these donors compensate for the low expression levels on NK cells, e.g. increased expression of TLR3 by DC.

Taken together these data show that NK cells, besides their crucial role in host defence for the elimination of virally infected or malignantly transformed self-cells, also serve an important role in the amplification of adaptive immune responses. In the current study, we demonstrated that NK cells can sense viral as well as bacterial PAMPs, which is enhanced in the presence of cytokines from accessory cells. TLR-induced NK helper cells can augment the pro-inflammatory phenotype of DC via the production of IFN- $\gamma$. The magnitude of this amplification depends on the dose of NK cell-derived IFN- $\gamma$ and this dose is determined by the triggered PRR, the choice of ligand for a particular PRR, and the cytokine environment in which the NK cell recognizes the microbial pattern. This illustrates once more the importance of TLR network and how the invasion of pathogens regulates a specific tailored immune response. Moreover, this knowledge can be of importance to generate more potent and functional type 1-polarized cells in vitro and in vivo, e.g. for boosting vaccines. 


\section{ACKNOWLEDGEMENTS}

This work was supported by the 'Fonds National de la Recherche', Luxembourg (project 1039369; T.O.). The funders had no role in study design, data collection and analysis, decision to publish, or preparation of the manuscript.

\section{REFERENCES}

1. Oldham RK, Herberman RB. Evaluation of cell-mediated cytotoxic reactivity against tumor associated antigens with 125I-iododeoxyuridine labeled target cells. J Immunol. 1973;111(6):862-871.

2. Vivier E, Raulet DH, Moretta A, et al. Innate or adaptive immunity? The example of natural killer cells. Science. 2011;331(6013):44-49.

3. Vivier E, Tomasello E, Baratin M, Walzer T, Ugolini S. Functions of natural killer cells. Nat Immunol. 2008;9(5):503-510.

4. Lanier LL. Up on the tightrope: natural killer cell activation and inhibition. Nat Immunol. 2008;9(5):495-502.

5. Agaugue S, Marcenaro E, Ferranti B, Moretta L, Moretta A. Human natural killer cells exposed to IL2, IL-12, IL-18, or IL-4 differently modulate priming of naive T cells by monocyte-derived dendritic cells. Blood. 2008;112(5):1776-1783.

6. Biron CA, Nguyen KB, Pien GC, Cousens LP, Salazar-Mather TP. Natural killer cells in antiviral defense: function and regulation by innate cytokines. Annu Rev Immunol. 1999;17:189-220.

7. Welsh RM, Brubaker JO, Vargas-Cortes M, O’Donnell CL. Natural killer (NK) cell response to virus infections in mice with severe combined immunodeficiency. The stimulation of NK cells and the NK cell-dependent control of virus infections occur independently of T and B cell function. J Exp Med. 1991;173(5):1053-1063.

8. Biron CA, Byron KS, Sullivan JL. Severe herpesvirus infections in an adolescent without natural killer cells. N Engl J Med. 1989;320(26):1731-1735.

9. Orange JS. Human natural killer cell deficiencies and susceptibility to infection. Microbes Infect. 2002;4(15):1545-1558.

10. Orange JS. Human natural killer cell deficiencies. Curr Opin Allergy Clin Immunol. 2006;6(6):399409.

11. Orange JS, Ballas ZK. Natural killer cells in human health and disease. Clin Immunol. 2006;118(1):110.

12. Byrne P, McGuirk P, Todryk S, Mills KH. Depletion of NK cells results in disseminating lethal infection with Bordetella pertussis associated with a reduction of antigen-specific Th1 and enhancement of Th2, but not Tr1 cells. Eur J Immunol. 2004;34(9):2579-2588.

13. Sporri R, Joller N, Albers U, Hilbi H, Oxenius A. MyD88-dependent IFN-gamma production by NK cells is key for control of Legionella pneumophila infection. J Immunol. 2006;176(10):6162-6171.

14. Small CL, McCormick S, Gill N, et al. NK cells play a critical protective role in host defense against acute extracellular Staphylococcus aureus bacterial infection in the lung. J Immunol. 2008;180(8):55585568.

15. Trinchieri G, Sher A. Cooperation of Toll-like receptor signals in innate immune defence. Nat Rev Immunol. 2007;7(3):179-190.

16. Iwasaki A, Medzhitov R. Control of adaptive immunity by the innate immune system. Nat Immunol. 2015;16(4):343-353.

17. Lee HK, Iwasaki A. Innate control of adaptive immunity: dendritic cells and beyond. Semin Immunol. 
2007;19(1):48-55.

18. Borg C, Jalil A, Laderach D, et al. NK cell activation by dendritic cells (DCs) requires the formation of a synapse leading to IL-12 polarization in DCs. Blood. 2004;104(10):3267-3275.

19. Fernandez NC, Flament C, Crepineau F, Angevin E, Vivier E, Zitvogel L. Dendritic cells (DC) promote natural killer $(\mathrm{NK})$ cell functions: dynamics of the human $\mathrm{DC} / \mathrm{NK}$ cell cross talk. Eur Cytokine Netw. 2002;13(1):17-27.

20. Van Elssen CH, Vanderlocht J, Frings PW, et al. Klebsiella pneumoniae-triggered DC recruit human NK cells in a CCR5-dependent manner leading to increased CCL19-responsiveness and activation of NK cells. Eur J Immunol. 2010;40(11):3138-3149.

21. Mailliard RB, Alber SM, Shen H, et al. IL-18-induced CD83+CCR7+ NK helper cells. J Exp Med. 2005;202(7):941-953.

22. Hart OM, Athie-Morales V, O’Connor GM, Gardiner CM. TLR7/8-mediated activation of human NK cells results in accessory cell-dependent IFN-gamma production. J Immunol. 2005;175(3):16361642.

23. Marcenaro E, Ferranti B, Falco M, Moretta L, Moretta A. Human NK cells directly recognize Mycobacterium bovis via TLR2 and acquire the ability to kill monocyte-derived DC. Int Immunol. 2008;20(9):1155-1167.

24. Hornung V, Rothenfusser S, Britsch S, et al. Quantitative expression of toll-like receptor 1-10 mRNA in cellular subsets of human peripheral blood mononuclear cells and sensitivity to CpG oligodeoxynucleotides. J Immunol. 2002;168(9):4531-4537.

25. Gorski KS, Waller EL, Bjornton-Severson J, et al. Distinct indirect pathways govern human NK-cell activation by TLR-7 and TLR-8 agonists. Int Immunol. 2006;18(7):1115-1126.

26. Athie-Morales V, O'Connor GM, Gardiner CM. Activation of human NK cells by the bacterial pathogen-associated molecular pattern muramyl dipeptide. J Immunol. 2008;180(6):4082-4089.

27. Perrot I, Deauvieau F, Massacrier C, et al. TLR3 and Rig-like receptor on myeloid dendritic cells and Rig-like receptor on human NK cells are both mandatory for production of IFN-gamma in response to double-stranded RNA. J Immunol. 2010;185(4):2080-2088.

28. Duluc D, Tan F, Scotet M, et al. PolyI:C plus IL-2 or IL-12 induce IFN-gamma production by human NK cells via autocrine IFN-beta. Eur J Immunol. 2009;39(10):2877-2884.

29. Girart MV, Fuertes MB, Domaica CI, Rossi LE, Zwirner NW. Engagement of TLR3, TLR7, and NKG2D regulate IFN-gamma secretion but not NKG2D-mediated cytotoxicity by human NK cells stimulated with suboptimal doses of IL-12. J Immunol. 2007;179(6):3472-3479.

30. Sivori S, Carlomagno S, Moretta L, Moretta A. Comparison of different CpG oligodeoxynucleotide classes for their capability to stimulate human NK cells. Eur J Immunol. 2006;36(4):961-967.

31. Sivori S, Falco M, Della Chiesa M, et al. CpG and double-stranded RNA trigger human NK cells by Toll-like receptors: induction of cytokine release and cytotoxicity against tumors and dendritic cells. Proc Natl Acad Sci U S A. 2004;101(27):10116-10121.

32. Mailliard RB, Son YI, Redlinger R, et al. Dendritic cells mediate NK cell help for Th1 and CTL responses: two-signal requirement for the induction of $\mathrm{NK}$ cell helper function. J Immunol. 2003;171(5):2366-2373.

33. Wong JL, Berk E, Edwards RP, Kalinski P. IL-18-primed helper NK cells collaborate with dendritic cells to promote recruitment of effector CD8+ T cells to the tumor microenvironment. Cancer Res. 2013;73(15):4653-4662.

34. Wong JL, Mailliard RB, Moschos SJ, et al. Helper activity of natural killer cells during the dendritic cell-mediated induction of melanoma-specific cytotoxic T cells. J Immunother. 2011;34(3):270-278.

35. Oth T, Schnijderberg MC, Senden-Gijsbers BL, Germeraad WT, Bos GM, Vanderlocht J. Monitoring the initiation and kinetics of human dendritic cell-induced polarization of autologous naive CD4+ T cells. PLoS One. 2014;9(8):e103725.

36. Nieto M, Navarro F, Perez-Villar JJ, et al. Roles of chemokines and receptor polarization in NK-target cell interactions. J Immunol. 1998;161(7):3330-3339. 
37. Oliva A, Kinter AL, Vaccarezza M, et al. Natural killer cells from human immunodeficiency virus (HIV)-infected individuals are an important source of CC-chemokines and suppress HIV-1 entry and replication in vitro. J Clin Invest. 1998;102(1):223-231.

38. Oth T, Van Elssen, CHMJ., Schnijderberg, MCA., Senden-Gijsbers, BLMG., Germeraad, WTV., Bos, GMJ., Vanderlocht J. Potency of both human Th1 and NK helper cell activation is determined by IL-12p70-producing PAMP-matured DC. Journal of interferon and cytokine research. 2015; In press.

39. Marcenaro E, Della Chiesa M, Bellora F, et al. IL-12 or IL-4 prime human NK cells to mediate functionally divergent interactions with dendritic cells or tumors. J Immunol. 2005;174(7):3992-3998.

40. Leong JW, Chase JM, Romee R, et al. Preactivation with IL-12, IL-15, and IL-18 induces CD25 and a functional high-affinity IL-2 receptor on human cytokine-induced memory-like natural killer cells. Biol Blood Marrow Transplant. 2014;20(4):463-473.

41. Ni J, Miller M, Stojanovic A, Garbi N, Cerwenka A. Sustained effector function of IL-12/15/18preactivated NK cells against established tumors. J Exp Med. 2012;209(13):2351-2365.

42. Vitale M, Della Chiesa M, Carlomagno S, et al. NK-dependent DC maturation is mediated by TNFalpha and IFNgamma released upon engagement of the NKp30 triggering receptor. Blood. 2005;106(2):566-571.

43. Zakharova M, Ziegler HK. Paradoxical anti-inflammatory actions of TNF-alpha: inhibition of IL-12 and IL-23 via TNF receptor 1 in macrophages and dendritic cells. J Immunol. 2005;175(8):5024-5033.

44. Ebihara T, Masuda H, Akazawa T, et al. Induction of NKG2D ligands on human dendritic cells by TLR ligand stimulation and RNA virus infection. Int Immunol. 2007;19(10):1145-1155.

45. Ma F, Zhang J, Zhang J, Zhang C. The TLR7 agonists imiquimod and gardiquimod improve DCbased immunotherapy for melanoma in mice. Cell Mol Immunol. 2010;7(5):381-388.

46. Schierloh P, Yokobori N, Aleman M, et al. Mycobacterium tuberculosis-induced gamma interferon production by natural killer cells requires cross talk with antigen-presenting cells involving Toll-like receptors 2 and 4 and the mannose receptor in tuberculous pleurisy. Infect Immun. 2007;75(11):53255337.

47. Muntasell A, Costa-Garcia M, Vera A, Marina-Garcia N, Kirschning CJ, Lopez-Botet M. Priming of NK cell anti-viral effector mechanisms by direct recognition of human cytomegalovirus. Front Immunol. 2013;4:40.

48. Sivori S, Falco M, Carlomagno S, Romeo E, Moretta L, Moretta A. Heterogeneity of TLR3 mRNA transcripts and responsiveness to poly (I:C) in human NK cells derived from different donors. Int Immunol. 2007;19(12):1341-1348. 


\section{SUPPORTING INFORMATION}
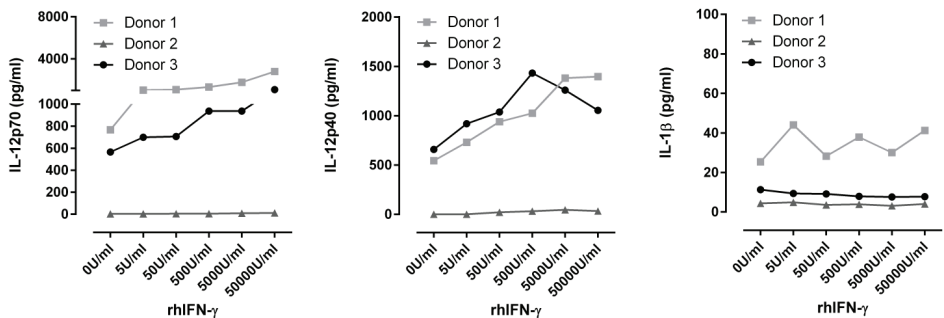

rhIFN- $\gamma$
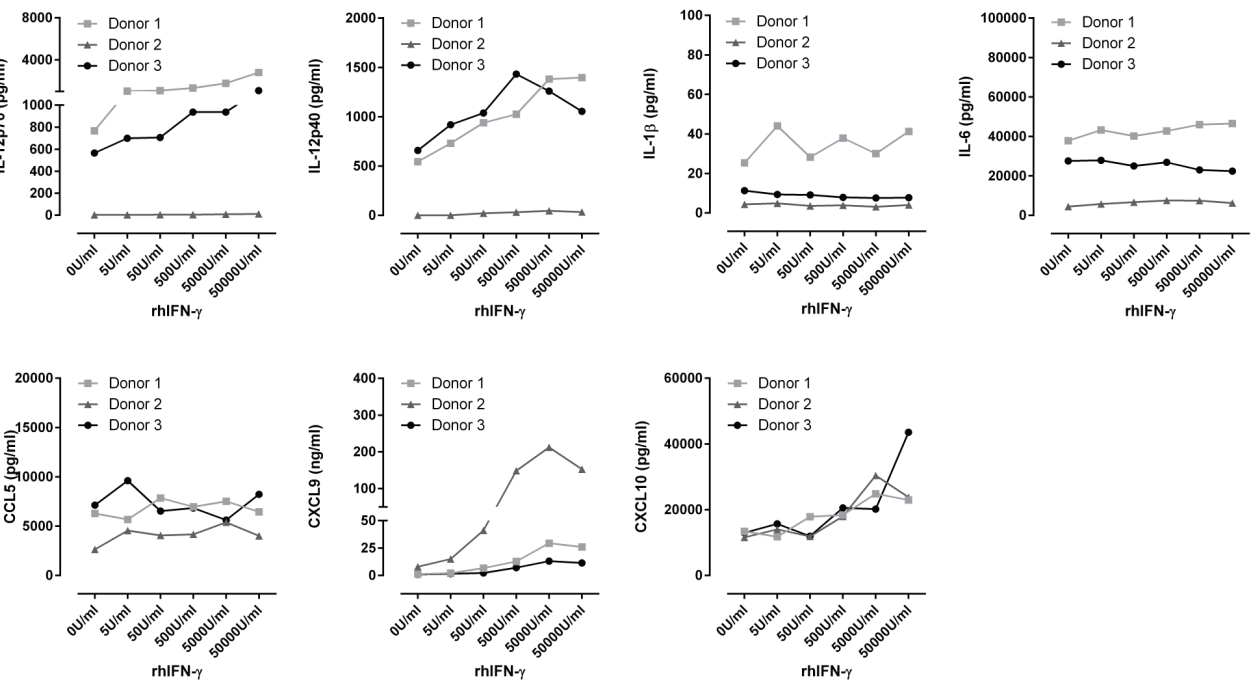

Supplementary Figure S1 | Supplementation of rhIFN- $\gamma$ during poly(I:C)/IFN- $\gamma$ DC maturation and its effect on cytokine and chemokine secretion. iDC were matured in serum-free medium supplemented with poly(I:C), IL-4, and GM-CSF in the presence of increasing concentrations of rhIFN- $\gamma$. Cytokine and chemokine profiles were determined in the culture supernatants after $48 \mathrm{~h}$ of maturation by CBA. Three individual donors are shown. 

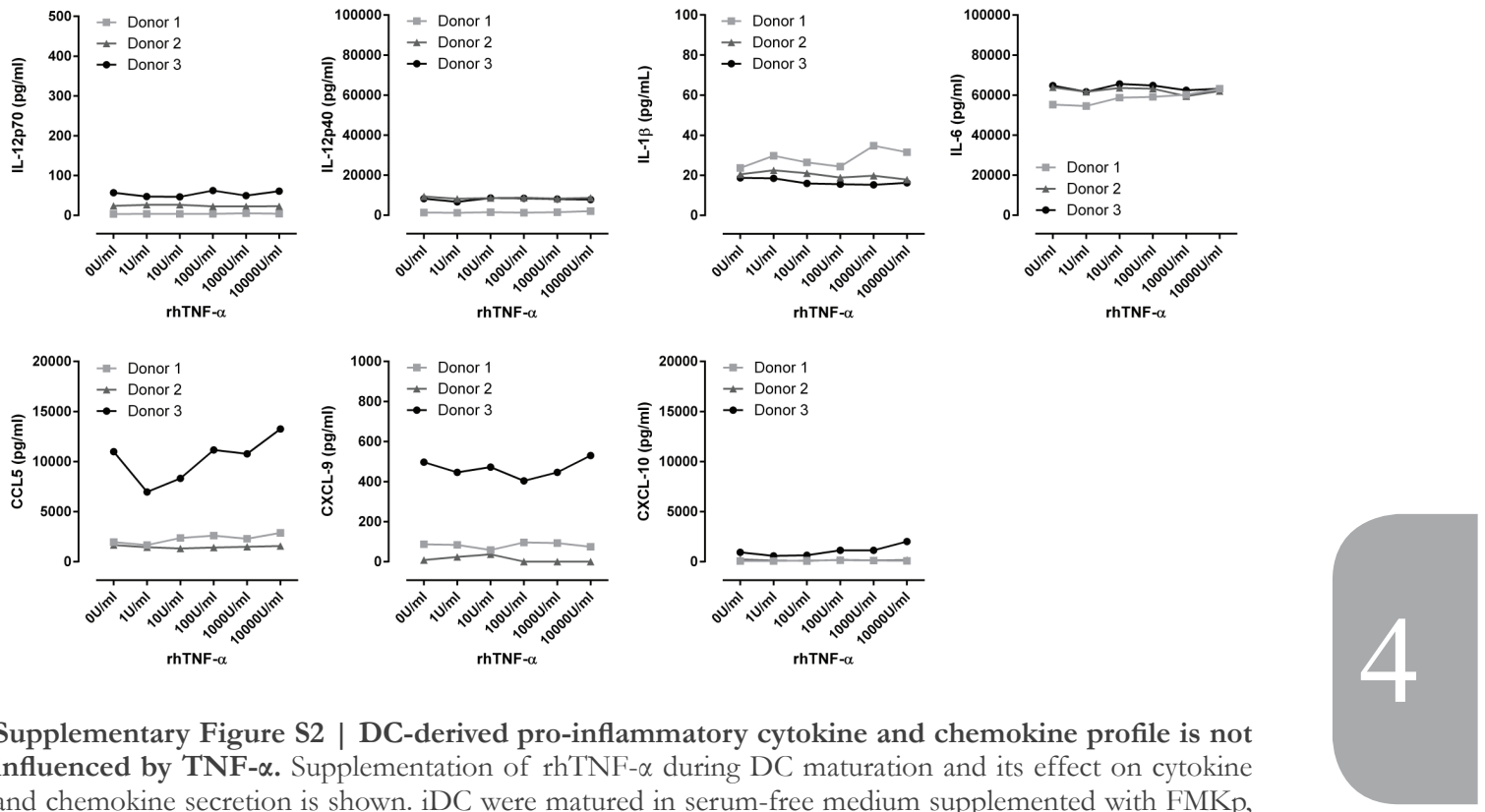

Supplementary Figure S2 | DC-derived pro-inflammatory cytokine and chemokine profile is not influenced by TNF- $\alpha$. Supplementation of rhTNF- $\alpha$ during DC maturation and its effect on cytokine and chemokine secretion is shown. iDC were matured in serum-free medium supplemented with FMKp, IL-4, and GM-CSF in the presence of increasing concentrations of rhTNF- $\alpha$. Cytokine and chemokine profiles were determined in the culture supernatants after $48 \mathrm{~h}$ of maturation by CBA. Three individual donors are shown. 


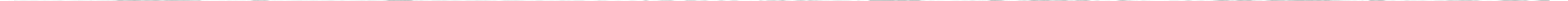




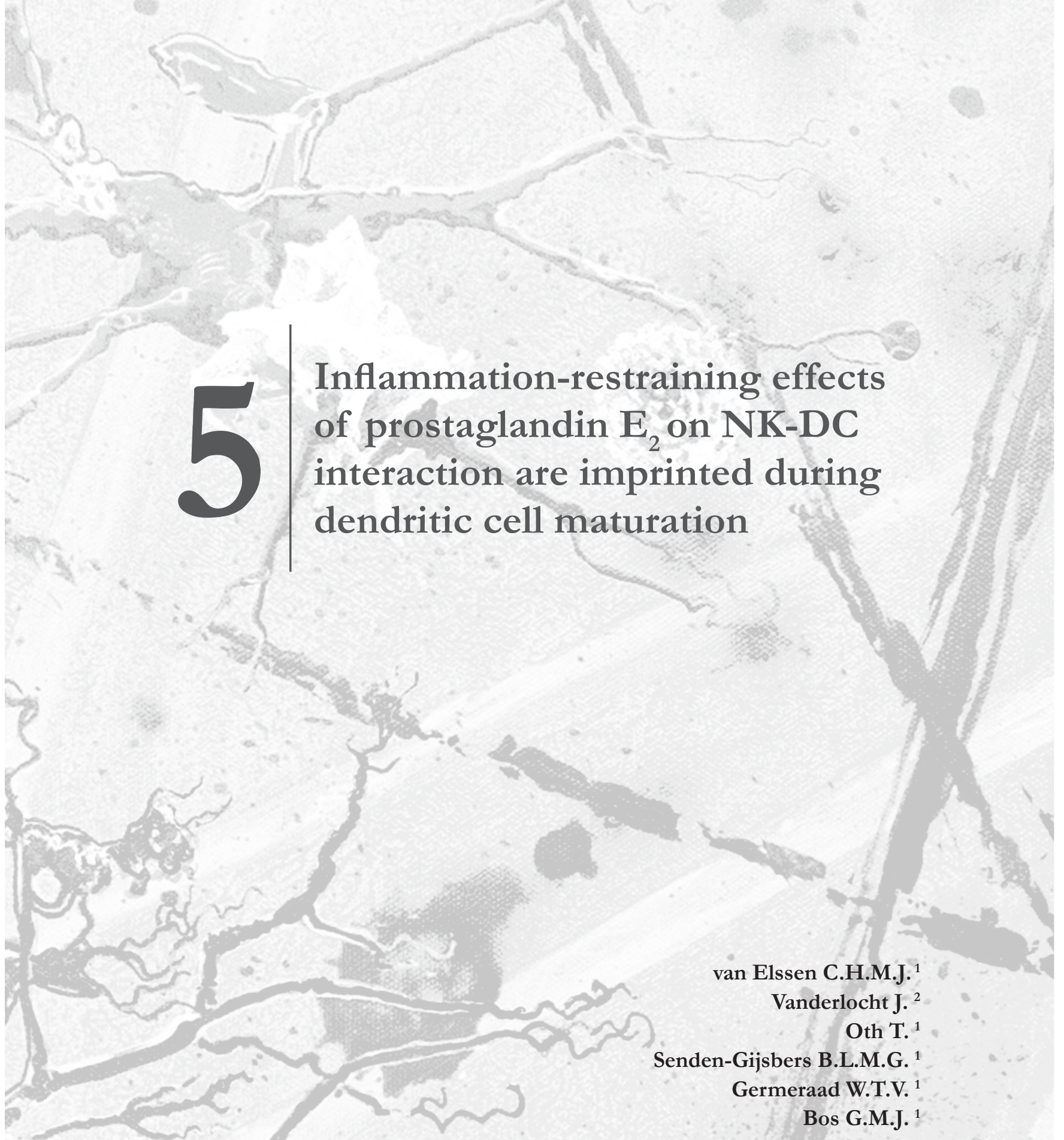

${ }^{1}$ Division of Haematology, Department of Internal Medicine, MUMC+, Maastricht ${ }^{2}$ Tissue Typing Laboratory, Department of Transplantation Immunology, MUMC+, Maastricht 


\begin{abstract}
Among prostaglandins (PG), $\mathrm{PGE}_{2}$ is abundantly expressed in various malignancies and is probably one of many factors promoting tumour growth by inhibiting tumour immunesurveillance. In the current study, we report on a novel mechanism by which PGE 2 inhibits in vitro natural killer cell-dendritic cell (NK-DC) crosstalk and thereby innate and adaptive immune responses via its effect on NK-DC crosstalk. The presence of $\mathrm{PGE}_{2}$ during FMKp/IFN- $\gamma$ dendritic cell (DC) maturation inhibits the production of chemokines (CCL5, CCL19, and CXCL10) and cytokines (IL-12 and IL-18), which is cAMP-dependent and imprinted during DC maturation. As a consequence, these DC fail to attract NK cells and show a decreased capacity to trigger $\mathrm{NK}$ cell IFN- $\gamma$ production, which in turn leads to reduced $\mathrm{T}$ helper 1 (Th1) polarization. In addition, the presence of $\mathrm{PGE}_{2}$ during DC maturation impairs DC-mediated augmentation of NK cell cytotoxicity. Opposed to their inhibitory effects on peripheral blood-derived NK cells, $\mathrm{PGE}_{2}$-matured DC induce IL-22 secretion of inflammation-constraining $\mathrm{NKp} 44^{+} \mathrm{NK}$ cells present in mucosa-associated lymphoid tissue. The inhibition of NK-DC interaction is a novel regulatory property of $\mathrm{PGE}_{2}$ that is of possible relevance in dampening immune responses in vivo.
\end{abstract}




\section{INTRODUCTION}

Prostaglandins (PG) are potent immune modulators, which are produced during inflammation after the conversion of arachidonic acid by cyclooxygenase (COX) ${ }^{1}$. Furthermore, PG are also abundantly produced by various types of tumours ${ }^{2}$. COX2 expression, which is correlated with a poor prognosis, is induced in a variety of human premalignant and malignant tumours, including solid tumours as well as haematological malignancies ${ }^{3-6}$. Several lines of evidence demonstrate that COX2-derived PG are involved in the promotion of tumour growth by regulation of cancer cell proliferation, apoptosis, migration and invasion ${ }^{7-11}$. PG are also produced by tumour-surrounding cells, creating a tumour-supporting environment by enhancing angiogenesis and inhibiting tumour immune surveillance ${ }^{2,11-14}$.

Of all PG, $\mathrm{PGE}_{2}$ has a pivotal role in tumour immunosuppression. It has been hypothesized that this effect is caused by the induction of a permanent state of inflammation ${ }^{2}$, resulting in phenotypic and functional changes of $\mathrm{T}$ helper (Th) cells, cytotoxic $\mathrm{T}$ (CTL) cells, dendritic cells (DC), natural killer (NK) cells, and myeloid-derived suppressor cells (MDSC) ${ }^{12}$. PGE 2 has been shown to deviate Th cell skewing from an anti-tumour Th1 response towards a Th2/Th17 response by directly binding to these cells ${ }^{15-17}$. Additionally, $\mathrm{PGE}_{2}$ is responsible for shifting the balance of IL-12/IL-23 production by DC towards IL-23, which is a very potent cytokine responsible for Th17 expansion and survival ${ }^{18,19}$. As a consequence, less IL-12 and other pro-inflammatory cytokines are produced, thus inhibiting Th1 polarization ${ }^{17,20}$. PGE $_{2}$ also directly decreases the cytotoxic capacity of CTL by inducing the expression of inhibitory receptors on CTL ${ }^{21}$ and indirectly by inhibiting DC maturation and antigen presentation ${ }^{22,23}$. Moreover, tumour-associated $\mathrm{PGE}_{2}$ has been reported to be responsible for the preferential attraction and induction of regulatory $\mathrm{T}$ (Treg) cells, creating an immune-regulatory microenvironment ${ }^{24,25}$.

Next to the modulating effects of $\mathrm{PGE}_{2}$ on the effector mechanisms of the adaptive immune response, $\mathrm{PGE}_{2}$ also has an effect on the innate immune response. NK cells, which are implicated in the innate defence against virally infected and malignantly transformed cells, have been reported to be affected by $\mathrm{PGE}_{2}$. It has been shown that $\mathrm{PGE}_{2}$ suppresses proliferation, cytokine secretion, migration, and $\mathrm{NK}$ cell-mediated cytotoxicity both in vivo and in vitro ${ }^{26-30}$.

Even though $\mathrm{PGE}_{2}$ has these direct effects on NK cells, it remains to be established whether $\mathrm{PGE}_{2}$ also has an effect on NK-DC crosstalk. We and others have previously reported on the importance of NK-DC crosstalk in modulating adaptive immune responses ${ }^{29,31,32}$. This crosstalk is characterized by DC-dependent recruitment of NK cells and IFN- $\gamma$ production 
by NK cells, of which the latter contributes to strong Th1 polarization ${ }^{32}$. Additionally, DC augment NK cell-mediated cytotoxicity of tumour cells. The DC-derived cytokines IL-12, IL-18, and IL-15 have been implicated in NK cell activation and IL-15 is also responsible for proliferation and survival of NK cells ${ }^{32,33}$.

In the current study, we investigated how PGE 2 influences NK-DC interactions. We identified the effects of $\mathrm{PGE}_{2}$ signalling on the production of key chemokines and cytokines responsible for NK cell interaction with DC matured with IFN- $\gamma$ and a membrane fraction

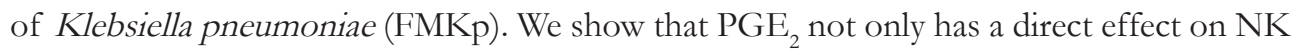
cells, but also indirectly alters DC-mediated NK cell effector functions.

\section{MATERIAL AND METHODS}

\section{Cell isolation}

Mononuclear cells from peripheral blood (PBMC) of healthy donors were isolated by density gradient separation using lymphoprep ${ }^{\mathrm{TM}}$ (Axis-Shield). NK cells and naive $\mathrm{CD}^{+}$ $\mathrm{T}$ cells were negatively selected by immunomagnetic cell separation (Miltenyi Biotec). The purity of isolated populations exceeded $95 \%$ as determined by flow cytometry.

Human tonsils were obtained from the Department of Otorhinolaryngology-Head \& Neck Surgery, Maastricht University Medical Center. NK cells were isolated to a purity of $70-80 \%$ as described by Cella et al. ${ }^{34}$.

\section{Generation of DC}

DC were prepared from peripheral blood-derived monocytes, isolated by density centrifugation and adherence as previously described ${ }^{35}$. In addition, highly purified monocyte fractions obtained by elutriation of leukapheresis products were used (purity $>95 \%$ ). Written informed consent was obtained from all leukapheresis donors in accordance with the Declaration of Helsinki. For every experiment, DC from both isolation methods were used to avoid the effect of contaminating $\mathrm{NK}$ cells $(<5 \%$ in density centrifugation isolated monocytes) on the results. Differentiation of monocytes was induced during 6 days of culture in AIM-V ${ }^{\circledR}$ medium (Gibco Life Technologies) containing 2000U/ml IL-4 (Strathmann Biotech) and 400U/ml GM-CSF (Berlex). DC were matured for 6h in AIMV $^{\circledR}$ medium containing 500U/ml IFN- $\gamma$ (Strathmann Biotech), $1 \mu \mathrm{g} / \mathrm{ml} \mathrm{FMKp} \mathrm{(Pierre}$ Fabre) and different concentrations of $\mathrm{PGE}_{2}$ (Sigma-Aldrich). After washing, to remove all maturation factors, DC were incubated for another $18 \mathrm{~h}$ in medium only (total maturation 


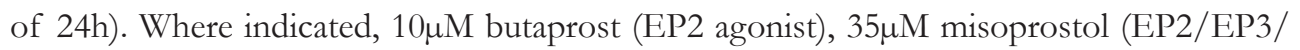
EP4 agonist), $10 \mu \mathrm{M}$ sulprostone (EP1/EP3 agonist; Cayman Chemical), or $100 \mu \mathrm{M}$ of dibutyryl-cAMP (Alexis Biochemicals) were added. When selective EP-receptor agonists were compared, $10 \mu \mathrm{M} \mathrm{PGE}_{2}$ was used.

\section{Flow cytometry}

All antibodies for flow cytometry were obtained from BD Biosciences, except for CCR7, 2B4, CXCR3, CCR5, NKp80, NKp44, IL-22 (R\&D Systems), NKp30 (BioLegend) and NKG2A, NKG2D, CD158A, CD158B, CD158D, CD158E (Miltenyi Biotec GMbH). Cells were incubated with antibodies at proper dilutions for $30 \mathrm{~min}$ at RT. Analyses were performed on a FACSCanto ${ }^{\mathrm{TM}}$ II (BD Biosciences) and analysed with BD CellQuest ${ }^{\mathrm{TM}}$ Pro Software (BD Biosciences), WinMDI (Joe Trotter, http://facs.scripps.edu/) or Flowjo (Treestar, Ashland, OR) software.

\section{Migration assay}

Migration of NK cells was analysed as described previously ${ }^{32}$. To analyse the effect of CCL5 reconstitution on NK cell recruitment, supernatant of FMKp/IFN- $\gamma$-DC matured in the presence of $\mathrm{PGE}_{2}$ was supplemented with $50 \mathrm{ng} / \mathrm{ml} \mathrm{CCL5}$. Migration of DC was analysed as described previously ${ }^{35}$.

\section{Cytokine and chemokine secretion by DC}

Quantification of IL-18, IL-12, IL-23, CCL5, CXCL10, and CCL19 in 24h maturation supernatants was performed using ELISA (MBL International Corporation and R\&D Systems) according to manufacturer's instructions.

\section{Cytokine production by NK cells}

$\mathrm{NK}$ cell cells were either cultured in the presence of $\mathrm{PGE}_{2}$ and stimulated with $2.5 \mu \mathrm{g} / \mathrm{ml}$ phorbol 12 -myristate 13 -acetate (PMA) and $2 \mu \mathrm{g} / \mathrm{ml}$ ionomycin or with supernatant of DC matured with different concentrations of $\mathrm{PGE}_{2}$. To analyse the effect of CCL5 on NK cell recruitment, supernatant of FMKp/IFN- $\gamma$-DC matured in the presence of $\mathrm{PGE}_{2}$ were supplemented with $2 \mathrm{ng} / \mathrm{ml} \mathrm{IL}-12$ and/or $100 \mathrm{pg} / \mathrm{ml}$ IL-18. Quantification of IFN- $\gamma$ production was performed after $16 \mathrm{~h}$ of stimulation using an IFN- $\gamma$ ELISA kit (R\&D systems).

To evaluate IL-22 production by NK cells obtained from tonsils, NK cells were incubated 
with DC in a 1:2 ratio. Flow cytometric analysis of IL-22-secreting NK cells was performed as described by Cella et al. ${ }^{34}$.

\section{Th cell priming}

In a 96-well plate, FMKp/IFN- $\gamma$-matured DC ( $0.4 \times 10^{5}$ cells/well $)$ were coated with $1 \mathrm{ng} / \mathrm{ml}$ Staphylococcal Enterotoxin B (SEB, Sigma-Aldrich) for 1h. SEB-coated DC, were washed and placed in culture with $\mathrm{CD}_{4} 5 \mathrm{RA}^{+} \mathrm{CD} 45 \mathrm{RO}^{-} \mathrm{CD} 4^{+} \mathrm{T}$ cells $\left(10^{5} \mathrm{cells} /\right.$ well). Every other day stimulation medium was replaced with supernatant of NK-DC cultures. In these NK-DC cultures, FMKp/IFN- $\boldsymbol{\gamma}$-matured DC or FMKp/IFN- $\boldsymbol{\gamma}+1000 \mathrm{ng} / \mathrm{ml} \mathrm{PGE} \mathrm{P}_{2}$-matured DC $\left(2 \times 10^{5}\right.$ cells/well $)$ were cultured with/without NK cells $\left(10^{5}\right.$ cells/well). At day 10 the expanded Th cells were washed, plated in 96-well plates $\left(10^{5}\right.$ cells/well), and stimulated with PMA/ionomycin (BD Biosciences). After 4h, cells were harvested and surface and intracellular staining was performed as described ${ }^{32}$.

\section{NK cell cytotoxicity assay}

For NK cell-mediated lysis of K562, unstimulated NK cells were co-cultured with K562 cells for $4 \mathrm{~h}$ in the presence of different concentrations of $\mathrm{PGE}_{2}$. For NK cell-mediated lysis of Raji, NK cells were pre-activated for $18 \mathrm{~h}$ by either supernatant of FMKp/IFN- $\gamma$-DC matured in the presence of different concentrations of $\mathrm{PGE}_{2}$, medium alone or medium containing 1000U/ml IL-2 (Proleukin, Chiron Benelux BV). Target cells were labelled with 3'-dioctadecyloxacarbocyanine (DiO) according to the manufacturer's instructions (Sigma) and $2 \times 10^{4}$ target cells were incubated with pre-activated NK cells at various effector:target (E:T) ratios for $12 \mathrm{~h}$, each ratio in triplicate. Percentages of killed target cells $\left(\mathrm{PI}^{+} \mathrm{DiO}^{+}\right)$were determined by flow cytometry. Percentages specific lysis were calculated as follows ${ }^{36}$ :

$\frac{\% \text { total target cell death }-\% \text { spontaneous target cell death }\left(\mathrm{PI}^{+}\right)}{\% \text { vital cells }\left(\% \mathrm{PI}^{-} \text {cells not incubated with effector cells) }\right.} \times 100$

\section{Statistics}

Statistical significance of differences between experimental samples was determined using Student's t-test for paired samples, ANOVA or Wilcoxon signed-rank test. Significance was accepted at the ${ }^{*} P<0.05,{ }^{* *} P<0.01$, and ${ }^{* * *} P<0.001$ levels. Data were analysed using Prism software version 5.0 (GraphPad Software). 


\section{RESULTS}

\section{$P G E_{2}$ directly inhibits $N K$ cell cytokine production and NK cell-mediated cytotoxicity}

We investigated whether $\mathrm{PGE}_{2}$ affects the expression of inhibitory and activating receptors on the NK cell surface. To this end, freshly isolated NK cells were cultured for $24 \mathrm{~h}$ in the presence or absence of $\mathrm{PGE}_{2}$. As shown in Figure 1A, only expression of NKG2D (NK

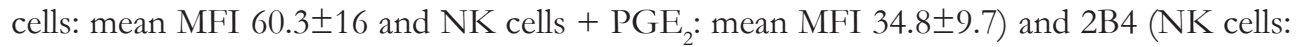
mean MFI 103 \pm 4.5 and NK cells + PGE $_{2}$ : mean MFI 70.8 \pm 2.9$)$ is significantly $(P<0.05)$ reduced in six different donors (Wilcoxon signed rank test) due to $\mathrm{PGE}_{2}$ treatment. The expression of the other activating and inhibitory NK cell surface markers, including specific Killer Immunoglobulin Receptors (KIRs), did not change.

\section{A}
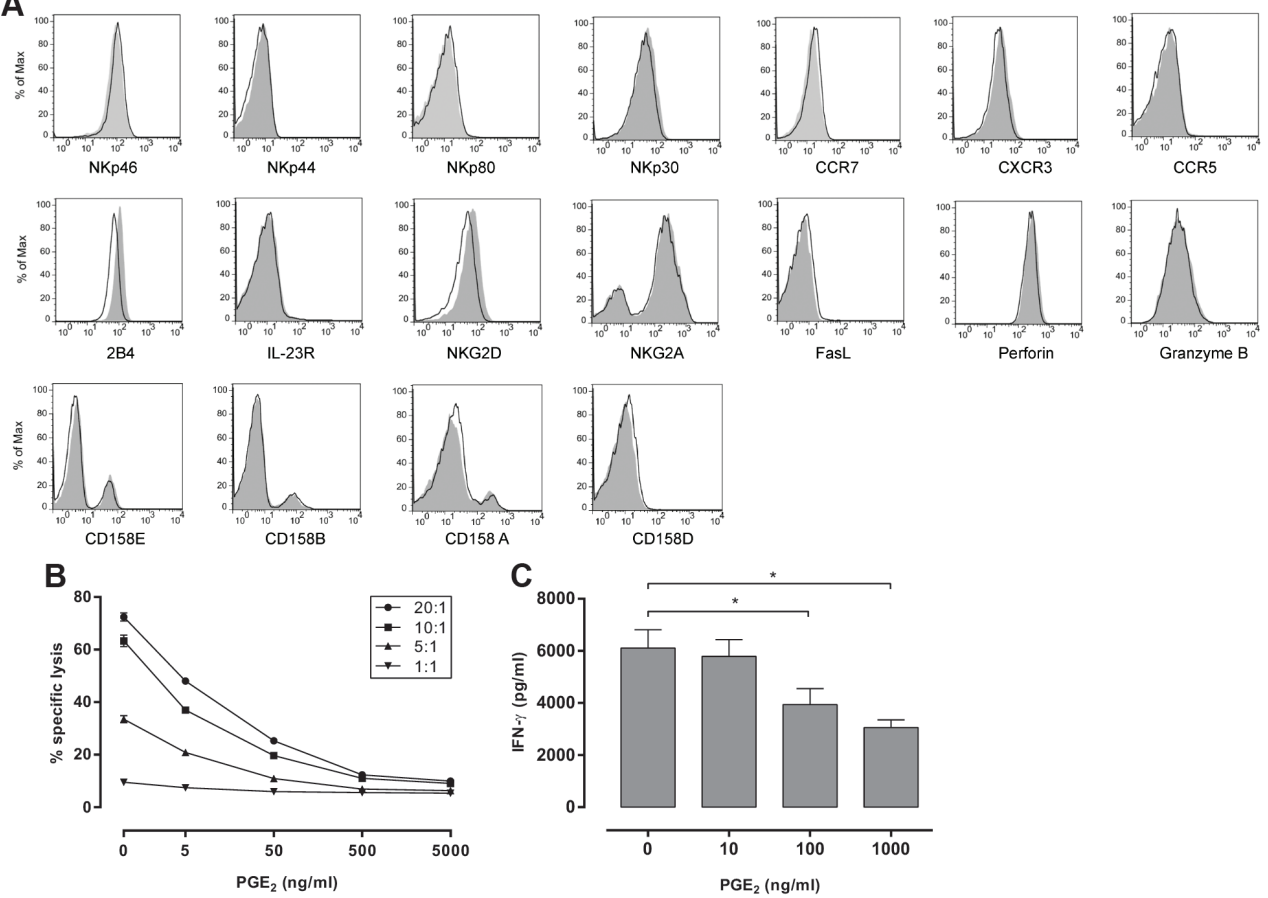

Figure 1 | Direct effect of PGE $_{2}$ on NK cell phenotype, cytotoxicity, and cytokine secretion. Freshly isolated NK cells were cultured for $24 \mathrm{~h}$ in the presence of $\mathrm{PGE}_{2}$. (A) Phenotypic analysis of NK cell surface receptor expression. Filled histograms, NK cells without PGE ${ }_{2}$; Black lines, NK cells with $1000 \mathrm{ng} / \mathrm{ml} \mathrm{PGE}$. Representative data of one out of 6 different donors. (B) Flow cytometry-based NK cell cytotoxicity assay against K562 by NK cells cultured with different concentrations of $\mathrm{PGE}_{2}$. Data shown are triplicates of one representative experiment out of 4 different experiments. (C) IFN- $\gamma$ production by NK cells cultured with different concentrations of $\mathrm{PGE}_{2}$ and stimulated for $16 \mathrm{~h}$ with PMA and ionomycin, as evaluated by ELISA. Results are presented as mean plus SEM and are obtained from 3 different donors. ${ }^{*} P<0.05$. 
Additionally, the expression of chemokine receptors CCR5, CXCR3, and CCR7 was evaluated, since these chemokine receptors are implicated in $\mathrm{NK}$ cell migration ${ }^{29,31}$. $\mathrm{PGE}_{2}$, however, had no effect on the expression of these receptors. As PGE 2 has been shown to enhance IL-23 receptor expression by Th17 cells ${ }^{15}$, we evaluated if $\mathrm{PGE}_{2}$ had the same effect on NK cells. Flow cytometric analysis showed that IL-23 receptor expression on $\mathrm{NK}$ cells was not altered. The effect of $\mathrm{PGE}_{2}$ on surface expression of the activating receptors $2 \mathrm{~B} 4$ and $\mathrm{NKG} 2 \mathrm{D}$ suggests that $\mathrm{PGE}_{2}$ has an inhibitory impact on $\mathrm{NK}$ cell effector functions. To evaluate this impact, cytotoxicity assays were performed in either the presence or absence of $\mathrm{PGE}_{2}$. As target cells, K562 cells were used, since these cells fail to express HLA class I and are therefore efficiently killed by NK cells. A dose-dependent decrease in cytolytic activity was observed when $\mathrm{PGE}_{2}$ was present during the cytotoxicity assay (Figure 1B). Similar data have been reported previously ${ }^{37}$. To evaluate the effect of $\mathrm{PGE}_{2}$ on IFN- $\gamma$ production, a second $\mathrm{NK}$ cell effector function, NK cells were stimulated with PMA and ionomycin in the presence or absence of different concentrations of $\mathrm{PGE}_{2}$ and $16 \mathrm{~h}$ supernatant was evaluated by ELISA for the presence of IFN- $\gamma$ production. PGE $_{2}$ dose-dependently inhibited IFN- $\gamma$ secretion (Figure 1C).

Taken together these results show that $\mathrm{PGE}_{2}$ has a direct effect on NK cells, as it downregulates the expression of the NK cell-activating receptors $2 \mathrm{~B} 4$ and NKG2A and it dose-dependently inhibits NK cell-mediated cytotoxicity and IFN- $\gamma$ secretion.

\section{Effect of $P G E_{2}$ on DC-derived chemokines is imprinted during maturation and inhibits NK cell recruitment}

NK cells can be recruited by mature DC ultimately leading to NK cell activation ${ }^{31,32,38}$. This recruitment depends on DC-derived chemokines of which CCL5, CXCL10 and CCL19 are the most important. To study whether PGE $_{2}$ treatment of DC influences NK cell recruitment linked to effects on the DC chemokine profile, we evaluated CCL19, CXCL10 and CCL5 secretion by DC after maturation in the presence or absence of PGE ${ }_{2}$. To this end, monocyte-derived DC were matured with a membrane fraction of Klebsiella pneumoniae (FMKp) and IFN- $\gamma$ as previously described ${ }^{35}$. DC were matured for $6 \mathrm{~h}$ with FMKp/IFN- $\gamma$ and different concentrations of $\mathrm{PGE}_{2}$. After washing, to remove all maturation factors, DC were incubated for another $18 \mathrm{~h}$ in medium only (total maturation of 24h). Effectiveness of DC washing was evaluated by detection of $\mathrm{PGE}_{2}$ by ELISA. In none of the samples $\mathrm{PGE}_{2}$ was found (data not shown), indicating that FMKp/IFN- $\gamma$ matured DC do not produce $\mathrm{PGE}_{2}$. Addition of $\mathrm{PGE}_{2}$ during $\mathrm{DC}$ maturation did not affect upregulation of HLA-DR and co-stimulatory molecules (CD80, CD83, CD86 and CD40), suggesting that addition of $\mathrm{PGE}_{2}$ to the maturation cocktail did not hinder the development 
of mature DC (Figure S1 A). However, $\mathrm{PGE}_{2}$ did induce a significant increase in surface expression of CCR7 (Figure S1 B). Increased CCR7 expression by TLR-triggered DC cultured in the presence of $\mathrm{PGE}_{2}$ has been described previously ${ }^{39}$. FMKp/IFN- $\boldsymbol{\gamma}$-matured DC also showed a dose-dependent increase of CCR7 expression, which indeed resulted in functionally increased responsiveness to the lymph-node associated chemokine CCL19 (Figure S1 C).

Chemokine (CXCL10, CCL19 and CCL5) production was evaluated by culturing DC for 14h in the presence of different PGE $_{2}$ concentrations and quantified by ELISA (Figure 2A). Production of these chemokines significantly decreased with increasing concentrations of $\mathrm{PGE}_{2}$. Since CCR5 has been identified to be the most important chemokine receptor responsible for $\mathrm{NK}$ cell recruitment by FMKp/IFN- $\gamma$-matured $\mathrm{DC}^{32}$, the negative effect of $\mathrm{PGE}_{2}$ on CCL5 production suggested a decrease in the capacity of $\mathrm{PGE}_{2}$-matured DC to recruit NK cells. To test this hypothesis, migration assays were performed. Freshly isolated NK cells were allowed to migrate during $1.5 \mathrm{~h}$ towards the supernatant of DC matured in the presence of different concentrations of $\mathrm{PGE}_{2}$. NK cell recruitment was significantly decreased when increasing doses of $\mathrm{PGE}_{2}$ were added during DC maturation (Figure 2B). Since DC were extensively washed after $6 \mathrm{~h}$ of maturation, DC supernatant did not contain any $\mathrm{PGE}_{2}$ anymore, therefore $\mathrm{NK}$ cells were not directly exposed to $\mathrm{PGE}_{2}$. This indicates that the negative effect on NK cell migration does not depend on an effect of $\mathrm{PGE}_{2}$ on $\mathrm{NK}$ cell chemokine receptors, which has previously been described ${ }^{29}$. After supplementing the supernatant of $\mathrm{PGE}_{2}$-matured DC with CCL5, NK cell recruitment was restored, indicating that indeed the effect of $\mathrm{PGE}_{2}$ on CCL5 production was responsible for decreased NK cell recruitment (Figure 2C).

DC have been shown to express all four different EP receptors ${ }^{40}$. To evaluate which $\mathrm{EP}$ receptors mediate the effect of $\mathrm{PGE}_{2}$ on chemokine production by $\mathrm{DC}$, they were stimulated with specific agonists that preferentially bind to one or more EP receptors (Figure 2D). Stimulation with butaprost and misoprostol reduced CXCL10 and misoprostol also inhibited CCL5 secretion significantly, whereas sulprostone did not alter secretion of these chemokines. This indicates that mainly EP2 and EP4 signalling are responsible for the effect of $\mathrm{PGE}_{2}$ on the reduced secretion of CXCL10 and CCL5. In contrast, CCL19 production was equally affected by mistoprostol and butaprost, demonstrating that EP2 is the most important EP receptor involved in the inhibition of CCL19 production. The addition of the intracellular cAMP analogue dibutyryl-cAMP mimicked the effect of $\mathrm{PGE}_{2}$ for production of all three chemokines, suggesting that the effect of $\mathrm{PGE}_{2}$ was dependent on cAMP signalling.

To evaluate whether the effect of $\mathrm{PGE}_{2}$ on chemokine production by $\mathrm{DC}$ is imprinted 
A

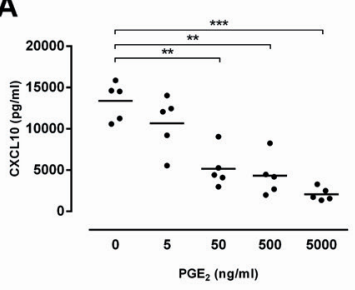

B

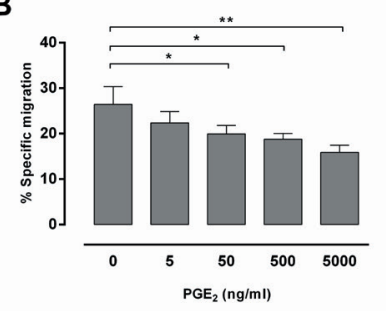

D

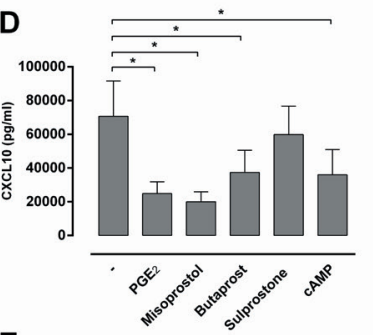

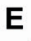

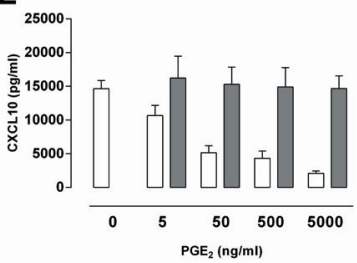

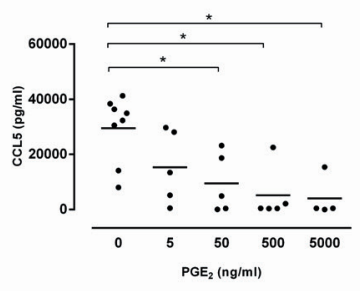

C
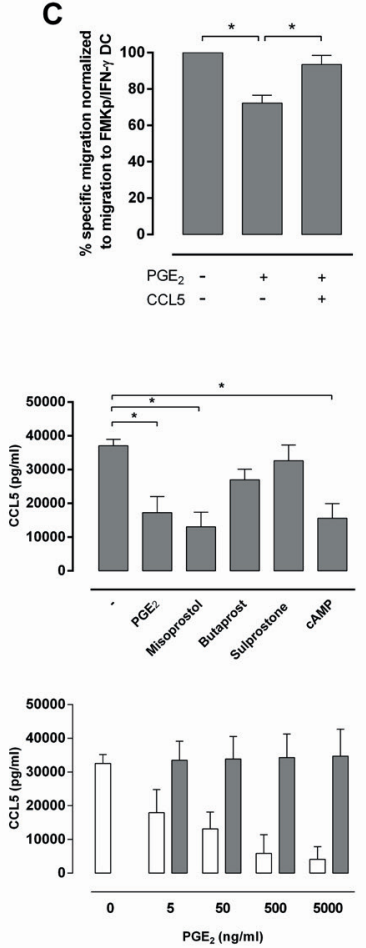
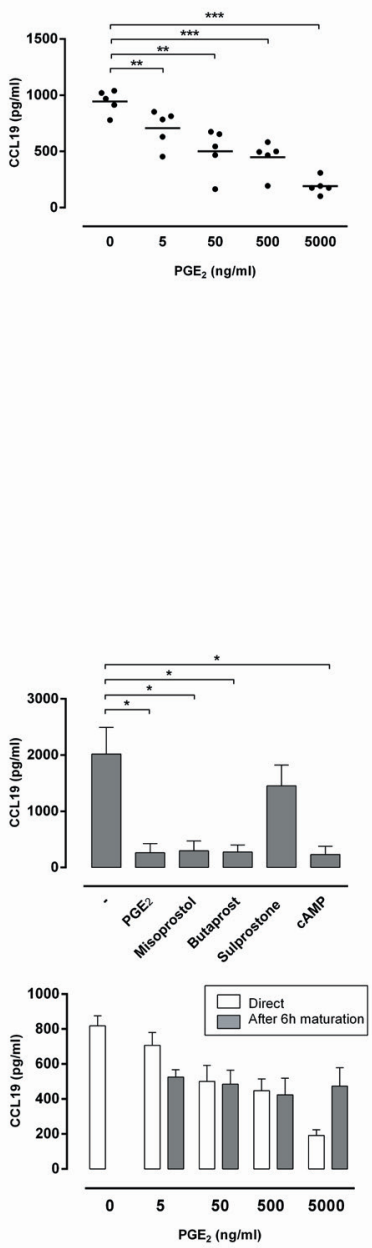

(1)

Figure 2 | PGE 2 inhibits DC-derived CXCL10, CCL5 and CCL19 secretion. Monocyte-derived DC were matured with FMKp/IFN- $\gamma$ in the presence of different concentrations of PGE . After $6 \mathrm{~h}$ maturation, DC were washed to remove the stimulation medium, and matured for an additional $18 \mathrm{~h}$ in AIM-V ${ }^{\circledR}$ medium only. (A) Quantitative comparison of CXCL10, CCL5 and CCL19 production as measured by ELISA. Results shown are the mean plus SEM of combined data of at least 5 different donors. (B) Percentage of NK cells migrated in $1.5 \mathrm{~h}$ towards cell-free supernatant of FMKp/IFN- $\gamma$-DC matured in the presence of different concentrations of $\mathrm{PGE}_{2}$. Data were calculated as percentage of migrated NK cells. Results presented are the mean plus SEM of combined data of 11 different donors. (C) Percentage of NK cells migrated in $1.5 \mathrm{~h}$ towards cell-free supernatant of FMKp/IFN- $\gamma$ DC matured in the presence of $\mathrm{PGE}_{2}$ and supplemented with $50 \mathrm{ng} / \mathrm{ml}$ CCL5. Data were calculated as percentage of migrated NK cells, normalized to NK cell migration towards FMKp/IFN- $\gamma$-DC matured without PGE $_{2}$. Results presented are the mean plus SEM of combined data of 4 different donors. (D) Quantitative comparison of CXCL10, CCL5 and CCL19 production after stimulation with different EP receptor agonists and cAMP as measured by ELISA. Results shown are the mean plus SEM of combined data of at least 4 different donors. (E) Quantitative comparison of CXCL10, CCL5 and CCL19 production after stimulation with $\mathrm{PGE}_{2}$ either during or after DC maturation as measured by ELISA. Results shown are the mean plus SEM of combined data of at least 4 different donors. ${ }^{*} P<0.05 ;{ }^{* *} P<0.01 ;{ }^{* * *} P<0.001$. 
during maturation or whether $\mathrm{PGE}_{2}$ can also exert its suppressive effect after initiation of maturation, chemokine production of DC was analysed when $\mathrm{PGE}_{2}$ was added during or after the first $6 \mathrm{~h}$ of DC maturation. After a total of $24 \mathrm{~h}$ maturation, chemokine production was evaluated (Figure 2E). A decrease in CXCL10 and CCL5 secretion could only be detected when $\mathrm{PGE}_{2}$ was present during the first $6 \mathrm{~h}$ of maturation. CCL19 production was also affected by $\mathrm{PGE}_{2}$ after the $6 \mathrm{~h}$ maturation period, however the effect was less pronounced as compared to the effect of immediate addition of $\mathrm{PGE}_{2}$.

These results indicate that the negative effect of $\mathrm{PGE}_{2}$ on production of DC-derived CXCL10, CCL5 and CCL19 is imprinted during maturation and depends on EP2/EP4mediated cAMP signalling. In addition, we show that the NK cell recruiting capacity of DC is reduced due to the influence of $\mathrm{PGE}_{2}$.

\section{Effect of $\mathrm{PGE}_{2}$ on DC-derived IL-12/IL-18 production is imprinted during maturation and inhibits NK cell-derived IFN- $\gamma$ secretion}

We previously showed that production of IL-12 and IL-18 by FMKp/IFN- $\gamma$-matured DC is needed to induce $\mathrm{NK}$ cell activation ${ }^{32}$. To evaluate the effect of $\mathrm{PGE}_{2}$ on $\mathrm{NK}$ cell activation, production of these cytokines by FMKp/IFN- $\gamma$-DC stimulated with PGE $_{2}$ was determined in $24 \mathrm{~h}$ DC supernatant. As described previously, TLR-triggered DC produce less IL-12 when matured in the presence of $\mathrm{PGE}_{2}{ }^{17,39}$. We show here that $\mathrm{PGE}_{2}$ also has this effect on IL-12 production by FMKp/IFN- $\boldsymbol{\gamma}$-matured DC and, additionally, PGE $\mathrm{E}_{2}$-triggering results in less IL-18 secretion (Figure 3A). Moreover, PGE $_{2}$ exerted its effect on the secretion of these cytokines only when it was present during DC maturation, as evidenced by lack of inhibition of IL-12 and IL-18 production when PGE $_{2}$ was added after the $6 \mathrm{~h}$ DCmaturation period (Figure 3B).

NK cell activation, evaluated by IFN- $\gamma$ production of $\mathrm{NK}$ cells cultured for $16 \mathrm{~h}$ in DC supernatant, was significantly reduced when DC were matured in the presence of $\mathrm{PGE}_{2}$ (Figure 3C). NK cell activation was completely restored after addition of IL-12 to the supernatant of FMKp/IFN- $\gamma$ DC matured in the presence of $\mathrm{PGE}_{2}$, indicating that the effect of $\mathrm{PGE}_{2}$ on DC-mediated $\mathrm{NK}$ cell activation mainly depends on the inhibition of IL-12 secretion (Figure 3D). Although the decrease in DC-mediated NK cell activation is caused by the decrease in IL-12 secretion, these data do not exclude that other factors might contribute. One candidate cytokine produced by TLR-triggered DC in the presence of $\mathrm{PGE}_{2}$ is IL-23, a cytokine implicated in the induction of Th17 responses ${ }^{19}$. Also FMKp/IFN- $\gamma$-matured DC produce IL-23, which is enhanced when DC are matured in the presence of $\mathrm{PGE}_{2}$ (Figure $3 \mathbf{E}$ ), albeit with an apparent optimum at $50 \mathrm{ng} / \mathrm{ml} \mathrm{PGE}{ }_{2}$. The addition of IL-23 to DC supernatant during NK cell activation did not affect IFN- $\gamma$ 
production by NK cells (data not shown).

These data indicate that $\mathrm{PGE}_{2}$ added to the maturation of $\mathrm{DC}$ is not only responsible for decreased production of the NK cell-activating cytokines IL-12 and IL-18, but also enhances IL-23 secretion.
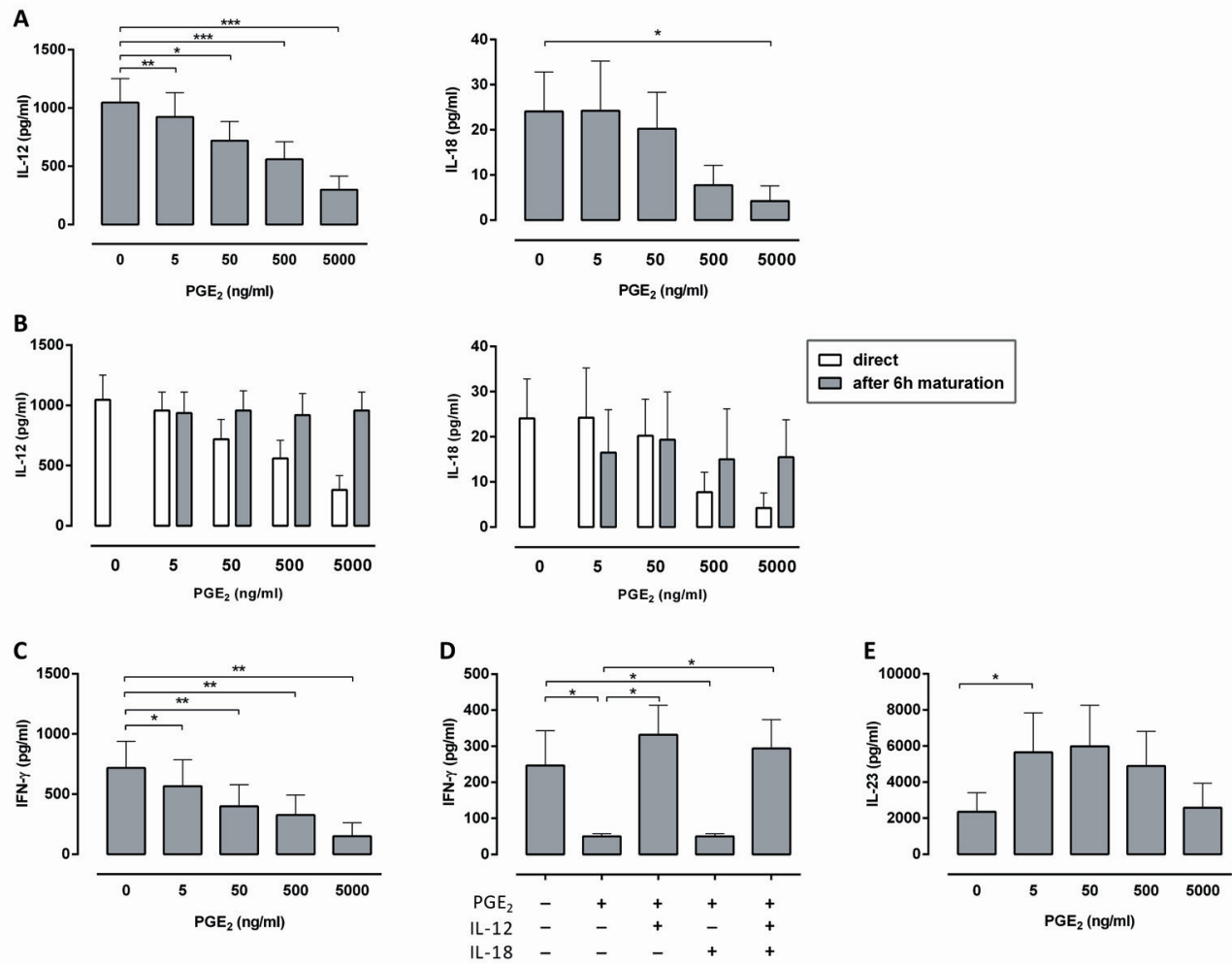

Figure 3 | PGE inhibits DC-derived NK cell activation. Monocyte-derived DC were matured with FMKp/IFN- $\gamma$ in the presence of different concentrations of $\mathrm{PGE}_{2}$. After $6 \mathrm{~h}$ maturation, DC were washed to remove the stimulation medium, and matured for an additional $18 \mathrm{~h}$ in AIM- $\mathrm{V}^{\circledR}$ medium only. (A) Quantitative comparison of IL-12 and IL-18 production as measured by ELISA. Results shown are the mean of combined data of at least 4 different donors plus SEM (IL-12, $n=16$; IL-18, n=4). (B) Quantitative comparison of IL-12 and IL-18 production after stimulation with PGE 2 either during or after 6h DC maturation as measured by ELISA. Results shown are the mean of combined data of at least 3 different donors plus SEM. (C) NK cell IFN- $\gamma$ production, as measured by ELISA, after incubation for $16 \mathrm{~h}$ with DC supernatant. Results presented are the mean plus SEM of combined data of 11 different donors. (D) NK cell IFN- $\gamma$ production, as measured by ELISA, after incubation for $16 \mathrm{~h}$ with

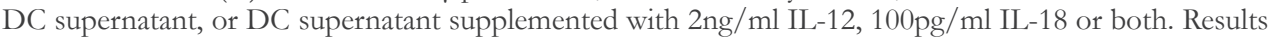
presented are the mean plus SEM of combined data of 6 different donors. (E) Quantitative comparison of IL-23 production as measured by ELISA. Results shown are the mean plus SEM of combined data of 4 different donors. ${ }^{*} P<0.05 ;{ }^{* *} P<0.01 ;{ }^{* * *} P<0.001$. 


\section{Presence of $P G E_{2}$ during DC maturation stimulates $I L-22$ production by $\mathrm{NKp} 44^{+}$ NK cells isolated from human tonsils}

Recent studies showed that in mucosa-associated lymphoid tissue, an NK cell subset with inflammation-restraining properties resides. This $\mathrm{NKp}_{4} 4^{+}$subset produces IL-22, IL-26, and LIF in response to IL-23 or after co-culture with TLR-matured DC and is not proficient at typical $\mathrm{NK}$ cell functions such as cytotoxicity and IFN- $\gamma$ secretion ${ }^{34}$. In contrast to conventional NK cells, that secrete cytokines in response to IL-12, this NK cell subpopulation produces IL-22 after IL-23 triggering and, to a lesser extent, after triggering with IL-6 and IL-15 ${ }^{34}$. Furthermore, these NKp44+ ${ }^{+} \mathrm{NK}$ cells express the transcription factor ROR $\gamma \mathrm{T}$ and therefore show functional and phenotypic similarity to Th17 cells ${ }^{41,42}$. Given the positive effect of $\mathrm{PGE}_{2}$-matured DC on the induction of Th17 cells ${ }^{15}$, we hypothesized that the addition of $\mathrm{PGE}_{2}$ to FMKp/IFN- $\gamma$ maturation of DC may enhance activation of $\mathrm{NKp} 44^{+}$cells.

To test this hypothesis, NK cells were isolated from human tonsils and co-cultured for $16 \mathrm{~h}$ with DC that were matured in the presence or absence of $50 \mathrm{ng} / \mathrm{ml} \mathrm{PGE} \mathrm{F}_{2}$. Production of IL-22 by NKp44+ NK cells was evaluated by flow cytometry. There was a significant increase in percentage of NK cells accumulating IL-22 when NK cells were co-cultured with $\mathrm{PGE}_{2}$-stimulated DC as compared to co-cultures with DC matured in the absence of $\mathrm{PGE}_{2}$ (Figure 4A, B). Notably, the IL-22 producing NK cell subset expressed NKp44 ${ }^{+}$and did not accumulate IFN- $\gamma$.

Taken together, these data indicate that $\mathrm{PGE}_{2}$ is responsible for the induction of $\mathrm{DC}$ that activate inflammation-restraining NK cells.
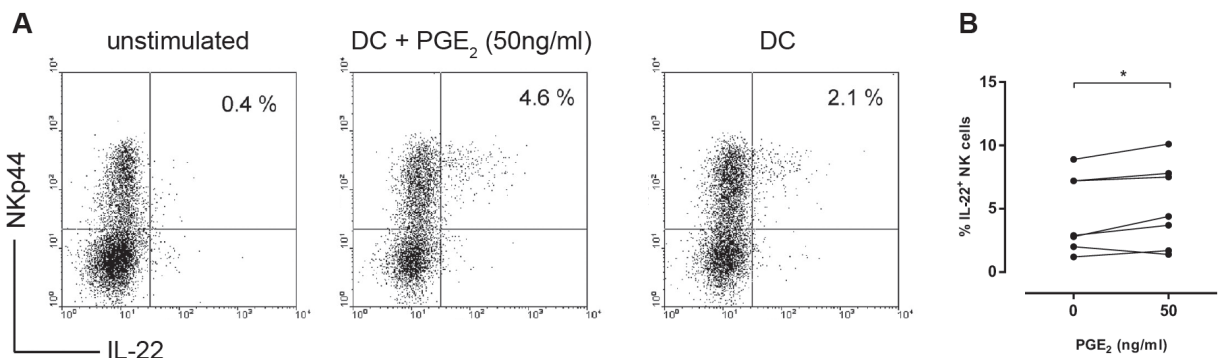

Figure 4 | Effect of PGE $_{2}$-matured DC on IL-22 production by NK cells residing in the tonsil. Monocyte-derived DC were matured with FMKp/IFN- $\gamma$ in the presence or absence of $50 \mathrm{ng} / \mathrm{ml} \mathrm{PGE}_{2}$. After 6h maturation, DC were washed to remove the stimulation medium, and matured for an additional $18 \mathrm{~h}$ in AIM-V ${ }^{\circledR}$ medium only. (A) Percentage of $\mathrm{NKp}_{4} 4^{+} \mathrm{NK}$ cells isolated from tonsils, accumulating IL-22 after $16 \mathrm{~h}$ of co-culture as analysed by flow cytometry, gated on $\mathrm{CD} 56^{+} \mathrm{CD} 3^{-}$cells. Representative data of one out of 6 independent experiments are shown. (B) NKp44 $4^{+} \mathrm{NK}$ cells accumulating intracellular IL22 of 7 different donors. In 6 out of 7 donors an increase in \% of IL-22 positive NK cells was observed. Wilcoxon signed-rank test significance, ${ }^{*} P<0.05$. 
A
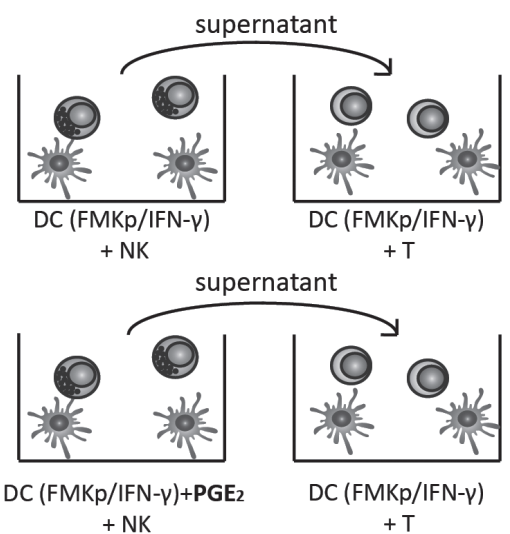

B
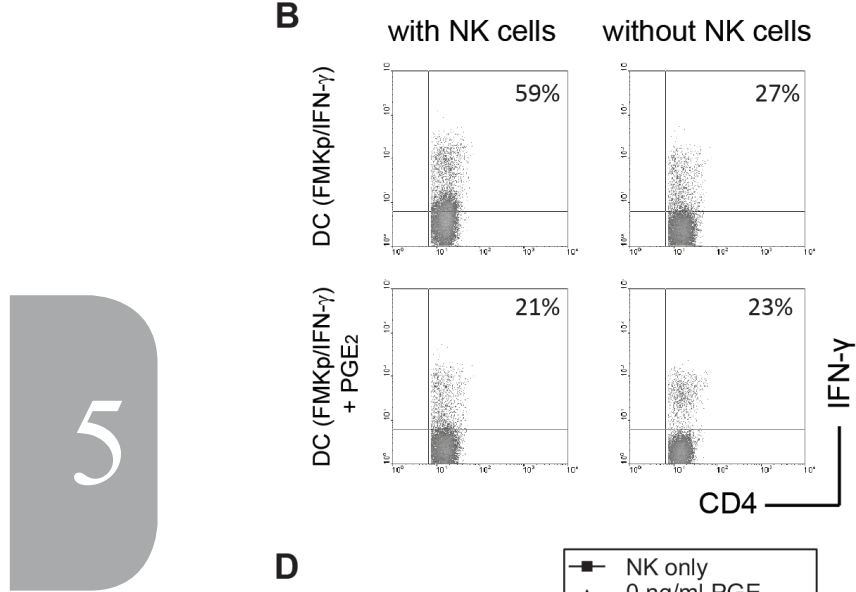

C
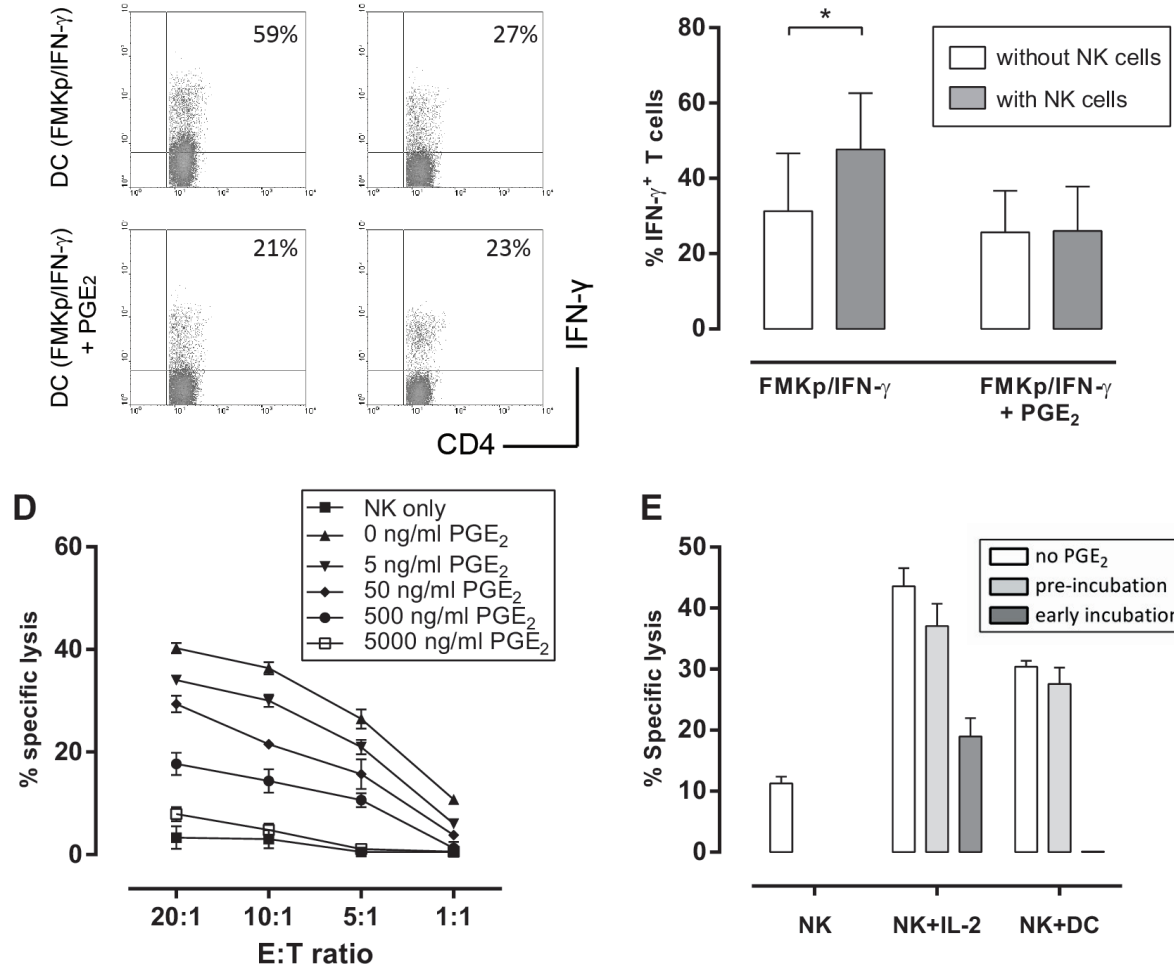

E

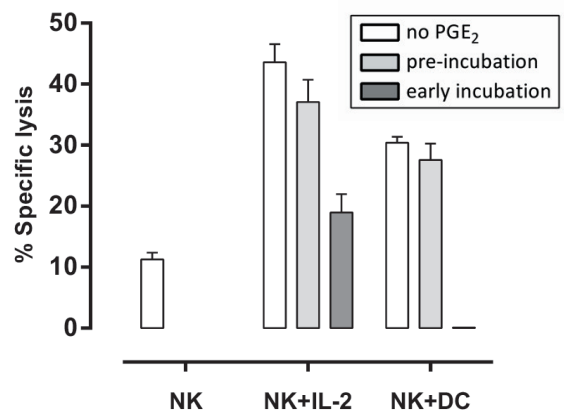

Figure 5 | Effect of PGE -matured DC on NK cell functions. (A) FMKp/IFN- $\gamma$-matured DC with or without $5 \mu \mathrm{g} / \mathrm{ml} \mathrm{PGE}$, were cultured for $24 \mathrm{~h}$ in the presence or absence of freshly isolated NK cells. FMKp/IFN- $\gamma$-matured DC were coated with Staphylococcal Enterotoxin B and co-cultured with freshly isolated $\mathrm{CD}^{-} 5 \mathrm{RA}^{+} \mathrm{CD} 45 \mathrm{RO}^{-} \mathrm{CD} 4^{+}$Th cells. Every other day stimulation medium was exchanged with supernatant from FMKp/IFN- $\gamma$-matured DC (with or without $5 \mu \mathrm{g} / \mathrm{ml} \mathrm{PGE}_{2}$ ) cultured with or without NK cells. (B) Percentage of naive $\mathrm{CD}^{+} \mathrm{T}$ cells accumulating IFN- $\gamma$ after 10 days of co-culture and stimulation with PMA/ionomycin for $4 \mathrm{~h}$ as analysed by flow cytometry, gated on $\mathrm{CD}^{+}{ }^{+} \mathrm{CD} 3^{+} \mathrm{T}$ 
cells. Representative data of one out of 5 independent experiments are shown. (C) CD45RA CD45RO$\mathrm{CD}^{+}$Th cells accumulating intracellular IFN- $\gamma$. Results are represented as mean of combined data of 5 different donors plus SEM. (D) Freshly isolated human NK cells and undiluted, filtered supernatants of FMKp/IFN- $\gamma$-DC matured in the presence of different concentrations of $\mathrm{PGE}_{2}$ were used for induction of NK cell cytotoxicity. NK cell cytotoxicity towards Raji cells was assessed by a flow cytometrybased kill assay. Data represent means \pm SEM of triplicate wells. Data shown are representative of 3 independent experiments. (E) Cytotoxicity towards Raji cells without, after pre-incubation and early incubation of NK cells with $\mathrm{PGE}_{2}$ and activation in DC supernatant. Data represent means plus SEM of triplicate wells of E:T ratio of 10:1. Data are representative of 3 independent experiments. ${ }^{*} P<0.05$.

\section{Decreased activation of NK cells by $P G E_{2}$-matured DC inhibits NK cell-dependent Th1 polarization and augmentation of cytotoxicity}

NK cell-derived IFN- $\gamma$ has been implicated in the induction of Th1 polarization ${ }^{31,43}$. Consequently, it can be anticipated that the decreased activation of NK cells by DC matured in the presence of $\mathrm{PGE}_{2}$ results in decreased Th1 polarization. To evaluate whether this hypothesis is true, DC (washed after 6h maturation) were matured with or without $\mathrm{PGE}_{2}$ and after $24 \mathrm{~h} \mathrm{NK}$ cells were added. In this experiment we were only interested in the effect of NK cell-derived cytokines on Th1 polarization and not in the previously reported negative effect of $\mathrm{PGE}_{2}$-matured DC on Th1 skewing. Therefore, DC without $\mathrm{PGE}_{2}$ stimulation were coated with SEB and used in a T cell stimulation assay. To study the effect of NK cell-secreted cytokines, $\mathrm{T}$ cell stimulation medium was exchanged every other day by the supernatant of the NK-DC co-cultures (Figure 5A). Th1 polarization was detected by accumulation of the Th1 cytokine IFN- $\gamma$ (Figure 5B). Only T cells stimulated with medium of NK-DC co-cultures, in which the DC were not triggered with $\mathrm{PGE}_{2}$ during maturation, benefited from the Th1 polarizing effect of NK cells, as more IFN- $\gamma$ producing $\mathrm{T}$ cells were detected (Figure 5C).

Previously, we showed that FMKp/IFN- $\gamma$-matured DC are able to augment NK cell cytotoxicity, which is mediated by DC-derived IL-12 ${ }^{32}$. These observations opened the possibility that $\mathrm{PGE}_{2}$-triggering of $\mathrm{DC}$ could abrogate the beneficial effect on $\mathrm{NK}$ cell cytotoxicity. To evaluate this, kill assays against the NK-cell resistant Raji cells were performed. Raji cells are insensitive for lysis by naive NK cells, however, if NK cells are pre-activated, they become able to kill Raji cells. When DC were matured with increasing concentrations of $\mathrm{PGE}_{2}$, NK cell-mediated lysis of target cells decreased (Figure 5D). These data indicate that $\mathrm{PGE}_{2}$ does not only inhibit $\mathrm{NK}$ cell cytotoxicity via direct action on NK cells (Figure 1B), but also indirectly affects augmentation of NK cell cytotoxicity via its effect on DC maturation. Taken together, these data show that PGE ${ }_{2}$ inhibits NK cell-mediated cytotoxicity via two independent mechanisms.

To determine whether activation of NK cells by NK-DC crosstalk could overcome the 
negative effect of $\mathrm{PGE}_{2}$ on $\mathrm{NK}$ cell-mediated cytotoxicity, killing of Raji cells was tested with either NK cells pre-incubated with $\mathrm{PGE}_{2}$ (pre-incubation) before stimulation with DC supernatant or $\mathrm{NK}$ cells triggered with $\mathrm{PGE}_{2}$ during stimulation with DC supernatant (early incubation). Flow cytometric analysis showed that $\mathrm{NK}$ cells pre-incubated with $\mathrm{PGE}_{2}$ are able to kill Raji cells when activated by DC (Figure 5E). When PGE ${ }_{2}$ was present during the NK cell activation, the killing of Raji cells was decreased. However, when NK cells are pre-activated by $\mathrm{DC}, \mathrm{PGE}_{2}$ had a minor inhibitory effect on $\mathrm{NK}$ cell cytotoxicity, indicating that the negative effect of $\mathrm{PGE}_{2}$ on $\mathrm{NK}$ cells is partly overcome.

In summary, these results show that $\mathrm{PGE}_{2}$-matured DC inhibit NK-cell mediated Th1 polarization and also suppress augmentation of NK cell killing capacity.

\section{DISCUSSION}

COX2-derived $\mathrm{PGE}_{2}$ is abundantly expressed in various malignancies and is one of many factors that directly promote tumour growth by regulation of cancer cell proliferation, apoptosis, migration, and invasion ${ }^{7-11}$. Moreover, $\mathrm{PGE}_{2}$ plays a pivotal role in immunosuppression creating a tumour supportive environment by inhibiting tumour immunosurveillance. Increasing the knowledge about the mechanisms by which $\mathrm{PGE}_{2}$ mediates immunosuppression is crucial in understanding tumour formation and might lead to the development of new immunotherapeutic strategies for cancer.

In this paper, we report on a novel mechanism by which $\mathrm{PGE}_{2}$ inhibits $\mathrm{NK}$ cell effector functions. In addition to its inhibition of $\mathrm{NK}$ cell activation by direct binding to $\mathrm{NK}$ cells, PGE ${ }_{2}$ also inhibits crosstalk with FMKp/IFN- $\gamma$-matured DC. This is mediated via modulation of chemokine and cytokine secretion of FMKp/IFN- $\gamma$-matured DC, which is responsible for inhibition of $\mathrm{NK}$ cell recruitment and activation. We show that $\mathrm{PGE}_{2}$ has an inhibitory effect on the secretion of CCL5, CXCL10, and CCL19, which are implicated in NK cell migration ${ }^{31,38}$. Decreased production of DC-derived CCL19 (implicated in naive T cell recruitment) and CCL5 due to $\mathrm{PGE}_{2}$-triggering has recently been described ${ }^{22,44}$. Interestingly, the effect of $\mathrm{PGE}_{2}$ on chemokine secretion is imprinted during DC maturation as we show that $\mathrm{PGE}_{2}$ stimulation after maturation does not influence chemokine secretion.

Additionally, our data evidence that $\mathrm{NK}$ cell activation is altered due to the effect of

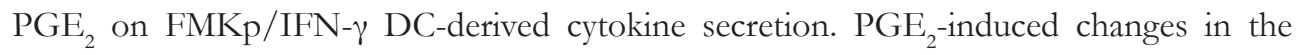
IL-12/IL-23 balance of DC have been described to account for skewing of Th1 responses towards Th2/Th17 responses ${ }^{15,16,19}$. Here, we show that it is also responsible for decreased IFN- $\gamma$ secretion by $\mathrm{NK}$ cells. In addition, $\mathrm{PGE}_{2}$ is responsible for decreased production 
of IL-18, which is besides IL-12 an important cytokine for NK cell activation. This is in apparent paradox to the reported IL-18-mediated induction of $\mathrm{PGE}_{2}$ secretion in the synovial fluid of osteoarthritis patients ${ }^{45}$. Possibly, this represents a feed-back loop by which $\mathrm{PGE}_{2}$ constrains inflammation during a normal immune response. Mainly the decreased production of IL-12 by FMKp/IFN- $\gamma$-matured DC due to PGE 2 accounts for the inhibition on IFN- $\gamma$ secretion, since addition of IL-12 restores IFN- $\gamma$ secretion by NK cells. However, our data do not preclude that other cytokines that have an inhibitory effect on $\mathrm{NK}$ cell activation are produced by $\mathrm{DC}$ in response to $\mathrm{PGE}_{2}$-triggering. As a functional consequence of the DC-mediated effect of $\mathrm{PGE}_{2}$ on NK cell activation, NK celldependent Th1 polarization and tumour cell lysis are inhibited. Interestingly, the reported effect of $\mathrm{PGE}_{2}$ on NK-DC interaction was not only demonstrated for monocyte-derived DC, but also for blood-derived BDCA- $1^{+}$DC that were matured with FMKp/IFN- $\gamma$ in the presence of $\mathrm{PGE}_{2}$ (Figure S2). Additionally, the effect of $\mathrm{PGE}_{2}$ could also be induced by tumour cell-derived $\mathrm{PGE}_{2}$. Under different cell culture conditions the same tumour cells did not produce $\mathrm{PGE}_{2}$, but were still able, though less efficiently, to inhibit NK-DC crosstalk (Figure S3 A, B). A candidate for this inhibition is TGF- $\beta$, which is possibly one of many immunosuppressive factors produced by this cell line (Figure S3 C). These data illustrate the redundancy of different tumour-derived factors on NK-DC crosstalk during different culture conditions. We anticipate that among the many mechanisms tumours have to escape immunosurveillance, $\mathrm{PGE}_{2}$ is very potent to prevent $\mathrm{NK}-\mathrm{DC}$ interactions because the application of COX-inhibitors in tumour-bearing mice completely restores the reduced CCL5 and IL-12 production of myeloid cells ${ }^{14,44}$.

In relation to the enhanced production of $\mathrm{IL}_{-2} 3$ by $\mathrm{PGE}_{2}$-stimulated $\mathrm{DC}$, it is relevant to note that Cella et al. reported on an NK cell subset (NK-22 cells) that resides in mucosaassociated lymphoid tissue, expresses NKp44 and produces IL-22 rather than IFN- $\gamma$ upon IL-23, IL-6, and IL-15 stimulation ${ }^{34}$. Additionally, they showed that these NK cells produce IL-22, IL-26, and leukemia inhibitory factor after contact with IL-23-producing monocytes that were stimulated with LPS. This NK cell subset was suggested to contribute to mucosal homeostasis, since IL-22 induces production of the anti-inflammatory cytokine IL-10 by epithelial cells $34,41,46,47$. We show here that $\mathrm{PGE}_{2}$ is responsible for the maturation of DC that are capable of inducing mucosal NKp44+, IL-22-secreting NK cells and not IFN- $\gamma$-secreting peripheral NK cells. Given the fact that NKp44 ${ }^{+} \mathrm{NK}$ cells produce IL-22 in response to IL-23, the increased IL-23 secretion of $\mathrm{PGE}_{2}$-matured FMKp/IFN- $\gamma$ DC could represent one of several mechanisms by which DC induce IL-22 secretion of these NK cells ${ }^{34}$.In this light, it is interesting to note that IL-22 as well as tumour-derived PGE 2 have the same immune-protective effects on epithelial cells, which is characterized by increased proliferation and decreased apoptosis ${ }^{7}$. It can be hypothesized that the IL-22, secreted by NK cells, also has this effect on tumour cells (Figure S4). Future studies addressing this 
question are of significance to elucidate the function of these $\mathrm{NKp} 44^{+} \mathrm{NK}$ cells in cancer.

As demonstrated by us and others, PGE $_{2}$ induces expression of CCR7 on DC and functionally increases their migratory responsiveness to lymph node-homing chemokines in vitro $22,35,39$. Based on these observations, $\mathrm{PGE}_{2}$ is often incorporated in DC maturation cocktails used in clinical vaccination studies. Our data on the inhibitory effect of PGE $_{2}$ on NK-DC interaction in combination with previous reports on enhanced Th17 and Th2 induction by $\mathrm{PGE}_{2}$-matured DC and the decreased ability to induce antigen-specific CTL ${ }^{35}$ argue against the use of $\mathrm{PGE}_{2}$-matured $\mathrm{DC}$ in DC-based vaccines, as it does not contribute to in vivo DC migration and has detrimental effects on immune effector mechanisms. In addition, Muthuswamy et al. showed that increased CCR7 expression of $\mathrm{PGE}_{2}$-matured DC, as compared to TLR-matured DC, correlates with their lack of CCL19 production ${ }^{48}$. If TLR-matured DC that express low levels of CCR7 are cultured in an environment with low concentrations of CCL19, CCR7 expression is increased. Additionally, they showed in a clinical trial that $\mathrm{PGE}_{2}$-matured DC demonstrated no advantage over TLR-triggered DC in lymph node homing. In the current study, we show that the effect of $\mathrm{PGE}_{2}$ is imprinted during FMKp/IFN- $\gamma$-DC maturation since cytokine and chemokine secretion is only affected by $\mathrm{PGE}_{2}$ in the first $6 \mathrm{~h}$ of maturation and this effect is mainly mediated via EP2 and EP4 and depends on cAMP signalling. In terms of vaccination protocols, these data support the application of ex vivo-matured DC in patients with tumours secreting $\mathrm{PGE}_{2}$. Moreover, our data indicate that $\mathrm{PGE}_{2}$ does not induce permanent changes in NK cell cytotoxic capacity, since the suppressive effect of $\mathrm{PGE}_{2}$ on NK cells can be easily overcome by DC-induced NK cell activation. However, to effectively activate NK cells, NK-DC interaction should take place in an environment with low concentrations of PGE $_{2}$, emphasizing the need of NK cell recruitment by DC. Our results also open the possibility to combine DC vaccination with COX2-inhibitory therapy, which has previously been shown in mouse models to enhance the efficacy of cancer vaccines ${ }^{49,50}$.

In conclusion, we report on a novel immunosuppressive effect of $\mathrm{PGE}_{2}$, mediated by FMKp/IFN- $\gamma$-matured DC, on NK cell function. These current data help to understand the complex role of $\mathrm{PGE}_{2}$ in the regulation of immune responses during inflammation. The extent of the $\mathrm{PGE}_{2}$-effect on the immune system in relation to other tumour-derived factors and thereby the redundancy of this mechanism is yet not completely elucidated and in vivo studies should be performed to answer this question. However, we show in vitro that the immunosuppressive effect of $\mathrm{PGE}_{2}$ on NK-DC interaction possibly represents one of many tumour-mediated mechanisms to hamper acute immune responses. 


\section{ACKNOWLEDGEMENTS}

The authors thank Prof. Dr. R.J. Stokroos (Department of Otorhinolaryngology-Head \& Neck Surgery, Maastricht University Medical Centre, Maastricht, the Netherlands) for the logistics to obtain tonsils and M.I. Zonneveld (BSc) for technical assistance. This work was supported by SenterNovem (project IS055002 to W. T. V. G. and G. M. J. B.) and the National Research Fund, Luxembourg (T.O.)

\section{REFERENCES}

1. Funk CD. Prostaglandins and leukotrienes: advances in eicosanoid biology. Science. 2001;294(5548):1871-1875.

2. Wang D, Dubois RN. Eicosanoids and cancer. Nat Rev Cancer. 2010;10(3):181-193.

3. Williams ED, Karim SM, Sandler M. Prostaglandin secretion by medullary carcinoma of the thyroid. A possible cause of the associated idarrhoea. Lancet. 1968;1(7532):22-23.

4. Hoang B, Zhu L, Shi Y, et al. Oncogenic RAS mutations in myeloma cells selectively induce cox2 expression, which participates in enhanced adhesion to fibronectin and chemoresistance. Blood. 2006;107(11):4484-4490.

5. Trojan A, Tinguely M, Vallet S, et al. Clinical significance of cyclooxygenase-2 (COX-2) in multiple myeloma. Swiss Med Wkly. 2006;136(25-26):400-403.

6. Ladetto M, Vallet S, Trojan A, et al. Cyclooxygenase-2 (COX-2) is frequently expressed in multiple myeloma and is an independent predictor of poor outcome. Blood. 2005;105(12):4784-4791.

7. Wang D, Wang H, Shi Q, et al. Prostaglandin E(2) promotes colorectal adenoma growth via transactivation of the nuclear peroxisome proliferator-activated receptor delta. Cancer Cell. 2004;6(3):285-295.

8. Tsujii M, Kawano S, DuBois RN. Cyclooxygenase-2 expression in human colon cancer cells increases metastatic potential. Proc Natl Acad Sci U S A. 1997;94(7):3336-3340.

9. Tsujii M, DuBois RN. Alterations in cellular adhesion and apoptosis in epithelial cells overexpressing prostaglandin endoperoxide synthase 2. Cell. 1995;83(3):493-501.

10. Sheng H, Shao J, Kirkland SC, et al. Inhibition of human colon cancer cell growth by selective inhibition of cyclooxygenase-2. J Clin Invest. 1997;99(9):2254-2259.

11. Williams CS, Tsujii M, Reese J, Dey SK, DuBois RN. Host cyclooxygenase-2 modulates carcinoma growth. J Clin Invest. 2000;105(11):1589-1594.

12. Harris SG, Padilla J, Koumas L, Ray D, Phipps RP. Prostaglandins as modulators of immunity. Trends Immunol. 2002;23(3):144-150.

13. Sinha P, Clements VK, Fulton AM, Ostrand-Rosenberg S. Prostaglandin E2 promotes tumor progression by inducing myeloid-derived suppressor cells. Cancer Res. 2007;67(9):4507-4513.

14. Mitsuhashi M, Liu J, Cao S, Shi X, Ma X. Regulation of interleukin-12 gene expression and its anti-tumor activities by prostaglandin E2 derived from mammary carcinomas. J Leukoc Biol. 2004;76(2):322-332.

15. Boniface K, Bak-Jensen KS, Li Y, et al. Prostaglandin E2 regulates Th17 cell differentiation and function through cyclic AMP and EP2/EP4 receptor signaling. J Exp Med. 2009;206(3):535-548.

16. Katamura K, Shintaku N, Yamauchi Y, et al. Prostaglandin E2 at priming of naive CD4+ T cells inhibits acquisition of ability to produce IFN-gamma and IL-2, but not IL-4 and IL-5. J Immunol. 1995;155(10):4604-4612.

17. Snijdewint FG, Kalinski P, Wierenga EA, Bos JD, Kapsenberg ML. Prostaglandin E2 differentially modulates cytokine secretion profiles of human T helper lymphocytes. J Immunol. 1993;150(12):5321- 
5329.

18. Sheibanie AF, Tadmori I, Jing H, Vassiliou E, Ganea D. Prostaglandin E2 induces IL-23 production in bone marrow-derived dendritic cells. Faseb J. 2004;18(11):1318-1320.

19. Khayrullina T, Yen JH, Jing H, Ganea D. In vitro differentiation of dendritic cells in the presence of prostaglandin E2 alters the IL-12/IL-23 balance and promotes differentiation of Th17 cells. J Immunol. 2008;181(1):721-735.

20. Stolina M, Sharma S, Lin Y, et al. Specific inhibition of cyclooxygenase 2 restores antitumor reactivity by altering the balance of IL-10 and IL-12 synthesis. J Immunol. 2000;164(1):361-370.

21. Zeddou M, Greimers R, de Valensart N, et al. Prostaglandin E2 induces the expression of functional inhibitory CD94/NKG2A receptors in human CD8+ T lymphocytes by a cAMP-dependent protein kinase A type I pathway. Biochem Pharmacol. 2005;70(5):714-724.

22. Watchmaker PB, Berk E, Muthuswamy R, et al. Independent regulation of chemokine responsiveness and cytolytic function versus CD8+ T cell expansion by dendritic cells. J Immunol. 2010;184(2):591597.

23. Ahmadi M, Emery DC, Morgan DJ. Prevention of both direct and cross-priming of antitumor CD8+ T-cell responses following overproduction of prostaglandin E2 by tumor cells in vivo. Cancer Res. 2008;68(18):7520-7529.

24. Sharma S, Yang SC, Zhu L, et al. Tumor cyclooxygenase-2/prostaglandin E2-dependent promotion of FOXP3 expression and CD4+ CD25+ T regulatory cell activities in lung cancer. Cancer Res. 2005;65(12):5211-5220.

25. Baratelli F, Lin Y, Zhu L, et al. Prostaglandin E2 induces FOXP3 gene expression and T regulatory cell function in human CD4+ T cells. J Immunol. 2005;175(3):1483-1490.

26. Joshi PC, Zhou X, Cuchens M, Jones Q. Prostaglandin E2 suppressed IL-15-mediated human NK cell function through down-regulation of common gamma-chain. J Immunol. 2001;166(2):885-891.

27. Yakar I, Melamed R, Shakhar G, et al. Prostaglandin e(2) suppresses NK activity in vivo and promotes postoperative tumor metastasis in rats. Ann Surg Oncol. 2003;10(4):469-479.

28. Linnemeyer PA, Pollack SB. Prostaglandin E2-induced changes in the phenotype, morphology, and lytic activity of IL-2-activated natural killer cells. J Immunol. 1993;150(9):3747-3754.

29. Mailliard RB, Alber SM, Shen H, et al. IL-18-induced CD83+CCR7+ NK helper cells. J Exp Med. 2005;202(7):941-953.

30. Walker W, Rotondo D. Prostaglandin E2 is a potent regulator of interleukin-12- and interleukin-18-induced natural killer cell interferon-gamma synthesis. Immunology. 2004;111(3):298-305.

31. Martin-Fontecha A, Thomsen LL, Brett S, et al. Induced recruitment of NK cells to lymph nodes provides IFN-gamma for T(H)1 priming. Nat Immunol. 2004;5(12):1260-1265.

32. Van Elssen CH, Vanderlocht J, Frings PW, et al. Klebsiella pneumoniae-triggered DC recruit human NK cells in a CCR5-dependent manner leading to increased CCL19-responsiveness and activation of NK cells. Eur J Immunol. 2010;40(11):3138-3149.

33. Ferlazzo G, Pack M, Thomas D, et al. Distinct roles of IL-12 and IL-15 in human natural killer cell activation by dendritic cells from secondary lymphoid organs. Proc Natl Acad Sci U S A. 2004;101(47):16606-16611.

34. Cella M, Fuchs A, Vermi W, et al. A human natural killer cell subset provides an innate source of IL-22 for mucosal immunity. Nature. 2009;457(7230):722-725.

35. Vanderlocht J, Van Elssen CH, Senden-Gijsbers BL, et al. Increased tumor-specific CD8+ T cell induction by dendritic cells matured with a clinical grade TLR-agonist in combination with IFN-gamma. Int J Immunopathol Pharmacol. 2010;23(1):35-50.

36. Papadopoulos NG, Dedoussis GV, Spanakos G, Gritzapis AD, Baxevanis CN, Papamichail M. An improved fluorescence assay for the determination of lymphocyte-mediated cytotoxicity using flow cytometry. J Immunol Methods. 1994;177(1-2):101-111.

37. Fulton AM, Chong YC. Prostaglandin E2 receptor activity and susceptibility to natural killer cells. J Leukoc Biol. 1992;51(2):176-180. 
38. Gustafsson K, Ingelsten M, Bergqvist L, Nystrom J, Andersson B, Karlsson-Parra A. Recruitment and activation of natural killer cells in vitro by a human dendritic cell vaccine. Cancer Res. 2008;68(14):5965-5971.

39. Boullart AC, Aarntzen EH, Verdijk P, et al. Maturation of monocyte-derived dendritic cells with Toll-like receptor 3 and 7/8 ligands combined with prostaglandin E2 results in high interleukin-12 production and cell migration. Cancer Immunol Immunother. 2008;57(11):1589-1597.

40. Harizi H, Grosset C, Gualde N. Prostaglandin E2 modulates dendritic cell function via EP2 and EP4 receptor subtypes. J Leukoc Biol. 2003;73(6):756-763.

41. Colonna M. Interleukin-22-producing natural killer cells and lymphoid tissue inducer-like cells in mucosal immunity. Immunity. 2009;31(1):15-23.

42. Sanos SL, Bui VL, Mortha A, et al. RORgammat and commensal microflora are required for the differentiation of mucosal interleukin 22-producing NKp46+ cells. Nat Immunol. 2009;10(1):83-91.

43. Morandi B, Bougras G, Muller WA, Ferlazzo G, Munz C. NK cells of human secondary lymphoid tissues enhance T cell polarization via IFN-gamma secretion. Eur J Immunol. 2006;36(9):2394-2400.

44. Qian X, Zhang J, Liu J. Tumor-secreted PGE2 inhibits CCL5 production in activated macrophages through cAMP/PKA signaling pathway. J Biol Chem. 2010.

45. Futani H, Okayama A, Matsui K, et al. Relation between interleukin-18 and PGE2 in synovial fluid of osteoarthritis: a potential therapeutic target of cartilage degradation. J Immunother. 2002;25 Suppl 1:S61-64.

46. Luci C, Reynders A, Ivanov, II, et al. Influence of the transcription factor RORgammat on the development of NKp46+ cell populations in gut and skin. Nat Immunol. 2009;10(1):75-82.

47. Wolk K, Sabat R. Interleukin-22: a novel T- and NK-cell derived cytokine that regulates the biology of tissue cells. Cytokine Growth Factor Rev. 2006;17(5):367-380.

48. Muthuswamy R, Mueller-Berghaus J, Haberkorn U, Reinhart TA, Schadendorf D, Kalinski P. PGE(2) transiently enhances DC expression of CCR7 but inhibits the ability of DCs to produce CCL19 and attract naive T cells. Blood. 2010;116(9):1454-1459.

49. Basu GD, Tinder TL, Bradley JM, et al. Cyclooxygenase-2 inhibitor enhances the efficacy of a breast cancer vaccine: role of IDO. J Immunol. 2006;177(4):2391-2402.

50. Mukherjee P, Basu GD, Tinder TL, et al. Progression of pancreatic adenocarcinoma is significantly impeded with a combination of vaccine and COX-2 inhibition. J Immunol. 2009;182(1):216-224. 


\section{SUPPORTING INFORMATION}

A
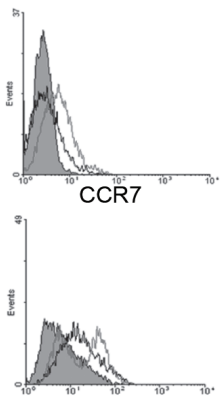

CD86
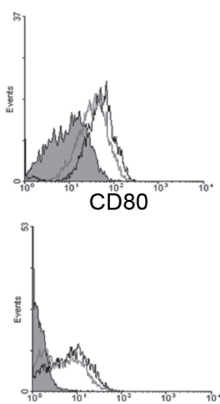

CD83
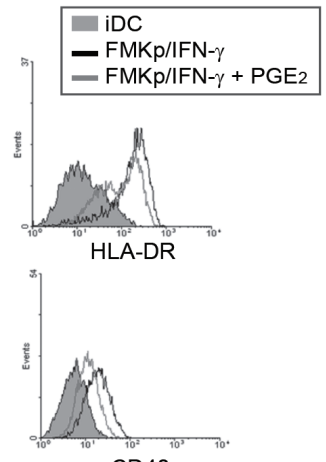

CD40

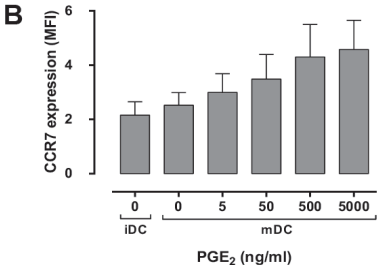

C

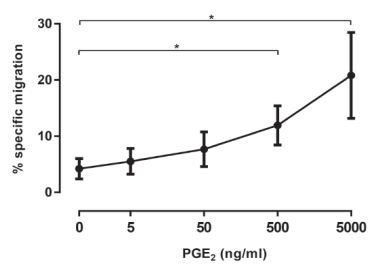

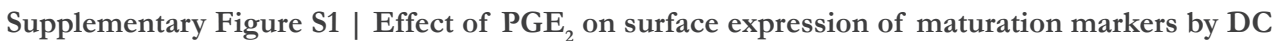
matured with FMKp/IFN- $\gamma$ and migration toward CCL19. Monocyte-derived DC were differentiated for 6 days by IL-4 and GM-CSF into immature DC. Maturation was induced by FMKp/IFN- $\gamma$ in the presence or absence of $5 \mu \mathrm{g} / \mathrm{ml} \mathrm{PGE}$. After $6 \mathrm{~h}$ maturation, DC were washed to remove the stimulation medium. DC were matured for an additional $18 \mathrm{~h}$ in AIM- $V^{\circledR}$ medium only. (A) Surface expression of HLA-DR, CCR7, CD80, CD83, CD86 and CD40 was evaluated by flow cytometric analysis. Grey filled histograms represent immature DC, solid black lines FMKp/IFN- $\gamma$-matured DC and grey lines represent FMKp/IFN- $\gamma$-matured DC in the presence of $5 \mu \mathrm{g} / \mathrm{ml} \mathrm{PGE}_{2}$. Representative data of one out of four different donors. (B) Expression of CCR7 as evaluated by flow cytometry. Results are presented as mean MFI plus SEM and are obtained from 3 different donors. (C) Percentage of DC specifically migrated towards a CCL19 gradient $(250 \mathrm{ng} / \mathrm{ml})$. Results are presented as mean plus SEM and are obtained from 3 different donors that were analysed in triplicate. ANOVA significance, ${ }^{*} P<0.05,{ }^{* *} P<0.01$. 
A
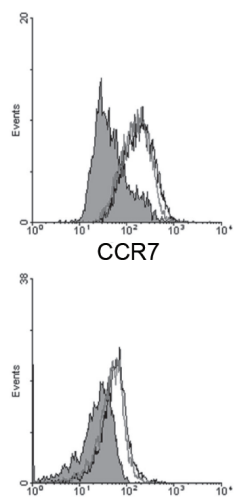

CD86
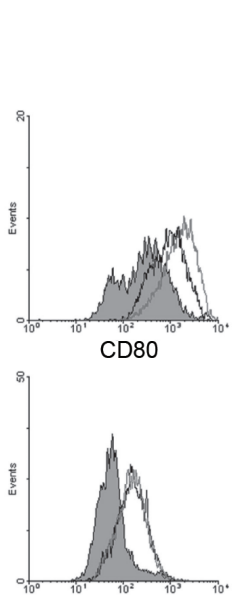

CD83
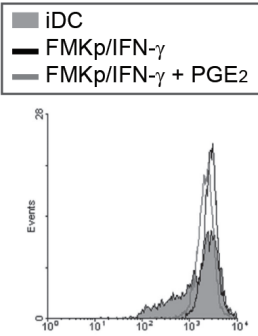

HLA-DR

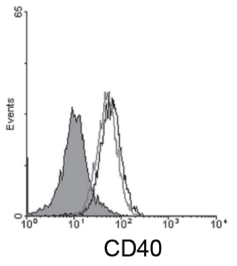

B

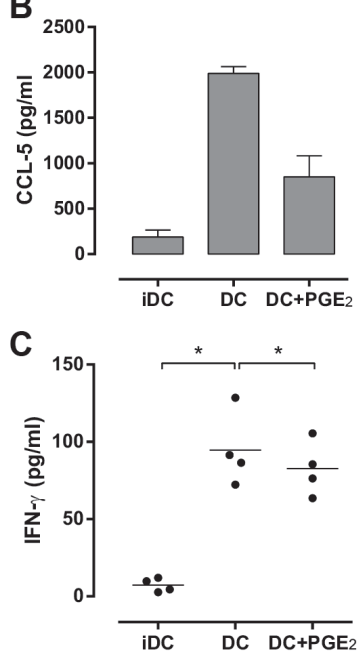

Supplementary Figure S2 | Phenotype, cytokine production and NK cell-activating properties of blood-derived BDCA-1 $1^{+}$DC. BDCA- $1^{+}$DC were isolated from $500 \mathrm{ml}$ of fresh blood using an immunomagnetic, negative isolation kit (Miltenyi Biotec). Cells were seeded at a density of $5 \times 10^{5}$ cells/ml in a 24-well plate and matured with FMKp/IFN- $\gamma$ or with FMKp/IFN- $\gamma$ in the presence of PGE $.6 \mathrm{~h}$ after maturation induction, the maturation stimuli were removed by extensive washing and DC were incubated in serum-free medium for $42 \mathrm{~h}$. (A) Flow cytometric characterization of differently matured BDCA-1 ${ }^{+}$DC. Grey, filled histograms represent the surface expression observed in non-matured BDCA- $1^{+}$DC, black line histograms represent the FMKp/IFN- $\gamma$-matured BDCA- $1^{+}$DC and grey line histograms represent FMKp/IFN- $\gamma$-BDCA- $1^{+}$DC matured in the presence of PGE ${ }_{2}$. Representative data of 2 independent experiments are shown. (B) CCL 5 production by differently matured BDCA-1 $1^{+}$DC as measured by ELISA. Data show the mean $+\mathrm{SD}$ of 2 independent experiments. (C) IFN- $\gamma$ secretion of NK cells cultured in the supernatant of the three differently matured $B D C A 1^{+}$DC. Fresh NK cells were cultured in the supernatant of differently matured BDCA $1^{+}$DC. After $24 \mathrm{~h}$ the supernatant was harvested and IFN- $\gamma$ was quantified with ELISA. NK cells from 2 different donors were cultured in supernatants of 2 different BDCA $-1^{+}$DC donors (ANOVA significance, ${ }^{*} P<0.05$ ). 

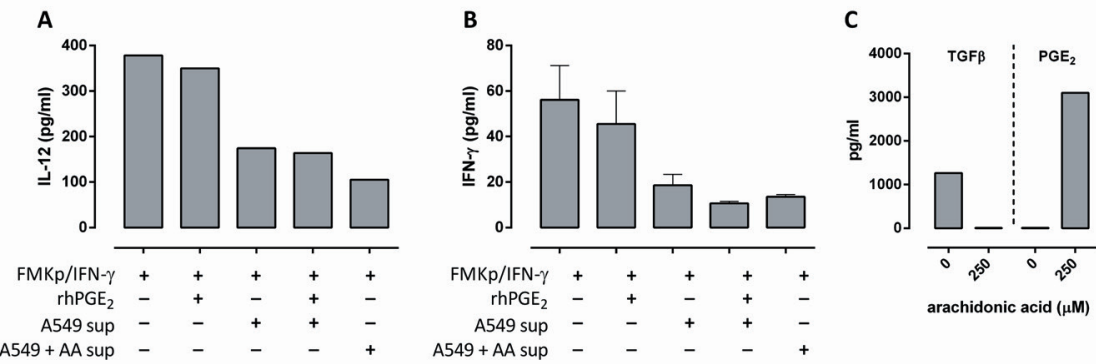

Supplementary Figure S3 | Effect of A549 cell-derived factors on NK-DC interaction. (A) IL-12 secretion of FMKp/IFN- $\gamma$ matured DC in serum-free or A549 tumour cell-conditioned medium with or without PGE. The A549 cell line was cultured for $48 \mathrm{~h}$ in serum-free AIM- $\mathrm{V}^{\circledR}$ medium in presence or absence of $(250 \mu \mathrm{M})$ arachidonic acid (AA). Immature DC were matured either in tumour cell-conditioned medium ( $\mathrm{PGE}_{2}$-producing or not) or in $\mathrm{AIM}-\mathrm{V}^{\circledR}$ supplemented with $\mathrm{FMKp} / \mathrm{IFN}-\gamma$ in the presence or absence of $\mathrm{rhPGE}_{2}$. After $6 \mathrm{~h}$, maturation stimuli were washed away and DC were incubated for an additional $18 \mathrm{~h}$ in AIM-V ${ }^{\circledR}$. Supernatant was collected and IL-12 was determined by ELISA. Data show the mean of 2 donors. (B) NK cell-derived IFN- $\gamma$ production in supernatant of FMKp/IFN- $\gamma$-DC matured in AIM- $V^{\circledR}$ or tumour cell-conditioned medium in presence or absence of $\mathrm{PGE}_{2}$ (recombinant or tumour cell-derived). Freshly isolated NK cells were co-cultured for $16 \mathrm{~h}$ with differently matured DC. IFN- $\gamma$ was quantified using Cytometric Bead Array (CBA). Shown results represent the mean plus SEM of NK cells from 2 different donors added to the supernatants of 2 different DC donors ( $\mathrm{n}=4$ ). (C) The A549 cell line was cultured for 4 days in serum-free medium with $(250 \mu \mathrm{M})$ or without AA. TGF- $\beta$ and PGE $_{2}$ were quantified using ELISA. 


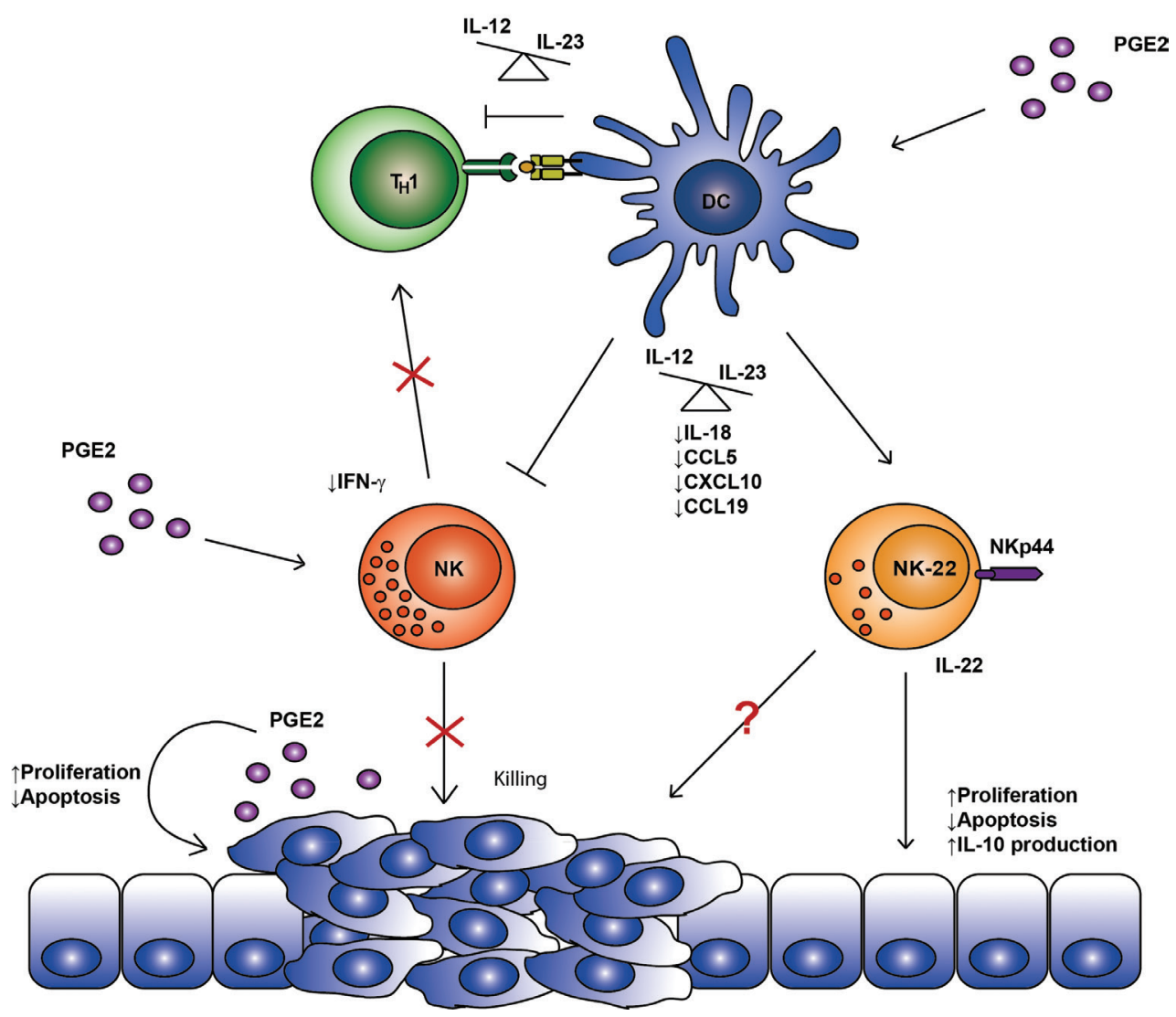

Supplementary Figure S4 | Model of the inflammation-restraining effects of PGE $_{2}$ on NK-DC interaction on tumour development. Presence of tumour-derived PGE during DC maturation inhibits the production of NK cell-recruiting chemokines (CCL5, CCL19, and CXCL10) and thereby decreases NK cell recruitment. Additionally, PGE ${ }_{2}$ reduces IL-18 production by DC and shifts the IL-12/IL-23 balance toward IL-23 production. This results in decreased IFN- $\gamma$ production and cytotoxic capacity of peripheral blood NK cells and enhanced secretion of IL-22 by NK cells residing in mucosa-associated lymphoid tissue. Decreased IFN- $\gamma$ production of NK cells together with the altered cytokine profile of $\mathrm{PGE}_{2}$-matured DC is responsible for inhibition of Th1 polarization. Tumour development is possibly stimulated by three independent effects of PGE: 1) Direct effect of $\mathrm{PGE}_{2}$ on tumour cell proliferation and apoptosis, 2) decreased killing of tumour cells by NK cells that were either directly stimulated with $\mathrm{PGE}_{2}$ or interacted with $\mathrm{PGE}_{2}$ triggered $\mathrm{DC}$ and 3) effects of IL-22, produced by NK cells that interacted with $\mathrm{PGE}_{2}$-stimulated DC, on tumour cell proliferation and apoptosis. 


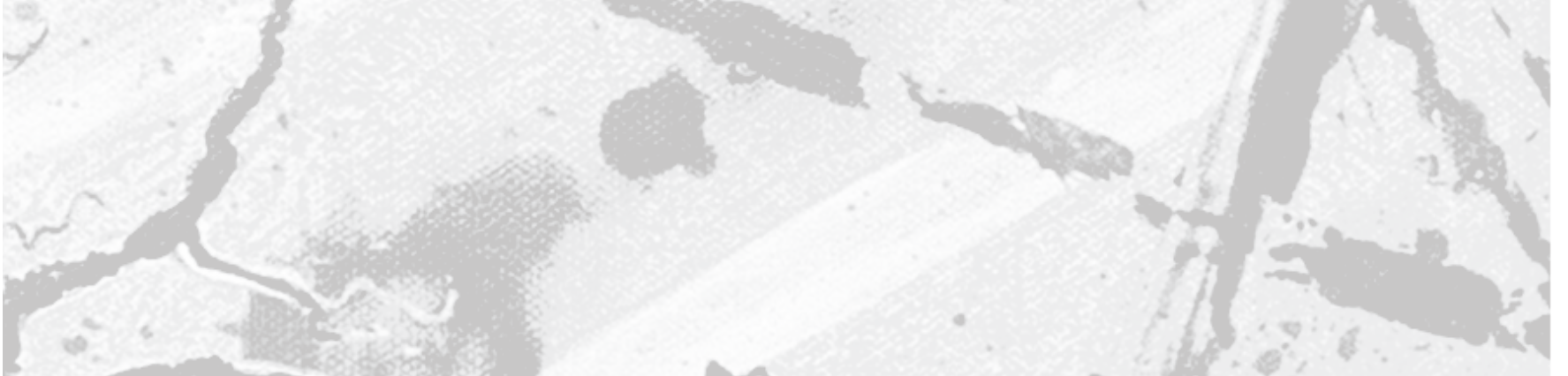

\section{General discussion}

Parts of this chapter have been adapted from:

Natural killer cells: the secret weapon in dendritic cell vaccination strategies Van Elssen C.H.M.J. ${ }^{1}$, Oth T. ${ }^{1}$, Germeraad W.T.V. ${ }^{1}$, Bos G.M.J. ${ }^{1}$, Vanderlocht J. ${ }^{2}$ Clin Cancer Res. 2014 Mar 1;20(5):1095-103. Review.

Tri-party crosstalk between dendritic cells, $T$ and natural killer helper cells will improve cancer vaccination

Oth T. ${ }^{1}$, Vanderlocht J. ${ }^{2}$, Van Elssen C.H.M.J. ${ }^{1}$, Bos G.M.J. ${ }^{1}$, Germeraad W.T.V. ${ }^{1}$ Submitted for publication. Review.

${ }^{1}$ Division of Haematology, Department of Internal Medicine, MUMC+, Maastricht

2 Tissue Typing Laboratory, Department of Transplantation Immunology, MUMC+, Maastricht 



\section{INTRODUCTION}

In 2011, Hanahan and Weinberg published 'the next generation of hallmarks of cancer' in which the classical hallmarks were extended from six to eight core hallmarks and two enabling characteristics ${ }^{1}$. Evasion of immune destruction is one of the newly recognized hallmarks and tumour-promoting (chronic) inflammation represents an enabling characteristic. This indicates on the one hand emerging complexity of tumour cell biology, but on the other hand also great progress in understanding initiation, sustainment, and progression of cancer.

The role of the immune system in the elimination but also in the development and progression of cancer as well as possible treatment target has been explored by scientists since the early 1890's. In the majority of the cases, the immune system recognizes and eliminates invading pathogens as well as altered cells and ensures protection of the host, (immunosurveillance). This concept was proven to hold true in several studies using genetically engineered mice, e.g. lacking IFN- $\gamma$ receptor, which showed higher tumour incidence as compared to their immunocompetent counterparts ${ }^{2}$. In case of cancer, the concept of immunosurveillance has been extended to cancer immunoediting, including the elimination phase (immunosurveillance), the equilibrium phase (survival of poorly immunogenic cells which undergo editing) and the escape phase (edited tumour cells grow out) ${ }^{2,3}$. As the immune system can both antagonize and enhance tumour progression, its targeting represents an interesting therapeutic approach.

Immunotherapy aims to stimulate or modulate the body's own immune response to specifically recognize and attack the tumour cells. This is different from conventional anticancer treatment regimens (e.g. chemotherapy, radiotherapy and surgery) whose primary goal is the direct targeting of the tumour; thus immunotherapy presents a different treatment approach. The development of cancer immunotherapy dates back more than a century and includes various strategies (recombinant protein technologies and cell-based therapies) as the tumour employs various strategies to evade immune-mediated attack. Several immunotherapeutic treatments have been approved as cancer treatment in the 80's and 90's including monoclonal antibodies $(\mathrm{mAb})$ as well as cytokines, however, it is only more recently that a revival of cancer immunotherapy has occurred. The FDA-approval of the first therapeutic cellular vaccine Provenge ${ }^{\circledR}$ (2010) was followed by the approval of two different checkpoint inhibitors (anti-CTLA-4 and PD-1) ${ }^{4}$. The latter target a receptor mainly expressed on $\mathrm{T}$ cells, which ligation would normally prevent the effector cells to attack tumour cells, a phenomenon sometimes referred to as 'releasing the breaks'. Anti-CTLA-4 (ipilimumab) treatment in patients with advanced melanoma increased the median survival by 4 months compared with patients treated with an experimental vaccine (gp100; 10 vs. 6 months median survival) ${ }^{5}$. Results for anti-PD-1 treatment were even more promising, in 
which $30 \%$ of patients with metastatic melanoma showing significant tumour regression ${ }^{6}$. Moreover, another cell-based therapy, the chimeric antigen-receptor (CAR) therapy, which aims to program the $T$ cells to kill the cancer cells, displayed promising results in clinical trials ${ }^{7}$. Altogether, these novel approaches with very promising success rates of clinical studies did lead to the designation of cancer immunotherapy as breakthrough of the year in $2013^{8}$.

As mentioned earlier several approaches of immunotherapy exist, which are currently under development and optimization, among them cellular therapeutic vaccines, exemplified by the Provenge ${ }^{\circledR}$. The advantage of such a specific active immunotherapy (as mono- or combination therapy) using dendritic cells (DC) is besides the potential modulation of existing memory responses (also achieved e.g. by checkpoint blockers) mainly the priming of de novo anti-tumour-specific immune responses and the induction of immunological memory to prevent tumour relapse. This requires the coordinated induction of innate and adaptive immune responses including cytotoxic T lymphocytes (CTL), T helper 1 (Th1) and natural killer $(\mathrm{NK})$ cells. Even though the feasibility of this approach was demonstrated in several studies, there is still need to increase its efficacy. Understanding and translating the knowledge on how DC induce and cooperate with innate and adaptive immune responses in vivo upon pathogen encounter a possible approach.

The coordinated cellular interplay is of crucial importance in host defence against pathogens. In this thesis, we explored the interaction of DC, NK and Th1 cells under the influence of a variety of pathogen-associated molecular patterns (PAMPs). Specific pattern recognition receptor (PRR)-triggering during the maturation of DC enabled them to enhance Th1 as well as NK helper cell responses. This effect was positively correlated with the amount of IL-12p70 released by the DC. Moreover, we showed that PAMPs could also directly activate NK helper cells. PAMP-activated NK cells were able to amplify the pro-inflammatory cytokine profile of DC via the release of IFN- $\gamma$. The knowledge on how PAMP recognition can directly (or indirectly) modulate the different effector cells of the immune system is of importance for the design of preventive and therapeutic vaccines and will be discussed in this chapter. Moreover, since specific PAMP-matured DC were efficient inducers both Th1 and NK cell responses, we will discuss their potential role in optimizing DC-based vaccines. Moreover, we revealed direct inhibitory effects of tumour-derived suppressive factors on the NK-DC crosstalk. In the last part of this chapter, we will discuss the role tumour microenvironment (TME) in vaccination efficacy and how it can be reversed. 


\section{ADJUVANTS: CRITICAL COMPONENTS IN ALL VACCINATION STRATEGIES}

The prevention of infectious diseases through the implementation of vaccination is one of the milestones of modern medicine saving countless lives. One of the key compounds of vaccines are adjuvants, which are added to induce, shape, enhance, accelerate, and prolong the immune responses against a desired vaccine antigen (Ag). These immunomodulators can be divided into three classes: delivery systems (non-immunogenic) increasing the delivery to target cells and influencing Ag-presentation, immune-stimulatory compounds (e.g. ligands of immune receptors) and the combination of both. The switch of modern vaccines from live attenuated or inactivated vaccines (mostly containing natural adjuvants) to the use of recombinant $\mathrm{Ag}$ and thus purified, defined, and safer components requires the inclusion of (defined) adjuvants to increase their immunogenicity. The change from natural to defined adjuvants requires the knowledge of their working mechanisms. Several parameters may influence the selection as well as the induced responses, such as properties of the $\mathrm{Ag}$, vaccination route, and target population ${ }^{9}$. Interestingly, the mechanisms of action of aluminium salt, the oldest adjuvant used in vaccination strategies, are still not yet completely elucidated.

DC represent a crucial target of most vaccine adjuvants, both in preventive and therapeutic vaccination strategies ${ }^{10,11}$. Depending on the environmental stimuli DC encounter, they transmit signals to immune effector cells inducing immunogenic or tolerogenic immune responses. Identifying how DC perceive danger signals leading to the generation of de novo immune responses against disease-associated $\mathrm{Ag}$ and which signals induce and enhance the interaction of DC with different immune effector cells is important to increase the efficacy of vaccination strategies.

Defining optimal adjuvants is important to e.g. (I) reduce number of immunizations, (II) ensure a rapid response towards pathogens, (III) reduce amount of Ag needed, (IV) to broaden the induced antibody (Ab) response, and $(\mathrm{V})$ to guide the induced immune responses and ensure the most effective and suitable response towards a particular $\mathrm{Ag}{ }^{9,12}$.

\section{PRR-triggering agents: Next-generation adjuvants in preventive vaccination?}

Over the last decades it has become clear that adjuvants such as oil-in-water emulsions and alum are a requirement for the effectiveness of vaccines against certain pathogens. However, these most frequently used adjuvants only induce suboptimal cellular immune responses. More recently, the use of selected innate triggers (PAMPs), which have been naturally part of live attenuated or inactivated vaccines, has been tested in clinical trials 
exploring the safety and effectiveness of these innate adjuvants on the promise they induce superior cellular immune responses ${ }^{13,14}$.

The induction of Th cells is a crucial step for vaccination efficacy. $\mathrm{CD} 4^{+} \mathrm{T}$ cells are important for helping both the cellular as well as the humoral arm of immune responses. Moreover, they are necessary for the induction of $\mathrm{CD}^{+}{ }^{+} \mathrm{T}$ cells as well as B cell memory ${ }^{15}$. Th cell polarization is influenced by antigen-presenting cells (APC), such as DC. Both the subset of DC being activated as well as the encountered trigger will influence the fate of Th cells. Even though a lot of promising adjuvants are revealed in experimental studies, clinical trials with beneficial outcome are scarce (reviewed in ${ }^{16}$ ). This discrepancy is at least in part explained by crucial differences between the animal models used and the complexity of the human immune system in vivo. For instance, TLR expression pattern and ligand specificity differ between mice and men 9,17,18. Therefore, it is important to study the polarization kinetics of naive $\mathrm{CD}^{+}{ }^{+} \mathrm{T}$ cells by differently matured $\mathrm{DC}$ in an autologous human system, as set up in chapter 2 . We provided proof-of-principle for the applicability of this assay for monocyte-derived (mo)DC as well as for the naturally circulating plasmacytoid DC (pDC). This assay can also be applied to study myeloid DC subsets. Even though it is a non-antigenspecific assay, such a method can be easily used to test different potential adjuvants (e.g. new classes of PRR triggers) on various DC subsets and monitor the resulting Th cell responses. This may confirm candidate adjuvants tested in animal models or identify new ones to be further evaluated in clinical trials. Furthermore, this assay can possibly be extended to study B cell class switching capacities of DC-induced Th cell subsets, another important aspect of adjuvants. The defined impact of the different adjuvants on $\mathrm{CD} 4^{+} \mathrm{T}$ cell responses and subsequent induction of humoral responses may help to predict vaccine adjuvant responses in vivo. However, in vitro cell culture systems still have the disadvantage of not being able to take into account the complex environment the adjuvant will exert its activities in vivo. As such, they are good tools to define the responses on a specific cell type level, but not taking into account contributions of inflammatory cytokines released, e.g. by non-circulating tissue cells due to adjuvant interaction.

In chapter 4, we showed that NK cells can also be directly targeted by TLR which enables NK cells to amplify DC responses and possibly enhances subsequent type-1 immune responses. The promotion of NK-DC crosstalk is an important parameter to consider during the selection process of an appropriate adjuvant. NK-DC crosstalk is important to enhance Th1 responses by providing IFN- $\gamma^{19,20}$. In this line, the yellow fever vaccine, a live attenuated vaccine, induces potent memory responses upon a single injection. Vaccine injection induced upregulation of TLR on NK cells, increased activation, and enhanced IFN- $\gamma$ levels ${ }^{21}$. Arguably, NK cells play a crucial role as amplifiers of vaccine-induced responses. Unpublished data by our group also showed the potential of TLR-activated 
NK cells to enhance cytokine secretion of $\mathrm{pDC}$. Thus, if potent cellular responses are desired (e.g. against intracellular pathogens), the choice of adjuvant should have direct NK cell-activating properties as well as indirect capacity via maturation of APC and enhancement NK-DC crosstalk.

T cells also express PRR and their expression pattern varies according to $T$ cell subset and maturation status ${ }^{22}$. $\mathrm{CD}^{+} \mathrm{T}$ cells do express a range of TLR; expression levels are low on naive $\mathrm{CD}^{+} \mathrm{T}$ cells but are upregulated upon TCR-signalling ${ }^{23-28}$. The stimulation of TLR acts as a co-stimulatory signal and enhances the proliferation, survival, and cytokine production of these cells. Likewise, triggering TLR2, TLR5 and TLR7/8 on human $\mathrm{CD}^{+} \mathrm{T}$ cells enhances proliferation and IFN- $\gamma$ secretion ${ }^{23,29}$. Importantly, the effect of TLR-triggering required TCR-stimulation of $\mathrm{CD}^{+} \mathrm{T}$ cells. Also $\mathrm{CD}^{+} \mathrm{T}$ cell responses can be modified by TLR recognition ${ }^{30}$. Thus, the potential direct effect of adjuvants on $T$ cells may offer a potent additional way to enhance vaccine-induced immune responses. However, more studies are still needed that focus on the direct effect of TLR- and other PRR-triggering on human T cell responses.

The key to determine the optimal use of TLR triggers as adjuvants lies most probably in vivo. During a pathogenic insult, the invader is able to trigger several PRR (on various cell types) leading to the induction of multiple signalling pathways and an optimal cooperation between different immune cells. As such, several experimental studies revealed additive or synergistic activation of DC and a resulting enhanced interaction with immune cells when multiple PRR pathways were stimulated ${ }^{31-34}$. This is in line with our data described in chapter 3, in which moDC triggered with a combination of TLR2, 3, and 4 induced more efficiently Th1 and NK cell responses compared to the single triggers. Likewise, live attenuated vaccines, such as yellow fever vaccine, can naturally trigger various TLR and thus multiple receptors on one DC or on different DC subsets and probably also directly stimulate other immune effector cells ${ }^{35}$. Strategies to optimize adjuvants by employing innate mechanisms of TLR-triggering should target multiple receptors. Therefore, there is rational to investigate which PRR triggers can be combined to activate synergistic signalling pathways. We screened various PRR triggers for their capacities to activate moDC by determining the expressing of costimulatory molecules and IL-12p70 production. It is plausible that several combinations will also be of inhibitory nature, e.g. when combining triggers of two different classes of pathogens. Possibly, a mixed response is induced in these cases. Moreover, recent evidence suggests that targeting non-immune cells, such as stromal cells, influences Th1 and $\mathrm{CD}^{+} \mathrm{T}$ cell responses, which is mediated by the release of type I IFNs after stimulation of MDA-5 on stromal cells ${ }^{36-39}$. This complex expression pattern of TLR/PRR on various immune and non-immune cells offers new combination strategies to maximize adjuvant capacities. As such, modern adjuvant selection could benefit 
from identifying potential synergic combinations of PRR triggers to enhance the induced immune responses against a particular Ag. Possibly, choosing a specific PRR trigger allows to better predict the induced responses in vivo as compared with the rather non-specific molecules (e.g. alum, MPL).

\section{PAMPs as tool to improve anti-cancer immunotherapy}

Despite great success of prophylactic vaccination against external pathogens, until now the application of therapeutic cancer vaccination is less effective. Even though, a stabilization of disease and prolonged survival were observed in some cases, limited effect on eliminating bulky tumours was observed ${ }^{40-43}$. The challenge of therapeutic vaccination is not only to induce memory, but also homing of appropriate immune cells into the tumour environment, inducing killing of tumour cells and avoiding immune suppression.

In order to obtain these desired immunologic responses it is an attractive strategy to exploit the nature's own mechanisms for inducing these responses under pathogenic threats. The recognition of PAMPs by cells of the immune system readily programs these mechanisms in vivo and therefore the use of carefully selected PAMPs holds promise for the application in therapeutic cancer immunotherapy. PAMPs can be used as stand-alone therapy, vaccine adjuvant, modulator for ex vivo DC generation or in combination strategies with radiotherapy, chemotherapy or targeted therapies in the treatment of cancer ${ }^{44}$.

Various TLR agonists have been applied as stand-alone therapies mainly in patients with melanoma but also other cancer types (table $1 \mathrm{in}^{44}$ ). Overall the success of these therapies has been limited and up-to-date only BCG (TLR2, 4, 9), MPL (TLR2, 4) and imiquimod (TLR7) have been approved by the FDA as TLR anti-cancer agents. One of the main differences between preventive and therapeutic use of PAMPs to stimulate the immune system is the presence of an immunosuppressive environment induced by the TME. The tumour is embedded in a complex microenvironment formed by lymphoid myeloid cells, stromal cells, vasculature, lymphatic vessel, cytokines and chemokines. The tumour itself can interfere by the expression of inhibitory ligands (e.g. PD-L1), creation of a tolerogenic environment (e.g. expression of IDO), and recruitment of regulatory cells (e.g. Treg, myeloidderived suppressor cells [MDSC], tumor-associated macrophages[TAM]). Apparently, these suppressive mechanisms of the TME prevail over the immunostimulatory mechanisms that are boosted if PAMPs are used as stand-alone therapy. Optimally, as illustrated in Figure 1, the desired effects of PAMPs used in anti-cancer therapeutic strategies should induce direct and indirect stimulatory effects on mainly APC, $\mathrm{CD}^{+}{ }^{+} \mathrm{T}$ cells, $\mathrm{CD}^{+} \mathrm{T}$ cells and $\mathrm{NK}$ cells. Ideally, therapies should be able to reverse the inhibitory effects of the TME (breaking the tolerance). 


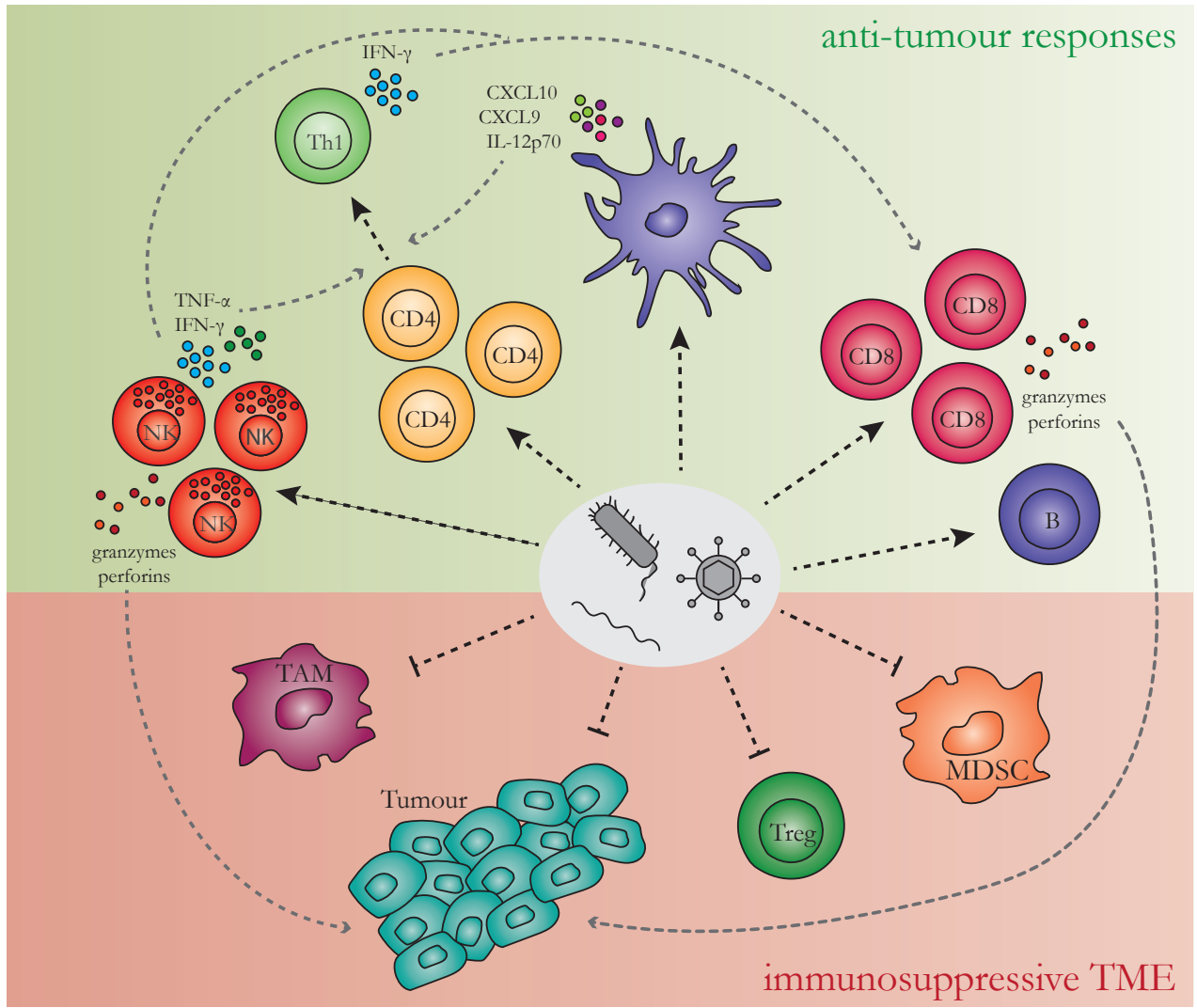

Figure 1 | Desired immune interactions upon PAMP stimulation. PAMPs should directly trigger cells involved in anti-tumour responses ( $\mathrm{NK}$ cells, $\mathrm{CD}^{+}$and $\mathrm{CD} 8^{+} \mathrm{T}$ cells, DC). Moreover, the cytokine milieu generated by their activation can break the tolerizing effects of the TME. Also, by choosing the proper PAMPs, a direct negative effect can be mediated on tumour cells and Treg.

Notably, tumour cells have been reported to express various PRR enabling them to respond to PAMPs and damage-associated molecular patterns (DAMPs) ${ }^{45-50}$. The induced effects by PRR-triggering are, however, still controversial. Several reports show that triggering of TLR on tumour cells leads to induction of apoptosis or potentiation of the tumour cells to be more easily killed by CTL or chemotherapeutic drugs. The latter is also referred to as 'tolerized' state of the tumour cell, induced by a strong stimulation of TLR. These cells were reported to be incapable to produce pro-inflammatory cytokines upon re-stimulation ${ }^{45,46}$. However, engagement of TLR by tumour cells has not only anti-tumour effects but can also induce pro-tumour effects. The expression levels of TLR by the tumour has been associated with poor prognosis ${ }^{47-49}$. The induced effects seem to be partly dependent on the type of cancer as reviewed in ${ }^{31,50}$. Moreover, the TME in which tumour cells encounter PAMPs may also influence the outcome, such as hypoxia, as well as a possible heterogeneous expression level on tumour cells. In vivo, the outcome of intra-tumoral injection of TLR may be 
dependent on the balance of tumour-infiltrating lymphocytes (TIL) and TME that can be tumour-specific.

Besides the dual function of TLR-triggering on tumour cells, the stimulation of TLR on Treg also has consequences for tumour progression. Similarly to effector T cells, also Treg cells express various TLR and were shown to enhance or inhibit suppression. Many studies analysed the expression pattern and addressed functional consequences of Tregtriggering in mice. Until now, human studies are limited; in one study, flagellin (TLR5 ligand) increased the suppressive capacity of Treg ${ }^{51}$. The triggering of TLR8 on $\mathrm{CD} 4{ }^{+} \mathrm{CD} 25^{+}$ Treg cells inhibited their regulatory effect ${ }^{52}$. Another study showed that the presence of TLR7/8, 2, 4 or 9 trigger inhibited the suppressive effect of Treg on $\mathrm{CD}^{+}$and $\mathrm{CD}^{+}{ }^{+} \mathrm{T}$ cell proliferation ${ }^{30}$. However, a more straightforward comparison of TLR expression on Treg and functional relevance in the human setting is needed to clearly allocate a role of these receptors in immune surveillance.

Even though TLR are by far the best described and characterized family of PRR, a down-side of applying TLR-triggering PAMPs as stand-alone therapy or as vaccine adjuvants may be their broad induction of immune responses targeting not only APC, NK, $\mathrm{CD}^{+}$or $\mathrm{CD}^{+} \mathrm{T}$ cells. The selection of single or a combination of TLR triggers requires careful consideration of expression pattern by tumour cells and Tregs as well as their functional effects on these cells. Moreover, even if some triggers are very potent immunomodulators, an accompanied toxicity upon systemic administration may limit the usage of the most effective dose or may require modulation of the PAMP to be less toxic. Predicting the effect of a specific TLR or a combination of several TLR being induced in a complex environment may be difficult; in vivo the interaction of different immune cells in combination with non-haematological cells as well as tumour type and TME composition potentially influences the outcome observed in vitro. However, the combination of TLR with other strategies aiming to reduce the immunosuppressive TME may be the key to success.

One way to counteract the immunosuppressive effects of the TME is the local delivery of IL-12 or IFN- $\alpha$. Whereas the systemic administration of these cytokines is toxic, intra-tumoral injection of PRR ligands may be used to locally produce these factors. Interesting in that respect is that some cytoplasmic receptors are expressed by almost all nucleated cells ${ }^{53}$. Engaging for instance RIG-I could locally lead to increased type I interferon production, but also block Treg suppression and induce the apoptotic programme in tumour cells 54, 55. Apoptotic material released from tumour cells may be taken up by DC favouring antigen-specific anti-tumour immune responses. This selective RIG-I trigger is currently tested in several experimental models. Exploring such tumour-targeting adjuvants having the properties to reverse suppressing TME and additionally have pro-apoptotic function on 
tumour cells may be more successful than APC (non-tumour)-targeting adjuvants.

Another approach to strengthen the effect of PPR ligands as adjuvants is coupling them to long synthetic peptides and assure their direct delivery to DC. Even though promising results have been shown by using $\mathrm{CpG}$ and Pam3CSK 4 as carriers by means of enhanced T cell responses and cross-priming ${ }^{56-58}$, using TLR may be suboptimal due to their non-APC specific expression. Other receptors specific for different DC subsets involved in Aguptake are better candidates for direct in vivo targeting of DC (e.g. DC-SIGN, DEC205, Mannose-1 receptor) as reviewed in ${ }^{59-61}$.

To conclude, the key approach of using PAMPs as stand-alone therapy or adjuvants in the setting of cancer relies in selecting triggers able to stimulate immune effector cells, to provide simultaneously a pro-inflammatory environment, and avoid pro-tumour activities and Treg activation. Moreover, the PRR ligand effect should be combined with other strategies to enhance the responses. Possibly, TLR triggers may not be the most appropriate PAMPs.

\section{INTERPLAY WITH HELPER CELLS AS A TOOL TO IMPROVE DC VACCINATION}

Since the first clinical trial with DC vaccination in $1996^{62}$, much effort on improving the efficacy of this potentially powerful anticancer therapeutic approach has been made. In 2010, the FDA approved the first DC-based vaccine against advanced prostate cancer ${ }^{42}$, called Provenge ${ }^{\circledR}$. This vaccine is prolonging the patient's progression-free survival for several months. Different ongoing clinical trials testing DC-based vaccination exemplify the potential role of DC-based vaccines in future standard treatments. However, the limited overall benefit on clinical outcome is indicative for the need of further optimizations.

\section{Importance of IL-12 - is it all we need?}

Whereas initial research focused on generating mainly tumour-specific CTL responses, it is becoming increasingly clear that the activation of multiple immune effector cells is the key to success for curative cancer vaccination. Ex vivo-matured DC should have the capacity to interact with endogenous immune cells of the patient and induce a potent type-1 immune response enabling the elimination of the tumour cells ${ }^{61}$. The criteria which a potent vaccine should fulfil are challenging, including co-activation of $\mathrm{CD}^{+}$and $\mathrm{CD} 8^{+} \mathrm{T}$ cells, priming of naive cells and modulating anergic memory $\mathrm{CD}^{+} \mathrm{T}$ cells, crosstalk with $\mathrm{DC}$ subsets and NK/NKT cells, and induction of long-lived memory. One way DC control and modulate adaptive immune responses is by their secretion of cytokines and chemokines. Different 
from signal 1 (TCR-MHC) and 2 (co-stimulation) required for proper tumour-antigenspecific T cell activation ${ }^{63,64}$, signal 3 (cytokines) is not only able to polarize T helper cells into a specific lineage, but can also recruit and activate other immune cells, such as NK cells ${ }^{19,65-70}$. Furthermore, the delivery of signal 4 (homing properties) is important to ensure recruitment of activated T cells ${ }^{71}$.

In chapter 3 of this thesis, we observed a significant positive correlation between the amount of IL-12 produced by moDC and the resulting polarization of naive $\mathrm{CD}^{+}{ }^{+} \mathrm{T}$ cell into Th1 cells and the induction of IFN- $\gamma$-producing NK cells. Even though IL-12 is known to be an essential factor driving Th1 responses ${ }^{67,72}$, this quantitative requirement needs to be taken into account while screening for new superior maturation cocktails or methods. These findings are strengthened by recent studies indicating a positive correlation between high IL-12p70-producing-DC and time to progression ${ }^{73}, 74$. Moreover, older studies tested the systemic application of IL-12 and revealed a positive anti-cancer effect. However, the implementation of rhIL-12p70 in cancer treatment approaches was hindered by its dose-limiting toxicities ${ }^{67,75-80}$. Altogether, these findings emphasize the use of IL-12p70-producing DC to ensure local production and delivery of this cytokine to come one step closer to successful vaccination strategies.

The failure of DC to produce ('high enough') IL-12p70 could be one of the factors explaining the marginal effects of DC-based vaccination clinical trials applying mainly $\mathrm{PGE}_{2} / \mathrm{TNF} \alpha( \pm \mathrm{IL}-6, \mathrm{IL}-1 \beta)$-matured DC (listed in ${ }^{81}$ ). We tested various DC maturation cocktails used in clinical trials $\left(\mathrm{PGE}_{2} / \mathrm{TNF}-\alpha[ \pm\right.$ IL-6, IL-1 $\beta]$, alpha-DC and LPS/IFN- $\gamma$ ) and we observed significantly less IL-12p70 levels compared to FMKp/IFN- $\gamma$-matured DC (unpublished data). FMKp/IFN- $\gamma$-DC were by far the highest IL-12-producers compared with other PRR triggers used in combination with IFN- $\gamma$. Moreover, in chapter 2, the importance of IL-12 on de novo generation of Th1 responses is underpinned, as only FMKp/IFN- $\gamma$-DC were able to polarize and induce IFN- $\gamma$ production in naive $\mathrm{CD}^{+}{ }^{+}$cells after co-culture. Such FMKp/IFN- $\gamma$-matured DC also induced the highest NK cell-derived IFN- $\gamma$ production, followed by LPS/IFN- $\gamma$ and alpha-DC-activated NK cells. Of note, soluble factors derived from PGE ${ }_{2} / \mathrm{TNF}_{-} \alpha$ ( \pm IL-6, IL-1 $\beta$ )-matured DC did not lead to NK helper activation (unpublished data and ${ }^{19}$ ).

Besides the finding that $\mathrm{PGE}_{2}$ exerts a direct inhibiting effect on DC-derived IL-12p70 production (chapter 5) another possible explanation for the $\mathrm{PGE}_{2}$-cocktail not to induce IL-12 production in DC is the absence of IFN- $\gamma$ in the maturation cocktail. It has been shown in several reports that IFN- $\gamma$ boosts DC cytokine production ${ }^{82}$ and additionally prevents DC from exhaustion status. In chapter 4 , we demonstrated that rhIFN- $\gamma$ dose-dependently determined the magnitude of IL-12p70 production (and production of $\mathrm{T}$ cell recruiting 
CXCL9 and CXCL10) by DC, whereas TNF- $\alpha$ had no effect on the DC-derived cytokine and chemokine production during the priming phase. However, $\mathrm{TNF}-\alpha$ was shown to be important for the up-regulation of co-stimulatory markers on DC ${ }^{83}$.

Different strategies to maximize the IL-12 production can be applied. One approach is the genetic manipulation of the dendritic cells ex vivo which was demonstrated to shape key immunological outcome parameters. Another approach is the use of PRR triggers during the ex vivo maturation of DC. Several murine and human in vitro studies illustrate that the combination of multiple PRR triggers and thus engaging multiple PRR-signalling pathways leads to synergistic effects on DC maturation ${ }^{39,84}$. As such, the selection of appropriate PAMPs for priming of DC having capacities to induce type- 1 immune responses is desired. In chapter 3, we showed that the strength of PRR-signalling by a single trigger can considerably enhance the IL-12p70 production. Furthermore, cooperative PRR-signalling by using the bacterial trigger FMKp and the viral trigger poly(I:C) (chapter 3) or CL075 ${ }^{85}$ leads to synergistic IL-12p70 production, followed by increased helper cell induction. This approach requires a thorough search for the most optimal combination of PAMPs of different origins (bacterial, viral, fungal) or triggering different PRR families (TLR, NOD, CLR, RLR). As illustrated in a publication of Jensen et al. ${ }^{82}$, the choice of proinflammatory cytokines incorporated into the maturation cocktails can lead to further optimization of cytokine-producing DC. In this line, NK cell-derived cytokines do have a decisive influence on DC-derived IL-12p70 production as illustrated in chapter 4. An increased IL-12p70 production can be achieved by simply adding higher concentrations of rhIFN- $\gamma$ to a particular PRR-containing cocktail. This provides proof-of-principle that pro-inflammatory cytokines can be applied to fine-tune the maturation conditions. In a similar approach, Berk et al. ${ }^{86,87}$ recently showed the possibility to use the supernatant of activated lymphocytes to induce maturation of DC including up-regulation of phenotype markers, IL-12p70 and CXCL10 production. These crosstalk features of DC with immune helper cells can be exploited to further boost the potential of moDC.

Even though high IL-12-producing DC can be generated in vitro by manipulating the composition of the maturation cocktail, one crucial criterion for efficient induction of immune responses is the production of IL-12p70 (and other cytokines and chemokines) in vivo upon DC re-administration into the patient. The cytokine measurement in the studies of this thesis were performed on 24/48h-matured DC. Most of the cytokines produced by moDC are released within the first $24 \mathrm{~h}{ }^{88}$. In addition, we and others previously showed that the cytokine induction programme is irreversibly primed in 6h-matured DC ${ }^{19,89,90}$. Clinical trials employ diverse strategies to mature DC; several studies use $24 \mathrm{~h} / 48 \mathrm{~h}$-matured exhausted DC which are not able anymore to produce IL-12p70, but regain this capacity after $\mathrm{T}$ cell encounter and the ligation of CD40. Others employ 6h maturation protocols, generating 
semi-mature DC retaining the capacity to produce IL-12 even before the encounter with T cells in vivo ${ }^{91}$. The latter approach is favorable since DC should retain the capacity to produce NK cell-recruiting chemokines well as NK cell-activating cytokines upon injection.

As diverse polymorphisms affect the IL-12p70 production of DC ${ }^{92-95}$, another option is to engineer DC via the usage of RNA, DNA or recombinant viruses to constitutively produce IL-12. mRNA electroporation of DC has been shown to be efficient and a clinically safe transfection method ${ }^{96,97}$. Another advantage of engineering DC is the specific selection of 'desired' cytokines produced by DC without the production of anti-inflammatory cytokines, e.g. IL-10, or silencing undesired properties. Interestingly, a study by Lipscomb et al. described an IL-12p70-independent mechanism for Th1 polarization when DC expressed ectopic T-bet (via adenoviral infection) ${ }^{98}$. These findings were translated into engineering syngeneic T-bet and IL-12p70 expressing DC. Injection of these DC into mice bearing subcutaneous tumours led to synergistic and robust Ag-specific type 1 immune responses including tumour rejection, cross-priming of $\mathrm{Ag}$ and infiltration of $\mathrm{CD}^{+} \mathrm{T}$ cells ${ }^{99}$. Thus, engineering DC provides a multitude of intervention points ${ }^{100}$ and displays a powerful approach to ensure long-lasting provision of cytokines, possibly in combination with other signals (enhancing stimulating or blocking negative modulators) in the TME.

Although we showed the importance of high IL-12p70-producing moDC for the induction of Th1 and NK cells responses, also other cytokines were shown in several studies to contribute in an additive or synergic manner to improved helper responses (e.g. IL-15, IL-18, IFN- $\alpha$ ). In chapter 2 , we showed that pDC activated by diverse PAMPs lead to the polarization of naive $\mathrm{CD}^{+} \mathrm{T}$ cells into Th1 cells. $\mathrm{pDC}$ can produce IL-12p70, however, compared to moDC and myeloid DC (myDC), their IL-12p70 production levels are very limited. Other mechanisms have been shown to facilitate IFN- $\gamma$ production, such as IL-18, IFN- $\alpha$, and IL-27 101, 102. Possibly, different DC subsets employ adjusted pathways to activate NK cells or Th1 cells. IFN- $\alpha$-secreted in high amount by pDC was shown to induce T-bet expression, however, this pathway is less stable compared to IL-12 induction. It remains to be established whether the potency of the different subsets to polarize naive cells into Th1 cells is comparable or whether high IL-12-producing DC subsets favour this induction. Also for NK cell activation, a two-signal activation is much more effective ${ }^{103,104}$. Likewise, IL-15 can potently enhance proliferation and survival of NK and T cells, as well as enhance NK-DC crosstalk ${ }^{105,106}$. Arguably, by choosing appropriate maturation stimuli, the DC cytokine profile can be fine-tuned or alternatively DC can be engineered to produce the 'optimal' cytokine combination. 


\section{Choosing the 'proper' DC subset}

Since DC are the starting point of inducing appropriate adaptive immune responses, such as generating Th cell responses, the DC subset choice is depending on the desired response. In therapeutic cancer vaccination type 1 immune response is desirable. Different DC subsets have been allocated with the induction of specific Th responses; CD14 ${ }^{+} \mathrm{DC}$ induce Tfh, LC prime Th2 and CD1c ${ }^{+}$DC lead to Th17 induction ${ }^{107,108}$. This knowledge is of crucial significance for DC vaccination approaches such as in vivo DC targeting or generating ex vivo-matured DC.

The discovery of methods to generate large numbers of monocytes and differentiate them into moDC ex vivo was the starting point for their use in cellular vaccines ${ }^{109,110}$. As a consequence, the vast majority of clinical trials has been using moDC as source of DC ${ }^{81}$. Depending on the maturation stimuli applied, these inflammatory DC are able to induce type $1 \mathrm{immune}$ responses including among others the secretion of pro-inflammatory cytokines (e.g. IL-12, IL-18), T and NK cell-recruiting chemokines, induction of Th1 polarization and CTL responses, and crosstalk with NK cells. Together with improvements in Ag-loading, maturation stimuli, administration regimens, and the measured clinical outcomes, ongoing and planned clinical trials applying 'next' generation DC vaccines may result in better and more promising clinical outcomes.

Compared to the naturally circulating DC, myDC and pDC, inflammatory moDC have all the functional capacities required to induce proper type 1 immune responses. One major difference with naturally circulating DC is the limited production of IFN- $\alpha$. pDC are able to secrete large amounts of this cytokine upon viral triggering which is important for the activation of B cells, T cells, and NK cells ${ }^{111,112}$. pDC are able to mediate direct cytotoxicity, but also play a role in cross-priming and $\mathrm{T}$ cell activation like myDC ${ }^{113-120}$. IFN- $\alpha$ has been shown to have adjuvant properties on innate and adaptive anti-tumour immunity ${ }^{121-124}$, however, the systemic administration of IFN- $\alpha$ as cancer treatment has been accompanied by toxic side-effects ${ }^{120,121,125,126}$. Thus, a more targeted delivery could be achieved by applying pDC as subset for ex vivo generated DC. pDC have been applied as DC-based vaccination approach in patients with melanoma ${ }^{114}$. The administration of $\mathrm{pDC}$ did lead to increased IFN- $\alpha$ levels as well as to the mounting of T cell responses. Interestingly, a recent study ${ }^{127}$ showed that the electroporation of moDC with IFN- $\alpha$ mRNA enhanced NK cell responses as well as WT-1-specific CTL compared to control DC. As moDC used in this study were matured with $\mathrm{PGE}_{2} / \mathrm{TNF}-\alpha$, it would be interesting to study the effect of a type-1 inducing DC maturation cocktail (e.g. FMKp/IFN- $\gamma$ ) inducing IL-12p70-producing DC in combination with IFN- $\alpha$ mRNA electroporation on immune effector cells. In addition, as one mechanism of action of $\mathrm{pDC}$ in vivo is thought to be the activation of myDC ${ }^{128-130}$ 
and thus enhancing anti-tumour responses, it would be interesting to study whether these engineered moDC are also able to interact with myDC.

Each subset is specialized in mediating appropriate immune responses upon pathogen encounter which is predicted by their repertoire of PRR. A logical step would be to combine naturally circulating DC and moDC obtained from one elutriation product as cancer vaccination and exploit their complementarity. Different scenarios are conceivable; likewise $\mathrm{pDC}$ and myDC cells can be activated together as it has been shown that the crosstalk between these two cell types enhances their activities ${ }^{128-131}$. For this approach the identification of common maturation conditions and optimal activation time frames as well as administration regimens has to be considered. The different subsets could also be activated separately and injected at different intervals in order induce the crosstalk only at the moment of injection.

Besides ex vivo generation or manipulation of DC, another more broadly applicable strategy is the in vivo targeting of naturally circulating DC and the reversal of their dysfunctionality in patients with cancer. In this respect, the administration of TLR9 trigger CpG did induce re-activation of impaired $\mathrm{pDC}$ in patients with multiple myeloma ${ }^{132}$. The use of TLR to stimulate DC in vivo has been discussed earlier. Thus instead of exploring the use of different DC subsets for the application of ex vivo-generated DC, improving in vivo-targeting of DC could be a more broadly applicable approach of future standard anti-cancer treatments. As DC population consists of a heterogeneous combination of subsets able to efficiently communicate with each other and instruct immune effector cells, several approaches can be applied to boost their anti-tumour inducing capacities; the choice of the proper subset as well as DC vaccine approach may be selected upon the cancer type and/or stage, as well as patient's immune system and TME.

\section{Importance of $\mathrm{CD}^{+} \mathrm{T}$ cells - more than helpers?}

Numerous lines of evidence indicate the crucial role of $\mathrm{CD}^{+}{ }^{+} \mathrm{T}$ cells in the generation of different aspects of adaptive immune responses. They are mainly important for the induction of potent CTL responses and for the generation of long-lived memory responses ${ }^{133}$. Furthermore, they also play an important role in modulating DC maturation by providing diverse cytokines. In mice, $\mathrm{CD}^{+}{ }^{+} \mathrm{T}$ cells were shown to be required for improved tumour elimination by $\mathrm{CD}^{+} \mathrm{T}$ cells ${ }^{134,135}$. $\mathrm{CD}^{+} \mathrm{T}$ cells enhanced the clonal expansion of $\mathrm{CD}^{+}$ $\mathrm{T}$ cells in secondary lymphoid tissue after vaccination and tumour-specific $\mathrm{CD} 4^{+} \mathrm{T}$ cells also facilitated recruitment, proliferation, and effector function of $\mathrm{CD}^{+}$into the TME by secretion of IFN- $\gamma$ and IL-2. Therefore, it is widely assumed that immunotherapeutic approaches require the involvement of $\mathrm{CD}^{+} \mathrm{T}$ cells. In vivo targeting of $\mathrm{DC}$ or ex vivo 
maturation of DC should enable them to prime Th1 responses. As mentioned earlier, we set up an assay to screen the capacity of differently matured DC (of different subsets) to induce the polarization of naive $\mathrm{CD}^{+}{ }^{+} \mathrm{T}$ cells. This system allows to monitor DC-mediated direction, potency, and kinetics of Th cell differentiation. As such not only the Th fate can be determined, but also valuable insight on the initiation of a de novo Th response can be obtained. It allows studying the effect of different PRR stimuli on DC-induced $\mathrm{T}$ cell polarization taking into account the interaction of all DC-derived soluble factors together with co-stimulatory molecules during priming of naive $\mathrm{CD}^{+} \mathrm{T}$ cell responses. Moreover, the effect of environmental factors, such as tumour-derived soluble factors, as well as immunomodulatory drugs on the priming phase of naive $\mathrm{CD}^{+} \mathrm{T}$ cell polarization can be studied. Another interesting aspect is the possibility for the parallel study of different $T$ helper cell subsets. As such, we revealed that $\mathrm{PGE}_{2} / \mathrm{TNF}-\alpha$ which has been mostly used in clinical studies induces a Th2-like response. Furthermore, in chapter 3, we screened over 40 different DC maturation cocktails for their capacity to promote Th1 responses. We observed a huge difference in Th1 polarization between the different DC, highlighting once more that the selection of appropriate DC maturation cocktails is a delicate task.

Recently, the targeting of $\mathrm{CD}^{+}$cells by vaccination with polytope mRNA vaccine (encoding immunogenic mutant class II epitopes) has shown to be very efficient in mice by meditating strong anti-tumour responses ${ }^{136}$. The vaccination led to reversal of TME and to the induction of CTL. Adding a human leukocyte antigen (HLA)-class II-targeting signal (DC-LAMP) to mRNA encoding tumour antigens will also activate Th1 and CTL responses ${ }^{137}$. These findings highlight the importance of $\mathrm{CD}^{+} \mathrm{T}$ cells in immunotherapy and consist a very promising approach to be applied in the clinic.

Importantly, $\mathrm{CD}^{+} \mathrm{T}$ cells are also directly involved in tumour killing ${ }^{138,139}$. Such $\mathrm{CD}^{+}$ CTL, comprise a subset of $\mathrm{CD}^{+} \mathrm{T}$ cells that loose the expression of ThPOK, a transcription factor repressing cytolytic development in $\mathrm{MHC}$ class II-restricted $\mathrm{CD} 4^{+}$ cells during development in the thymus. These $\mathrm{CD} 4^{+}$CTL have also been described as important players in viral infections. Similar to what occurs in $\mathrm{CD}^{+} \mathrm{CTL}$, the termination of ThPOK expression by $\mathrm{CD}^{+}$effector cells results in the up-regulation of granzyme $\mathrm{B}$, perforin and IFN- $\gamma$ secretion. The importance of this $\mathrm{CD}^{+}$-dependent killing mechanism remains to be established but the association between a reduced number of $\mathrm{CD} 4^{+} \mathrm{CTL}$ and survival in patients with hepatocellular carcinoma indicates that this may be a major mechanism of tumour control in certain malignancies ${ }^{140}$. Regarding their potential role in direct tumour killing, investigating how these cells can be primed and targeted in vivo could be an interesting target for enhanced anti-tumour responses. 


\section{Importance of NK cells}

Whereas previous approaches to optimize DC vaccination were mainly based on maximizing intra-tumoral $\mathrm{T}$ cell responses, also other players of the immune system may be important in the process of tumour cell elimination. NK cells are able to exert direct cytotoxic effects on tumour cells or iDC and indirectly modulate the adaptive immunity by cytokine secretion and communication with other immune cells ${ }^{141-144}$. In the past decade allogeneic NK cells were shown to be effective after haplo-identical stem cell transplantation in acute myeloid leukemia (AML) patients ${ }^{145,146}$. Moreover, low cytolytic activity of NK cells has been associated with $40 \%$ increased cancer risk compared to individuals with NK cells having high cytolytic activity ${ }^{147}$. Likewise, levels of intra-tumoral NK cells and NK cell activity are positively correlated with clinical outcome ${ }^{148-151}$. In patients with cancer, NK cell functions are often impaired displaying reduced cytolytic and cytokine-secreting capacities and reduced DC editing ${ }^{152-155}$. This can be partly explained by immune suppressive TME and the use of escape mechanisms by tumour cells.

The reciprocal effects of NK-DC interaction provide a strong rationale for the combined use of NK cells and DC in immunotherapeutic strategies to overcome dysfunction and enhance anti-tumour responses. With our recent understanding of the NK-DC interaction, one could argue that DC used in vaccination strategies should be matured in vitro in the presence of $\mathrm{NK}$ cells or $\mathrm{NK}$ cell-derived factors ${ }^{156}$ to maximize their maturation. These findings are strengthened in chapter 4 of this thesis, in which soluble factors derived from PAMP-activated NK cells did enhance the cytokine and chemokine profile of ex vivo-matured moDC.

From another point of view, there is rationale to optimize ex vivo maturation of DC as such that they are able to optimally recruit and activate NK cells ${ }^{19,157}$. The capacity of DC vaccination to efficiently interact with NK cells is influenced by multiple parameters such as the differentiation and maturation of DC, as well as the choice and delivery of Ag. We and others have shown that for optimal NK cell activation and recruitment, DC maturation protocols should contain TLR agonists. Also the cytokines used during the differentiation of monocytes (e.g. IFN- $\alpha$ or IL-15) can have an effect on the capacities of DC to recruit and activate NK cells ${ }^{157-161}$. PGE ${ }_{2}$, another DC-activating molecule produced during inflammation, has a negative effect on NK-DC cross-talk as shown in chapter $\mathbf{5}$. Of note, in a study of Jensen et al. ${ }^{82}$ investigating the effect of different combinations of recombinant human cytokines with PRR triggers, revealed that $\mathrm{PGE}_{2}$ production by moDC could also be induced upon selected maturation stimuli. The alpha-DC cocktail described by Mailliard et al. ${ }^{162}$ was among the PGE ${ }_{2}$-inducing cocktails. Despite the reports on the negative effects of $\mathrm{PGE}_{2}$-mediated $\mathrm{DC}$ maturation, most clinical trials use $\mathrm{PGE}_{2}$-matured 
DC. The rationale behind this is the in vitro capacity of these DC to migrate ${ }^{163}$. However, in in vivo studies, these DC migrate just as poor as non-PGE -matured DC $^{164}$. The lack of migratory capacity of TLR-matured DC in combination with their NK cell-recruiting capability opens the possibility for the combination of NK-DC therapy. In these therapies, NK cells and DC can be either simultaneously injected or only DC are injected to recruit NK cells. For the simultaneous injection of NK cells and DC, intra-tumoral injection may represent an attractive strategy. NK cells lyse tumour cells (NK cell-sensitive tumours), thereby making antigenic material available for DC to be taken up and presented. In addition, NK cells induce maturation of bystander DC and lyse inappropriately matured DC or iDC. Reciprocally, mature DC can activate NK cells to proliferate, secrete cytokines, and augment NK cell cytotoxicity. Another option is the injection of NK cells and DC in the tumour-draining lymph nodes where the Th1-polarizing capacity of the NK cells can be used to its fullest in this T cell-rich environment.

In addition to the simultaneous injection of both cell types, we propose a different strategy to enhance NK-DC interaction in DC vaccination: the development of a tertiary lymphoid structure (TLS). The density of such lymphoid islets adjacent to tumours in combination with mDC correlates with Th1/CTL TIL phenotype and with positive outcome ${ }^{165,166}$. In this strategy, only DC are administered and this option is based on the capacity of TLR-matured DC to produce chemokines and, thereby, selectively recruit effector cells ${ }^{167}$. Moreover, to ensure potent NK cell activation, selected TLR triggers could be co-administered with DC-based vaccines to ensure enhanced activation of NK cells as demonstrated in chapter 4. Even though, in a previous study we showed the requirement of IL-12 for efficient NK cell-derived IFN- $\gamma$-production activated by TLR-triggered DC, the co-administration of an additional PRR trigger as adjuvant could circumvent this need. In chapter 4, we showed that NK cells could also be activated by TLR triggers in the presence of another cytokine or a combination of cytokines different from IL-12p70. Because of the lack of in vivo DC migration, DC could be injected in tumour-draining lymph nodes or into the tumour vicinity, where they can recruit and interact with NK cells. DC-mediated chemokine production is also attractive for recruitment of CTL and Th1 cells ${ }^{168-170}$. We hypothesize that by recruiting all these effector cells by DC, the same interactions that take place in lymph nodes can be induced extranodally in a TLS. Whether the immunosuppressive effect of the TME has detrimental effects on effector cell induction by DC remains to be elucidated.

Besides targeting endogenous NK cells via DC vaccination or improving DC-based vaccination by NK cell-derived soluble factors, another approach is the adoptive transfer of NK cells. Even though adoptive transfer of NK cells is a separate line of anti-cancer immunotherapy, the proper manipulation of NK cells before administration to the patient could lead to enhancement of endogenous naturally circulating DC. Currently these 
optimizations aim to enhance the cytotoxic capacity of NK cells by the addition of various cytokines during expansion and the selection of appropriate allogeneic donors having KIR-ligand mismatched NK cells favouring their cytotoxic capacities. In chapter 4, we showed that the activation of NK cells in the presence of certain pathogenic triggers, such as poly(I:C) or FMKp, increased the helper function of NK cells. Moreover, increasing evidence in literature describes enhanced cytolytic capacities of NK cells after activation by PRR triggers ${ }^{171,172}$. Incorporation of TLR triggers to activate NK cells before injection could enhance the NK cell-mediated effects in vivo.

Notably, not all tumours are sensitive for NK cell-mediated cytotoxicity. Thus exploring the role of NK-DC crosstalk to enhance anti-tumour immunity besides the well-known lytic capacity of NK cells strengthens the importance of NK cells in immunotherapeutic approaches. Cytolytic capacity of NK cells is hampered by tumour cell evasion, which includes up-regulation of inhibitory ligands (MHC class I expression) and down-regulation of activating ligands for NK cell receptors ${ }^{173-178}$. Tumour-released factors, such as TGF- $\beta$, can down-regulate activating receptors on NK cells ${ }^{179}$ and additionally hamper NK cell-mediated lysis. Also the expansion of Treg in the TME was shown to constrain proliferation, cytolytic activity (NKG2D-dependent) and cytokine secretion of NK cells (via NK-DC crosstalk) ${ }^{180,181}$. Interestingly, the inhibiting effect of Treg on NK cells may be hampered depending on the activation of NK cells. Treg failed to repress IFN- $\gamma$ secretion by NK cells if they were activated by IL-2R $\gamma$-signalling (e.g. IL-2, IL-15) ${ }^{181}$. Furthermore, under specific circumstances, NK cells were shown to inhibit Treg expansion in an early phase of the immune response against intracellular pathogens ${ }^{182}$. Arguably, the mode of $\mathrm{NK}$ activation in combination with the tumour load may enhance direct and indirect $\mathrm{NK}$ cell-mediated effects during anti-tumour responses. Further research on how to stimulate Treg-resistant NK cells could, in addition to Treg-depleting regimens, increase NK cell-mediated anti-tumour effects.

NK-DC crosstalk, however, exerts not only immunostimulatory effects. In this line, a recent study of Sarhan et al. ${ }^{183}$ showed that NK-DC crosstalk is inhibited in the presence of IL-2 affecting $\mathrm{NK}$ cell-derived IFN- $\gamma$ production, cytolytic activity, and proliferation. IL-2 led to the phosphorylation of STAT3, which is in combination with p38 MAPK pathways known as negative regulator on DC function ${ }^{184}$. As consequence a reduced production of IL-12 and LT- $\alpha$ and increased secretion of the inhibitory cytokine TGF- $\beta$ were observed. Blocking of STAT3, as well as the addition of rhIL-12 reversed the IL-2 inhibiting effect on NK-DC crosstalk. Because NK helper cells will mostly interact with DC in the lymph nodes surrounded by naive T cells and Th1 cells and thus IL-2, this is an important aspect to consider for vaccination strategies. This could mean to select maturation cocktails leading to IL-12-producing DC with low STAT3 phosphorylation or pre-treating the DC with 
JAK/STAT inhibitor prior injection.

\section{INTERFERENCE OF TUMOUR MICROENVIRONMENT}

The direct effect of the TME on DC as well as the indirect effect on the DC-activated immune effector cells remains a major hurdle in therapeutic anti-cancer DC vaccine strategies and cancer immunotherapy in general. There is growing evidence that the host's immune system plays a crucial role in tumour progression ${ }^{149,185-187}$ and that the clinical outcome of treatment is dependent on the patient's TME acting as rheostat on induced immune responses. In this line, patients at the same stage of disease do display different clinical outcomes after intervention ${ }^{188}$.

The tumour is embedded in a complex microenvironment formed by lymphoid myeloid cells, stromal cells, vasculature, lymphatic vessel, cytokines and chemokines. The tumour itself can interfere by the expression of inhibitory ligands (e.g. PD-L1), creation of a tolerogenic environment (e.g. expression of IDO), and recruitment of regulatory cells (e.g. Treg, MDSC, TAM) ${ }^{189,190}$. Different approaches exist to turn the immunosuppressive environment into an immunosupportive milieu, which should avoid high amounts of TNF- $\alpha$, IL-1, IL-6, and IL-8 production and thus limiting chronic inflammatory state ${ }^{191}$.

\section{Myeloid-derived suppressor cells}

Cancer-derived factors, like G-CSF, GM-CSF, IL-1 $\beta$, PGE $_{2}$, TNF- $\alpha$, and VEGF, favour the generation and expansion of myeloid-derived suppressor cells (MDSC) 192, 193. This heterogeneous population of immature myeloid cells differentiates under normal physiological conditions into dendritic cells, neutrophils or macrophages. In the context of cancer and other pathologies, these cells can be recruited to the tumour site by CCL2, CXCL12 and CXCL5. Activated MDSC induce chronic tissue inflammation and immune suppression by producing factors such as reactive oxygen species (ROS), arginase-1, inducible nitric oxide synthase (iNOS), nitric oxide (NO), indoleamine 2, 3-dioxygenase (IDO), and immune suppressive cytokines ${ }^{194-197}$. These suppressive mediators affect the proliferation of $\mathrm{T}$ cells, increase apoptosis, induce anergic T cell status ${ }^{198-203}$ and promote the recruitment, induction and expansion of Treg ${ }^{182,204}$. Moreover, also NK cell functions are affected mainly via expression of TGF- $\beta$ by MDSC lowering the expression of NKG2D, cytolytic activity, and IFN- $\gamma$ production ${ }^{205,206}$. MDSC also negatively influence the phagocytosis, maturation, migration, and T cell stimulating capacities of DC. Furthermore, MSDC can also promote the differentiation of monocytes into TAM which release IL-6, IL-1 $\beta$, IL-10, TGF- $\beta$ and arginase-I ${ }^{193,202,207}$ and thus increase the tumour supportive environment. Altogether, these 
modulations on DC, T and NK cells responses (mainly in a non-antigen-specific manner) together with a balance shift towards Treg in the TME 208, 209, favour tumour progression. Thus, MDSC may be a component of the tumour environment responsible for the limited response induced by cancer vaccination. Importantly, in the absence of tumour-derived factors, MDSC retain the capacity to differentiate into mature myeloid cells. Hence, targeting MDSC may help to revert their immunosuppressive state. Cancer vaccination was shown to be more efficient in mouse models applying the blockage of MDSC ${ }^{210}$. Since the impact of MDSC is quite broad, multiple intervention strategies can be applied to reverse the mediated effects, including deactivation or differentiation into mature cells, inhibition of their development or depletion of MDSC ${ }^{211}$.

Several strategies to target MDSC are under investigation in the human setting for various types of cancer. Promoting the differentiation of MDSC seems to be an attractive approach to on the one hand restore the immune supportive tumour environment and on the other hand increase anti-tumour activity by generation of intra-tumoral mature myeloid cells. This approach was tested by using all-trans retinoic acid in patients with metastatic renal cell carcinoma and vitamin D3 in patients with head and neck cancer ${ }^{32,212}$. In mouse models it has been shown that IL-12 or IFN- $\alpha$ were able to convert MDSC into functional APC ${ }^{213-215}$. Furthermore, the administered IL-12 favours up-regulation of co-stimulatory molecules, limits the infiltration of MDSC and supports CTL recruitment induction and their survival 216,217 . This effect was also observed in a murine model of liver metastasis and a treatment consisting of gene transfer of IL-12 and chemotherapy ${ }^{218}$. A similar effect was shown by IFN- $\alpha$ favouring differentiation and maturation of MDSC and favouring an effector T cell-supportive environment ${ }^{219}$. Interestingly, CTL responses generated in the presence of IL-12 were shown to be more efficient in controlling the tumour due to lower levels of PD-1 expression as compared to CTL induced in IFN- $\alpha$ environment ${ }^{220}$.

Of note, MDSC have been shown to not only influence the outcome of injected DC-based vaccines, but they can also interfere during the preparation of ex-vivo-generated DC ${ }^{221}$. Cancer patients show increased numbers of circulating MDSC which negatively correlate with clinical outcome. Using standard operating procedures to isolate monocytes from patient's elutriation product, co-isolate these HLA-DR MDSC. As the presence of MDSC during ex vivo differentiation and maturation influences the maturation status of DC, Ag uptake, and induced $\mathrm{T}$ cell activation, it is desirable to monitor the purity of obtained monocytes and if necessary perform additional purification steps before inducing differentiation into DC. 


\section{Treg}

Chemokines released by tumour cells and immune cells present in the TME also attract lymphocytes (TIL). Low numbers of CD $8^{+}$TIL and high number of Treg TIL are associated with poor prognosis ${ }^{222}$. The presence of abundant numbers of Treg in the tumour, tumourdraining lymph nodes and peripheral blood is one of the interfering components hampering DC-induced activation and expansion of type- 1 immune responses ${ }^{223}$. Treg can efficiently suppress innate and adaptive arms of anti-tumour immune responses on multiple levels. Likewise, Treg interfere with NK cell responses, by limiting their recruitment, proliferation, cytolytic activity and IFN- $\gamma$ secretion. Moreover they suppress proliferation of naive T cells, and negatively interfere with antigen-presenting functions of DC and macrophages as well as B lymphocytes. Hence, the depletion or functional modulation of these cells is a possible way to restore the immunosuppression which can be accomplished by modulating Treg activity according to their surface marker expression.

Treg are characterized as $\mathrm{CD} 4{ }^{+} \mathrm{CD} 25^{+} \mathrm{CCR} 4^{+} \mathrm{GITR}^{+}$cells. The depletion based on CD25 can be achieved with e.g. monoclonal $\mathrm{Ab}(\mathrm{mAb})$ against $\mathrm{CD} 25$ or denileukin diftitox (an immunotoxin conjugated to IL-2). However, this CD25-based depletion also affects other (effector) $\mathrm{T}$ cell populations which upregulate CD25 as a consequence of their activation 224,225 . The chemokine receptor CCR4 is highly expressed on effector Treg cells and displays low expression on naive Treg and non-Treg cells ${ }^{226}$. This selective expression makes CCR4 an interesting target to deplete Treg by using anti-CCR4 mAb. Another possible approach consists in targeting co-stimulatory molecules specifically expressed on Treg, such as GITR or OX40. Application of agonist anti-GITR mAb, respectively anti-OX40, led to attenuation of suppressive function of Treg and increased effector antitumor $\mathrm{T}$ cell functions in several studies ${ }^{227-231}$. Another way to ensure depletion of Treg is the administration of immune checkpoint inhibitors, e.g. anti-CTLA-4, which is discussed later on in this section. The blocking of Treg by stimulating OX40 or GITR to reverse immunosuppressive milieu in the tumour may be a more safe approach than depleting Treg. However, depleting Treg according to their CCR4 expression displays another possibility as naive Treg are not influenced and as such the induction of autoimmunity can be limited by such treatments.

\section{Soluble factors}

Tumour cells as well as cells residing in the TME secrete various immunosuppressive soluble factors among which are IL-10, IL-6, M-CSF, GM-CSF, TGF- $\beta$, VEGF, lactic acid and prostaglandins. The effects of tumour-derived factors on the different APC functions (e.g. migration, survival, interaction with $\mathrm{T}$ and $\mathrm{NK}$ cells) are extensively reviewed in ${ }^{232}$. 
Several studies addressed the effect of these immune modulators on DC differentiation and maturation ${ }^{233-236}$. In chapter 5 of this thesis we showed that the influence of an immunosuppressive factor, $\mathrm{PGE}_{2}$, is imprinted during DC maturation. Once DC maturation was induced, $\mathrm{PGE}_{2}$ had no negative effect on cytokine and chemokine secretion. However, the negative effect of $\mathrm{PGE}_{2}$ on NK-DC crosstalk persisted. Besides $\mathrm{PGE}_{2}$ also other tumour-derived soluble factors have been shown to negatively affect DC maturation status and cytokine profile such as IL-10, IL-6, and M-CSF 232, 234, 236. This argues for the use of ex vivo-matured DC for cancer therapy instead of stimulating DC in vivo ensuring at least proper DC maturation and Ag processing and presentation.

Dying tumour cells release ATP; this extracellular ATP can be catabolized in several steps into adenosine via CD39 and CD73 expressed by tumour cells or lymphocytes such as Treg ${ }^{237,238}$. Adenosine can bind to adenosine receptors expressed by various immune cells. Binding of adenosine to A2aR on $\mathrm{T}$ cells leads to their inhibition and to FOXP3 expression in $\mathrm{CD}^{+} \mathrm{T}$ cells ${ }^{239}$. Moreover, cytotoxicity (perforin and FasL-mediated) and cytokine production (IFN- $\gamma, \mathrm{MIP}-1 \alpha, \mathrm{TNF}-\alpha)$ of NK cells is inhibited through binding of adenosine ${ }^{240}$. Blocking of CD73-adenosine pathway or receptor-binding demonstrates promising results to reverse the inhibitory effect on anti-tumour responses ${ }^{241-246}$.

In general, by taking into account the multitude of different inhibitory factors in the TME, arguably the best option is to target the source rather than the individual components. In this respect, the previously described possibilities to reverse immunosuppressive TME by targeting directly MDSC or Treg are more attractive approaches.

\section{Inhibitory receptors on tumour-infiltrating lymphocytes}

Besides the presence of immune suppressive MDSC and Treg in the tumour environment, effector cells recruited to the tumour site upregulate inhibitory receptors (mainly $\mathrm{T}$ cells). Activated $\mathrm{CD}^{+}{ }^{+} \mathrm{T}$ cells express molecules such as CTLA-4, PD-1/2, LAG-3, and TIM-3 which can interact with ligands expressed by tumours cells and thus impede tumour antigen-specific $\mathrm{T}$ cell responses. These inhibitory pathways are responsible to regulate the immune responses under physiological conditions and control self-tolerance, duration and magnitude of the induced responses. Tumours are able to co-opt these immune inhibitory pathways to increase their immune resistance. These so-called checkpoints can be controlled by checkpoint-inhibitors. This approach has gained a lot of attention in the past few years. To date antibodies against two checkpoints have been approved by the FDA: Ipilimumab (anti-CTLA-4), pembrolizumab and nivolumab (both anti-PD-1). The principle of most 
checkpoint inhibitors is to reverse the inhibitory effect of Treg and T cell anergy.

The CTLA-4 checkpoint inhibitor Ipilimumab was the first one to be approved by the FDA and its success led to further research on targeting possible other inhibitory receptors. In effector $\mathrm{T}$ cells, intracellular granules containing CTLA-4 are transported to the cell membrane upon Ag recognition ${ }^{247,248}$. On Treg cells, CTLA-4 is constitutively expressed. It binds to costimulatory molecules CD80/CD86 expressed on APC and exerts its effects via different suppressive mechanisms. The first one is competition with CD28 for binding of CD80/CD86 ${ }^{249}$. Second, the binding to CD80 allows T cells to co-opt ligands and to internalize them and thus leaving APC with less co-stimulatory signals ${ }^{250}$. Third, binding of CTLA-4 reduces the duration of immune synapses ${ }^{251}$. Fourth, the triggering of CTLA-4 activated protein phosphatases, which are able to inhibit MHC-TCR-mediated signalling effect in the T cells. Fifth, the triggering of CTLA-4 is involved in the activation of Treg ${ }^{252}$. Hence, the application of CTLA-4 checkpoint inhibitors reduces the activity of Treg and positively influences the clinical outcome ${ }^{253}$. Several studies showed that the observed effect is mainly attributable to the depletion of Treg via macrophage-mediated ADCC rather than blocking the inhibitory pathway on $\mathrm{CD}^{+}$and $\mathrm{CD}^{+} \mathrm{T}$ cells ${ }^{254-256}$. The integration of CTLA-4 in a DC-based vaccine treatment regimen could enhance its efficacy by reversing Treg-mediated inhibitory effects as well as preventing exhaustion of de novo $\mathrm{T}$ cell responses. Thus, administration of CTLA-4 should be performed before and after injection of DC-based vaccines. However, even Ipilimumab is very effective, it is accompanied by many severe side effects ${ }^{257}$. Therefore, the utilization of another checkpoint-inhibitor, e.g. PD-1 (described below), is more attractive.

PD-1 (programmed cell death; CD279) is another inhibitory receptor which belongs to the CD28 family and is more broadly expressed than CTLA- $4{ }^{258}$. PD-1 is upregulated on activated T cells ${ }^{258,259}$, NK cells, and B cells ${ }^{260,261}$ and cells acquire an exhausted phenotype upon interaction with PD-1 ligands as well as facilitating their apoptosis. Two ligands for PD-1 have been identified up-to-date, PD-L1 (B7-H1) and PD-L2 (B7-DC), which are part of the B7 family. Whereas PD-L1 is broadly expressed by various tissues (including various human tumours) ${ }^{262-265}$ and is inducible upon IFN- $\gamma$ and type I interferons ${ }^{265-267}$, PD-L2 expression is restricted to activated DC, macrophages, and several tumours (e.g. $\mathrm{B}$ cell lymphoma) and is involved in down-regulation of $\mathrm{T}$ cell activation ${ }^{268,269}$. PD-1PD-L1/PD-L2 interactions down modulate immune responses via activation of tyrosine phosphatases SHP-1/2 which deactivate signal 1 (CD3/CD28-TCR) 270-273. Under physiological conditions, this pathway prevents autoimmunity by reducing activation, cytokine secretion, and adhesion of $\mathrm{T}$ cells ${ }^{274}$ as well as limiting the proliferation of $\mathrm{NK}$ cells ${ }^{261}$. However, in the case of cancer, this interaction inhibits anti-tumour activity. Expression of PD-L1 on tumours cells is heterogeneous and can be either present initially 
on tumour cells (innate immune resistance) or be upregulated in the course of anti-tumour responses (adaptive immune resistance). In the latter case the infiltrating immune effector cells, such as $\mathrm{CD}^{+}, \mathrm{CD}^{+}$and $\mathrm{NK}$ cells, will lead to a local increase of IFN- $\gamma$, which not only promotes tumour elimination but also leads to upregulation of PD-L1 on tumour cells and thus inhibition of PD-1-expressing TIL ${ }^{275,276}$. Expression of PD-L1 by tumours is associated with poor prognosis and blocking of this pathway in cancer has a positive influence on anti-tumour responses ${ }^{277,278}$. Blocking this pathway has broader influence on immune cells than CTLA-4 and has also been associated with less cytotoxicity. Thus using PD-1 blockage in combination with DC-based vaccine represents a promising strategy.

Other inhibitory receptors are currently under investigation as promising target strategy, such as LAG-3, B7-H3, B7-H4 and TIM-3, but will not be further discussed here.

\section{COMBINATION THERAPIES: NECESSITY OF MULTILEVELED THERAPIES}

Almost 20 years after the results on the first therapeutic anti-cancer DC-based vaccine trial have been published, DC vaccination has been proven to be a safe and non-toxic approach to treat cancer. Even though, in the majority of patients an increased immune response was observed after vaccine administration, this effect could not yet be reflected in the overall outcome. Many improvements have been made on the choice of TAA, the loading of Ag, optimal administration sites and intervals, cell numbers and maturation protocols. Clinical trials applying these optimized DC-based vaccines are currently ongoing or starting within short period of time.

A major problem with previous vaccination strategies could be the hampering of efficient responses by the natural occurring regulating mechanism induced by immune system activation. This escaping phenomenon is described as immunoediting and can be divided into three phases: elimination, equilibrium, escape. Each time an anti-tumour treatment induces a potent anti-tumour response by inducing diverse immune effector cells, the pressure on the tumour cells to adapt and to survive is increased. Thus, each treatment will induce partial resistance of the tumour due to its heterogeneity and leads to selective outgrowth of surviving cells (less immunogenic cells). As such, the tumour adapts its phenotype over time ${ }^{279-282}$.

The key to success of immunotherapy will most probably be to circumvent the inhibition and escape mechanisms of the tumour. Whereas various single-targeted approaches have shown partial success in tumour remission or increase in overall survival, the solution may be 
a multileveled treatment approach combining non-specific (adjuvants, cytokines, checkpoint inhibitors, and conventional therapies) and specific treatment regimens (vaccination), but also the inclusion of conventional anti-cancer therapies. Especially checkpoint inhibitors have gained great attention. $\mathrm{mAb}$ against inhibitory molecules expressed on $\mathrm{T}$ cells like CTLA-4 and PD-1 block the brake of the immune system, resulting in longer lasting immune responses. Although very encouraging clinical results have been obtained as recently reviewed by Mahoney et al. ${ }^{283}$, the treatment is still accompanied by toxicity issues ${ }^{284}$ that remain to be solved.

The biggest challenge in this approach is the lack of biomarkers predicting when to apply which therapy, as tumour biopsies are not always available. A recent study by Hannani et al. ${ }^{285}$ revealed that elevated levels of soluble CD25 detected in the serum of patients with melanoma are predictive for resistance to Ipilimumb (anti-CTLA-4) treatment. If biopsies are available, in addition to histopathology, also immunophenotyping should be performed because of the involvement of the immune host defence in tumour progression. This will facilitate better prognosis and clinical decision. This approach was defined as 'immunoscore' ${ }^{187}$ and consists in detecting TIL in the centre and invasive margin of the tumour (number of $\mathrm{CD} 3 / \mathrm{CD} 8$ or $\mathrm{CD} 8 / \mathrm{CD} 45 \mathrm{RO}$ ). As TIL are heterogeneous between tumours and patients, this analysis of immune contexture will help to give a better prognosis and make better clinical decisions. Even though this strategy only considers $\mathrm{T}$ cells, it provides good survival prognosis ${ }^{286}$. Patients with low immunoscore, meaning low infiltration of $\mathrm{CD}^{+} \mathrm{T}$ cells in the tumour, would be good targets for adjuvant therapy to increase immunogenicity of the tumour.

Another key factor is the tumour burden at the start of the intervention. Low tumour burden seem to be more effectively killed by immunotherapeutic approaches. Likewise, an initial treatment of tumour with conventional therapies may be necessary to remove the majority of the tumour burden. An exception to this seems to be the checkpoint blockers; they also reached high response rates even in patients with advanced melanoma, with antiPD-1 being most favorable ${ }^{4,6}$.

Considering the large heterogeneity between tumour types, disease stages but also between patients makes the definition of a golden standard therapy approach questionable. A possible option for applying DC-based vaccines is considering a basic treatment approach around a DC-based vaccine (or in vivo targeting of DC) which has to be adjusted and complemented with different combination strategies depending on both histopathological features as well as the characterization of the TME of the patient (if possible). The rationale for combination therapies is also reflected in ongoing clinical trials applying DC vaccine strategies and as such a DC-vaccine in combination with anti-CTLA-4 is currently evaluated 
in clinical trials. A general prerequisite for the application of checkpoint inhibitors is the immunogenicity of tumours.

Presumably this immunogenicity can and should be enhanced locally e.g. by the (intra-tumoral) administration of RIG-I triggers inducing direct toxicity on tumour cells and generating an immunosupportive environment. Also chemotherapeutic agents as well as radiotherapy will continue to have a crucial role in the pre-conditioning of the tumour. The subsequent administration of a DC vaccine would enhance anti-tumour specific responses. Once initiated, blocking e.g. PD-L1 could retain anti-tumour specific cells in an active state. However, timing will be a crucial factor in any multileveled approach.

\section{CONCLUSIONS}

In this thesis, we provided an assay to study naive $\mathrm{CD}^{+} \mathrm{T}$ cell responses in a human setting. We studied the interaction of DC with both Th1 and NK cells and revealed that high IL-12p70-secreting DC have the capacity to activate both helper responses. Additionally, we provided evidence that NK cells act as amplifiers during viral and bacterial infections to enhance cytokine production by DC. Furthermore, we showed that one of the mechanisms by which TME inhibits immune responses is the blocking of NK-DC crosstalk. Moreover, we identified a promising new combination of TLR triggers to mature DC showing enhanced capacities to interact with NK cells and to induce Th1 polarization in vitro.

Here, we discussed which criteria should be taken into account when selecting PAMPs as adjuvants for vaccination. Moreover, we provided an overview of multiple factors explaining the so far overall limited clinical outcome of immunotherapy and specifically of DC-based vaccination. Immunotherapy as stand-alone approach may not reach the expected results as the TME is an adaptive environment possessing multiple redundant pathways to inhibit initiated anti-tumour immune responses. Combinations of immunotherapy, including e.g. checkpoint inhibitors, with chemo- and/or radiotherapy will yield better results, overcoming the suppressive TME by attacking multiple pathways to initiate and elongate desired anti-tumour immune responses. 


\section{REFERENCES}

1. Hanahan D, Weinberg RA. Hallmarks of cancer: the next generation. Cell. 2011;144(5):646-674.

2. Kim R, Emi M, Tanabe K. Cancer immunoediting from immune surveillance to immune escape. Immunology. 2007;121(1):1-14.

3. Vesely MD, Schreiber RD. Cancer immunoediting: antigens, mechanisms, and implications to cancer immunotherapy. Ann N Y Acad Sci. 2013;1284:1-5.

4. Callahan MK, Wolchok JD. At the bedside: CTLA-4- and PD-1-blocking antibodies in cancer immunotherapy. J Leukoc Biol. 2013;94(1):41-53.

5. Hodi FS, O’Day SJ, McDermott DF, et al. Improved survival with ipilimumab in patients with metastatic melanoma. N Engl J Med. 2010;363(8):711-723.

6. Hamid O, Robert C, Daud A, et al. Safety and tumor responses with lambrolizumab (anti-PD-1) in melanoma. N Engl J Med. 2013;369(2):134-144.

7. Sangiolo D. Redirected T cells in cancer therapy. Expert Opin Biol Ther. 2015:1-4.

8. Couzin-Frankel J. Breakthrough of the year 2013. Cancer immunotherapy. Science. 2013;342(6165):14321433.

9. Reed SG, Orr MT, Fox CB. Key roles of adjuvants in modern vaccines. Nat Med. 2013;19(12):15971608.

10. Kalantari T, Kamali-Sarvestani E, Ciric B, et al. Generation of immunogenic and tolerogenic clinicalgrade dendritic cells. Immunol Res. 2011;51(2-3):153-160.

11. Gluckman JC, Canque B, Rosenzwajg M. Dendritic cells: a complex simplicity. Transplantation. 2002;73(1 Suppl):S3-6.

12. Coffman RL, Sher A, Seder RA. Vaccine adjuvants: putting innate immunity to work. Immunity. 2010;33(4):492-503.

13. Steinhagen F, Kinjo T, Bode C, Klinman DM. TLR-based immune adjuvants. Vaccine. 2011;29(17):33413355.

14. Mbow ML, De Gregorio E, Valiante NM, Rappuoli R. New adjuvants for human vaccines. Curr Opin Immunol. 2010;22(3):411-416.

15. Bourgeois C, Tanchot C. Mini-review CD4 T cells are required for CD $8 \mathrm{~T}$ cell memory generation. Eur J Immunol. 2003;33(12):3225-3231.

16. Banday AH, Jeelani S, Hruby VJ. Cancer vaccine adjuvants--recent clinical progress and future perspectives. Immunopharmacol Immunotoxicol. 2015;37(1):1-11.

17. Hajjar AM, Ernst RK, Tsai JH, Wilson CB, Miller SI. Human Toll-like receptor 4 recognizes hostspecific LPS modifications. Nat Immunol. 2002;3(4):354-359.

18. Mestas J, Hughes CC. Of mice and not men: differences between mouse and human immunology. J Immunol. 2004;172(5):2731-2738.

19. Van Elssen CH, Vanderlocht J, Frings PW, et al. Klebsiella pneumoniae-triggered DC recruit human NK cells in a CCR5-dependent manner leading to increased CCL19-responsiveness and activation of NK cells. Eur J Immunol. 2010;40(11):3138-3149.

20. Mailliard RB, Alber SM, Shen H, et al. IL-18-induced CD83+CCR7+ NK helper cells. J Exp Med. 2005;202(7):941-953.

21. Neves PC, Matos DC, Marcovistz R, Galler R. TLR expression and NK cell activation after human yellow fever vaccination. Vaccine. 2009;27(41):5543-5549.

22. Liu G, Zhang L, Zhao Y. Modulation of immune responses through direct activation of Toll-like receptors to T cells. Clin Exp Immunol. 2010;160(2):168-175.

23. Komai-Koma M, Jones L, Ogg GS, Xu D, Liew FY. TLR2 is expressed on activated T cells as a costimulatory receptor. Proc Natl Acad Sci U S A. 2004;101(9):3029-3034.

24. Hornung V, Rothenfusser S, Britsch S, et al. Quantitative expression of toll-like receptor 1-10 mRNA in cellular subsets of human peripheral blood mononuclear cells and sensitivity to CpG oligodeoxynucleotides. J Immunol. 2002;168(9):4531-4537. 
25. Zarember KA, Godowski PJ. Tissue expression of human Toll-like receptors and differential regulation of Toll-like receptor mRNAs in leukocytes in response to microbes, their products, and cytokines. J Immunol. 2002;168(2):554-561.

26. Dai J, Liu B, Li Z. Regulatory $\mathrm{T}$ cells and Toll-like receptors: what is the missing link? Int Immunopharmacol. 2009;9(5):528-533.

27. Jin B, Sun T, Yu XH, Yang YX, Yeo AE. The effects of TLR activation on T-cell development and differentiation. Clin Dev Immunol. 2012;2012:836485.

28. Rahman AH, Taylor DK, Turka LA. The contribution of direct TLR signaling to T cell responses. Immunol Res. 2009;45(1):25-36.

29. Caron G, Duluc D, Fremaux I, et al. Direct stimulation of human T cells via TLR5 and TLR7/8: flagellin and R-848 up-regulate proliferation and IFN-gamma production by memory CD4+ T cells. J Immunol. 2005;175(3):1551-1557.

30. Voo KS, Bover L, Harline ML, Weng J, Sugimoto N, Liu YJ. Targeting of TLRs inhibits CD4+ regulatory $\mathrm{T}$ cell function and activates lymphocytes in human peripheral blood mononuclear cells. J Immunol. 2014;193(2):627-634.

31. Kaczanowska S, Joseph AM, Davila E. TLR agonists: our best frenemy in cancer immunotherapy. J Leukoc Biol. 2013;93(6):847-863.

32. Lathers DM, Clark JI, Achille NJ, Young MR. Phase 1B study to improve immune responses in head and neck cancer patients using escalating doses of 25-hydroxyvitamin D3. Cancer Immunol Immunother. 2004;53(5):422-430.

33. Joffre O, Nolte MA, Sporri R, Reis e Sousa C. Inflammatory signals in dendritic cell activation and the induction of adaptive immunity. Immunol Rev. 2009;227(1):234-247.

34. Sporri R, Reis e Sousa C. Inflammatory mediators are insufficient for full dendritic cell activation and promote expansion of CD4+ T cell populations lacking helper function. Nat Immunol. 2005;6(2):163170 .

35. Cottalorda A, Verschelde C, Marcais A, et al. TLR2 engagement on CD 8 T cells lowers the threshold for optimal antigen-induced T cell activation. Eur J Immunol. 2006;36(7):1684-1693.

36. Hou B, Reizis B, DeFranco AL. Toll-like receptors activate innate and adaptive immunity by using dendritic cell-intrinsic and -extrinsic mechanisms. Immunity. 2008;29(2):272-282.

37. Longhi MP, Trumpfheller C, Idoyaga J, et al. Dendritic cells require a systemic type I interferon response to mature and induce CD4+ Th1 immunity with poly IC as adjuvant. J Exp Med. 2009;206(7):15891602.

38. Trumpfheller C, Caskey M, Nchinda G, et al. The microbial mimic poly IC induces durable and protective CD4+ T cell immunity together with a dendritic cell targeted vaccine. Proc Natl Acad Sci U S A. 2008;105(7):2574-2579.

39. Warger T, Osterloh P, Rechtsteiner G, et al. Synergistic activation of dendritic cells by combined Tolllike receptor ligation induces superior CTL responses in vivo. Blood. 2006;108(2):544-550.

40. Schlom J, Arlen PM, Gulley JL. Cancer vaccines: moving beyond current paradigms. Clin Cancer Res. 2007;13(13):3776-3782.

41. Schlom J, Gulley JL, Arlen PM. Paradigm shifts in cancer vaccine therapy. Exp Biol Med (Maywood). 2008;233(5):522-534.

42. Patel PH, Kockler DR. Sipuleucel-T: a vaccine for metastatic, asymptomatic, androgen-independent prostate cancer. Ann Pharmacother. 2008;42(1):91-98.

43. Srivastava PK. Therapeutic cancer vaccines. Curr Opin Immunol. 2006;18(2):201-205.

44. Adams S. Toll-like receptor agonists in cancer therapy. Immunotherapy. 2009;1(6):949-964.

45. Spaner DE, Shi Y, White D, et al. Immunomodulatory effects of Toll-like receptor-7 activation on chronic lymphocytic leukemia cells. Leukemia. 2006;20(2):286-295.

46. Shi Y, White D, He L, Miller RL, Spaner DE. Toll-like receptor-7 tolerizes malignant B cells and enhances killing by cytotoxic agents. Cancer Res. 2007;67(4):1823-1831.

47. Sato Y, Goto Y, Narita N, Hoon DS. Cancer Cells Expressing Toll-like Receptors and the Tumor 
Microenvironment. Cancer Microenviron. 2009;2 Suppl 1:205-214.

48. Chatterjee S, Crozet L, Damotte D, et al. TLR7 promotes tumor progression, chemotherapy resistance, and poor clinical outcomes in non-small cell lung cancer. Cancer Res. 2014;74(18):5008-5018.

49. Ridnour LA, Cheng RY, Switzer CH, et al. Molecular pathways: toll-like receptors in the tumor microenvironment--poor prognosis or new therapeutic opportunity. Clin Cancer Res. 2013;19(6):13401346.

50. Yu L, Wang L, Chen S. Dual character of Toll-like receptor signaling: pro-tumorigenic effects and antitumor functions. Biochim Biophys Acta. 2013;1835(2):144-154.

51. Crellin NK, Garcia RV, Hadisfar O, Allan SE, Steiner TS, Levings MK. Human CD4+ T cells express TLR5 and its ligand flagellin enhances the suppressive capacity and expression of FOXP3 in CD4+CD25+ T regulatory cells. J Immunol. 2005;175(12):8051-8059.

52. Peng G, Guo Z, Kiniwa Y, et al. Toll-like receptor 8-mediated reversal of CD4+ regulatory $\mathrm{T}$ cell function. Science. 2005;309(5739):1380-1384.

53. Chow J, Franz KM, Kagan JC. PRRs are watching you: Localization of innate sensing and signaling regulators. Virology. 2015.

54. Anz D, Koelzer VH, Moder S, et al. Immunostimulatory RNA blocks suppression by regulatory T cells. J Immunol. 2010;184(2):939-946.

55. Besch R, Poeck H, Hohenauer T, et al. Proapoptotic signaling induced by RIG-I and MDA-5 results in type I interferon-independent apoptosis in human melanoma cells. J Clin Invest. 2009;119(8):23992411.

56. Khan S, Bijker MS, Weterings JJ, et al. Distinct uptake mechanisms but similar intracellular processing of two different toll-like receptor ligand-peptide conjugates in dendritic cells. J Biol Chem. 2007;282(29):21145-21159.

57. Zom GG, Khan S, Filippov DV, Ossendorp F. TLR ligand-peptide conjugate vaccines: toward clinical application. Adv Immunol. 2012;114:177-201.

58. Schuurhuis DH, Ioan-Facsinay A, Nagelkerken B, et al. Antigen-antibody immune complexes empower dendritic cells to efficiently prime specific CD8+ CTL responses in vivo. J Immunol. 2002;168(5):22402246.

59. Caminschi I, Maraskovsky E, Heath WR. Targeting Dendritic Cells in vivo for Cancer Therapy. Front Immunol. 2012;3:13.

60. Kastenmuller W, Kastenmuller K, Kurts C, Seder RA. Dendritic cell-targeted vaccines--hope or hype? Nat Rev Immunol. 2014;14(10):705-711.

61. Steinman RM. Dendritic cells in vivo: a key target for a new vaccine science. Immunity. 2008;29(3):319324.

62. Hsu FJ, Benike C, Fagnoni F, et al. Vaccination of patients with B-cell lymphoma using autologous antigen-pulsed dendritic cells. Nat Med. 1996;2(1):52-58.

63. Banchereau J, Steinman RM. Dendritic cells and the control of immunity. Nature. 1998;392(6673):245252.

64. Schuler G, Schuler-Thurner B, Steinman RM. The use of dendritic cells in cancer immunotherapy. Curr Opin Immunol. 2003;15(2):138-147.

65. Kalinski P, Hilkens CM, Wierenga EA, Kapsenberg ML. T-cell priming by type-1 and type-2 polarized dendritic cells: the concept of a third signal. Immunol Today. 1999;20(12):561-567.

66. Ikeda $\mathrm{H}$, Chamoto $\mathrm{K}$, Tsuji $\mathrm{T}$, et al. The critical role of type-1 innate and acquired immunity in tumor immunotherapy. Cancer Sci. 2004;95(9):697-703.

67. Trinchieri G. Interleukin-12 and the regulation of innate resistance and adaptive immunity. Nat Rev Immunol. 2003;3(2):133-146.

68. Pulendran B. Modulating TH1/TH2 responses with microbes, dendritic cells, and pathogen recognition receptors. Immunol Res. 2004;29(1-3):187-196.

69. Czerniecki BJ, Cohen PA, Faries M, Xu S, Roros JG, Bedrosian I. Diverse functional activity of CD83+ monocyte-derived dendritic cells and the implications for cancer vaccines. Crit Rev Immunol. 
2001;21(1-3):157-178.

70. Ferlazzo G, Pack M, Thomas D, et al. Distinct roles of IL-12 and IL-15 in human natural killer cell activation by dendritic cells from secondary lymphoid organs. Proc Natl Acad Sci U S A. 2004;101(47):16606-16611.

71. Kalinski P, Okada H. Polarized dendritic cells as cancer vaccines: directing effector-type T cells to tumors. Semin Immunol. 2010;22(3):173-182.

72. Athie-Morales V, Smits HH, Cantrell DA, Hilkens CM. Sustained IL-12 signaling is required for Th1 development. J Immunol. 2004;172(1):61-69.

73. Carreno BM, Becker-Hapak M, Huang A, et al. IL-12p70-producing patient DC vaccine elicits Tc1polarized immunity. J Clin Invest. 2013;123(8):3383-3394.

74. Okada H, Kalinski P, Ueda R, et al. Induction of CD8+ T-cell responses against novel gliomaassociated antigen peptides and clinical activity by vaccinations with \{alpha\}-type 1 polarized dendritic cells and polyinosinic-polycytidylic acid stabilized by lysine and carboxymethylcellulose in patients with recurrent malignant glioma. J Clin Oncol. 2011;29(3):330-336.

75. Atkins MB, Robertson MJ, Gordon M, et al. Phase I evaluation of intravenous recombinant human interleukin 12 in patients with advanced malignancies. Clin Cancer Res. 1997;3(3):409-417.

76. Leonard JP, Sherman ML, Fisher GL, et al. Effects of single-dose interleukin-12 exposure on interleukin-12-associated toxicity and interferon-gamma production. Blood. 1997;90(7):2541-2548.

77. Hamid O, Solomon JC, Scotland R, et al. Alum with interleukin-12 augments immunity to a melanoma peptide vaccine: correlation with time to relapse in patients with resected high-risk disease. Clin Cancer Res. 2007;13(1):215-222.

78. Peterson AC, Harlin H, Gajewski TF. Immunization with Melan-A peptide-pulsed peripheral blood mononuclear cells plus recombinant human interleukin-12 induces clinical activity and T-cell responses in advanced melanoma. J Clin Oncol. 2003;21(12):2342-2348.

79. Colombo MP, Trinchieri G. Interleukin-12 in anti-tumor immunity and immunotherapy. Cytokine Growth Factor Rev. 2002;13(2):155-168.

80. Del Vecchio M, Bajetta E, Canova S, et al. Interleukin-12: biological properties and clinical application. Clin Cancer Res. 2007;13(16):4677-4685.

81. Anguille S, Smits EL, Lion E, van Tendeloo VF, Berneman ZN. Clinical use of dendritic cells for cancer therapy. Lancet Oncol. 2014;15(7):e257-267.

82. Jensen SS, Gad M. Differential induction of inflammatory cytokines by dendritic cells treated with novel TLR-agonist and cytokine based cocktails: targeting dendritic cells in autoimmunity. J Inflamm (Lond). 2010;7:37.

83. Vitale M, Della Chiesa M, Carlomagno S, et al. NK-dependent DC maturation is mediated by TNFalpha and IFNgamma released upon engagement of the NKp30 triggering receptor. Blood. 2005;106(2):566571.

84. Kreutz M, Bakdash G, Dolen Y, et al. Type I IFN-mediated synergistic activation of mouse and human DC subsets by TLR agonists. Eur J Immunol. 2015;45(10):2798-2809.

85. Bos GMJ, Germeraad WTV, Gijsbers LMG, Oth T, Vanderlocht J. Method for the in vitro maturation of dendritic cells: Google Patents; 2013.

86. Berk E, Kalinski P. Lymphocyte-polarized DC1s: Effective inducers of tumor-specific CTLs. Oncoimmunology. 2012;1(8):1443-1444.

87. Berk E, Muthuswamy R, Kalinski P. Lymphocyte-polarized dendritic cells are highly effective in inducing tumor-specific CTLs. Vaccine. 2012;30(43):6216-6224.

88. Langenkamp A, Messi M, Lanzavecchia A, Sallusto F. Kinetics of dendritic cell activation: impact on priming of TH1, TH2 and nonpolarized T cells. Nat Immunol. 2000;1(4):311-316.

89. Vieira PL, de Jong EC, Wierenga EA, Kapsenberg ML, Kalinski P. Development of Th1-inducing capacity in myeloid dendritic cells requires environmental instruction. J Immunol. 2000;164(9):45074512.

90. Luger R, Valookaran S, Knapp N, Vizzardelli C, Dohnal AM, Felzmann T. Toll-like receptor 4 
engagement drives differentiation of human and murine dendritic cells from a pro- into an antiinflammatory mode. PLoS One. 2013;8(2):e54879.

91. Dohnal AM, Graffi S, Witt V, et al. Comparative evaluation of techniques for the manufacturing of dendritic cell-based cancer vaccines. J Cell Mol Med. 2009;13(1):125-135.

92. Yilmaz V, Yentur SP, Saruhan-Direskeneli G. IL-12 and IL-10 polymorphisms and their effects on cytokine production. Cytokine. 2005;30(4):188-194.

93. Seegers D, Zwiers A, Strober W, Pena AS, Bouma G. A TaqI polymorphism in the 3'UTR of the IL-12 p40 gene correlates with increased IL-12 secretion. Genes Immun. 2002;3(7):419-423.

94. Muller-Berghaus J, Kern K, Paschen A, et al. Deficient IL-12p70 secretion by dendritic cells based on IL12B promoter genotype. Genes Immun. 2004;5(5):431-434.

95. Peng JC, Abu Bakar S, Richardson MM, et al. IL10 and IL12B polymorphisms each influence IL-12p70 secretion by dendritic cells in response to LPS. Immunol Cell Biol. 2006;84(2):227-232.

96. Smits EL, Anguille S, Cools N, Berneman ZN, Van Tendeloo VF. Dendritic cell-based cancer gene therapy. Hum Gene Ther. 2009;20(10):1106-1118.

97. Van Tendeloo VF, Ponsaerts P, Berneman ZN. mRNA-based gene transfer as a tool for gene and cell therapy. Curr Opin Mol Ther. 2007;9(5):423-431.

98. Lipscomb MW, Chen L, Taylor JL, et al. Ectopic T-bet expression licenses dendritic cells for IL-12independent priming of type $1 \mathrm{~T}$ cells in vitro. J Immunol. 2009;183(11):7250-7258.

99. Qu Y, Chen L, Lowe DB, Storkus WJ, Taylor JL. Combined Tbet and IL12 gene therapy elicits and recruits superior antitumor immunity in vivo. Mol Ther. 2012;20(3):644-651.

100. Boudreau JE, Bonehill A, Thielemans K, Wan Y. Engineering dendritic cells to enhance cancer immunotherapy. Mol Ther. 2011;19(5):841-853.

101. Lucas S, Ghilardi N, Li J, de Sauvage FJ. IL-27 regulates IL-12 responsiveness of naive CD4+ T cells through Stat1-dependent and -independent mechanisms. Proc Natl Acad Sci U S A. 2003;100(25):1504715052.

102. Tominaga K, Yoshimoto T, Torigoe K, et al. IL-12 synergizes with IL-18 or IL-1beta for IFN-gamma production from human T cells. Int Immunol. 2000;12(2):151-160.

103. Wong JL, Berk E, Edwards RP, Kalinski P. IL-18-primed helper NK cells collaborate with dendritic cells to promote recruitment of effector CD8+ T cells to the tumor microenvironment. Cancer research. 2013;73(15):4653-4662.

104. Mailliard RB, Son YI, Redlinger R, et al. Dendritic cells mediate NK cell help for Th1 and CTL responses: two-signal requirement for the induction of NK cell helper function. J Immunol. 2003;171(5):23662373.

105. Mortier E, Woo T, Advincula R, Gozalo S, Ma A. IL-15Ralpha chaperones IL-15 to stable dendritic cell membrane complexes that activate NK cells via trans presentation. J Exp Med. 2008;205(5):1213-1225.

106. Vujanovic L, Szymkowski DE, Alber S, Watkins SC, Vujanovic NL, Butterfield LH. Virally infected and matured human dendritic cells activate natural killer cells via cooperative activity of plasma membranebound TNF and IL-15. Blood. 2010;116(4):575-583.

107. Schlitzer A, Ginhoux F. Organization of the mouse and human DC network. Curr Opin Immunol. 2014;26:90-99.

108. Klechevsky E, Morita R, Liu M, et al. Functional specializations of human epidermal Langerhans cells and CD14+ dermal dendritic cells. Immunity. 2008;29(3):497-510.

109. Markowicz S, Engleman EG. Granulocyte-macrophage colony-stimulating factor promotes differentiation and survival of human peripheral blood dendritic cells in vitro. J Clin Invest. 1990;85(3):955-961.

110. Sallusto F, Lanzavecchia A. Efficient presentation of soluble antigen by cultured human dendritic cells is maintained by granulocyte/macrophage colony-stimulating factor plus interleukin 4 and downregulated by tumor necrosis factor alpha. J Exp Med. 1994;179(4):1109-1118.

111. Kadowaki N, Antonenko S, Lau JY, Liu YJ. Natural interferon alpha/beta-producing cells link innate and adaptive immunity. J Exp Med. 2000;192(2):219-226. 
112. Shaw J, Wang YH, Ito T, Arima K, Liu YJ. Plasmacytoid dendritic cells regulate B-cell growth and differentiation via CD70. Blood. 2010;115(15):3051-3057.

113. Tel J, Schreibelt G, Sittig SP, et al. Human plasmacytoid dendritic cells efficiently cross-present exogenous Ags to CD8+ T cells despite lower Ag uptake than myeloid dendritic cell subsets. Blood. 2013;121(3):459-467.

114. Tel J, Aarntzen EH, Baba T, et al. Natural human plasmacytoid dendritic cells induce antigen-specific T-cell responses in melanoma patients. Cancer Res. 2013;73(3):1063-1075.

115. Tel J, van der Leun AM, Figdor CG, Torensma R, de Vries IJ. Harnessing human plasmacytoid dendritic cells as professional APCs. Cancer Immunol Immunother. 2012;61(8):1279-1288.

116. Tel J, Anguille S, Waterborg CE, Smits EL, Figdor CG, de Vries IJ. Tumoricidal activity of human dendritic cells. Trends Immunol. 2014;35(1):38-46.

117. Di Pucchio T, Chatterjee B, Smed-Sorensen A, et al. Direct proteasome-independent cross-presentation of viral antigen by plasmacytoid dendritic cells on major histocompatibility complex class I. Nat Immunol. 2008;9(5):551-557.

118. Hoeffel G, Ripoche AC, Matheoud D, et al. Antigen crosspresentation by human plasmacytoid dendritic cells. Immunity. 2007;27(3):481-492.

119. Ascierto PA, Gogas HJ, Grob JJ, et al. Adjuvant interferon alfa in malignant melanoma: an interdisciplinary and multinational expert review. Crit Rev Oncol Hematol. 2013;85(2):149-161.

120. Kirkwood JM, Bender C, Agarwala S, et al. Mechanisms and management of toxicities associated with high-dose interferon alfa-2b therapy. J Clin Oncol. 2002;20(17):3703-3718.

121. Anguille S, Lion E, Willemen Y, Van Tendeloo VF, Berneman ZN, Smits EL. Interferon-alpha in acute myeloid leukemia: an old drug revisited. Leukemia. 2011;25(5):739-748.

122. Arico E, Belardelli F. Interferon-alpha as antiviral and antitumor vaccine adjuvants: mechanisms of action and response signature. J Interferon Cytokine Res. 2012;32(6):235-247.

123. Kirkwood JM, Butterfield LH, Tarhini AA, Zarour H, Kalinski P, Ferrone S. Immunotherapy of cancer in 2012. CA Cancer J Clin. 2012;62(5):309-335.

124. Hervas-Stubbs S, Perez-Gracia JL, Rouzaut A, Sanmamed MF, Le Bon A, Melero I. Direct effects of type I interferons on cells of the immune system. Clin Cancer Res. 2011;17(9):2619-2627.

125. Atzpodien J, Kirchner H, Rebmann U, et al. Interleukin-2/interferon-alpha2a/13-retinoic acid-based chemoimmunotherapy in advanced renal cell carcinoma: results of a prospectively randomised trial of the German Cooperative Renal Carcinoma Chemoimmunotherapy Group (DGCIN). Br J Cancer. 2006;95(4):463-469.

126. Hudes G, Carducci M, Tomczak P, et al. Temsirolimus, interferon alfa, or both for advanced renal-cell carcinoma. N Engl J Med. 2007;356(22):2271-2281.

127. Willemen Y, Van den Bergh JM, Lion E, et al. Engineering monocyte-derived dendritic cells to secrete interferon-alpha enhances their ability to promote adaptive and innate anti-tumor immune effector functions. Cancer Immunol Immunother. 2015.

128. Kadowaki N. The divergence and interplay between $\mathrm{pDC}$ and $\mathrm{mDC}$ in humans. Front Biosci (Landmark Ed). 2009;14:808-817.

129. Lou Y, Liu C, Kim GJ, Liu YJ, Hwu P, Wang G. Plasmacytoid dendritic cells synergize with myeloid dendritic cells in the induction of antigen-specific antitumor immune responses. J Immunol. 2007;178(3):1534-1541.

130. Piccioli D, Sammicheli C, Tavarini S, et al. Human plasmacytoid dendritic cells are unresponsive to bacterial stimulation and require a novel type of cooperation with myeloid dendritic cells for maturation. Blood. 2009;113(18):4232-4239.

131. Bakdash G, Schreurs I, Schreibelt G, Tel J. Crosstalk between dendritic cell subsets and implications for dendritic cell-based anticancer immunotherapy. Expert Rev Clin Immunol. 2014;10(7):915-926.

132. Chauhan D, Singh AV, Brahmandam M, et al. Functional interaction of plasmacytoid dendritic cells with multiple myeloma cells: a therapeutic target. Cancer Cell. 2009;16(4):309-323.

133. Filipazzi P, Pilla L, Mariani L, et al. Limited induction of tumor cross-reactive T cells without a 
measurable clinical benefit in early melanoma patients vaccinated with human leukocyte antigen class I-modified peptides. Clin Cancer Res. 2012;18(23):6485-6496.

134. Bos R, Sherman LA. CD4+ T-cell help in the tumor milieu is required for recruitment and cytolytic function of CD8+ T lymphocytes. Cancer Res. 2010;70(21):8368-8377.

135. Wong SB, Bos R, Sherman LA. Tumor-specific CD4+ T cells render the tumor environment permissive for infiltration by low-avidity CD8+ T cells. J Immunol. 2008;180(5):3122-3131.

136. Kreiter S, Vormehr M, van de Roemer N, et al. Mutant MHC class II epitopes drive therapeutic immune responses to cancer. Nature. 2015;520(7549):692-696.

137. Wilgenhof S, Corthals J, Van Nuffel AM, et al. Long-term clinical outcome of melanoma patients treated with messenger RNA-electroporated dendritic cell therapy following complete resection of metastases. Cancer Immunol Immunother. 2015;64(3):381-388.

138. Cheroutre H, Husain MM. CD4 CTL: living up to the challenge. Semin Immunol. 2013;25(4):273-281.

139. Quezada SA, Simpson TR, Peggs KS, et al. Tumor-reactive CD4(+) T cells develop cytotoxic activity and eradicate large established melanoma after transfer into lymphopenic hosts. J Exp Med. 2010;207(3):637-650.

140. Fu J, Zhang Z, Zhou L, et al. Impairment of CD4+ cytotoxic T cells predicts poor survival and high recurrence rates in patients with hepatocellular carcinoma. Hepatology. 2013;58(1):139-149.

141. Van Elssen CH, Oth T, Germeraad WT, Bos GM, Vanderlocht J. Natural killer cells: the secret weapon in dendritic cell vaccination strategies. Clin Cancer Res. 2014;20(5):1095-1103.

142. Vivier E, Tomasello E, Baratin M, Walzer T, Ugolini S. Functions of natural killer cells. Nat Immunol. 2008;9(5):503-510.

143. Vivier E, Raulet DH, Moretta A, et al. Innate or adaptive immunity? The example of natural killer cells. Science. 2011;331(6013):44-49.

144. Kalinski P, Giermasz A, Nakamura Y, et al. Helper role of NK cells during the induction of anticancer responses by dendritic cells. Mol Immunol. 2005;42(4):535-539.

145. Miller JS, Soignier Y, Panoskaltsis-Mortari A, et al. Successful adoptive transfer and in vivo expansion of human haploidentical NK cells in patients with cancer. Blood. 2005;105(8):3051-3057.

146. Ruggeri L, Capanni M, Urbani E, et al. Effectiveness of donor natural killer cell alloreactivity in mismatched hematopoietic transplants. Science. 2002;295(5562):2097-2100.

147. Imai K, Matsuyama S, Miyake S, Suga K, Nakachi K. Natural cytotoxic activity of peripheral-blood lymphocytes and cancer incidence: an 11-year follow-up study of a general population. Lancet. 2000;356(9244):1795-1799.

148. Lion E, Smits EL, Berneman ZN, Van Tendeloo VF. NK cells: key to success of DC-based cancer vaccines? Oncologist. 2012;17(10):1256-1270.

149. Senovilla L, Vacchelli E, Galon J, et al. Trial watch: Prognostic and predictive value of the immune infiltrate in cancer. Oncoimmunology. 2012;1(8):1323-1343.

150. Turkseven MR, Oygur T. Evaluation of natural killer cell defense in oral squamous cell carcinoma. Oral Oncol. 2010;46(5):e34-37.

151. Ishigami S, Natsugoe S, Tokuda K, et al. Prognostic value of intratumoral natural killer cells in gastric carcinoma. Cancer. 2000;88(3):577-583.

152. Cai L, Zhang Z, Zhou L, et al. Functional impairment in circulating and intrahepatic NK cells and relative mechanism in hepatocellular carcinoma patients. Clin Immunol. 2008;129(3):428-437.

153. Carrega P, Morandi B, Costa R, et al. Natural killer cells infiltrating human nonsmall-cell lung cancer are enriched in CD56 bright CD16(-) cells and display an impaired capability to kill tumor cells. Cancer. 2008;112(4):863-875.

154. Esendagli G, Bruderek K, Goldmann T, et al. Malignant and non-malignant lung tissue areas are differentially populated by natural killer cells and regulatory T cells in non-small cell lung cancer. Lung Cancer. 2008;59(1):32-40.

155. Fauriat C, Just-Landi S, Mallet F, et al. Deficient expression of NCR in NK cells from acute myeloid leukemia: Evolution during leukemia treatment and impact of leukemia cells in NCRdull phenotype 
induction. Blood. 2007;109(1):323-330.

156. Wong JL, Mailliard RB, Moschos SJ, et al. Helper activity of natural killer cells during the dendritic cell-mediated induction of melanoma-specific cytotoxic T cells. J Immunother. 2011;34(3):270-278.

157. Gustafsson K, Ingelsten M, Bergqvist L, Nystrom J, Andersson B, Karlsson-Parra A. Recruitment and activation of natural killer cells in vitro by a human dendritic cell vaccine. Cancer Res. 2008;68(14):59655971.

158. Gustafsson K, Junevik K, Werlenius O, Holmgren S, Karlsson-Parra A, Andersson PO. Tumour-loaded alpha-type 1-polarized dendritic cells from patients with chronic lymphocytic leukaemia produce a superior NK-, NKT- and CD8+ T cell-attracting chemokine profile. Scand J Immunol. 2011;74(3):318326.

159. Jinushi M, Takehara T, Kanto T, et al. Critical role of MHC class I-related chain A and B expression on IFN-alpha-stimulated dendritic cells in NK cell activation: impairment in chronic hepatitis $\mathrm{C}$ virus infection. J Immunol. 2003;170(3):1249-1256.

160. Anguille S, Smits EL, Cools N, Goossens H, Berneman ZN, Van Tendeloo VF. Short-term cultured, interleukin-15 differentiated dendritic cells have potent immunostimulatory properties. J Transl Med. 2009;7:109.

161. Hardy MY, Kassianos AJ, Vulink A, et al. NK cells enhance the induction of CTL responses by IL-15 monocyte-derived dendritic cells. Immunol Cell Biol. 2009;87(8):606-614.

162. Mailliard RB, Wankowicz-Kalinska A, Cai Q, et al. alpha-type-1 polarized dendritic cells: a novel immunization tool with optimized CTL-inducing activity. Cancer Res. 2004;64(17):5934-5937.

163. Watchmaker PB, Berk E, Muthuswamy R, et al. Independent regulation of chemokine responsiveness and cytolytic function versus CD8+ T cell expansion by dendritic cells. J Immunol. 2010;184(2):591597.

164. Muthuswamy R, Mueller-Berghaus J, Haberkorn U, Reinhart TA, Schadendorf D, Kalinski P. PGE(2) transiently enhances DC expression of CCR7 but inhibits the ability of DCs to produce CCL19 and attract naive T cells. Blood. 2010;116(9):1454-1459.

165. Goc J, Germain C, Vo-Bourgais TK, et al. Dendritic cells in tumor-associated tertiary lymphoid structures signal a Th1 cytotoxic immune contexture and license the positive prognostic value of infiltrating CD8+ T cells. Cancer Res. 2014;74(3):705-715.

166. Cipponi A, Mercier M, Seremet T, et al. Neogenesis of lymphoid structures and antibody responses occur in human melanoma metastases. Cancer Res. 2012;72(16):3997-4007.

167. Vanderlocht J, Van Elssen CH, Senden-Gijsbers BL, et al. Increased tumor-specific CD8+ T cell induction by dendritic cells matured with a clinical grade TLR-agonist in combination with IFNgamma. Int J Immunopathol Pharmacol. 2010;23(1):35-50.

168. Nakanishi Y, Lu B, Gerard C, Iwasaki A. CD8(+) T lymphocyte mobilization to virus-infected tissue requires CD4(+) T-cell help. Nature. 2009;462(7272):510-513.

169. Kurts C, Robinson BW, Knolle PA. Cross-priming in health and disease. Nat Rev Immunol. 2010;10(6):403-414.

170. Castellino F, Huang AY, Altan-Bonnet G, Stoll S, Scheinecker C, Germain RN. Chemokines enhance immunity by guiding naive CD8+ T cells to sites of CD4+ T cell-dendritic cell interaction. Nature. 2006;440(7086):890-895.

171. Hart OM, Athie-Morales V, O’Connor GM, Gardiner CM. TLR7/8-mediated activation of human NK cells results in accessory cell-dependent IFN-gamma production. J Immunol. 2005;175(3):1636-1642.

172. Sivori S, Falco M, Carlomagno S, Romeo E, Moretta L, Moretta A. Heterogeneity of TLR3 mRNA transcripts and responsiveness to poly (I:C) in human NK cells derived from different donors. Int Immunol. 2007;19(12):1341-1348.

173. Hayakawa Y, Smyth MJ. Innate immune recognition and suppression of tumors. Adv Cancer Res. 2006;95:293-322.

174. Malmberg KJ. Effective immunotherapy against cancer: a question of overcoming immune suppression and immune escape? Cancer Immunol Immunother. 2004;53(10):879-892. 
175. Malmberg KJ, Ljunggren HG. Escape from immune- and nonimmune-mediated tumor surveillance. Semin Cancer Biol. 2006;16(1):16-31.

176. Costello RT, Sivori S, Marcenaro E, et al. Defective expression and function of natural killer celltriggering receptors in patients with acute myeloid leukemia. Blood. 2002;99(10):3661-3667.

177. Jager MJ, Hurks HM, Levitskaya J, Kiessling R. HLA expression in uveal melanoma: there is no rule without some exception. Hum Immunol. 2002;63(6):444-451.

178. Salih HR, Rammensee HG, Steinle A. Cutting edge: down-regulation of MICA on human tumors by proteolytic shedding. J Immunol. 2002;169(8):4098-4102.

179. Castriconi R, Cantoni C, Della Chiesa M, et al. Transforming growth factor beta 1 inhibits expression of NKp30 and NKG2D receptors: consequences for the NK-mediated killing of dendritic cells. Proc Natl Acad Sci U S A. 2003;100(7):4120-4125.

180. Smyth MJ, Teng MW, Swann J, Kyparissoudis K, Godfrey DI, Hayakawa Y. CD4+CD25+ T regulatory cells suppress NK cell-mediated immunotherapy of cancer. J Immunol. 2006;176(3):1582-1587.

181. Ghiringhelli F, Menard C, Terme M, et al. CD4+CD25+ regulatory T cells inhibit natural killer cell functions in a transforming growth factor-beta-dependent manner. J Exp Med. 2005;202(8):1075-1085.

182. Roy S, Barnes PF, Garg A, Wu S, Cosman D, Vankayalapati R. NK cells lyse T regulatory cells that expand in response to an intracellular pathogen. J Immunol. 2008;180(3):1729-1736.

183. Sarhan D, Palma M, Mao Y, et al. Dendritic cell regulation of NK-cell responses involves lymphotoxinalpha, IL-12, and TGF-beta. Eur J Immunol. 2015.

184. Oosterhoff D, Lougheed S, van de Ven R, et al. Tumor-mediated inhibition of human dendritic cell differentiation and function is consistently counteracted by combined p38 MAPK and STAT3 inhibition. Oncoimmunology. 2012;1(5):649-658.

185. Galon J, Costes A, Sanchez-Cabo F, et al. Type, density, and location of immune cells within human colorectal tumors predict clinical outcome. Science. 2006;313(5795):1960-1964.

186. Galon J, Fridman WH, Pages F. The adaptive immunologic microenvironment in colorectal cancer: a novel perspective. Cancer Res. 2007;67(5):1883-1886.

187. Galon J, Pages F, Marincola FM, et al. Cancer classification using the Immunoscore: a worldwide task force. J Transl Med. 2012;10:205.

188. Giraldo NA, Becht E, Remark R, Damotte D, Sautes-Fridman C, Fridman WH. The immune contexture of primary and metastatic human tumours. Curr Opin Immunol. 2014;27:8-15.

189. Gajewski TF. Cancer immunotherapy. Mol Oncol. 2012;6(2):242-250.

190. Madar S, Goldstein I, Rotter V. 'Cancer associated fibroblasts'--more than meets the eye. Trends Mol Med. 2013;19(8):447-453.

191. Balkwill F, Coussens LM. Cancer: an inflammatory link. Nature. 2004;431(7007):405-406.

192. Almand B, Clark JI, Nikitina E, et al. Increased production of immature myeloid cells in cancer patients: a mechanism of immunosuppression in cancer. J Immunol. 2001;166(1):678-689.

193. Gabrilovich DI, Ostrand-Rosenberg S, Bronte V. Coordinated regulation of myeloid cells by tumours. Nat Rev Immunol. 2012;12(4):253-268.

194. Gabrilovich DI, Nagaraj S. Myeloid-derived suppressor cells as regulators of the immune system. Nat Rev Immunol. 2009;9(3):162-174.

195. Heusinkveld M, de Vos van Steenwijk PJ, Goedemans R, et al. M2 macrophages induced by prostaglandin E2 and IL-6 from cervical carcinoma are switched to activated M1 macrophages by CD4+ Th1 cells. J Immunol. 2011;187(3):1157-1165.

196. Meyer C, Sevko A, Ramacher M, et al. Chronic inflammation promotes myeloid-derived suppressor cell activation blocking antitumor immunity in transgenic mouse melanoma model. Proc Natl Acad Sci U S A. 2011;108(41):17111-17116.

197. Bunt SK, Sinha P, Clements VK, Leips J, Ostrand-Rosenberg S. Inflammation induces myeloid-derived suppressor cells that facilitate tumor progression. J Immunol. 2006;176(1):284-290.

198. Apolloni E, Bronte V, Mazzoni A, et al. Immortalized myeloid suppressor cells trigger apoptosis in antigen-activated T lymphocytes. J Immunol. 2000;165(12):6723-6730. 
199. Mazzoni A, Bronte V, Visintin A, et al. Myeloid suppressor lines inhibit T cell responses by an NOdependent mechanism. J Immunol. 2002;168(2):689-695.

200. Rodriguez PC, Ochoa AC. Arginine regulation by myeloid derived suppressor cells and tolerance in cancer: mechanisms and therapeutic perspectives. Immunol Rev. 2008;222:180-191.

201. Yu J, Du W, Yan F, et al. Myeloid-derived suppressor cells suppress antitumor immune responses through IDO expression and correlate with lymph node metastasis in patients with breast cancer. J Immunol. 2013;190(7):3783-3797.

202. Rodriguez PC, Quiceno DG, Zabaleta J, et al. Arginase I production in the tumor microenvironment by mature myeloid cells inhibits T-cell receptor expression and antigen-specific T-cell responses. Cancer Res. 2004;64(16):5839-5849.

203. Ochoa AC, Zea AH, Hernandez C, Rodriguez PC. Arginase, prostaglandins, and myeloid-derived suppressor cells in renal cell carcinoma. Clin Cancer Res. 2007;13(2 Pt 2):721s-726s.

204. Terabe M, Matsui S, Park JM, et al. Transforming growth factor-beta production and myeloid cells are an effector mechanism through which CD1d-restricted T cells block cytotoxic T lymphocyte-mediated tumor immunosurveillance: abrogation prevents tumor recurrence. J Exp Med. 2003;198(11):17411752.

205. Li H, Han Y, Guo Q, Zhang M, Cao X. Cancer-expanded myeloid-derived suppressor cells induce anergy of NK cells through membrane-bound TGF-beta 1. J Immunol. 2009;182(1):240-249.

206. Elkabets M, Ribeiro VS, Dinarello CA, et al. IL-1beta regulates a novel myeloid-derived suppressor cell subset that impairs NK cell development and function. Eur J Immunol. 2010;40(12):3347-3357.

207. Chong H, Vodovotz Y, Cox GW, Barcellos-Hoff MH. Immunocytochemical localization of latent transforming growth factor-beta1 activation by stimulated macrophages. J Cell Physiol. 1999;178(3):275283.

208. Corzo CA, Condamine T, Lu L, et al. HIF-1alpha regulates function and differentiation of myeloidderived suppressor cells in the tumor microenvironment. J Exp Med. 2010;207(11):2439-2453.

209. Motz GT, Coukos G. Deciphering and reversing tumor immune suppression. Immunity. 2013;39(1):6173.

210. Wesolowski R, Markowitz J, Carson WE, 3rd. Myeloid derived suppressor cells - a new therapeutic target in the treatment of cancer. J Immunother Cancer. 2013;1:10.

211. Coward J, Kulbe H, Chakravarty P, et al. Interleukin-6 as a therapeutic target in human ovarian cancer. Clin Cancer Res. 2011;17(18):6083-6096.

212. Mirza N, Fishman M, Fricke I, et al. All-trans-retinoic acid improves differentiation of myeloid cells and immune response in cancer patients. Cancer Res. 2006;66(18):9299-9307.

213. Kerkar SP, Restifo NP. The power and pitfalls of IL-12. Blood. 2012;119(18):4096-4097.

214. Raue HP, Beadling C, Haun J, Slifka MK. Cytokine-mediated programmed proliferation of virusspecific CD8(+) memory T cells. Immunity. 2013;38(1):131-139.

215. Curtsinger JM, Schmidt CS, Mondino A, et al. Inflammatory cytokines provide a third signal for activation of naive CD4+ and CD8+ T cells. J Immunol. 1999;162(6):3256-3262.

216. Schurich A, Pallett LJ, Lubowiecki M, et al. The third signal cytokine IL-12 rescues the anti-viral function of exhausted HBV-specific CD8 T cells. PLoS Pathog. 2013;9(3):e1003208.

217. Steding CE, Wu ST, Zhang Y, Jeng MH, Elzey BD, Kao C. The role of interleukin-12 on modulating myeloid-derived suppressor cells, increasing overall survival and reducing metastasis. Immunology. 2011;133(2):221-238.

218. Hernandez-Alcoceba R, Berraondo P. Immunochemotherapy against colon cancer by gene transfer of interleukin-12 in combination with oxaliplatin. Oncoimmunology. 2012;1(1):97-99.

219. Xiao Z, Casey KA, Jameson SC, Curtsinger JM, Mescher MF. Programming for CD8 T cell memory development requires IL-12 or type I IFN. J Immunol. 2009;182(5):2786-2794.

220. Gerner MY, Heltemes-Harris LM, Fife BT, Mescher MF. Cutting edge: IL-12 and type I IFN differentially program CD8 T cells for programmed death 1 re-expression levels and tumor control. J Immunol. 2013;191(3):1011-1015. 
221. Poschke I, Mao Y, Adamson L, Salazar-Onfray F, Masucci G, Kiessling R. Myeloid-derived suppressor cells impair the quality of dendritic cell vaccines. Cancer Immunol Immunother. 2012;61(6):827-838.

222. Huang Y, Wang FM, Wang T, et al. Tumor-infiltrating FoxP3+ Tregs and CD8+ T cells affect the prognosis of hepatocellular carcinoma patients. Digestion. 2012;86(4):329-337.

223. Pedroza-Gonzalez A, Verhoef C, Ijzermans JN, et al. Activated tumor-infiltrating CD4+ regulatory $\mathrm{T}$ cells restrain antitumor immunity in patients with primary or metastatic liver cancer. Hepatology. 2013;57(1):183-194.

224. Williams MA, Bevan MJ. Effector and memory CTL differentiation. Annu Rev Immunol. 2007;25:171192.

225. Jacobs JF, Punt CJ, Lesterhuis WJ, et al. Dendritic cell vaccination in combination with anti-CD25 monoclonal antibody treatment: a phase I/II study in metastatic melanoma patients. Clin Cancer Res. 2010;16(20):5067-5078.

226. Sugiyama D, Nishikawa H, Maeda Y, et al. Anti-CCR4 mAb selectively depletes effector-type FoxP3+CD4+ regulatory T cells, evoking antitumor immune responses in humans. Proc Natl Acad Sci U S A. 2013;110(44):17945-17950.

227. Shimizu J, Yamazaki S, Takahashi T, Ishida Y, Sakaguchi S. Stimulation of CD25(+)CD4(+) regulatory T cells through GITR breaks immunological self-tolerance. Nat Immunol. 2002;3(2):135-142.

228. Ko K, Yamazaki S, Nakamura K, et al. Treatment of advanced tumors with agonistic anti-GITR $\mathrm{mAb}$ and its effects on tumor-infiltrating Foxp3+CD25+CD4+ regulatory $\mathrm{T}$ cells. J Exp Med. 2005;202(7):885-891.

229. Mitsui J, Nishikawa H, Muraoka D, et al. Two distinct mechanisms of augmented antitumor activity by modulation of immunostimulatory/inhibitory signals. Clin Cancer Res. 2010;16(10):2781-2791.

230. Valzasina B, Guiducci C, Dislich H, Killeen N, Weinberg AD, Colombo MP. Triggering of OX40 (CD134) on CD4(+)CD25+ T cells blocks their inhibitory activity: a novel regulatory role for OX40 and its comparison with GITR. Blood. 2005;105(7):2845-2851.

231. Piconese S, Valzasina B, Colombo MP. OX40 triggering blocks suppression by regulatory $\mathrm{T}$ cells and facilitates tumor rejection. J Exp Med. 2008;205(4):825-839.

232. Seliger B, Massa C. The dark side of dendritic cells: development and exploitation of tolerogenic activity that favor tumor outgrowth and immune escape. Front Immunol. 2013;4:419.

233. Gottfried E, Kunz-Schughart LA, Ebner S, et al. Tumor-derived lactic acid modulates dendritic cell activation and antigen expression. Blood. 2006;107(5):2013-2021.

234. Steinbrink K, Wolf M, Jonuleit H, Knop J, Enk AH. Induction of tolerance by IL-10-treated dendritic cells. J Immunol. 1997;159(10):4772-4780.

235. Sombroek CC, Stam AG, Masterson AJ, et al. Prostanoids play a major role in the primary tumorinduced inhibition of dendritic cell differentiation. J Immunol. 2002;168(9):4333-4343.

236. Menetrier-Caux C, Montmain G, Dieu MC, et al. Inhibition of the differentiation of dendritic cells from CD34(+) progenitors by tumor cells: role of interleukin-6 and macrophage colony-stimulating factor. Blood. 1998;92(12):4778-4791.

237. Parodi A, Battaglia F, Kalli F, et al. CD39 is highly involved in mediating the suppression activity of tumor-infiltrating CD8+ T regulatory lymphocytes. Cancer Immunol Immunother. 2013;62(5):851862.

238. Deaglio S, Dwyer KM, Gao W, et al. Adenosine generation catalyzed by CD39 and CD73 expressed on regulatory T cells mediates immune suppression. J Exp Med. 2007;204(6):1257-1265.

239. Zarek PE, Huang CT, Lutz ER, et al. A2A receptor signaling promotes peripheral tolerance by inducing T-cell anergy and the generation of adaptive regulatory T cells. Blood. 2008;111(1):251-259.

240. Lokshin A, Raskovalova T, Huang X, Zacharia LC, Jackson EK, Gorelik E. Adenosine-mediated inhibition of the cytotoxic activity and cytokine production by activated natural killer cells. Cancer Res. 2006;66(15):7758-7765.

241. Antonioli L, Blandizzi C, Pacher P, Hasko G. Immunity, inflammation and cancer: a leading role for adenosine. Nat Rev Cancer. 2013;13(12):842-857. 
242. Beavis PA, Divisekera U, Paget C, et al. Blockade of A2A receptors potently suppresses the metastasis of CD73+ tumors. Proc Natl Acad Sci U S A. 2013;110(36):14711-14716.

243. Beavis PA, Milenkovski N, Henderson MA, et al. Adenosine Receptor 2A Blockade Increases the Efficacy of Anti-PD-1 through Enhanced Antitumor T-cell Responses. Cancer Immunol Res. 2015;3(5):506-517.

244. Kumar V. Adenosine as an endogenous immunoregulator in cancer pathogenesis: where to go? Purinergic Signal. 2013;9(2):145-165.

245. Sitkovsky M, Ohta A. Targeting the hypoxia-adenosinergic signaling pathway to improve the adoptive immunotherapy of cancer. J Mol Med (Berl). 2013;91(2):147-155.

246. Waickman AT, Alme A, Senaldi L, Zarek PE, Horton M, Powell JD. Enhancement of tumor immunotherapy by deletion of the A2A adenosine receptor. Cancer Immunol Immunother. 2012;61(6):917-926.

247. Linsley PS, Bradshaw J, Greene J, Peach R, Bennett KL, Mittler RS. Intracellular trafficking of CTLA-4 and focal localization towards sites of TCR engagement. Immunity. 1996;4(6):535-543.

248. Pentcheva-Hoang T, Egen JG, Wojnoonski K, Allison JP. B7-1 and B7-2 selectively recruit CTLA-4 and CD28 to the immunological synapse. Immunity. 2004;21(3):401-413.

249. van der Merwe PA, Bodian DL, Daenke S, Linsley P, Davis SJ. CD80 (B7-1) binds both CD28 and CTLA-4 with a low affinity and very fast kinetics. J Exp Med. 1997;185(3):393-403.

250. Qureshi OS, Zheng Y, Nakamura K, et al. Trans-endocytosis of CD80 and CD86: a molecular basis for the cell-extrinsic function of CTLA-4. Science. 2011;332(6029):600-603.

251. Schneider H, Downey J, Smith A, et al. Reversal of the TCR stop signal by CTLA-4. Science. 2006;313(5795):1972-1975.

252. Read S, Malmstrom V, Powrie F. Cytotoxic T lymphocyte-associated antigen 4 plays an essential role in the function of $\mathrm{CD} 25(+) \mathrm{CD} 4(+)$ regulatory cells that control intestinal inflammation. J Exp Med. 2000;192(2):295-302.

253. Nishikawa H, Sakaguchi S. Regulatory T cells in cancer immunotherapy. Curr Opin Immunol. 2014;27:1-7.

254. Bulliard Y, Jolicoeur R, Windman M, et al. Activating Fc gamma receptors contribute to the antitumor activities of immunoregulatory receptor-targeting antibodies. J Exp Med. 2013;210(9):1685-1693.

255. Selby MJ, Engelhardt JJ, Quigley M, et al. Anti-CTLA-4 antibodies of IgG2a isotype enhance antitumor activity through reduction of intratumoral regulatory T cells. Cancer Immunol Res. 2013;1(1):32-42.

256. Simpson TR, Li F, Montalvo-Ortiz W, et al. Fc-dependent depletion of tumor-infiltrating regulatory T cells co-defines the efficacy of anti-CTLA-4 therapy against melanoma. J Exp Med. 2013;210(9):16951710 .

257. Fecher LA, Agarwala SS, Hodi FS, Weber JS. Ipilimumab and its toxicities: a multidisciplinary approach. Oncologist. 2013;18(6):733-743.

258. Keir ME, Butte MJ, Freeman GJ, Sharpe AH. PD-1 and its ligands in tolerance and immunity. Annu Rev Immunol. 2008;26:677-704.

259. Ishida Y, Agata Y, Shibahara K, Honjo T. Induced expression of PD-1, a novel member of the immunoglobulin gene superfamily, upon programmed cell death. EMBO J. 1992;11(11):3887-3895.

260. Benson DM, Jr., Bakan CE, Mishra A, et al. The PD-1/PD-L1 axis modulates the natural killer cell versus multiple myeloma effect: a therapeutic target for CT-011, a novel monoclonal anti-PD-1 antibody. Blood. 2010;116(13):2286-2294.

261. Norris S, Coleman A, Kuri-Cervantes L, Bower M, Nelson M, Goodier MR. PD-1 expression on natural killer cells and CD8(+) T cells during chronic HIV-1 infection. Viral Immunol. 2012;25(4):329332.

262. Thompson RH, Dong H, Lohse CM, et al. PD-1 is expressed by tumor-infiltrating immune cells and is associated with poor outcome for patients with renal cell carcinoma. Clin Cancer Res. 2007;13(6):17571761.

263. Zitvogel L, Kroemer G. Targeting PD-1/PD-L1 interactions for cancer immunotherapy. 
Oncoimmunology. 2012;1(8):1223-1225.

264. Mellman I, Coukos G, Dranoff G. Cancer immunotherapy comes of age. Nature. 2011;480(7378):480489.

265. Dong H, Strome SE, Salomao DR, et al. Tumor-associated B7-H1 promotes T-cell apoptosis: a potential mechanism of immune evasion. Nat Med. 2002;8(8):793-800.

266. Lee SJ, Jang BC, Lee SW, et al. Interferon regulatory factor-1 is prerequisite to the constitutive expression and IFN-gamma-induced upregulation of B7-H1 (CD274). FEBS Lett. 2006;580(3):755-762.

267. Muhlbauer M, Fleck M, Schutz C, et al. PD-L1 is induced in hepatocytes by viral infection and by interferon-alpha and -gamma and mediates T cell apoptosis. J Hepatol. 2006;45(4):520-528.

268. Tseng SY, Otsuji M, Gorski K, et al. B7-DC, a new dendritic cell molecule with potent costimulatory properties for T cells. J Exp Med. 2001;193(7):839-846.

269. Latchman Y, Wood CR, Chernova T, et al. PD-L2 is a second ligand for PD-1 and inhibits T cell activation. Nat Immunol. 2001;2(3):261-268.

270. Riley JL. PD-1 signaling in primary T cells. Immunol Rev. 2009;229(1):114-125.

271. Saunders PA, Hendrycks VR, Lidinsky WA, Woods ML. PD-L2:PD-1 involvement in T cell proliferation, cytokine production, and integrin-mediated adhesion. Eur J Immunol. 2005;35(12):3561-3569.

272. Yokosuka T, Takamatsu M, Kobayashi-Imanishi W, Hashimoto-Tane A, Azuma M, Saito T. Programmed cell death 1 forms negative costimulatory microclusters that directly inhibit $\mathrm{T}$ cell receptor signaling by recruiting phosphatase SHP2. J Exp Med. 2012;209(6):1201-1217.

273. Wei F, Zhong S, Ma Z, et al. Strength of PD-1 signaling differentially affects T-cell effector functions. Proc Natl Acad Sci U S A. 2013;110(27):E2480-2489.

274. Ghiotto M, Gauthier L, Serriari N, et al. PD-L1 and PD-L2 differ in their molecular mechanisms of interaction with PD-1. Int Immunol. 2010;22(8):651-660.

275. Ahmadzadeh M, Johnson LA, Heemskerk B, et al. Tumor antigen-specific CD 8 T cells infiltrating the tumor express high levels of PD-1 and are functionally impaired. Blood. 2009;114(8):1537-1544.

276. Sfanos KS, Bruno TC, Meeker AK, De Marzo AM, Isaacs WB, Drake CG. Human prostate-infiltrating CD8+ T lymphocytes are oligoclonal and PD-1+. Prostate. 2009;69(15):1694-1703.

277. Song MY, Park SH, Nam HJ, Choi DH, Sung YC. Enhancement of vaccine-induced primary and memory CD8(+) T-cell responses by soluble PD-1. J Immunother. 2011;34(3):297-306.

278. Tang X, Ye K. Pike tyrosine phosphorylation regulates its apoptotic cleavage during programmed cell death. Adv Enzyme Regul. 2006;46:289-300.

279. Gerlinger M, Rowan AJ, Horswell S, et al. Intratumor heterogeneity and branched evolution revealed by multiregion sequencing. N Engl J Med. 2012;366(10):883-892.

280. Greaves M, Maley CC. Clonal evolution in cancer. Nature. 2012;481(7381):306-313.

281. Merlo LM, Pepper JW, Reid BJ, Maley CC. Cancer as an evolutionary and ecological process. Nat Rev Cancer. 2006;6(12):924-935.

282. van den Boorn JG, Hartmann G. Turning tumors into vaccines: co-opting the innate immune system. Immunity. 2013;39(1):27-37.

283. Mahoney KM, Rennert PD, Freeman GJ. Combination cancer immunotherapy and new immunomodulatory targets. Nat Rev Drug Discov. 2015;14(8):561-584.

284. Haanen JB, Thienen H, Blank CU. Toxicity patterns with immunomodulating antibodies and their combinations. Semin Oncol. 2015;42(3):423-428.

285. Hannani D, Vetizou M, Enot D, et al. Anticancer immunotherapy by CTLA-4 blockade: obligatory contribution of IL-2 receptors and negative prognostic impact of soluble CD25. Cell Res. 2015;25(2):208-224.

286. Pages F, Kirilovsky A, Mlecnik B, et al. In situ cytotoxic and memory T cells predict outcome in patients with early-stage colorectal cancer. J Clin Oncol. 2009;27(35):5944-5951. 

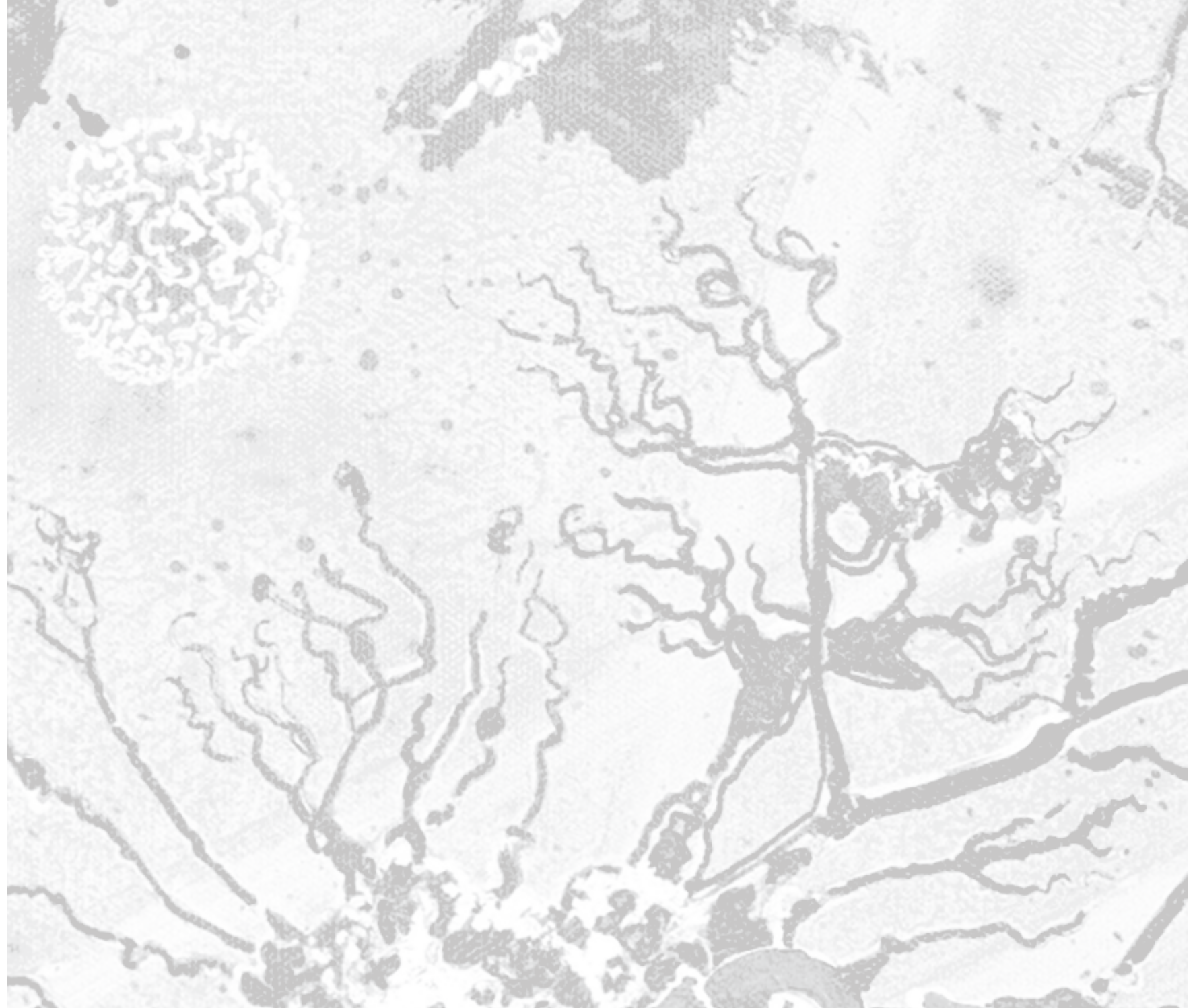

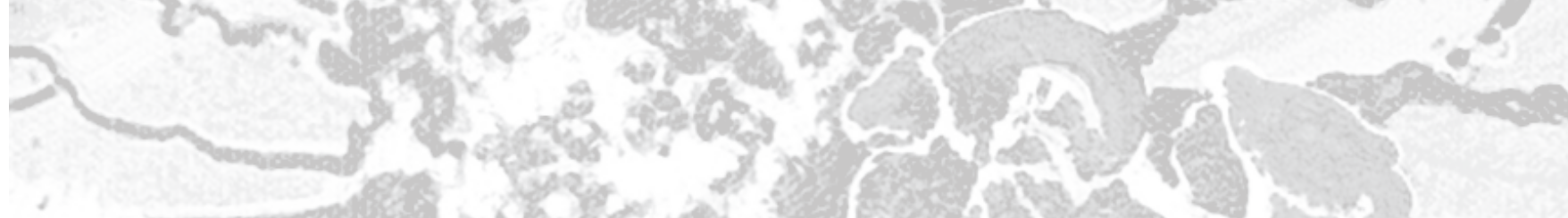

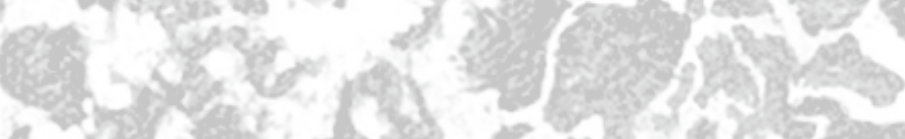

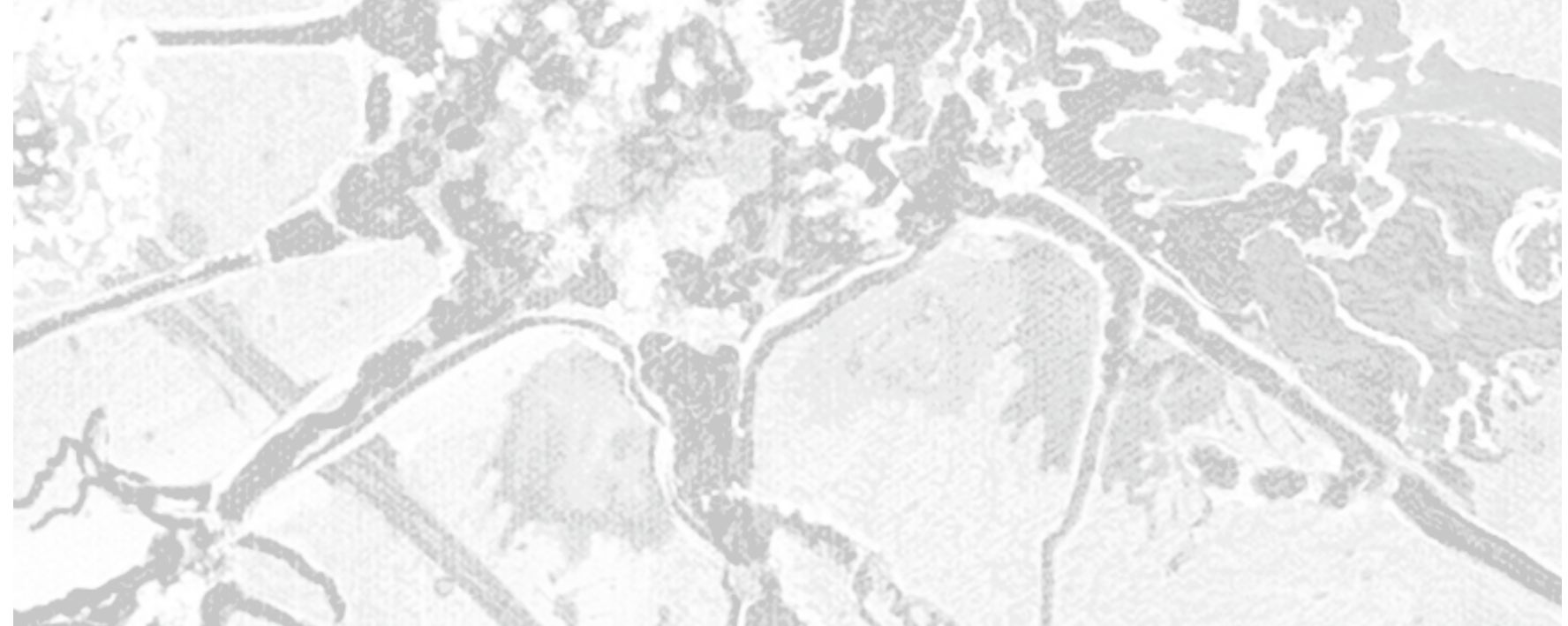




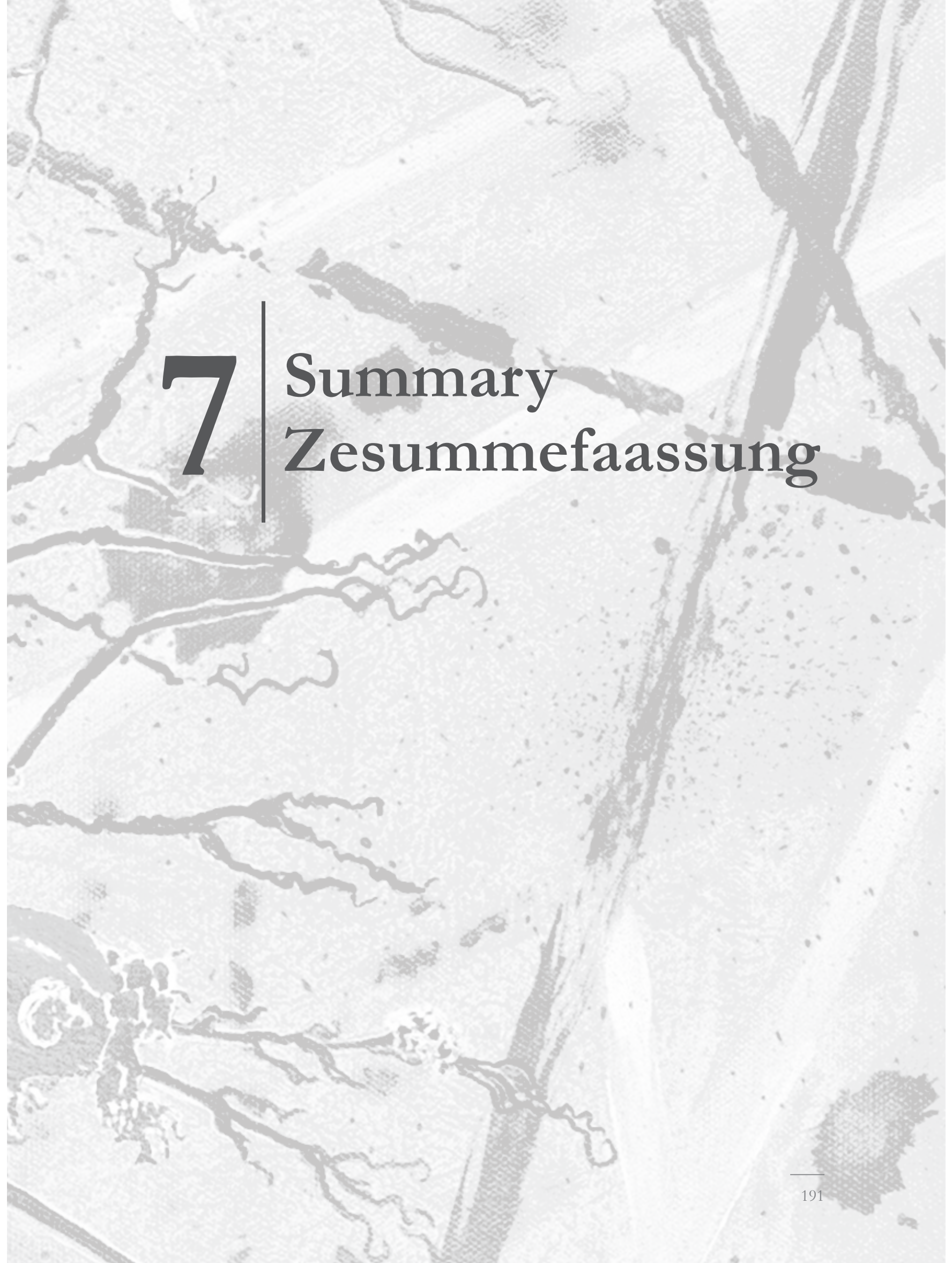





\section{SUMMARY}

During a pathogenic insult, the efficient cooperation of innate and adaptive immunity is needed to eradicate the invader. Pathogen recognition receptors (PRR), expressed on various types of immune cells, are important components of the innate immunity and are responsible for sensing and instructing appropriate and coordinated immune responses. The main cell type expressing these PRR and thus linking innate and adaptive immunity are antigen-presenting cells, such as dendritic cells (DC). Because of their importance and unique properties of instructing various immune effector cells, DC have been considered as promising targets in immunotherapeutic strategies against cancer.

Besides the conventional cancer treatments such as surgery, radiation-, and chemotherapy, immunotherapy has been implemented into standard treatment regimens for certain types of cancer, e.g. monoclonal antibodies like Rituximab for non-Hodgkin's lymphoma. Cancer immunotherapy aims to stimulate the patient's immune responses to eliminate tumour cells. One approach of cellular immunotherapy is DC-based vaccination, which has been proven to be safe and non-toxic. Nonetheless, the limited overall positive clinical outcome monitored is indicative for the need of further optimizations. Initial studies focused on generating DC having the potential to efficiently induce anti-tumour cytotoxic $\mathrm{T}$ lymphocyte responses. However, increasing evidence indicates that the induction of more complex type 1 immune responses, including also T helper 1 (Th1) and natural killer $(\mathrm{NK})$ cells, is crucial for the induction of efficient anti-tumour responses.

The main aim of this thesis was to study the cellular interplay of DC, NK cells and T helper cells after PAMP encounter with main focus on type 1-induced helper responses. Identifying which signals induce and enhance the interaction of DC with different immune effector cells is important to increase the efficacy of DC vaccination strategies.

In the human setting, standardized autologous DC-dependent systems to study de novo polarization of naive $\mathrm{CD} 4^{+} \mathrm{T}$ cells and the associated molecular events occurring during the initiation phase are lacking. In chapter 2 , we describe the development of an assay allowing the comparison of different pathogen-triggered human DC for their capacities to instruct functional polarization of autologous naive $\mathrm{CD}^{+} \mathrm{T}$ cells in a TCR-restricted manner. We demonstrated that differently matured DC can be evaluated according to kinetics, direction, and magnitude of the induced naive $\mathrm{CD}^{+} \mathrm{T}$ cell response. Comparing the capacity of three (pre-) clinical DC maturation cocktails used for the generation of ex vivo-matured DC for DC-based vaccines ( $\mathrm{PGE}_{2} / \mathrm{TNF}-\alpha, \mathrm{LPS} / \mathrm{IFN}-\gamma$, and FMKp/IFN- $\gamma$ ), we revealed that only FMKp/IFN- $\gamma$-matured DC efficiently polarized naive CD4 ${ }^{+}$T cells into Th1 cells. $\mathrm{PGE}_{2} / \mathrm{TNF}-\alpha$-matured DC, a maturation cocktail frequently used in early - and current - 
DC vaccine clinical trials, induce a Th2-like polarization. Moreover, we demonstrated that the applicability of this methodology is not limited to the study of $\mathrm{T}$ cell-polarizing capacity of monocyte-derived DC but also of low-frequency blood-derived DC subsets, exemplified by plasmacytoid DC. This is a valuable tool to gain more insight into molecular mechanisms occurring in the early phase of $\mathrm{T}$ cell polarization and may allow the study of pharmacological agents on DC-dependent $\mathrm{T}$ cell polarization.

For the induction of potent type 1 immune responses, mature DC should be able to polarize $\mathrm{CD}^{+} \mathrm{T}$ cells towards Th1 cells as well as activate NK (helper) cells. In chapter 3 , we studied the influence of specific PRR-triggering during the maturation of DC on their capacity to stimulate these helper processes. Moreover, we investigated whether the induction of helper responses is coupled and thus mediated by the same PRR-matured DC. We demonstrated that DC matured with a cocktail containing bacterial fragments of Klebsiella pneumoniae (FMKp) mounted Th1 as well as NK helper responses in a PRR trigger dose-dependent manner as determined by their capacity to produce IFN- $\gamma$. This effect was also observed by triggering an additional PRR pathway $(\mathrm{FMKp}+$ poly(I:C)). We revealed that both quantitative and cooperative PRR-triggering modulated the capacity of DC to produce IL-12p70 and that this cytokine is the key determinant of the DC-induced Th1 and NK cell helper responses. In addition, all PRR triggers able to induce IL-12-producing mature DC were sufficient to induce these helper responses. This knowledge can be of importance to select proper PRR triggers in preventive and therapeutic vaccine design.

NK cells do not only play crucial roles in eliminating virally infected and malignantly transformed cells, but have also been described as modulators of adaptive immune responses. Like DC, NK cells express various PRR. In chapter 4, we studied whether NK cells could directly sense bacterial and viral motifs and whether these PAMP-activated NK cells could enhance the maturation of DC via the release of soluble factors. We revealed that both bacterial- and viral-activated NK cells augment the pro-inflammatory cytokine profile of monocyte-derived DC via NK cell-derived soluble factors. Among viral and bacterial motifs, the enhancement of DC-derived IL-12p70 secretion was observed by NK cells directly sensing TLR1/2, TLR2, TLR2/6, TLR3, TLR4, TLR5, TLR7/8 and TLR8triggers. Notably this amplifying effect was not observed for TLR7-triggers. Moreover we revealed that not all PAMPs triggering one specific TLR induce similar responses. Besides IL-12p70 secretion, also DC-derived production of IL-6, IL-1 $\beta$, CXCL9 and CXCL10 was enhanced. The helper capacity of NK cells was dependent on the cytokine milieu in which they recognized the pathogens and thus influenced by accessory cell activation. Moreover, we revealed that NK cells amplify the DC cytokine profile via a mechanism independent of TNF- $\alpha$ and relying on IFN- $\gamma$. In addition to the results described in chapter 3 , the direct sensing of different PRR triggers by NK cells can be of interest to modulate immune 
responses and could be applied in search of more potent adjuvants for vaccination strategies.

In the context of cancer, the cellular interactions described in chapters 2-4 can be modulated by factors released in the tumour microenvironment (TME). In chapter $\mathbf{5}$, we studied the effect of such a factor, prostaglandin $\mathrm{E}_{2}\left(\mathrm{PGE}_{2}\right)$, on the NK-DC crosstalk. We showed that $\mathrm{PGE}_{2}$ directly inhibits cytolytic and cytokine-producing capacity of freshly isolated $\mathrm{NK}$ cells in a dose-dependent manner. In this line, $\mathrm{PGE}_{2}$ directly influences cytokine (IL-12, IL-18) and chemokine (CCL5, CCL19, CXCL10) secretion by FMKp/IFN- $\gamma$-matured DC reducing their capacity to recruit and activate NK cells. Consequently, NK cells were not able to provide help for Th1 polarization. The capacity of DC to interact with NK cells is imprinted during the early maturation phase, as 6h-matured DC were unsusceptible to the inhibitory effect of $\mathrm{PGE}_{2}$.

Chapter 6 reflects the most important findings described in this dissertation in the context of vaccine adjuvants and the possible impact of helper cells in future DC vaccination strategies. Moreover, the impact of TME on the efficacy of immunotherapy is discussed.

To conclude, the findings described in this dissertation contribute to the understanding on how different PAMPs can be applied to modulate immune responses with respect to DC maturation and subsequent helper cell induction as well as the direct effects on the NK helper cells. These findings contribute to the optimization of current cellular immunotherapeutic strategies. 


\section{ZESUMMEFAASSUNG}

Kriibs ass eng vun deenen heefegsten Doudesursaache weltwäit. 2012 goufe 14.1 Milliounen nei Fäll an 8.2 Milliounen Doudeger registréiert. Et gëtt sech erwaart, dass d'Zuel vun neie Fäll an deenen nächsten 20 Joer ëm 70\% klëmmt op ronn 24 Milliounen. Verbesserunge souwuel an der Fréierkennung wéi och an der Chirurgie, Chemo- a Radiotherapie hunn derzou bäigedroen, dass d'Stierflechkeet an deene leschte Jore liicht zréckgaangen ass. Trotzdem bleift e groussen Deel vun de Kriibspatienten onheelbar. Nieft dem Optimiséiere vu Screening Methoden an de klasseschen Therapien, ginn och nei Therapieméiglechkeete gebraucht, déi manner schiedlech an toxesch sinn. Dëst ass wichteg fir dem Patient eng besser Liewensqualitéit ze erméiglechen. An deene leschte Joren huet d'Immuntherapie groussen Interessi gewonnen als Alternativ an der Kriibsbehandlung. Immuntherapie besteet aus ville verschiddene Formen an Usätz; de Grondprinzip besteet doraus, dat natierlecht Ofwiersystem vum Patient ze stimuléieren/manipuléieren, soudass dëst d'Kriibszellen ugräift a schlussendlech futtimécht.

D’Ofwiersystem (och nach Immunsystem genannt) besteet ënner anerem aus verschiddene wäisse Bluttkierpercher, déi alleguer eng spezifesch Aufgab hunn. D’Immunsystem kann ënnerdeelt ginn an een onspezifeschen (ugebuerenen) an ee spezifeschen (ugeléierten) Deel. Eist ugebuerent Immunsystem wierkt direkt, och wa mir zum Beispill nach ni mat engem bestëmmte Mikrob konfrontéiert gi sinn. Déi spezifesch Immunitéit besteet aus Zellen, déi geziilt just bestëmmte Bakterien an Viren erkennen kënnen. Bei engem bakteriellen/viralen Infekt oder kierpereegene béisaartegen Zelle ginn dës wäiss Bluttkierpercher alarméiert, an duerch eng koordinéiert Kommunikatioun gi bestëmmte wäiss Bluttkierpercher geziilt op déi Plazen am Kierper geschéckt, wou d'Gefor ass a se gebraucht ginn. Am Normalfall gëtt den Eindringling sou bekämpft an de Mënsch gëtt erëm gesond. Falls de Mënsch nach eemol mat deemselwechte Mikrob konfrontéiert gëtt, da gëtt dësen Alarméierunsprozess méi séier ausgeléist, doduerch dass mir een immunologescht Gediechtnes opgebaut hunn. Dëst besteet aus de spezialiséierten Zellen. Op dësem Prinzip sinn och d'Impfstoffer opgebaut. An deene meeschte Fäll kann eist Ofwiersystem d'Mikroben an déi béisaarteg Zellen erkennen a se eliminéieren. Am Fall vum Kriibs ass dës Balance zerstéiert an déi béisaarteg Zelle kënnen ongestéiert wuessen.

Zellen, déi am Mëttelpunkt stinn an d'Bréck tëschent der ugebuerener an der ugeléierter Immunitéit maachen, sinn d'dendritesch Zellen. Dës wäiss Bluttkierpercher ginn aktivéiert duerch d'Erkenne vun bestëmmte Mierkmoler, déi spezifesch si fir Mikroben (sougenannte PAMP - pathogen-associated molecular patterns), mee net fir mënschlech Zellen. Dëst féiert derzou, dass d'dendritesch Zelle räifen a kleng Stécker vun de Mikroben (Antigener) op hirer Surface presentéieren. Räif dendritesch Zellen aktivéieren aner Zelle vum Ofwiersystem 
duerch engersäits d'Produktioun vu Moleküllen an anerersäits duerch d'Expressioun vun den Antigener déi duerch aner Zellen erkannt ginn. Op dës Manéier suergen dendritesch Zelle fir eng efficace a geziilten Ofwierreaktioun géint ee spezifesche Microorganismus. Betraffen Zelle sinn ënnert anerem natierlech Killer Zellen (NK Zellen), déi souwuel direkt Kriibszelle kënne futtimaachen, wéi och duerch d'Produktioun vu Moleküllen eng positiv Réckkopplung un dendritesch Zellen ginn an dës stäerken. Eng aner Zort sinn d’T HelferZellen, dës Zellen hëllefen den toxeschen $\mathrm{T}$ Lymphozyten méi effektiv ze schaffen an d'Kriibszelle méi efficace futtizemaachen.

Engersäits sinn dendritesch Zelle wichteg fir eng optimal an effektiv Ofwierreaktioun ze induzéieren. Anerersäits sinn dës Zelle bei Kriibspatienten zum gréissten Deel an engem onräifen Zoustand a kënnen d'Ofwiersystem net méi sou effektiv steieren. Well dës Zellen esou wichteg sinn, ass eng vun de Strategien an der Kriibs-Immuntherapie, dendritesch Zellen als therapeuteschen Impfstoff ze gebrauchen. Heifir gëtt ee Virleefer vun den dendriteschen Zellen aus dem Blutt vum Patient isoléiert. Dës Zelle ginn dann am Labo esou stimuléiert, dass se zu dendriteschen Zellen eruräifen, déi eng spezifesch Ofwierreaktioun géint Kriibszellen ausléise kënnen. Dës dendritesch Zelle ginn dem Patient da wéi een Impfstoff gesprëtzt. Als Resultat heivunner sollen aner Immunzellen am Kierper aktivéiert ginn an esou d'Kriibszellen attackéieren. Dës dendritsch Zell-Impfstoffer si schonn a klinesche Studië getest ginn. 2010 ass deen éischten Impfstoff géint Prostatakriibs op de Maart komm. Trotz de villverspriechende Resultater muss d'Efficacitéit vun dësen Impfstoffer nach verbessert ginn.

Eng Manéier, wéi dës Impfstoffer kënne verbessert ginn, ass de Räifungsprozess vun den dendritschen Zellen am Labo ze optiméieren. Sou wéi an enger normaler Ofwierreaktioun géint Mikroben, sollen och dës manipuléiert dendritesch Zelle mat verschiddenen Immunzelle kënnen interagéieren, fir eng optimal Immunreaktioun géint d'Kriibszellen auszeléisen. An deene leschte Joren ass spekuléiert ginn, dass d'Helfer-Zellen heibäi eng wichteg Roll solle spillen.

An dëser Thees 'PAMPering immune responses - Spotlight on helper cells for dendritic cell vaccination' gëtt, wéi den Titel et seet, d'Roll vun Helfer-Zellen (NK Zellen an T HelferZellen) am Kontext vun der Optimiséierung vun dendriteschen Zell-Impfstoffer géint Kriibs ënnersicht. Mir wollten haaptsächlech erausfannen, wéi een Afloss déi verschidden Aktivéierungspartikelen op d'Interaktioun vun den dendriteschen Zelle mat den HelferZellen hunn. Heifir hu mir d'dendritesch Zellen 'verwinnt' (pampering), wat heescht, dass mir versicht hunn, eng optimal Simulatioun ze fanne fir de Räifungsprozess, an dass mir heifir kleng Partikelen, déi spezifesch fir Mikroben - PAMP - sinn, gebraucht hunn. Zur Räifung vun den dendritschen Zellen gehéiert och, dass se trainéiert ginn, fir eng spezifesch 
Ofwierreaktioun just géint Kriibszellen auszeléisen. Dësen Aspekt ass an dëser Thees net behandelt ginn.

Am Kapitel 2 hu mir eng Method entwéckelt, fir d'Interaktioun tëscht den dendriteschen Zellen an den T Helfer-Zellen ze studéieren. Méi genee erméiglecht dës Method et, fir d'Induktioun vun naiven (d.h. neien) T Helfer-Zellen, déi duerch ënnerschiddlech aktivéiert dendritesch Zellen induzéiert ginn, an hirer Stäerkt an an hirer Vitesse ze beuerteelen. Dëst ass enorm wichteg, well bis elo keng Methode bestan hunn, fir dëst ausserhalb vum Kierper (an der Zellkultur, d.h. in vitro) mat mënschlechen Zellen ze erfuerschen. Mat dëser Method hu mir erausfonnt, dass d'Aktivéierungspartikelen, déi bis elo am heefegste gebraucht gi sinn fir d'Räifung vun den dendriteschen Zellen fir d'Impfstoffer, net sou efficace sinn. Mir weisen hei och, dass dendritesch Zellen, déi mat engem PAMP vu bakteriellem Ursprong (Klebsiella pneumoniae - FMKp) aktivéiert ginn, dat am Géigesaz ganz gutt kënnen.

Am Kapitel 3 hu mir ënnersicht, ob dendritesch Zellen in vitro kënne sou manipuléiert ginn, dass se souwuel NK Zellen, wéi och T Helfer-Zellen aktivéiere kënnen. Heifir hu mir verschidde bakteriell a viral PAMP als Aktivéierungspartikele fir dendritsch Zelle gebraucht. FMKp-aktivéiert dendritesch Zellen hunn dëst Potenzial. Desweidere war et méiglech, dëst Potenzial nach weider ze verstäerken, andeems 2 Aktivéierunsgpartikele gläichzäiteg benotzt gi sinn. Dës Method fir eng verbessert Räifung vun den dendriteschen Zellen hu mir patentéiere gelooss. D'Capacitéit vun dendritschen Zelle, fir d'Helfer-Zellen ze aktivéieren, gëtt gesteiert duerch ee Stoff, deen dës Zelle produzéieren: Interleukin-12. Wat méi Interleukin-12 produzéiert gëtt, ëmsou méi performant ginn d'Helfer-Zellen aktivéiert.

NK Zelle kënnen och direkt Mikroben erkennen. Dofir hu mir am Kapitel 4 analyséiert, ob NK Zellen de Räifungsprozess vun dendriteschen Zelle positiv beaflosse kënnen. PAMPaktivéiert NK Zelle produzéieren ee bestëmmtent Moleküll - Interferon-gamma - dat ee positiven Afloss op d'dendritesch Zellen huet.

Ee Problem bei der Immuntherapie ass d'Ëmfeld vum Kriibs. Fir sech géint d'Zelle vum Immunsystem ze schützen, huet de Kriibs verschidden Ofwierstrategien entwéckelt. Eng dervun ass d'Produktioun vu verschiddene Moleküllen, déi een negativen Effekt op d'Aktivitéit vun den Immunzellen hunn. Ee Beispill heifir ass Prostaglandin E2. Am Kapitel 5 hu mir d'Konsequenze vum Prostaglandin op dendritesch Zellen an NK Zellen analyséiert. Mir hunn een direkten negativen Effekt op déi zwou Zellpopulatioune festgestallt, souwéi op d'Interaktioun tëscht deenen zwee. Interessanterweis waren dendristesch Zellen, déi in vitro geräift goufen an dunn eréischt a Kontakt komm si mat Prostaglandin, immun géint d'negativ Effekter. 
An dëser Thees hu mir beschriwwen, dass bakteriell oder viral Aktivéierungspartikelen eng interessant Approche duerstellen, fir d'Interaktioun vun dendriteschen Zellen an den HelferZellen ze optiméieren. Virun allem d'Produktioun vun IL-12 duerch dendritesch Zellen ass heifir elementar. Dëst ass enorm wichteg, fir d'Impfstoffer mat dendriteschen Zelle géint Kriibs ze verbesseren. Dës verbessert Impfstoffer wäerten Ufank 2017 a klinesche Studien mat Longekriibspatienten a Patiente mat Multipel Myelom duerch d'Biotech Firma CiMaas getest ginn. 


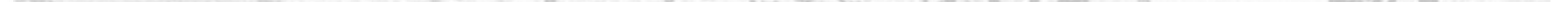




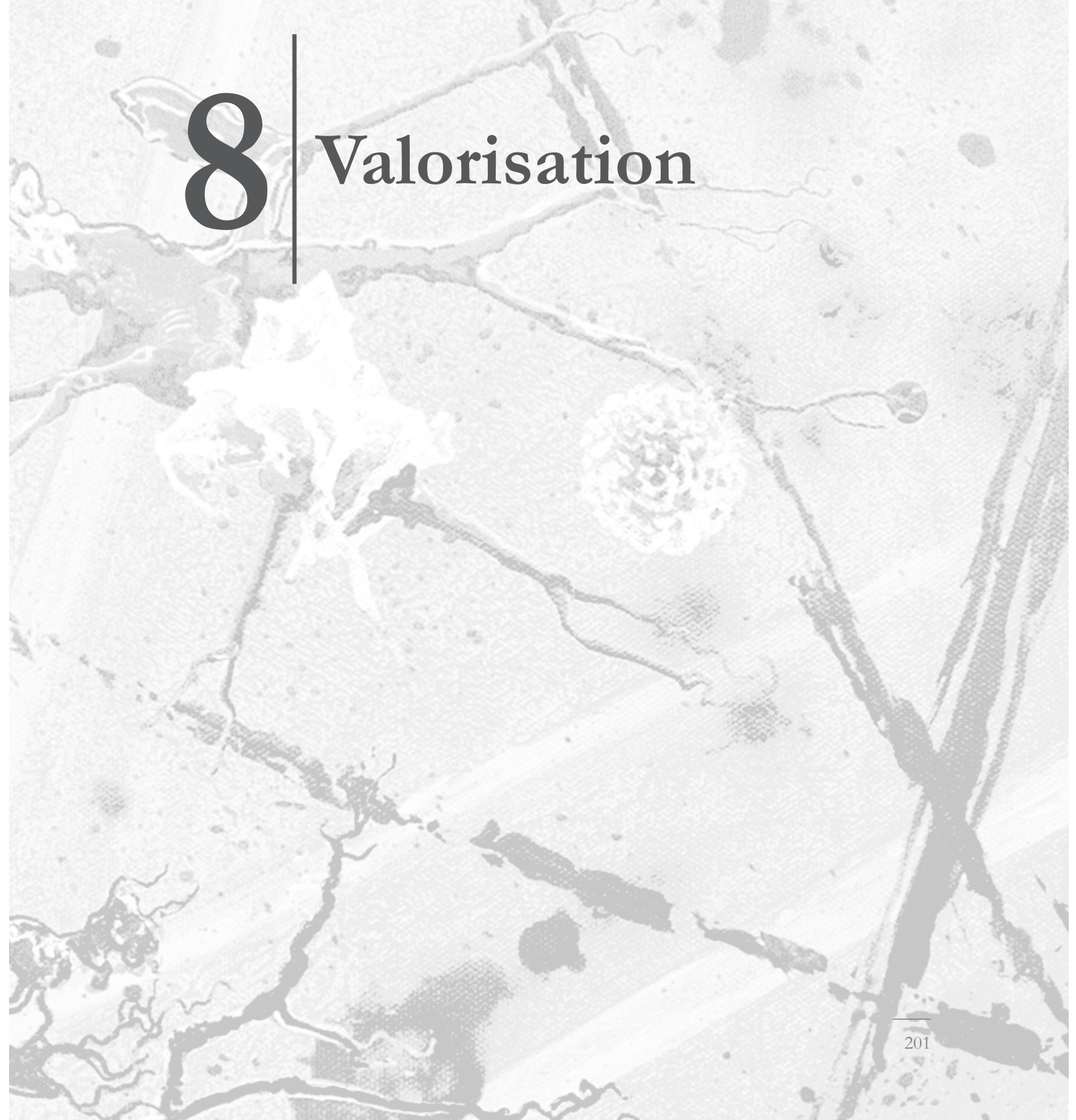



Cancer is one of the leading causes of death worldwide. In 2012, 14.1 million new cancer cases (101.210 cases in NL) and 8.2 million deaths (43.666 deaths in NL) have been registered with the majority of both incidence and mortality reported in less developed countries ${ }^{1-3}$. The number of new cases is expected to rise by $70 \%$ in the upcoming 20 years to 24 million ${ }^{4}$. In 2008, an estimated 83 million years of 'healthy life' were lost due to early death and disability caused by cancer. This implies an immense economic and social burden. Besides the direct costs for cancer treatment, also these indirect costs due to morbidity are included in the economic burden. As such, cancer accounts for the biggest economic impact worldwide among the leading causes of death ${ }^{5}$. Moreover, cancer diagnosis does not only affect the patients themselves but also their families and caregivers, and thus has an even broader physical, psychosocial, and economic impact ${ }^{6}$.

Early detection and current treatment strategies, such as surgery, radiotherapy and chemotherapy have been improved substantially during the last decades, leading to a decline of mortality. Nonetheless, a considerable high number of cancer cases remain incurable. Besides further improving screening methods as well as current anti-cancer treatments, there is need for developing innovative less invasive and non-toxic treatment options to ensure a better quality of life for patients with cancer.

The field of immunotherapy has gained particular interest among researchers for the development of novel anti-cancer treatment strategies. The general approach is to use or stimulate the patient's immune system in order to fight the cancer. Several approaches have been approved by the American Food and Drug Administration (FDA) and are currently implemented as part of standard anti-cancer treatment regimens for specific types of cancer. Different types of cancer immunotherapy exist, which can be divided into passive and active approaches as well as specific and non-specific mechanisms of action. One approach of cellular immunotherapy are dendritic cell (DC)-based vaccines. The use of DC as therapeutic vaccine is based on their primary role in detecting invading pathogens in our body. The principle of this approach is to isolate white blood cells of the patient and isolate a precursor of these cells (monocytes) and manipulate them ex vivo. This includes instructing them to recognize specific pattern expressed only by the cancer cells and boosting their capacity by adding specific triggers to maximize their potency, the so-called maturation stimuli. DC-based vaccines are already tested in clinical trials and have been proven to be safe and non-toxic, however overall clinical outcome is still limited. The first vaccine against advanced prostate cancer, Provenge ${ }^{\circledR}$, has been approved by the FDA in $2010^{7,8}$. This vaccine is prolonging the patient's life-time for several months without eradicating the tumour. Moreover, several clinical trials are currently ongoing testing various DC-based vaccination strategies illustrating the potential role of DC-based vaccines in future standard anti-cancer treatments. Nonetheless, the limited overall positive clinical outcome monitored 
thus far is indicative for the need of further optimizations.

This thesis aimed to improve these therapeutic anti-cancer DC-based vaccines. We focused on analysing the potency of different maturation stimuli on the capacity of DC to interact with helper cells of the immune system ( $T$ helper cells and natural killer cells) which is important to eliminate cancer cells.

We revealed that, at least in vitro, the potency of a dendritic cell to interact with natural killer cells and $\mathrm{T}$ cells is dependent on their capacity to produce one soluble factor: the cytokine IL-12. In the human system, this factor dose-dependently determines the outcome of the immune response and thus the potential anti-cancer response. These findings are strengthened by recent clinical trials indicating a positive correlation between high IL-12-producing DC and time to disease progression 9, ${ }^{10}$. Moreover, older studies tested the systemic application of IL-12 and revealed a positive anti-cancer effect. However, this implementation of systemic IL-12 administration in cancer treatment approaches was hindered by its dose-limiting toxicities ${ }^{11-17}$. Altogether, these findings emphasize on the use of IL-12-producing DC to ensure local production and delivery of this cytokine in order to come one step closer to successful vaccination strategies. This knowledge is very important to set new release criteria for DC maturation stimuli.

We showed that stimuli which have been used thus far by other groups did not lead to high IL-12-producing DC. However, we also revealed a huge donor-to-donor variation in the capacity of DC to produce IL-12 upon the same stimulation. Further research should investigate whether e.g. polymorphisms in the IL-12 gene are responsible for this in order to select only responding patients for clinical trials. Alternatively, DC-derived from low-responders could be engineered to constitutively produce high levels of IL-12. With introducing this new release criterion there is a possibility to increase the currently moderate clinical responses of anti-cancer DC-based vaccination.

In this line, we identified a maturation cocktail which is able to generate high IL-12-producing DC. This combination of maturation stimuli has been filed as patent in May $2012{ }^{18}$. Consequently, in March 2015, a spin-off company, CiMaas, has been founded by Prof. dr. GMJ Bos (CEO) and Dr. WTV Germeraad (CSO) being two of the inventors of the intellectual property. This biotech company focuses on the development of cellular immunotherapy against cancer. The target group for DC-based vaccines in initial clinical trials will be patients with lung cancer (5-year survival in NL: 17\%) and patients with multiple myeloma (5-year survival in NL: 40\%) ${ }^{19}$. During the upcoming two years the knowledge acquired in this project as well as preceding research by our group will be translated into the start of a clinical trial. Currently, the findings are validated and tested, 
which also includes regulatory affairs. All products need be available in good manufacturing practice (GMP) and standard operating procedures need to be set up. After the writing of the investigational medicinal product dossier and the permission of central committee on research involving human subjects, two phase I/II clinical trials are scheduled to start in the first quarter of 2017. DC made according to the procedure described in chapter 4 will be electroporated with mRNA coding for the Wilms-tumour I antigen, an important tumour antigen expressed in cancer cells and being essential for their survival. A collaboration with Prof. dr. K. Thielemans (University of Brussels, Belgium) has been set up from whom the mRNA will be supplied. The design of the trial is similar to the design of trials by Dr. V.F.I. van Tendeloo (University of Antwerp, Belgium) to allow some comparison of the different $\mathrm{DC}$ in a clinical context.

Even though the introduction of Provenge ${ }^{\circledR}$ to the market shows the potential of personalized cell therapy as new anti-cancer treatment, several aspects and patient inclusion criteria may be considered before starting the clinical trials with the optimized method to generate DC as described above. To prove the potential superiority of our new DC generation method, in initial trials only patients of which the DC have high IL-12-producing capacities determined on beforehand in vitro should be included. Once the success of this treatment has been proven, alternatives to also treat low-responders should be developed.

Another crucial hurdle for the effectiveness of cellular immunotherapy in general is the suppressive tumour environment. The tumour is embedded in a complex microenvironment formed by lymphoid myeloid cells, stromal cells, vasculature, lymphatic vessel, cytokines and chemokines. The tumour itself can interfere by the expression of inhibitory ligands, creation of a tolerogenic environment, and recruitment of regulatory cells ${ }^{20,21}$. Tumours are able to co-opt immune inhibitory pathways which are under physiological circumstances responsible to regulate immune responses and control self-tolerance, duration, and magnitude of the induced responses. As such tumours increase their immune resistance. To increase the efficacy of DC-based vaccination, combination therapies should be applied, targeting the tumours on multiple levels by using e.g. checkpoint inhibitors.

Besides the implementation of improved DC-based vaccines, CiMaas is also focussing on NK cell therapy. NK cells are important in killing virally infected cells of the human body and also play a crucial role in killing tumour cells. This adoptive cell therapeutic approach is based on the use of donor NK cells, selected according to specific criteria, to attack the cancer cells. In humanized mouse models for breast cancer and multiple myeloma, NK cells eliminated the tumours. CiMaas is currently focusing on methods to generate high numbers of NK cells in GMP complying conditions which are needed for translation of this therapy to cancer patients. Optimizations aim to enhance the cytotoxic capacity of NK cells by 
addition of various cytokines during expansion and the selection of appropriate allogeneic donors having KIR-ligand mismatched NK cells favouring their cytotoxic capacities. Even though studies described in this thesis where not primarily focusing on improving NK cell therapy, we did show that direct incubation of NK cells with pathogen-derived products (PAMPs) positively influenced the activation of NK cells and subsequent interaction with DC. Moreover, increasing evidence in literature describes enhanced cytolytic capacities of NK cells after PAMP-activation ${ }^{22,23}$. Incorporation of PAMPs to activate NK cells before injection could enhance the NK cell-mediated effects in vivo and may reduce the number of NK cells needed to treat a patient. Arguably, NK cells could also be injected with adjuvants in order to boost their activity in vivo. Further research is needed to evaluate the effect of these pathogen-derived products on NK cell function.

To sum up, the findings described in this dissertation mainly contribute to the progress of therapeutic DC-based anti-cancer vaccines. The obtained data of this thesis and previous research efforts of our laboratory are currently translated into clinical products and will be soon applied in clinical trials. Possibly, this form of personalized treatments will in the near future not only achieve prolongation of the patient's life-time but also attack the tumour itself more efficiently in non-toxic manner and be incorporated more and more in future standard anti-cancer treatment regimens. 


\section{REFERENCES}

1. Global Burden of Disease Cancer Collaboration. The global burden of cancer 2013. JAMA Oncology. 2015;1(4):505-527.

2. Torre LA, Bray F, Siegel RL, Ferlay J, Lortet-Tieulent J, Jemal A. Global cancer statistics, 2012. CA Cancer J Clin. 2015;65(2):87-108.

3. Ferlay J, Soerjomataram I, Dikshit R, et al. Cancer incidence and mortality worldwide: sources, methods and major patterns in GLOBOCAN 2012. Int J Cancer. 2015;136(5):E359-386.

4. World Health Organization. Cancer Fact sheet $N^{\circ} 297$. Updated February 2015.

5. John R, Ross, H. The Global Economic Cost of Cancer. American Cancer Society 2010.

6. Girgis A, Lambert S, Johnson C, Waller A, Currow D. Physical, psychosocial, relationship, and economic burden of caring for people with cancer: a review. J Oncol Pract. 2013;9(4):197-202.

7. Patel PH, Kockler DR. Sipuleucel-T: a vaccine for metastatic, asymptomatic, androgen-independent prostate cancer. Ann Pharmacother. 2008;42(1):91-98.

8. Kantoff PW, Higano CS, Shore ND, et al. Sipuleucel-T immunotherapy for castration-resistant prostate cancer. N Engl J Med. 2010;363(5):411-422.

9. Carreno BM, Becker-Hapak M, Huang A, et al. IL-12p70-producing patient DC vaccine elicits Tc1polarized immunity. J Clin Invest. 2013;123(8):3383-3394.

10. Okada H, Kalinski P, Ueda R, et al. Induction of CD8+ T-cell responses against novel gliomaassociated antigen peptides and clinical activity by vaccinations with $\{$ alpha\}-type 1 polarized dendritic cells and polyinosinic-polycytidylic acid stabilized by lysine and carboxymethylcellulose in patients with recurrent malignant glioma. J Clin Oncol. 2011;29(3):330-336.

11. Atkins MB, Robertson MJ, Gordon M, et al. Phase I evaluation of intravenous recombinant human interleukin 12 in patients with advanced malignancies. Clin Cancer Res. 1997;3(3):409-417.

12. Leonard JP, Sherman ML, Fisher GL, et al. Effects of single-dose interleukin-12 exposure on interleukin-12-associated toxicity and interferon-gamma production. Blood. 1997;90(7):2541-2548.

13. Hamid O, Solomon JC, Scotland R, et al. Alum with interleukin-12 augments immunity to a melanoma peptide vaccine: correlation with time to relapse in patients with resected high-risk disease. Clin Cancer Res. 2007;13(1):215-222.

14. Peterson AC, Harlin H, Gajewski TF. Immunization with Melan-A peptide-pulsed peripheral blood mononuclear cells plus recombinant human interleukin-12 induces clinical activity and T-cell responses in advanced melanoma. J Clin Oncol. 2003;21(12):2342-2348.

15. Trinchieri G. Interleukin-12 and the regulation of innate resistance and adaptive immunity. Nat Rev Immunol. 2003;3(2):133-146.

16. Colombo MP, Trinchieri G. Interleukin-12 in anti-tumor immunity and immunotherapy. Cytokine Growth Factor Rev. 2002;13(2):155-168.

17. Del Vecchio M, Bajetta E, Canova S, et al. Interleukin-12: biological properties and clinical application. Clin Cancer Res. 2007;13(16):4677-4685.

18. Bos GMJ, Germeraad WTV, Gijsbers LMG, Oth T, Vanderlocht J. Method for the in vitro maturation of dendritic cells: Europe 12167799.1. Issued May 12, 2012

19. IKN. Cijfers en grafieken over kanker. www.cijfersoverkankernl. 2008-2012.

20. Gajewski TF. Cancer immunotherapy. Mol Oncol. 2012;6(2):242-250.

21. Madar S, Goldstein I, Rotter V. 'Cancer associated fibroblasts'--more than meets the eye. Trends Mol Med. 2013;19(8):447-453.

22. Hart OM, Athie-Morales V, O'Connor GM, Gardiner CM. TLR7/8-mediated activation of human NK cells results in accessory cell-dependent IFN-gamma production. J Immunol. 2005;175(3):1636-1642.

23. Sivori S, Falco M, Carlomagno S, Romeo E, Moretta L, Moretta A. Heterogeneity of TLR3 mRNA transcripts and responsiveness to poly (I:C) in human NK cells derived from different donors. Int Immunol. 2007;19(12):1341-1348. 


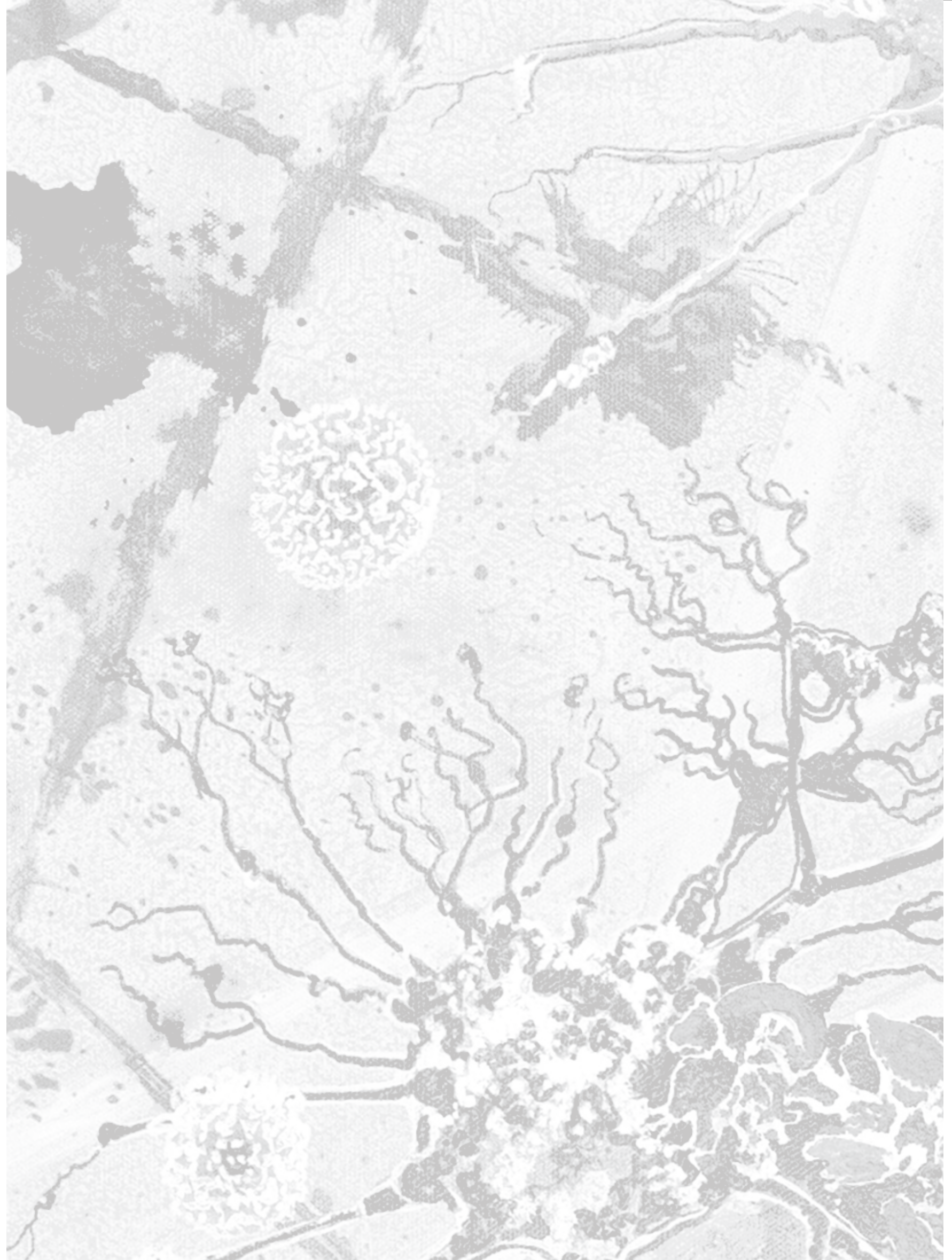




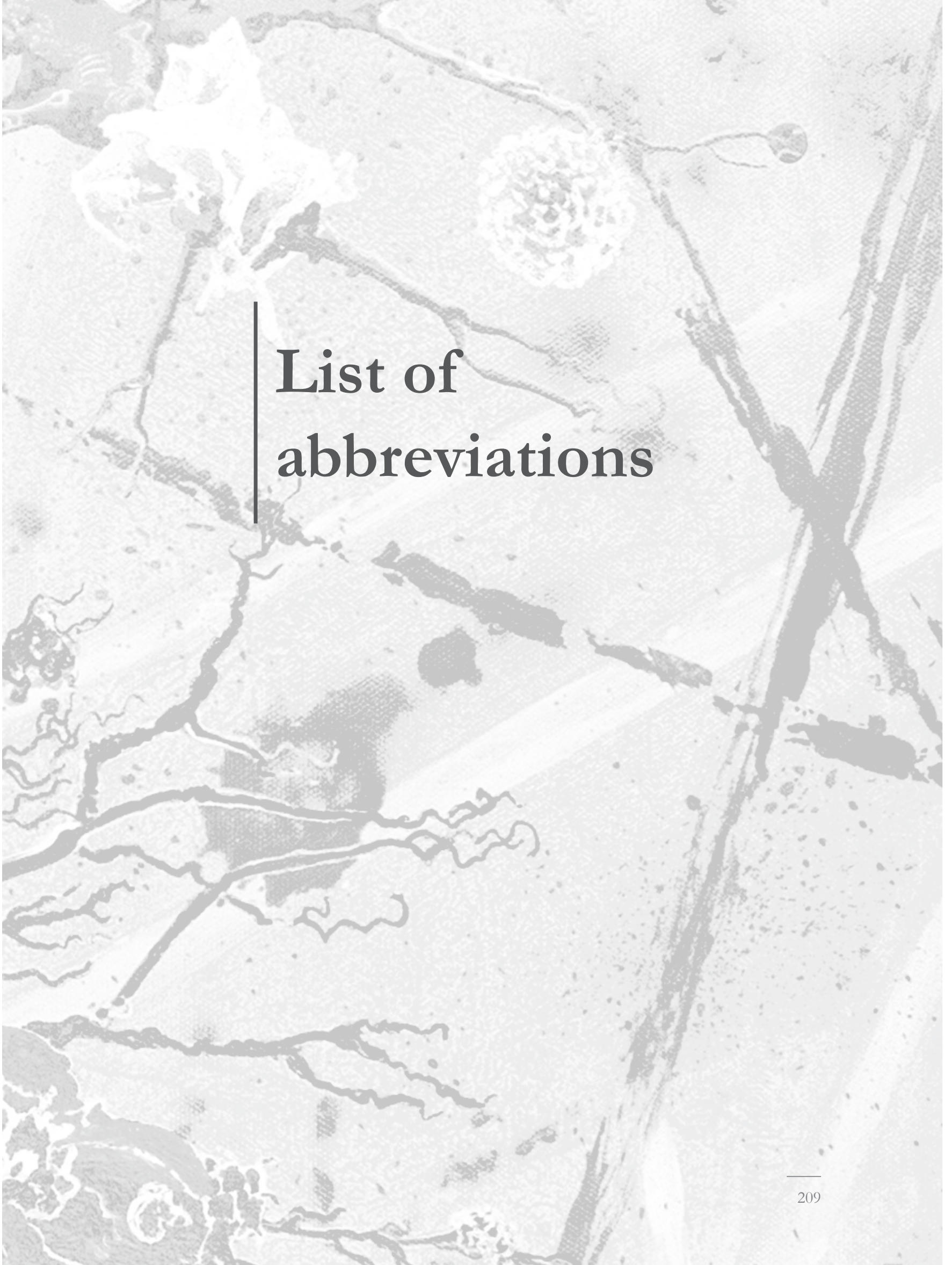


7-AAD 7-Aminoactinomycin D

A2aR A2a receptor

AA ascorbic acid

$\mathrm{Ab} \quad$ antibody

ADCC antibody-dependent cell-mediated cytotoxicity

Ag antigen

AIM-2 absent in melanoma-2

ALR AIM-2-like receptors

AML acute myeloid leukemia

AP-1 activation protein 1

APC allophycocyanin

APC antigen-presenting cell

ATP adenosine triphosphate

BCG Bacillus Calmette-Guérin

CAR chimeric antigen receptor

CBA cytometric bead array

CCL chemokine (C-C motif) ligand

CD cluster of differentiation

cDC conventional DC

CLR C-type lectin receptor

COX cyclooxygenase

CTL cytotoxic T lymphocyte

CTLA-4 cytotoxic T lymphocyte-associated protein 4

CXCL chemokine (C-X-C motif) ligand

DAMP damage-associated molecular pattern

DC dendritic cell

DC-SIGN DC-Specific Intercellular adhesion molecule-3-Grabbing Non-integrin

DiO 3'-dioctadecyloxacarbocyanine

DNA deoxyribonucleic acid

DNAM-1 DNAX accessory molecule-1

dsRNA double stranded RNA

ERF environmental response factors

FasL Fas ligand

FDA Food and Drug Administration

FITC fluorescein-isothiocyanate

FMKp membrane fractions of Klebsiella pneumoniae

FOXP3 forkhead box P3

GITR glucocorticoid-induced TNFR family related gene

GM-CSF granulocyte-macrophage colonystimulating factor

GMP good manufacturing practice

HKLM heat killed Listeria monocytogenes

HLA human leukocyte antigen

iDC immature DC

IDO indoleamine 2, 3-dioxygenase

IFI16 gamma-interferon-inducible protein 16

IFN interferon

IL interleukin

ILC innate lymphoid cells

iNOS inducible nitric oxide synthase

IRF IFN $-\gamma$ responsive factor

JAK Janus kinase

KIR killer immunoglobulin-like receptor

LAG-3 lymphocyte-activation gene 3

LPS lipopolysaccharide

$\mathrm{mAb}$ monoclonal antibody

MAP mitogen-activated protein

M-CSF macrophage colony-stimulation factor $\mathrm{mDC}$ mature $\mathrm{DC}$

MDSC myeloid-derived suppressor cell

MFI mean fluorescence intensity

MHC major histocompatibility complex

MIC A/B MHC class I polypeptide-related chain $\mathrm{A} / \mathrm{B}$

MIP macrophage inflammatory protein

moDC monocyte-derived DC

MPL monophosphoryl lipid A

mRNA messenger RNA

myD88 myeloid differentiation primary

response 88

myDC myeloid DC

NCR natural cytotoxicity receptor

NFkB nuclear factor kappa B 


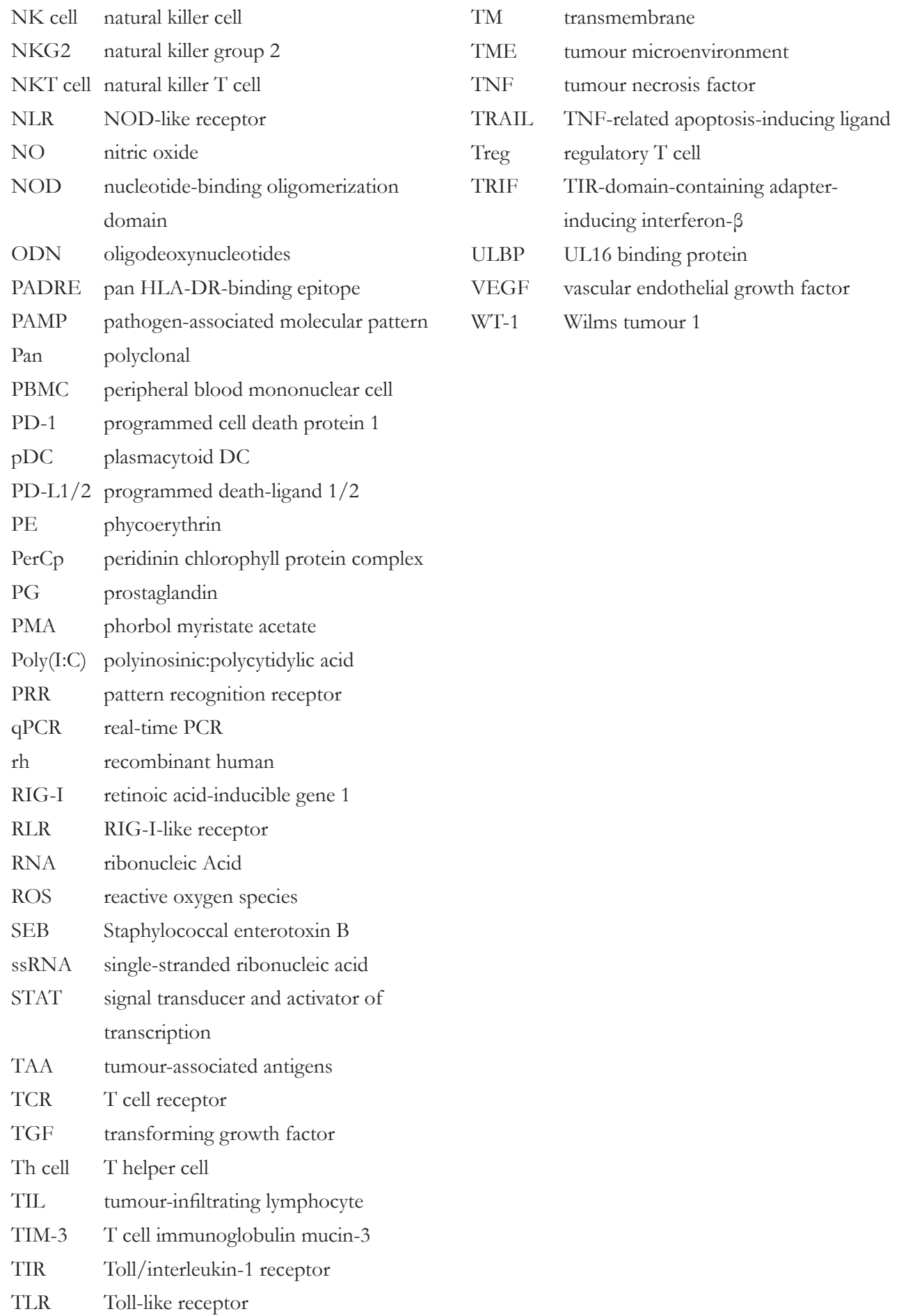




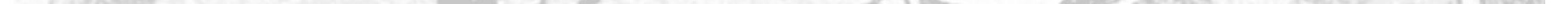


At the end of this dissertation, I have the opportunity to thank all the people that contributed to this achievement. The fact that you are holding a book right now, means that you contributed in one way or another to this success. For this, I would like to thank you very much!

First of all I would like to thank my supervision-team: Prof. dr. Gerard Bos, Dr. Joris Vanderlocht and Dr. Wilfred Germeraad. Joris, your trust in my scientific capacities led to the submission of a PhD grant and paved the way for my PhD trajectory. Thank you so much for your commitment to stay my co-supervisor despite the structural changes at an early phase of my $\mathrm{PhD}$. I really appreciate your dedication and all the extra time and effort you had to invest to combine your new position with the involvement in my project. It was a pleasure to work with you and getting inspired by our talks, your endless ideas and your philosophy of performing 'small' experiments. Thank you for all the support! Gerard, I appreciate your challenging and critical view during the project meetings. Your valuable comments definitively helped to increase the quality of the research described in this book. Staying on top of the project helped to prevent deviating from the main track. Thank you also for introducing me to the useful mind maps and visualization strategies. Wilfred, I would also like to thank you for all the support - our interesting discussions, your availability for daily troubleshooting, and all the scientific input on my project. Gerard and Wilfred, I wish you all the success with your new company CiMaas and I hope that all the research efforts of the past 15 years can be soon translated into the start of a DC-based clinical trial!

I would also like to thank the 'Fonds National de la Recherche' for giving me the opportunity to perform my $\mathrm{PhD}$ on this project. In this line, I would also like to thank Prof. dr. Harry Schouten for the financial support during the Grant writing period.

Moreover, I would like to thank the members of the dissertation assessment committee, Prof. dr. P. Lambin, Dr. V.F.I. van Tendeloo, Prof. dr. M.G.J. Tilanus, Prof. dr. I.J.M. de Vries, and Dr. T.G.A.M. Wolfs very much for reading, judging, and providing a positive evaluation of my thesis.

Of course a cheerful thank you goes to all the people sharing the daily 'hobbying' in the lab - Birgit, Silvie, Mirelle, Ariane, Janine, Melanie, Thomas, Subhashis, Niken, Ans, Michel and Mateusz. Birgit, thank you for your willingness to always give a hand if needed during an experimental day and of course also for performing all the elutriations and providing the starting point for the my research. It was very nice to discover Seoul together with you! Good luck with the setup of the clinical trials! Janine, it was nice to work along on your project. Ariane and Silvie, thanks for ensuring a joyful atmosphere in the lab. Michel, thank you for your input during the research meetings and for the nice chit-chats on the 
hallway. Mirelle, you did it - now it is my turn :) We were PhD-buddies with half-a-year shift. It was nice to share with you the ups and downs in this $\mathrm{PhD}$ period. Troubleshooting, interpretation of results, first paper submission, first publication, accepted abstracts, and talks on conferences (and in between filling goody bags) - thank you for all your support! Working with you just made it so much more fun! But also away from pipet tips and FACS buisjes we had good fun. From research to friendship - we stay in touch, for sure!

My roomies - Subhashis, Niken, Ans, Thomas, and Melanie - with you all I shared an office during my PhD-period. Subhashis, it was a pleasure to have you around. No matter how stressed you were, you always seemed so relaxed - an amazing capacity. Thanks for our nice scientific discussions over these years and mostly thank you for introducing me to Indian culture: the typical Indian games, the cooking, and of course also the fast introduction to the cricket world! I will always remember the chocolate muffin! :) Melanie, thank you so much for all the pipetting. It was very gezellig to work with you. I will not forget our funny dutchenglish way of communicating. Ans, we still shared the crowded office. Unfortunately, at the end you had to support my journey from distance. Nonetheless, I would like to thank you for the sunny breaks outside, enjoying the good coffee and high-tea - we had lots of joyful moments together with Mirelle. Thomas, you gave me a good example of how an organized desk could/should look like...thanks for providing work space for Joris and me :). I wish you good luck and power of endurance to finish up your $\mathrm{PhD}$, hang in there! Niken, I really appreciated to have you happy-person around me during the final phase of my $\mathrm{PhD}$. I am really happy to have shared with you lots of good scientific discussions, as well as girly-talk, and our passion for cookies :). Keep up the good work, I'm sure you will do great!!

I would like to thank my students, Marijke Zonneveld and Peter Rouw for their helping hands on my project. Marijke I wish you a lot of success with finishing your PhD!

I would also like to thank all the donors who volunteered to donate blood for my research. Without your generous amounts of blood I wouldn't have been able to plan such huge experiments. Special thanks to Annette and Fabienne from Transplantation Immunology for the blood withdrawing. Lotte, I would also like to thank you for your scientific input during meetings and for nice conversations during these past years. Good luck with the NK cell therapy project!

Liebe Dinner Club-Leute - Anette, Elke, Thomas, Kevin, Carla, Jo, Caro, Charlotte - wenn auch nur von kurzer Dauer, war es super ab und zu mit euch gemütlich beisamen zu sitzen, lecker zu essen und ein Gläschen Wein zu geniessen. Die wertvollen Informationen über die Bestseller der Kinowelt werde ich selbstverständlich nicht mehr vergessen! 
Liebe Mitbewohner der Bloemenweg-WG - Mareike, Hannah, Michelle, Manu, Patrick und Alex - danke für die tollen Kochabende (v.a. unser 5-Sterne Weihnachtsmenu), Mottoparties (Patrick, remember Black Swan!), Tatort-abende, stundenlanges Frühstücken, Maueren bemalen und noch sovieles mehr....Es war wunderbar mit euch ein Haus geteilt zu haben!!

Mareike, meine Liebste, du warst quasi von Anfang bis zum Schluss live mit dabei! :) Danke dafür dass deine Tür immer für mich offen stand! Danke für die vielen entspannten Momente, die kleinen Kaffeepausen zwischendurch und die vielen kleinen Aufmerksamkeiten um mir den Tag zu versüssen.

Beste Dames/Teamies - Aida, Aimée, Beke, Chantalle, Eva, Joelle, Katalina, Katharina, Kelly, Kim, Kimberly, Jana, Jindra, Marie-Lousie, Maud, Maxi, Michelle, Miranda, Nan, Siena, Svenja, Tanja \& Wanda - Dank jullie wel voor inmiddels al 5 gezellige jaren Basketball - on and off the court :) Ondanks dat jullie in het begin niet zo open stonden voor de 'buitenlanders' zijn we toch samengegroeid tot een kleine familie. Jullie hebben me wel een beetje in het Meestrechs leven geïntroduceerd. Onze winning season was heel erg leuk boe is dat feeske? :) Vooral Aimée en Michelle, bedankt voor het terug halen in het team afgelopen jaar...een beetje basketballen heeft me echt geholpen om even te ontspannen tijdens mijn schrijfperiode. Ik wens jullie allemaal veel succes met jullie toekomst! En hopelijk gaan we weer een leuk feestje vieren aan het eind van dit seizoen! :)

Katharina, es ist immer wieder schön dich zu sehen und mit dir zu quatschen. Danke für dein aufrichtiges Interesse! Ich weiss dass du immer ein offenes Ohr für mich hast.

Aida, und aufeinmal warst du wieder da! :) Es hat gut getan dich im Endspurt nochmal in Maastricht zu haben. Ich habe es sehr genossen mit dir ein Süppchen zu essen und einen leckeren Koffie zu trinken und den Alltagsstress für einen kleinen Moment (oder einen etwas längeren Moment) zu vergessen!

Beke, Schnegge, danke für deine Verrücktheit :) Danke für soviele schöne, lustige und entspannte Momente in Maasi (und in den Saunalandschaften drum rum). Danke aber vor allem auch für deine Freundschaft in Phasen wo es mal nicht so rund lief.

Mich, du hues däin Dokter schonn an der Täsch! Tschaka! :) Mir hunn eis zwar leider net sou oft gesinn, mee dofir waren eis Treffen zu Mannheim, Lëtzebuerg oder Maastricht ëmsou méi wäertvoll!

Dem Klassentreff - Cédric, Gregory a Nadine - och een décke Merci fir eis entspaant Conveniaten! :) 
Codewuert: rosae Flamingo! Jill, Nadine, a Myriam dir sidd einfach nëmmen TOP! Hei ass en endlech den Drot(h)! Egal wéi vill Zäit mir géifen mateneen verbrénge, et wier der einfach ni genuch. Ech weess dass mir eis ni aus den Aen wäerte verléieren an dat ass ee ganz schéint Gefill! Egal wou mir an der Weltgeschicht rondrëm reese wann mir eis gesinn ass et wéi wann alles beim alen wier obwuel eis Welten sech permanent weider dréinen. Merci fir all déi entspaante a witzeg Momenter, déi vill schéin Erënnerungen an är Ënnerstëtzung bei dësem Projet!

Maxilein - you make me smile :) Wie wunderbar einen Platz an deiner Seite zu haben. In vielen Momenten hast du mir den notwendigen Ausgleich zum stressigen Alltag gegeben bei dir kann ich meine Seele immer baumeln lassen!

Darko, dankjewel voor jouw steun in de laatste 3 jaar! Ik denk dat niemand anders zoveel heeft moeten toegeven zoals jij in deze periode. Ontzettend bedankt voor jouw geduld, motiveerende woorden en liefde! Volim te!

Mäin leschten ganz groussen Merci geet u meng wonnerbar Famill. Tessy a Gilles ech si frou iech als Geschwëster ze hunn. Leider gesi mir eis net souvill wei ech mir dat géif wënschen, mee et ass ëmmer rëm schéin Zäit mat iech zwee ze verbrénge. Ech weess dass ech ëmmer op är Ënnerstëtzung ziele kann. Sisi, d'Bakterien Zäit ass eriwwer :) Merci fir deng vill Besich zu Maas an deene leschten Jore, fir eng onvergiesslech Rees an Nei Zeeland, an esou villes méi! Mami a Papi, iech well ech och e grousse Merci soe. Merci dass dir mech ëmmer an allem ënnerstëtzt hutt och wann dir vläit net ëmmer sou genee verstanen hutt wat ech da lo genau géif maache. Heem, op Sëll ze kommen, war (an ass) ëmmer wéi eng Mini-Vakanz, wou ech ëmmer konnt Kraaft tanken an op aner Gedanken kommen. Merci fir all äert Vertrauen an mech. Papi, Merci och nach eemol fir dee fantasteschen Cover! Ech si ganz vill frou mat iech alleguer!

\section{MERCI!}




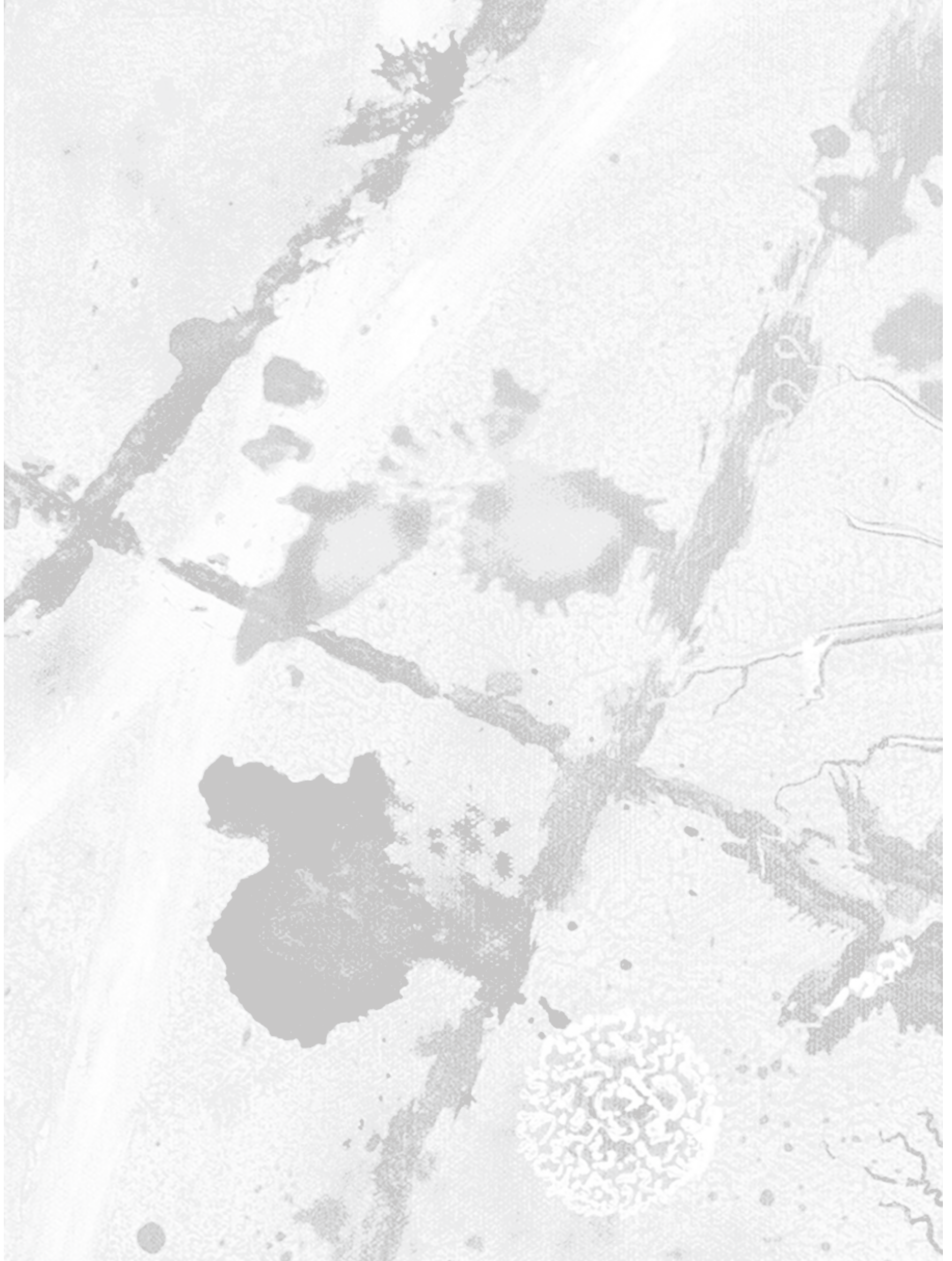




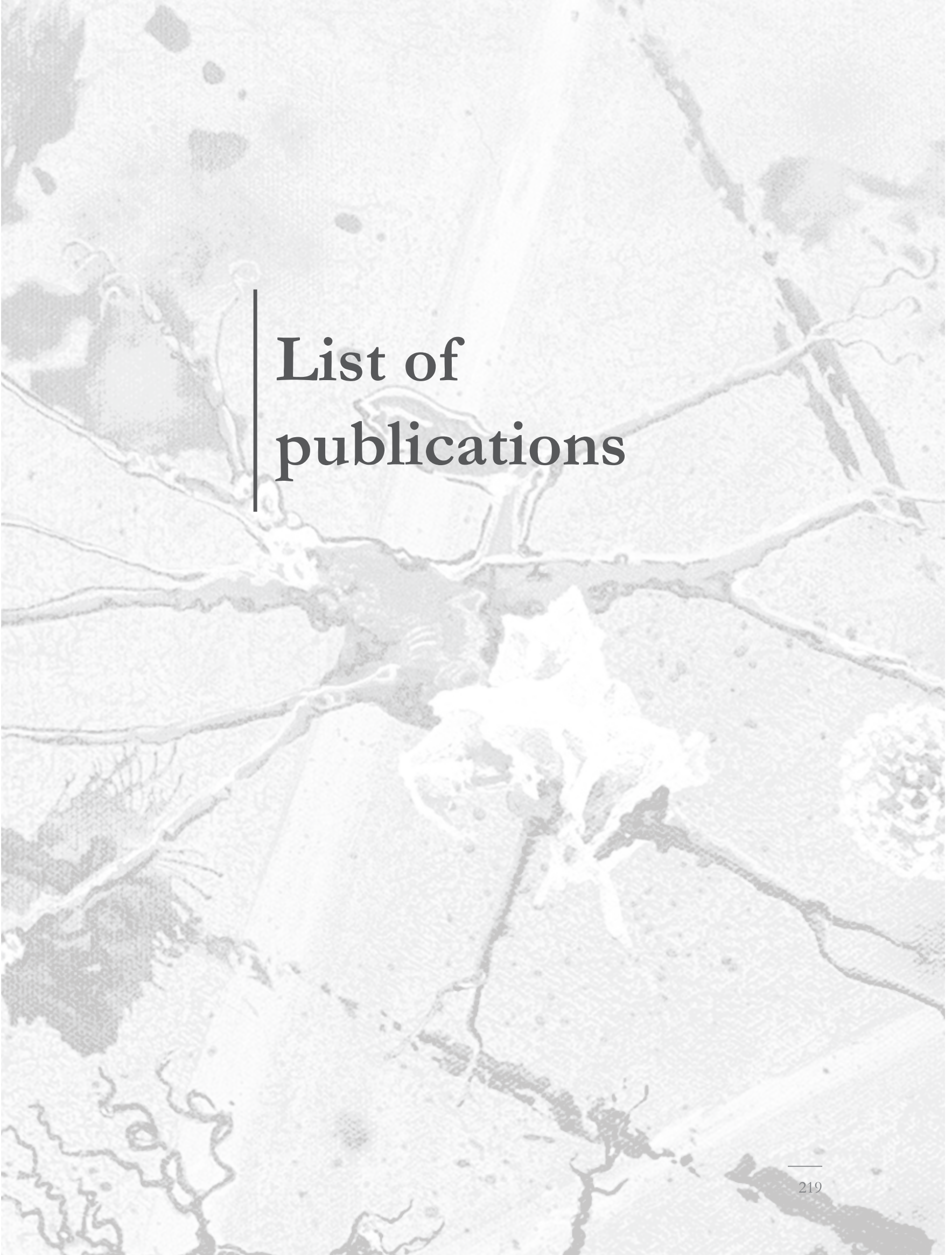




\section{PUBLICATIONS}

Inflammation-restraining effects of prostaglandin E2 on natural killer-dendritic cell (NK-DC) interaction are imprinted during DC maturation.

Van Elssen CHMJ, Vanderlocht J, Oth T, Senden-Gijsbers BLMG, Germeraad WTV, Bos GMJ.

Blood. 2011 Sep 1;118(9):2473-82.

Natural killer cells: the secret weapon in dendritic cell vaccination strategies.

Van Elssen CHMJ, Oth T, Germeraad WTV, Bos GMJ, Vanderlocht J.

Clin Cancer Res. 2014 Mar 1;20(5):1095-103. Review.

Monitoring the initiation and kinetics of human dendritic cell-induced polarization of autologous naive $\mathrm{CD}^{+} \mathrm{T}$ cells.

Oth T, Schnijderberg MCA, Senden-Gijsbers BLMG, Germeraad WTV, Bos GMJ, Vanderlocht J.

PLoS One. 2014 Aug 21;9(8):e103725.

Potency of both human Th1 and NK helper cell activation is determined by IL-12p70-producing PAMP-matured DCs.

Oth T, Van Elssen CHMJ, Schnijderberg MCA, Senden-Gijsbers BLMG, Germeraad WTV, Bos GMJ, Vanderlocht J.

J Interferon Cytokine Res. 2015 Sep;35(9):748-58.

Pathogen recognition by NK cells amplifies the pro-inflammatory cytokine production of monocyte-derived DC via IFN- $\gamma$ but not TNF- $\alpha$.

Oth T, Germeraad WTV, Zonneveld MI, Bos GMJ, Vanderlocht J.

Under revision.

Pattern recognition receptor triggering induces tri-party crosstalk between Dendritic cells, $T$ and Natural Killer helper cells and will improve vaccination.

Oth T, Vanderlocht J, Van Elssen CHMJ, Bos GMJ, Germeraad WTV.

Submitted for publication. Review. 
Targeted fractionated radiotherapy induces systemic anti-tumour responses and abscopal tumour inhibition without modulating the humoral anti-tumour immune response.

Habets THPM, Oth T, Huijskens MJAJ, Houben AW, Senden-Gijsbers BLMG, Schnijderberg MCA, Brans B, Dubois LJ, De Saint-Hubert M, Germeraad WTV, Tilanus MGJ, Mottaghy FM, Bos GMJ, Vanderlocht J.

In preparation.

\section{PATENT}

Method for the in vitro maturation of dendritic cells.

Bos GMJ, Germeraad WTV, Gijsbers BLMG, Oth T, Vanderlocht J.

Europe 12167799.1. Issued May 12, 2012. 


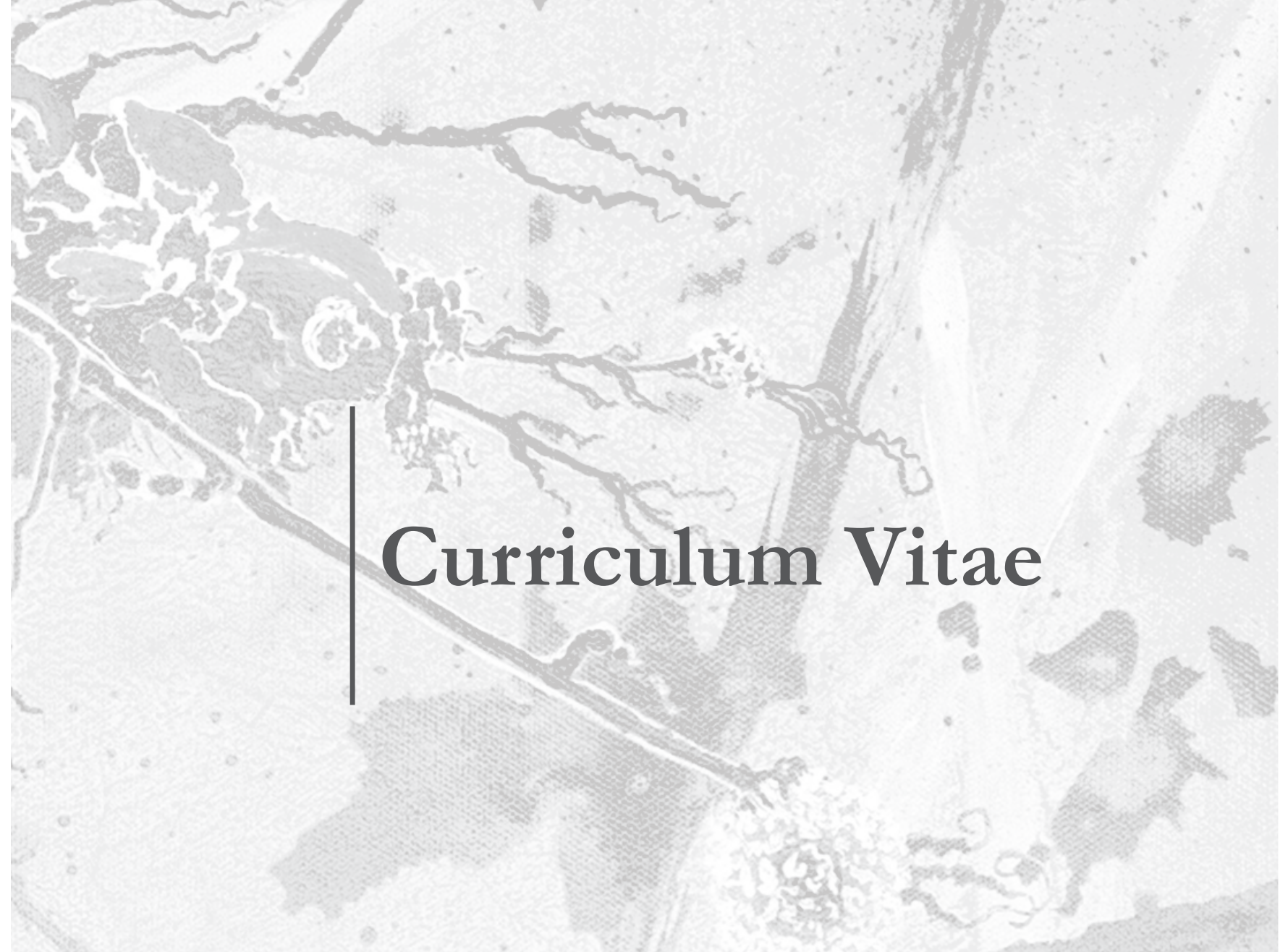



Tammy Oth was born on March 20 ${ }^{\text {th }}, 1986$ in Luxembourg City, Luxembourg. She grew up and went to the elementary school in Saeul. After finishing her secondary school in 2005 at the Lycée Michel-Rodange Luxembourg, she continued her education at the Technical University of Munich, Germany obtaining Bachelor of Science in Nutritional Sciences. She pursued her master's education in Molecular Life Sciences (Specialization in Molecular Health Sciences) at Maastricht University Medical Centre+, the Netherlands, where she graduated in 2010 with honours. In 2011, she received a personal PhD grant from the Luxembourgish Research Fund (AFR Grant Scheme; Project: 1039369 (PREDICT)) and started her doctoral research within GROW, School for Oncology and Developmental Biology, at the department of Haematology at the MUMC+ under the supervision of Prof. dr. G.M.J. Bos, Dr. J. Vanderlocht, and Dr. W.T.V. Germeraad. The results obtained during this research period are described in this dissertation. Since September 2015, she has been working as Application Specialist for Immunology \& Molecular Biology at bioMérieux Benelux in Brussels. 
Printed by Gildeprint 